\title{
Numerical simulation for parametric study of a two -stroke compression ignition direct injection linear engine
}

\author{
Ehab F. Shoukry \\ West Virginia University
}

Follow this and additional works at: https://researchrepository.wvu.edu/etd

\section{Recommended Citation}

Shoukry, Ehab F., "Numerical simulation for parametric study of a two -stroke compression ignition direct injection linear engine" (2003). Graduate Theses, Dissertations, and Problem Reports. 1889.

https://researchrepository.wvu.edu/etd/1889

This Dissertation is protected by copyright and/or related rights. It has been brought to you by the The Research Repository @ WVU with permission from the rights-holder(s). You are free to use this Dissertation in any way that is permitted by the copyright and related rights legislation that applies to your use. For other uses you must obtain permission from the rights-holder(s) directly, unless additional rights are indicated by a Creative Commons license in the record and/ or on the work itself. This Dissertation has been accepted for inclusion in WVU Graduate Theses, Dissertations, and Problem Reports collection by an authorized administrator of The Research Repository @ WVU.

For more information, please contact researchrepository@mail.wvu.edu. 


\title{
NUMERICAL SIMULATION FOR PARAMETRIC STUDY OF A TWO-STROKE COMPRESSION IGNITION DIRECT INJECTION LINEAR ENGINE
}

\author{
Ehab F. Shoukry \\ Dissertation submitted to \\ The College of Engineering and Mineral Resources \\ at \\ West Virginia University \\ in partial fulfillment of the requirements \\ for the degree of \\ Doctor of Philosophy \\ in \\ Mechanical Engineering
}

Nigel N. Clark, Ph.D., Chair

Parviz Famouri, Ph.D.

Larry Banta, Ph.D.

Gregory Thompson, Ph.D.

Scott Wayne, Ph.D.

Department of Mechanical and Aerospace Engineering

Morgantown, West Virginia

2003

Keywords: diesel engine, two-stroke, linear engine 


\section{ABSTRACT \\ NUMERICAL SIMULATION FOR PARAMETRIC STUDY OF A TWO-STROKE COMPRESSION IGNITION DIRECT INJECTION LINEAR ENGINE}

\section{EHAB SHOUKRY}

A time based numerical simulation program was built at West Virginia University to simulate the operation of a two-stroke compression ignition direct injection linear engine. The two-stroke linear engine consists of two pistons connected together with a yoke and allowed to move freely according to the frequent combustion that takes place in response to fueling and load applied along the full stroke of the internal combustion engine. The simulating program used a series of dynamic and thermodynamic equations that were solved simultaneously to predict the performance and analyze the different factors affecting the operation of the two-stroke compression ignition linear engine coupled with linear alternator. This dissertation presents a dimensionless analysis parametric study to explore this novel type of internal combustion engine. It was found that these types of engines have a nature to build up compression ratio, and this was the reason behind recommending to operate such engines with high air to fuel ratios. Indicated efficiency was found to have an average of $42 \%$. For stationary power generation a bore to effective stroke ratio equal to 1 , or 1.3 would result in an efficient power generation unit whereas a bore to effective stroke length equal to three or four would result in a highindicated power per cylinder volume, which may be suitable for automotive application. It was also found that a bore to effective stroke length of 2.2 would result in excessive compression ratio. This makes such a design limited to special applications where high indicated power per generator mass is needed. Advancing fuel injection close to the 
cylinder head during the compression stroke and burning the fuel with premixed to diffusive combustion ratio of $20 \%$ to $80 \%$ would enhance indicated efficiency and indicated power generated relative to injecting the fuel far from the cylinder head during the compression stroke and burning the fuel with premixed to diffusive combustion ratio of $40 \%$ to $60 \%$. 


\section{DEDICATION}

I would like to dedicate this dissertation to my Lord who strengthened me and guided me to this point.

Also, to my wife Hanan Z. Shoukry who stood by my side and suffered with me, sacrificed almost everything even though she was passing through a delicate health condition. Also, to my parents Mr. and Mrs. Fouad Shoukry who brought me to life, sacrificed with love for many years and taught me how to be a responsible person, how to work hard, how to focus on end goals and go for it ignoring difficulties and focusing on results, and for their generous support during so much difficult times. Also, to my little angels my daughter Merna and my son Michael David who were the reason that kept me working hard and moving forward regardless of how it was so difficult sometimes to move one-step forward.

I would like to say to all of you that I'm grateful to what you did for me and I will always be indebt for all of you till the end of my life. 


\section{ACKNOWLEDGEMENT}

I would like to take this opportunity to thank my advisor professor Nigel Clark for giving me the opportunity to continue my study in West Virginia University and for his valuable help that guided me throughout my dissertation. Also, I would like also to thank my committee members for their valuable comments and guidance. I wish also to thank Dr. Sorin Petreanu who helped me to build up my simulating program and allowed me to use his techniques. I would like also to extend my thanks to the US Army who funded this research to develop a numerical model for the two-stroke compression ignition linear engine $^{1}$.

\footnotetext{
${ }^{1}$ Contract Number: DAAD19-01-1-041
} 


\section{TABLE OF CONTENTS}

Abstract

Dedication $\quad$ iv

Acknowledgement $\mathrm{V}$

Table of Contents vi vi

$\begin{array}{ll}\text { List of Figures } & \text { ix }\end{array}$

List of Tables $\quad$ xxii

$\begin{array}{ll}\text { Nomenclature } & \text { xxiii }\end{array}$

Chapter 1 Introduction 1

$\begin{array}{lr}\text { Chapter } 2 \text { Literature Review } & 6\end{array}$

$\begin{array}{lr}2.1 \text { Two-Stroke Engine History } & 6\end{array}$

2.2 Two-Stroke Linear Engine Story and its Development 8

2.3 Modeling of Linear Engine $\quad 12$

2.4 Linear Engine Development at West Virginia University 13

2.5 Compression Ignition Linear Engine Prototype Development at West Virginia

$\begin{array}{ll}\text { University } & 23\end{array}$

Chapter 3 Computational Model and System Analysis 27

$\begin{array}{ll}\text { 3.1 Model Description } & 27\end{array}$

3.2 Dynamic Modeling 28

$\begin{array}{ll}3.3 \text { Alternator Modeling } & 30\end{array}$

3.4 Friction Modeling $\quad 31$

3.5 Thermodynamic Modeling 32

$\begin{array}{ll}\text { Chapter } 4 \text { Solution Method and Model Validation } & 37\end{array}$

4.1 Solution Method 37 
4.4 Heat Transfer Model

Chapter 5 Special Motoring Cases

Chapter 6 Dimensionless Analysis

6.1 The Effect of Dimensionless Load Constant

6.2 The Effect of Air to Fuel Ratio

6.3 The Effect of Injection Timing

6.4 The Effect of Combustion Distribution

6.5 Exploring Outside the Dimensionless Analysis Matrix

6.6 Global Optimum Relationship between Dimensionless Indicated Power per

Generator Mass and Indicated Efficiency

6.7 Dimensionless Analysis Check

6.8 Comparison between the Mass of Two-Stroke Compression Ignition Linear

Engine/Alternator with the Masses of Lead Acid Batteries

Chapter 8 Recommendation for Future Work

References 
Appendix E Exploring outside the Dimensionless Analysis matrix (Continue) 160

Appendix F Heat Transfer Factor for Woschni’s Correlation 166 


\section{LIST OF FIGURES}

Figure 1.1: A Cross Sectional of a Linear/Alternator Two-Stroke Spark-Plug Linear Engine

Figure 2.1: Experimental Data Obtained by the Prototype of the Two-Stroke Spark-Plug Linear Engine

Figure 2.2: P/V Diagram Obtained by the Numerical Simulation of the Two-Stroke Spark-Plug Linear Engine Mode

Figure 2.3: P/V Diagram Obtained by the Numerical Simulation of the Two-Stroke Spark-Plug Linear Engine Model for Different Combustion Duration Values and Same Heat Inputs

Figure 2.4: Speed Versus Displacement Obtained by the Numerical Simulation of the Two-Stroke Spark-Plug Linear Engine Model for Different Combustion Duration Values and Same Heat Inputs

Figure 2.5: P/V Diagram Obtained by the Numerical Simulation of the Two-Stroke Spark-Plug Linear Engine Model for Different Profiles of Load

Figure 2.6: Piston Speed Versus Displacement Obtained by the Numerical Simulation of the Two-Stroke Spark-Plug Linear Engine Model for Different Profiles of Load 20

Figure 2.7: P/V Diagram Obtained by the Numerical Simulation of the Two-Stroke Spark-Plug Linear Engine Model for Different Moving Mass Assemblies

Figure 2.8: Piston Speed Versus Displacement Obtained by the Numerical Simulation of the Two-Stroke Spark-Plug Linear Engine Model for Different Moving Mass Assemblies 
Figure 2.9: P/V Diagram Obtained by the Numerical Simulation of the Two-Stroke Spark-Plug Linear Engine Model for Different Heat Inputs

Figure 2.10: Experimental Prototype of Two-Stroke Compression-Ignition Linear Engine

Figure 3.1: Free Body Diagram for Linear Engine

Figure 3.2: Load Shape Considered in the Analysis 30

Figure 4.1: In-Cylinder Pressure / Displacement Diagrams for Different Manifold Pressures, Lambda $=1000$, no Friction, and no Heat Transfer

Figure 4.2: Comparison Adiabatic Relation Values for the Three Cases

Figure 4.3: Efficiency Comparison Theoretical Otto Efficiency and Special Case Model Output. Translator Mass $=4 \mathrm{~kg}$

Figure 4.4: Velocity Profile Over the Stroke Versus Displacement for Lambda=3, Translator Mass $=4 \mathrm{~kg}$, and $\mathrm{Ca}=25 \mathrm{~N} \mathrm{Sec} / \mathrm{m}$

Figure 4.5: In-Cylinder Pressure Versus Displacement for Lambda=3, Translator Mass $=4$ $\mathrm{kg}$, and $\mathrm{Ca}=25 \mathrm{~N} \mathrm{Sec} / \mathrm{m}$

Figure 4.6: Output Power and Compression Ratio for Different Lambda, Translator Mass $=4 \mathrm{~kg}$ and $\mathrm{Ca}=25 \mathrm{~N} \mathrm{Sec} / \mathrm{m}$

Figure 4.7: Pressure / Displacement Diagram for Two Different types of Fuels, Lambda $=3$, Translator Mass $=4 \mathrm{~kg}, \mathrm{Ca}=25 \mathrm{~N} \mathrm{Sec} / \mathrm{m}$

Figure 4.8: Velocity Profile Over the Stroke for Two Different Types of Fuels, Lambda $=3$, Translator Mass $=4 \mathrm{~kg}$ and $\mathrm{Ca}=25 \mathrm{~N} \mathrm{Sec} / \mathrm{m}$ 45

Figure 4.9: Fuel Input Energy and Its Dividing Channel 46 
Figure 4.10: Pie Chart Showing How Input Energy Divides for Lambda=3, Translator Mass $=4 \mathrm{~kg}$ and $\mathrm{Ca}=25 \mathrm{~N} \mathrm{Sec} / \mathrm{m}$

Figure 4.11: Pie Chart Showing How Input Energy Divides for Lambda=3, Translator Mass $=4 \mathrm{~kg}$ and $\mathrm{Ca}=25 \mathrm{~N} \mathrm{Sec} / \mathrm{m}$

Figure 5.1: Displacement Versus Time for Different Translator Mass for Motoring Cases

Figure 5.2: Velocity Versus Displacement for Different Translator Mass for Motoring Cases 50

Figure 5.3: Compression Ratio and Frequency Versus Translator Mass for Motoring Cases

Figure 6.1: Dimensionless Indicated Power Versus Bore to Effective Stroke Length for Lambda $=3$, and Dimensionless Injection Position $=0.081$ 56

Figure 6.2: Dimensionless Indicated Power Versus Dimensionless Air Mass for Lambda $=3$, and Dimensionless Injection Position $=0.081$ 57

Figure 6.3: Indicated Efficiency Versus Bore to Effective Stroke Length for Lambda = 3, and Dimensionless Injection Position=0.081

Figure 6.4: Dimensionless Average Piston Speed Versus Bore to Effective Stroke Length for Lambda $=3$, and Dimensionless Injection Position $=0.081$ 58 Figure 6.5: Dimensionless Frequency Versus Bore to Effective Stroke Length for Lambda $=3$, and Dimensionless Injection Position $=0.081$ 58 Figure 6.6: Dimensionless Velocity Versus Dimensionless Stroke Length for Lambda=3, Ca1, and Dimensionless Injection Position $=0.081$ 
Figure 6.7: Dimensionless Velocity Versus Dimensionless Stroke Length for Lambda=3, Ca4, and Dimensionless Injection Position $=0.081$

Figure 6.8: Compression Ratio Versus Bore to Effective Stroke Length for Lambda $=3$, and Dimensionless Injection Position $=0.081$

Figure 6.9: Dimensionless In-Cylinder Pressure Versus Dimensionless Stroke Length for Lambda $=3, \mathrm{Ca} 1$, and Dimensionless Injection Position $=0.081$ 62

Figure 6.10: Dimensionless In-Cylinder Pressure Versus Dimensionless Stroke Length for Lambda $=3, \mathrm{Ca} 4$, and Dimensionless Injection Position $=0.081$

Figure 6.11: Dimensionless Friction Force Versus Dimensionless Stroke Length for Lambda $=3, \mathrm{Ca} 1$, and Dimensionless Injection Position $=0.081$

Figure 6.12: Dimensionless Friction Force Versus Dimensionless Stroke Length for Lambda $=3, \mathrm{Ca} 2$, and Dimensionless Injection Position $=0.081$

Figure 6.13: Dimensionless Friction Force Versus Dimensionless Stroke Length for Lambda $=3, \mathrm{Ca} 4$, and Dimensionless Injection Position $=0.081$ 64

Figure 6.14: Dimensionless Energy per Generator Volume Versus Bore to Effective Stroke Length for Lambda $=3$, and Dimensionless Injection Position $=0.081$ 65

Figure 6.15: Dimensionless Indicated Power per Cylinder Volume Versus Bore to Effective Stroke Length for Lambda $=3$, and Dimensionless Injection Position $=0.081$

Figure 6.16: Dimensionless Indicated Power per Generator Mass Versus Bore to Effective Stroke Length for Lambda $=3$, and Dimensionless Injection Position=0.081 
Figure 6.17: Dimensionless Energy per Generator Mass Versus Bore to Effective Stroke for Lambda $=3$, and Dimensionless Injection Position $=0.081$ 68

Figure 6.18: Dimensionless Indicated Power Versus Bore to Effective Stroke Length for Different Lambda, Different Dimensionless Load Constants, and Dimensionless Injection Position $=0.081$

Figure 6.19: Dimensionless Indicated Power Versus Dimensionless Air Mass for Different Lambda, Different Dimensionless Load Constants, and Dimensionless Injection Position $=0.081$

Figure 6.20: Dimensionless Average Piston Speed Versus Bore to Effective Stroke Length for Different Lambda, Different Dimensionless Load Constants and Dimensionless Injection Position $=0.081$

Figure 6.21: Dimensionless Frequency Versus Bore to Effective Stroke length for Different Lambda, Different Dimensionless Load Constants and Dimensionless Injection Position $=0.081$ 72

Figure 6.22: Indicated Efficiency Versus Bore to Effective Stroke Length for Different Lambda, Different Dimensionless Load Constants and Dimensionless Injection Position $=0.081$

Figure 6.23: Dimensionless Velocity Versus Dimensionless Stroke Length for Lambda $=4, \mathrm{Ca} 1$, and Dimensionless Injection Position $=0.081$

Figure 6.24: Dimensionless Velocity Versus Dimensionless Stroke Length for Lambda $=4, \mathrm{Ca} 4$, and Dimensionless Injection Position $=0.081$

Figure 6.25: Dimensionless Velocity Versus Dimensionless Stroke Length for Lambda $=5, \mathrm{Ca} 1$, and Dimensionless Injection Position $=0.081$ 
Figure 6.26: Compression Ratio Versus Bore to Effective Stroke for Different Lambda, Different Dimensionless Load Constants, and Dimensionless Injection Position=0.081

Figure 6.27: Dimensionless In-Cylinder Pressure Versus Dimensionless Stroke Length for Lambda $=4, \mathrm{Ca} 1$, and Dimensionless Injection Position $=0.081$

Figure 6.28: Dimensionless In-Cylinder Pressure Versus Dimensionless Stroke Length for Lambda $=5, \mathrm{Ca} 1$, and Dimensionless Injection Position $=0.081$

Figure 6.29: Dimensionless Friction Force Versus Dimensionless Stroke Length for Lambda $=4, \mathrm{Ca} 1$, and Dimensionless Injection Position $=0.081$ 78

Figure 6.30: Dimensionless Energy per Generator Volume Versus Bore to Effective Stroke Length for Different Lambda, Different Dimensionless Load Constants, and Dimensionless Injection Position $=0.081$ 79

Figure 6.31: Dimensionless Indicated Power per Cylinder Volume Versus Bore to Effective Stroke Length for Different Lambda, Different Dimensionless Load Constants, and Dimensionless Injection Position $=0.081$ 80

Figure 6.32: Dimensionless Indicated Power per Generator Mass Versus Bore to Effective Stroke Length for Different Lambda, Different Dimensionless Load Constants, and Dimensionless Injection Position $=0.081$ 81

Figure 6.33: Dimensionless Energy per Generator Mass Versus Bore to Effective Stroke Length for Different Lambda, Different Dimensionless Load Constants, and Dimensionless Injection Position $=0.081$ 
Figure 6.34: Dimensionless Indicated Power Versus Bore to Effective Stroke Length for Different Lambda, Different Dimensionless Load Constants, and Dimensionless Injection Position $=0.19$ 84

Figure 6.35: Dimensionless Indicated Power Versus Dimensionless Air Mass for Different Lambda, Different Dimensionless Load Constants, and Dimensionless Injection Position $=0.19$ 85

Figure 6.36: Indicated Efficiency Versus Bore to Effective Stroke Length for Different Lambda, Different Dimensionless Load Constants, and Dimensionless Injection Position $=0.19$ 86

Figure 6.37: Dimensionless Average Piston Speed Versus Bore to Effective Stroke Length for Different Lambda, Different Dimensionless Load Constants, and Dimensionless Injection Position $=0.19$ 86

Figure 6.38: Dimensionless Frequency Versus Bore to Effective Stroke Length for Different Lambda, Different Dimensionless Load Constants, and Dimensionless Injection Position $=0.19$

Figure 6.39: Compression Ratio Versus Bore to Effective Stroke Length for Different Lambda, Different Dimensionless Load Constants, and Dimensionless Injection Position $=0.19$ 88

Figure 6.40: Dimensionless In-Cylinder Pressure Versus Dimensionless Stroke Length for Lambda $=4, \mathrm{Ca} 3$, and Injection Position $=0.19$ 89 Figure 6.41: Dimensionless In-Cylinder Pressure Versus Dimensionless Stroke Length for Lambda $=5, \mathrm{Ca} 3$, and Injection Position $=0.19$ 
Figure 6.42: Dimensionless Friction Force Versus Dimensionless Stroke Length for Lambda $=5, \mathrm{Ca} 1$, and Dimensionless Injection Position $=0.19$

Figure 6.43: Dimensionless Friction Force Versus Dimensionless Stroke Length for Lambda $=5, \mathrm{Ca} 3$, and Dimensionless Injection Position $=0.19$

Figure 6.44: Dimensionless Velocity Versus Dimensionless Stroke Length for Lambda $=5, \mathrm{Ca} 1$, and Dimensionless Injection Position $=0.19$

Figure 6.45: Dimensionless Velocity Versus Dimensionless Stroke Length for Lambda $=5, \mathrm{Ca} 3$, and Dimensionless Injection Position $=0.19$ 92

Figure 6.46: Dimensionless Energy per Generator Volume Versus Bore to Effective Stroke Length for Different Lambda, Different Dimensionless Load Constants, and Dimensionless Injection Position $=0.19$ 93

Figure 6.47: Dimensionless Indicated Power per Cylinder Volume Versus Bore to Effective Stroke Length for Different Lambda, Different Dimensionless Load Constants, and Dimensionless Injection Position $=0.19$

Figure 6.48: Dimensionless Indicated Power per Generator Mass Versus Bore to Effective Stroke Length for Different Lambda, Different Dimensionless Load Constants, and Dimensionless Injection Position=0.19

Figure 6.49: Dimensionless Energy per Generator Mass Versus Bore to Effective Stroke Length for Different Lambda, Different Dimensionless Load Constants, and Dimensionless Injection Position=0.19 96

Figure 6.50: Dimensionless Indicated Power Versus Bore to Effective Stroke Length for Different Lambda, Different Dimensionless Load Constants, and Dimensionless Injection Position $=0.081$ 
Figure 6.51: Dimensionless Indicated Power Versus Bore to Effective Stroke Length for Different Lambda, Different Dimensionless Load Constants, and Dimensionless Injection Position $=0.91$

Figure 6.52: Dimensionless Indicated Power Versus Bore to Effective Stroke Length for Different Lambda, Different Dimensionless Load Constants, and Dimensionless Injection Position $=0.018$ 100

Figure 6.53: Indicated Efficiency Versus Bore to Effective Stroke Length for Different Lambda, Different Dimensionless Load Constants, and Dimensionless Injection Position $=0.19$ 100

Figure 6.54: Dimensionless Average Piston Speed Versus Bore to Effective Stroke Length for Different Lambda, Different Dimensionless Load Constants, and Dimensionless Injection Position $=0.018$ 101

Figure 6.55: Dimensionless Average Piston Speed Versus Bore to Effective Stroke Length for Different Lambda, Different Dimensionless Load Constants, and Dimensionless Injection Position $=0.19$ 102

Figure 6.56: Dimensionless Frequency Versus Bore to Effective Stroke Length for Different Lambda, Different Dimensionless Load Constants, and Dimensionless Injection Position $=0.018$ 102

Figure 6.57: Dimensionless Frequency Versus Bore to Effective Stroke Length for Different Lambda, Different Dimensionless Load Constants, and Dimensionless Injection Position $=0.19$

Figure 6.58: Dimensionless In-Cylinder Pressure Versus Dimensionless Stroke Length for Lambda $=3$, Ca1, and Injection Position $=0.018$ 103 
Figure 6.59: Dimensionless In-Cylinder Pressure Versus Dimensionless Stroke Length for Lambda=3, Ca1, and Injection Position $=0.19$

Figure 6.60: Dimensionless Friction Force Versus Dimensionless Stroke Length for Lambda $=3, \mathrm{Ca}$, and Dimensionless Injection Position $=0.018$

Figure 6.61: Dimensionless Friction Force Versus Dimensionless Stroke Length for Lambda $=3, \mathrm{Ca} 1$, and Dimensionless Injection Position $=0.19$ 105

Figure 6.62: Dimensionless Velocity Versus Dimensionless Stroke Length for Lambda $=3, \mathrm{Ca} 1$, and Dimensionless Injection Position $=0.018$ 105

Figure 6.63: Dimensionless Velocity Versus Dimensionless Stroke Length for Lambda $=3, \mathrm{Ca}$, and Dimensionless Injection Position $=0.19$ 106

Figure 6.64: Compression Ratio Versus Bore to Effective Stroke for Different Lambda, Different Dimensionless Load Constants, and Dimensionless Injection Position=0.081

Figure 6.65: Compression Ratio Versus Bore to Effective Stroke for Different Lambda, Different Dimensionless Load Constants, and Dimensionless Injection Position=0.19

Figure 6.66: Compression Ratio and Indicated Efficiency Versus Bore to Effective Stroke Length for Lambda $=3, \mathrm{Ca}$, and Dimensionless Injection Position $=0.081$

Figure 6.67: Indicated Efficiency Versus Dimensionless Indicted Power per Generator Mass for Ca1, Different Lambda and Different Bore to Effective Stroke Length. 112 Figure 6.68: Indicated Efficiency Versus Dimensionless Indicted Power per Generator Mass for Ca4, Different Lambda and Different Bore to Effective Stroke Length. 112 
Figure 6.69: Dimensionless Frequency Versus Bore to Effective Stroke Length for Ca1, Lambda $=5$, and Dimensionless Injection Position $=0.081$

Figure 6.70: Dimensionless Frequency Versus Bore to Effective Stroke Length for Ca1, Lambda $=12.5$, and Dimensionless Injection Position $=0.081$

Figure 6.71: Comparison Between the Mass of 0.7 kW Two-Stroke Linear Engine Diesel Generator and the Masses of Lead Acid Batteries

Figure 6.72: Comparison Between the Mass of 4.4 kW Two-Stroke Linear Engine Diesel Generator and the Masses of Lead Acid Batteries

Figure C1: Load Constant Limit for two-Stroke Linear Engine for Lambda=4, Translator Mass $=4 \mathrm{~kg}$

Figure D1: Dimensionless Energy per Generator Volume Versus Bore to Effective Stroke Length for Different Lambda, Different Dimensionless Load Constants, and Dimensionless Injection Position $=0.018$ 155

Figure D2: Dimensionless Energy per Generator Volume Versus Bore to Effective Stroke Length for Different Lambda, Different Dimensionless Load Constants, and Dimensionless Injection Position $=0.19$ 156

Figure D3: Dimensionless Indicated Power per Cylinder Volume Versus Bore to Effective Stroke Length for Different Lambda, Different Dimensionless Load Constants, and Dimensionless Injection Position $=0.018$ 156

Figure D4: Dimensionless Indicated Power per Cylinder Volume Versus Bore to Effective Stroke Length for Different Lambda, Different Dimensionless Load Constants, and Dimensionless Injection Position $=0.19$ 
Figure D5: Dimensionless Indicated Power per Generator Mass Versus Bore to Effective Stroke Length for Different Lambda, Different Dimensionless Load Constants, and Dimensionless Injection Position $=0.018$ 158

Figure D6: Dimensionless Indicated Power per Generator Mass Versus Bore to Effective Stroke Length for Different Lambda, Different Dimensionless Load Constants, and Dimensionless Injection $=0.19$ 158

Figure D7: Dimensionless Energy per Generator Mass Versus Bore to Effective Stroke Length for Different Lambda, Different Dimensionless Load Constants, and Dimensionless Injection Position $=0.018$ 159

Figure D8: Dimensionless Energy per Generator Mass Versus Bore to Effective Stroke Length for Different Lambda, Different Dimensionless Load Constants, and Dimensionless Injection Position $=0.19$ 159

Figure E1: Dimensionless Frequency Versus Bore to Effective Stroke Length for Lambda $=3$, Different Dimensionless Load Constants, and Dimensionless Injection Position $=0.081$ 160

Figure E2: Dimensionless Indicated Power Versus Bore to Effective Stroke Length for Lambda $=3$, Different Dimensionless Load Constants, and Dimensionless Injection Position $=0.081$ 161

Figure E3: Dimensionless Average Piston Speed Versus Bore to Effective Stroke Length for Lambda=3, Different Dimensionless Load Constants, and Dimensionless Injection Position $=0.018$ 
Figure E4: Dimensionless Indicated Power per Cylinder Volume Versus Bore to Effective Stroke Length for Lambda=3, Different Dimensionless Load Constants, and Dimensionless Injection Position $=0.018$ 163

Figure E5: Dimensionless Indicated Power per Generator Mass Versus Bore to Effective Stroke Length for Lambda $=3$, Different Dimensionless Load Constants, and Dimensionless Injection Position $=0.018$ 164

Figure E6: Dimensionless Energy per Generator Mass Versus Bore to Effective Stroke Length for Lambda=3, Different Dimensionless Load Constants, and Dimensionless Injection Position $=0.018$

Figure F1. Indicated Power Versus Different Heat Transfer Factor for Lambda=4, Translator Mass $=4 \mathrm{~kg}$, and $\mathrm{Ca}=25 \mathrm{~N} \mathrm{Sec} / \mathrm{m}$ 166 


\section{LIST OF TABLES}

Table 2.1: Geometric parameters of a spark-ignition two-stroke linear engine prototype

Table 2.2: Experimental data for two-stroke spark ignited linear engine using friction brake to change load-operating condition

Table 2.3: Experimental data for the linear engine using permanent magnet alternator as

a load governor

15

Table 2.4: Summary of some of the results of the modeling simulation program of the two-stroke spark-ignition linear engine

Table 6.1: The dimensionless analysis matrix 


\section{NOMENCLATURE}

a Constant

A Constant

AV* Dimensionless average velocity

$\mathrm{a}^{*} \quad$ Acceleration $\left[\mathrm{m} / \mathrm{sec}^{2}\right]$

$\mathrm{A}_{\mathrm{p}} \quad$ Piston cross sectional area $\left[\mathrm{m}^{2}\right]$

$A_{R} \quad$ Piston ring area contacting the cylinder skirt $\left[\mathrm{m}^{2}\right]$

$\mathrm{A}_{\mathrm{cyl}} \quad$ Cylinder heat transfer area $\left[\mathrm{m}^{2}\right]$

Amp. Ampere

b Shape factor

B Cylinder bore $[\mathrm{m}]$

$\mathrm{B} / \mathrm{St} \quad$ Bore to effective stroke

$\mathrm{C}_{\mathrm{a}} \quad$ Load constant applied by alternator $[\mathrm{N} \mathrm{sec} / \mathrm{m}]$

$\mathrm{C}_{\mathrm{a}}{ }^{*} \quad$ Dimensionless load constant

Cd Combustion duration $[\mathrm{sec}]$

$\mathrm{c}_{\mathrm{v}} \quad$ Constant volume specific heat $[\mathrm{J} / \mathrm{kg} \mathrm{K}]$

CV Cylinder volume $\left[\mathrm{m}^{3}\right]$

D Cylinder bore $[\mathrm{m}]$

Dif* Diffusive combustion [\%]

E Young's modulus of elasticity $\left[\mathrm{N} / \mathrm{m}^{2}\right]$

$\mathrm{E}_{\mathrm{A}} \quad$ Apparent activation energy for the fuel autoignition process [ $\left.\mathrm{J} / \mathrm{Mole}\right]$

EM* Dimensionless energy per generator mass

$\mathrm{EV}^{*}$ Dimensionless energy per generator volume

ER Energy $[\mathrm{J}]$ 
f Frictional coefficient

f* Dimensionless frequency

$\mathrm{F}_{\mathrm{fl}} \quad$ Friction force resulted by boundary lubricating regime $[\mathrm{N}]$

$\mathrm{F}_{\mathrm{f}} \quad$ Friction force $[\mathrm{N}]$

Ff* Dimensionless friction force

$\mathrm{F}_{1} \quad$ Load force $[\mathrm{N}]$

fq. Frequency $[\mathrm{Hz}]$

g Gravitational force $\left[\mathrm{m} / \mathrm{sec}^{2}\right]$

G Specific heat ratio

GM Generator mass $[\mathrm{kg}]$

GV Generator volume $\left[\mathrm{m}^{3}\right]$

h Heat transfer coefficient $\left[\mathrm{W} / \mathrm{m}^{2} \mathrm{~K}\right]$

$\mathrm{h}_{\text {mot }} \quad$ Motoring heat transfer coefficient $\left[\mathrm{W} / \mathrm{m}^{2} \mathrm{~K}\right]$

I Moment of inertia $\left[\mathrm{m}^{4}\right]$

IP* Dimensionless in-cylinder pressure

IPM* Dimensionless indicated power per generator mass

IPV* Dimensionless indicated power per generator volume

J* Dimensionless injection position

K Exponential load factor

L Stroke length [m]

Lste Effective stroke length [m]

m Moving translator mass [kg]

m* Dimensionless air mass

$\mathrm{m}_{\mathrm{b}} \quad$ Burned fuel mass $[\mathrm{kg}]$

$\mathrm{m}_{\mathrm{in}} \quad$ Mass of the air $[\mathrm{kg}]$ 
$\mathrm{m}_{\mathrm{inj}} \quad$ Injected fuel mass $[\mathrm{kg}]$

M* Dimensionless mass

M Mass [kg]

$\mathrm{M}_{\mathrm{d}} \quad$ Shape Factor

$\mathrm{M}_{\mathrm{p}} \quad$ Shape Factor

MW Molecular weight $[\mathrm{kg} / \mathrm{kmol}]$

$\mathrm{P}_{\text {mot }}$ Motoring in-cylinder pressure $\left[\mathrm{N} / \mathrm{m}^{2}\right]$

$\mathrm{T}$ mot Motoring in-cylinder temperature [K]

P In-cylinder absolute pressure $\left[\mathrm{N} / \mathrm{m}^{2}\right]$

P* Dimensionless indicated power

P1 In-cylinder absolute pressure of cylinder no. $1\left[\mathrm{~N} / \mathrm{m}^{2}\right]$

P2 In-cylinder absolute pressure of cylinder no. $2\left[\mathrm{~N} / \mathrm{m}^{2}\right]$

Pr* Premixed combustion [\%]

Pa Pascal

$\mathrm{P}_{\mathrm{mp}} \quad$ Pressure just after closing the exhaust port $\left[\mathrm{N} / \mathrm{m}^{2}\right]$

$\mathrm{P}_{\mathrm{r}} \quad$ Working fluid pressure at some refrence state $\left[\mathrm{N} / \mathrm{m}^{2}\right]$

$\mathrm{p} \quad$ Radial force for the piston ring $[\mathrm{N} / \mathrm{m}]$

PW Power [W]

$\Delta \mathrm{P} \quad$ Differential pressure between the right and left cylinders $\left[\mathrm{N} / \mathrm{m}^{2}\right]$

Q Heat transfer $[\mathrm{J}]$

r Compression ratio

$\mathrm{R} \quad$ Universal gas constant $[\mathrm{J} / \mathrm{kmol} \mathrm{K}]$

s Length of the piston's ring [m]

$\bar{S}_{p} \quad$ Average piston speed [m/sec] 
$\mathrm{t}_{\mathrm{o}} \quad$ Time at which the combustion process starts [sec]

$\mathrm{t} \quad$ Time $[\mathrm{sec}]$

t* Dimensionless time

tsi Time at which injection starts[sec]

$\mathrm{T} \quad$ In-cylinder temperature $[\mathrm{K}]$

T1 In-cylinder temperature of cylinder no. $1[\mathrm{~K}]$

T2 In-cylinder temperature of cylinder no. $2[\mathrm{~K}]$

$T_{\mathrm{r}} \quad$ Working fluid temperature at some refrence state $[\mathrm{K}]$

$\mathrm{T}_{\mathrm{w}} \quad$ Wall temperature $[\mathrm{K}]$

$\mathrm{U} \quad$ Internal energy [J]

$\mathrm{v} \quad$ Velocity $[\mathrm{m} / \mathrm{sec}]$

$\mathrm{V} \quad$ Displaced volume of the cylinder $\left[\mathrm{m}^{3}\right]$

$\mathrm{V}^{*} \quad$ Dimensionless velocity over the stroke

$\mathrm{V}_{\mathrm{d}} \quad$ Displaced volume $\left[\mathrm{m}^{3}\right]$

$V_{\mathrm{r}} \quad$ Volume at some refrence state $\left[\mathrm{m}^{3}\right]$

YP1 Fuel mass fraction burned during premixed combustionin cylinder no.1 $[\mathrm{kg}]$

YP2 Fuel mass fraction burned during premixed combustion in cylinder no.2 [kg]

Yd1 Fuel mass fraction burned during diffusive combustionin cylinder no.1 [kg]

Yd2 Fuel mass fraction burned during diffusive combustionin cylinder no.2 [kg]

W Avarage cylinder gas velocity $[\mathrm{m} / \mathrm{sec}]$

w Work done $[\mathrm{J}]$

$\mathrm{x} \quad$ Displacement $[\mathrm{m}]$

$\mathrm{x}_{0} \quad$ Initial position $[\mathrm{m}]$

Xexp1 Distance of cylinder no. 1exhaust port from cylinder head [m]

Xexp2 Distance of cylinder no. 2exhaust port from cylinder head [m]

Xinj Distance between cylinder head and injection position [m]

$\mathrm{x}^{*} \quad$ Dimensionless displacement

$\mathrm{X}(\mathrm{t}) \quad$ Fuel mass fraction burned $[\mathrm{kg}]$ 


$$
\begin{array}{ll}
\frac{d x}{d t} & \text { Speed }[\mathrm{m} / \mathrm{sec}] \\
\frac{d^{2} x}{d t^{2}} & \text { Acceleration }\left[\mathrm{m} / \mathrm{sec}^{2}\right] \\
\gamma & \text { Specific heat ratio } \\
\psi & \text { Overall friction coefficient } \\
\lambda & \text { Lambda } \\
\eta & \text { Indicated efficiency [\%] } \\
\tau_{\text {id }} & \text { Ignition time delay [sec] } \\
\theta & \text { Crank angle [degrees] }
\end{array}
$$




\section{1-INTRODUCTION}

The industrial revolution started with the invention of the steam engine. The steam engine concept depends on changing the chemical energy of fuels to mechanical

work. Internal combustion engines have been the result of much research in the pursuit of producing more efficient heat engines. The internal combustion engine has been used on a very large scale for many fields including, but not limited to, transportation, power generation, industrial and construction equipment. Despite this enormous amount of research, the main concept of the internal combustion engine is still the same with minimum changes over the last decade. With the increase of fuel demand, the need for a more efficient and compact power device for domestic, industrial or military applications has arisen and become the core of much research. Accordingly, the idea to develop the linear engine has been proposed as a possible alternative and a further forward step in producing a new generation of internal combustion engine. This dissertation will focus on evaluating the performance of the two-stroke direct injection linear engine and study the possibility that this engine can be used as an efficient alternative to generate energy. It is known that linear engines are categories of engines that can run without the slider crank mechanism, which is considered a substantial friction source. This may be the first step on the way that may lead to a better design for an internal combustion engine generation with higher overall efficiency.

In 1876 Otto introduced the spark-ignition engine and in 1892 Diesel invented the compression-ignition engine. Since that time the development of these two types of engines has been changing with our increasing knowledge in thermal sciences and different engine processes. As technology advances, demand for energy increases and 
the need for new types of engines arises. Also, the needs for better types of engines that can handle fuel combustion in a more efficient and cleaner way that meets the environmental constraints become a striving need.

In recent years, researchers have shown interest in two-stroke engine technology for automotive and power generation applications. The fundamental attractions of the two-stroke engine, compared to the four-stroke, are its superior thermal efficiency, reduced weight, simple design and greater compactness. The double cycle frequency compared to four-stroke engines and low mechanical friction and pumping losses give to the two-stroke engine its qualities of high specific power, compactness, and low NO emissions [1].

It is known that the linear engine was first introduced by R. Pescara in the 1920's and has been the subject of intensive research ever since for better internal combustion engine design [2].

One of the applications of the free piston designs is the internal combustion linear engine. The internal combustion linear engine is composed of two opposed pistons connected solidly by a link rod and combustion occurs alternately at either end of the piston. The piston reverses its direction as a result of balancing the forces between the two cylinders. The rod of the linear engine that connects the two cylinders is oscillating inside an alternator and as a result of cutting the flux lines electricity is generated. Needless to say, that the use of linear engine would eliminate much of the friction by eliminating the crankshaft and bearings used in conventional internal combustion engines and also the friction on the piston due to side thrust caused by the slider-crank mechanism. However, in the linear engine the moving assembly mass slides back and 
force and the friction force is a result of the forces applied by the piston rings, weight of the moving assembly mass and net pressure force applied on the rings friction area.

Previous studies on linear engines indicated that the free piston engine has the potential to maximize cycle efficiencies relative to the ideal Otto cycle by utilizing high operating compression ratios (20-30:1) and a homogeneous charge compression-ignition (HCCI) combustion process [3].

Figure 1-1 shows a cross section of a two-stroke spark ignited linear engine coupled with a linear alternator that has been designed and operated by West Virginia University [4]. This technology, which is still at the research level, will lead to a better internal combustion engine design that can handle fuel consumption in a more efficient way than the conventional internal combustion engines.

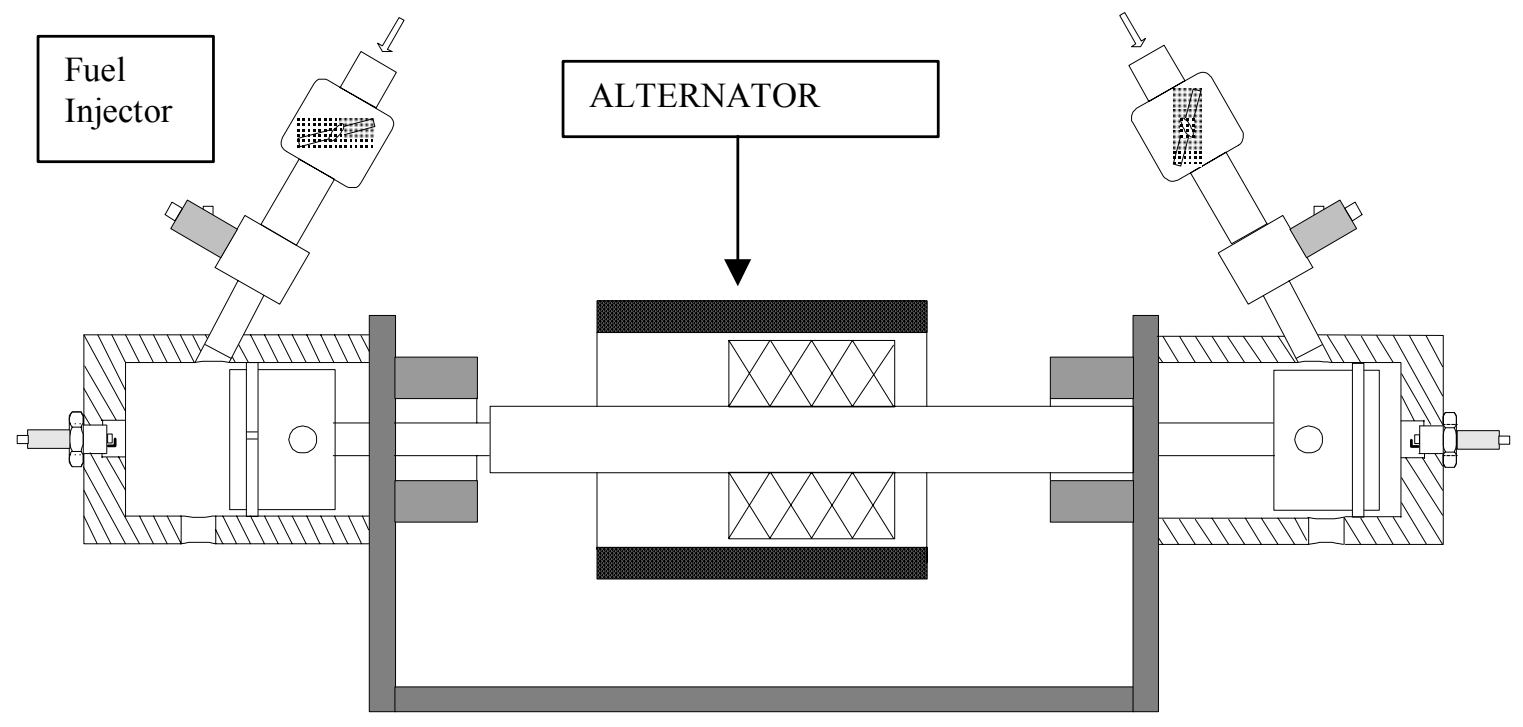

Figure 1.1. A Cross Section of a Linear/Alternator Two-Stroke Spark-Plug Linear Engine [4] 


\subsection{OBJECTIVES}

In this dissertation a numerical computer program has been designed to predict the performance of a two-stroke direct injection compression-ignition linear engine design and estimate the different factors that govern the operation of such a powergenerating unit.

The model consists of a series of mathematical equations that simulate the dynamics and thermodynamics of the two-stroke linear engine, and are solved simultaneously through a series of time steps. In addition, the model allows certain input values to be changed like fuel type, air to fuel ratio, injection of fuel position, combustion distribution of the fuel between premixed and diffusive combustion, alternator load, and moving assembly mass. By solving the mathematical equations many output parameters result like in-cylinder pressure, compression ratio, indicated efficiency, friction force, frequency, and average piston speed.

The objective of this dissertation was to explore the benefits of the two-stroke compression ignition linear engine coupled with linear alternator and find out its best operating conditions and the parameters that lead to effective design. To meet the objectives the following tasks must be completed:

1- A literature review study that focused on the latest techniques used in modeling linear engines at West Virginia University should be conducted.

2- Latest techniques used for modeling the two-stroke linear engine should be adopted.

3- A numerical model for the two-stroke compression-ignition linear engine that simulates the different processes that take place during the full stroke of the engine must be built. The simulation model must include dynamic, 
thermodynamic, combustion and heat release equations that are used in predicting the frequency, in-cylinder pressure, in-cylinder temperature, piston speed, piston displacement, indicated power, and indicated efficiency.

4- The model should be validated by running the program and comparing its output efficiency with the theoretical Otto cycle efficiency.

5- Another model validation method should be conducted using the adiabatic relation.

6- Special motoring case should be used to study the moving assembly mass effect on the dynamic, i.e. the displacement, the velocity profile, the compression ratio, and the frequency of the two-stroke compression-ignition direct injection linear engines.

7- A dimensionless parametric study should be carried out using dimensionless analysis technique to study the effect of different variables, like indicated efficiency, compression ratio, dimensionless indicated power output, dimensionless frequency, dimensionless average piston speed, etc. In this way the characteristics of the two-stroke compression-ignition linear engine will be generalized to a wider range of geometric designs for such an engine.

8- The parameters that lead to the highest obtained indicated efficiency and effective design for different applications must be recommended for the two-stroke compression-ignition direct injection linear engines.

9- The indicated efficiency should be correlated with the dimensionless indicated power per generator mass and the parameters affecting them must be discussed. 


\section{2-LITERATURE REVIEW}

\subsection{TWO-STROKE ENGINE HISTORY}

Motorcycles were one of the early applications of the two-stroke engine. Edward Butler produced the first engines in 1887. In 1892, J. D. Roots introduced the two-stroke engine of the day crankcase type; both of these types have been used in tricycles. Alfred Scott conducted considerable experimentation and development, and his flying squirrel machines were used to compete in Tourist Trophy races during the first three decades of the twentieth century [1].

Up to the present date, the two-stroke engine is used on a large scale in powering motorcycles and for general transportation equipment as well as recreational purposes. The two-stroke engine has not only been used in aircraft because of its lightweight, but also in hand-held power equipment as well. Of course, the high specific power performance and the lightweight of these types of engines played an important role in such designs. Such tools are chainsaws, brush cutters and concrete saws.

Evinrude in the USA pioneered the earliest outboard motors in 1909, with a 1.5 hp unit, and two-stroke engines have dominated the marine outboard engine units until the present day [1].

The use of the two-stroke engine in automobiles has had an interesting history, and many sophisticated designs were produced in the 1960's, such as the Auto Union vehicle from West Germany and the simpler Watburg from East Germany. A Saab car from Sweden with Eric Carlson driving it won the Monte Carlo Rally. In present time, Suzuki still builds a small two-stroke engined car that is used mainly in Japan. With increasing regulations associated with exhaust emissions and fuel consumption rate, the 
simple two-stroke engined car disappeared, but the interest in the design of such engines has been increasing as the pressure to produce engines with less exhaust acid emissions increased.

Almost all car manufacturers are experimenting with various forms of two-stroke engined vehicles equipped with direct fuel injection, or some variation of that concept in terms of stratified charging or combustion [1].

The two-stroke engine has been used in light aircraft, and today is most frequently employed in recreational microlite machines. There are numerous other applications for two-stroke spark-ignition engines, such as small electricity generating sets or engines for remotely piloted vehicles, i.e., aircraft for meteorological data gathering or military purposes. These are only two of a long list of multifarious examples.

The use of the two-stroke engine in compression-ignition form deserves special attention. The two-stroke diesel engine has been used by many companies, to power trucks such as General Motors or Rootes-Tilling-Stevens of England. Both companies were very successful in the production of this engine. Also, this type of engine has been a favorite for many military applications, such as tanks, for its high specific power output. One of the most remarkable and successful two-stroke compression-ignition engines that have been built was a marine diesel main propulsion unit, known as a "cathedral" engine. The engine was 12-meters tall, cylinder bore was $900 \mathrm{~mm}$ and the stroke was $1800 \mathrm{~mm}$, the engine ran at 60-100 rpm, producing some $4000 \mathrm{hp}$ per cylinder. The thermal efficiency of this engine was $50 \%$, which made it one of the most efficient main driving movers ever made [1].

Internal combustion engines are machines converting high temperature heat 
energy to mechanical work. These machines operate on different thermodynamic cycles where heat energy is added and removed at conditions of constant-volume and/or constant-pressure. The cycle in a two-stroke engine is completed in two strokes, which is equivalent to one crank revolution while it takes two crank revolutions to complete one cycle in four-stroke engines. Theoretically if all other parameters are equal for the two types of engine, the two-stroke engine develops twice the horsepower of a four-stroke engine having the same piston displacement.

There is also another technical difference between two-stroke and four-stroke engines, which is in the method of removing the burned gases, and filling the cylinder with a fresh charge. In a four-stroke engine the engine's piston performs these operations during the exhaust and suction strokes using intake and exhaust valves. While, in a twostroke engine these operations are performed near the bottom dead center, after the expansion stroke, by a stream of air or air-fuel mixture admitted under pressure and delivered by a separate pump through intake and exhaust ports.

In the conventional form of internal combustion engines, the engine converts the pistons' linear energy to rotational energy using a slider-crank mechanism. It is also known that components like crankshaft and bearings are the main cause of friction in the conventional internal combustion engine. In an attempt to design a better internal combustion engine with higher thermal efficiency the linear engine was introduced.

\subsection{TWO-STROKE LINEAR ENGINE STORY AND ITS DEVELOPMENT}

R. Pescara introduced the linear engine in the 1920 's, which was used as air compressors [2]. Ever since, there have been many attempts to use this engine as a powerful tool in automotive and power generation that can handle fossil fuel in a more efficient way. It is well known that rod and main bearings in internal combustion engines 
are responsible for significant frictional losses; these components are not parts of the linear engines.

In World War Two, Junkers in Germany developed a free piston engine for a German submarine [2]. In the 1950's crankless gas generator piston engines were employed to feed power turbines, which are known as a gasifiers. They consisted of opposite pistons that were driven outward by combustion simultaneously. These pistons were each directly connected to an air compressor piston to absorb the cycle work, and a mix of engine exhaust and compressed air was sent to drive a turbine [2]. The free piston gasifier Sigma has been used in France for years in stationary power stations.

The use of free piston engines in automotive applications peaked between 1952 and 1961 when both General Motors and the Ford Motor Company produced running prototypes [5-6].

Frey et al. [6] built and tested a free piston gas generator turbine set that was sized for an automobile.

Galitello [7] patented a two-stroke cycle, variable compression, free piston engine. The engine consisted of two directly opposed, identical, outward compressing pistons that were rigidly connected. Power was extracted from a central hydraulic cylinder or by a linear alternator. The engine was spark ignited and computer controlled. The computer-controlled system sensed the desired power; fuel combustion properties and energy generated and would adjust accordingly. This allowed the engine to use a variety of fuels. The inventor claimed ultra high frequency operation and no vibration.

Bock [8] presented a two-stroke cycle compression-ignition engine-pump combination. A central pump cylinder that was directly connected to the pistons 
extracted power. There were inlet and outlet valves as well as a common suction chamber in the central part of the engine. The engine had gas cushioning accomplished by a nitrogen filled elastic annular body. The gas cushion served as a shock absorber for the engine vibration. The engine also had oil cooling by means of cooling jackets around the cylinders.

Ritz [9] presented a linear type engine. The engine consisted of two cylinders connected by a solid rod in coaxial alignment with each other. The two cylinders were disposed coaxially and oppositely so that the free ends of the piston rods extended from the reciprocal pistons in the cylinders. The force developed by reciprocation of the pistons was converted to rotating driving motion by means of a rotary crank. The inventor claimed that "the improvements wherein the inner end of the piston rod was placed in abutment with the underside of the piston head and the yoke was modified to house a block slider instead of a rolling bearing to provide better bearing surfaces and lubrication thereof."

Cinquegrani [10] presented an internal combustion engine apparatus including a dual piston with a multiple intake ports and having reed type check valves.

Rittmaster et al. [11] presented a hydraulic motor operated by an engine. The engine consisted of two opposed pistons connected by a solid rod used to drive the hydraulic fluid under pressure through a series of crossover valves to and from the hydraulic motor. Sets of detectors were actuated by a series of embodiments within the connecting rod. The detectors were used to time the engine's operation and the valves without using any mechanical linkages. A hydraulic pump was used to start the engine. A blower was used to exhaust the burned gases and mix the fuel and air within the system 
where a flywheel was used to store the energy.

Heintz [12] presented a pump driven by a free piston engine to generate hydraulic power output. The free piston engine consisted of two double acting pistons linked together with a connecting rod. A position actuator fitted on the main reciprocating mass was used to actuate a common actuator that supplied air to the combustion chambers. Also, the same position actuator was used to control the fuel injection and exhaust valves, which controlled the exhaust of the burned gases from the combustion chamber. The exhaust valves were air-cooled. A special pressure valve was used to control the start up of the free engine pump.

Allais [13] presented a free piston engine operating with independent cam to generate electric power. The engine consisted of one or more units each composed of two opposed pistons connected to a connecting rod and moved within two opposed cylinders. The connecting rod was connected at its middle to an inductor of a linear alternator. An independent motor driven cam was used to limit the travel of the pistons units and provided the energy needed for the compression stroke in case of anomalous operation. The cam served also to start the engine, as well as to mutually synchronize the various units of pistons in engines having a plurality of units stroke. The inventor claimed that "coal dust or other solid fuel could run this engine."

Nerstrom [14] presented a two-stroke internal combustion engine with varying cylinder port timing. The engine block had a passage that could be used as an exhaust, or an intake port. A valve was mounted in the passage to vary the effective distance of the ports from the cylinder head. In this way the engine had the capability to vary the opening and closing timing of the engine and hence changed the overall performance of 
the engine at different operating conditions.

Deng et al. [15] presented a double-acting tandem free piston engine used to generate power for a hybrid vehicle. The engine consisted of two pistons, each of them connected to an opposite piston with a solid connecting rod. A linear conductor of a linear alternator was connected to each connecting rod. The alternators were used to power electric wheel driving motors and stored power in a storage battery.

Iliev et al. [16] presented a two-stroke spark ignited engine coupled with an electrical linear generated motor.

An interesting free piston engine design was presented by Kos [17]. The engine was a two-stroke linear engine coupled with an electromagnetic transducer for control and power output. The inventor claimed that his engine could be operated as a spark-ignition or a compression-ignition engine. The engine was designed to be computer operated with the engine stroke varied by tailoring the magnetic field.

\subsection{MODELING OF LINEAR ENGINE}

Various modeling techniques have evolved ever since the linear engine was introduced [18-24]. A complete model of the internal combustion engine should include a complete analysis for the basic processes of compression, combustion, expansion, and gas exchange. Mathematical descriptions of each of these have been used to investigate the effect of individual operating parameters on the performance of the engine [25-39].

Widener and Ingram [40] submitted a numerical model of a free piston linear generator for a hybrid vehicle modeling study. The model addressed the use of a free piston engine coupled with a linear generator as a potential auxiliary power unit in hybrid electric vehicles. The feasibility of such an engine was analyzed with regards to power output and efficiency of the unit with reference to conversion of mechanical power output 
of the linear engine to electric power output. The study was conducted on a two-stroke cycle engine and a reciprocating rig developed to characterize the operation of the generator.

Goldsborough [3] modeled a two-stroke cycle free piston engine. The study focused on homogenous charge compression-ignition (HCCI) using hydrogen as a fuel. The engine had been working on a lean fuel-air charge and constant speed with combustion occurring at either end of the piston. A linear alternator was used to directly convert the oscillating piston motion into electric energy. The author concluded that the compression ratio of the engine was variable and depended on the engine's operating conditions. The gas temperature at port closure seemed to have the greatest effect on the achievable compression ratio, since it fixed the amount of compression heating required for auto ignition.

\subsection{LINEAR ENGINE DEVELOPMENT AT WEST VIRGINIA UNIVERSITY}

A two-stroke spark ignited linear engine coupled with a linear alternator was designed and constructed at West Virginia University. On operating the engine it was noticed that the in-cylinder pressure versus time varied from one cycle to another. It was also noticed that the coefficient of variation was significant in the no-load case, and was reduced to less than $10 \%$ with load and retarding the ignition timing.

The ignition timing had to be highly advanced specially in the no-load case, so as to perform adverse work needed to slow down the piston speed near the cylinder head at the end of the compression stroke. The tested two-stroke linear engine coupled with linear alternated produced $316 \mathrm{~W}$ of electric power output and was reported to be successfully operated [41].

The geometric parameters of the engine are presented in Table 2-1: 
Table 2-1: Geometric parameters of a spark-ignition two-stroke linear engine prototype $[4,41,42,43,45]$.

\begin{tabular}{|ll|l|}
\hline Number of cylinders & 2 & \\
\hline Bore & $36.4 \mathrm{~mm}$ & \\
\hline Max. possible stroke & $50.0 \mathrm{~mm}$ & \\
\hline Exhaust port opening & $19.0 \mathrm{~mm}$ & from the end of maximum theoretical stroke \\
\hline Intake port opening & $21.0 \mathrm{~mm}$ & from the end of maximum theoretical stroke \\
\hline Exhaust port height & $10.0 \mathrm{~mm}$ & \\
\hline Intake port height & $10.0 \mathrm{~mm}$ & \\
\hline
\end{tabular}

Two-pulse width modulated gasoline fuel injectors were used to feed the linear engine with fuel. The engine was water cooled to keep the cylinder head in a reasonable operational temperature range. An electronic controller was designed specially to control the new design of the linear engine coupled with the linear alternator. The electronic unit was used to control the air to fuel ratio, the fuel injection timing, and the ignition timing. Also, starting coils were used to start up the engine. These coils were automatically disengaged after the engine started by means of the electronic controller unit. The starting coils served also in reversing the direction of the two-stroke linear engine in case of misfiring. On operating the engine electrical power was generated, as the engine was reversing its motion and cutting the linear alternator permanent magnet flux lines. Different permanent magnet linear alternator as well as friction brake were used to vary the operating load conditions of the two-stroke linear engine. In-cylinder pressure diagrams were experimentally plotted through extensive testing of the two-stroke linear engine coupled with the linear alternator using friction brake as a load governor and are presented in Table 2-2:

Table 2-2: Experimental data for two-stroke spark ignited linear engine using friction brake to change load-operating condition [4, 41, 42, 43, 45]. 


\begin{tabular}{|l|l|l|l|l|}
\hline Load & $\begin{array}{l}\text { Average Indicated Work } \\
\text { Output per Stroke [J] }\end{array}$ & $\begin{array}{l}\text { Average Positive } \\
\text { Power Output [W] }\end{array}$ & $\begin{array}{l}\text { Average } \\
\text { Stroke } \\
{[\mathrm{mm}]}\end{array}$ & $\begin{array}{l}\text { Average } \\
\text { Frequency } \\
{[\text { Cycle/min }]}\end{array}$ \\
\hline No & 1.55 & 81.3 & 44.3 & 1574 \\
\hline Yes & 6.25 & 262.5 & 35.5 & 1260 \\
\hline Yes & 10.79 & 438.0 & 37.6 & 1197 \\
\hline Yes & 16.40 & 804.0 & 47.0 & 1470 \\
\hline
\end{tabular}

A further analysis for the experimental operation of the two-stroke spark ignited linear engine results have been presented [41].

As mentioned before, based on the data gathered by the in-cylinder pressure, it was found that there were significant cycle-to-cycle variations of the in-cylinder pressure versus time for different operating regimes. The results of performance tests of the engine-alternator prototype combination are shown in Table 2-3:

Table 2-3: Experimental data for the linear engine using permanent magnet alternator as a load governor Ref. [4, 41, 42, 43, 45].

\begin{tabular}{|l|l|l|l|l|l|}
\hline Test & Load [ohms] & Voltage [v] & Current [A] & Load Power [W] & Frequency [Hz] \\
\hline 1 & Open Circuit & 132.0 & 0.00 & 0 & 25.0 \\
\hline 2 & 156.0 & 120.0 & 0.75 & 92 & 24.6 \\
\hline 3 & 130.0 & 119.0 & 0.88 & 104 & 24.4 \\
\hline 4 & 104.0 & 115.0 & 1.07 & 124 & 23.4 \\
\hline 5 & 78.0 & 110.0 & 1.38 & 153 & 24.1 \\
\hline 6 & 52.0 & 103.0 & 1.92 & 200 & 26.6 \\
\hline 7 & 26.0 & 90.0 & 3.30 & 300 & 23.6 \\
\hline 8 & 24.0 & 88.5 & 3.54 & 312 & 23.6 \\
\hline 9 & 23.4 & 87.5 & 3.58 & 313 & 23.6 \\
\hline 10 & 19.5 & 79.0 & 3.90 & 316 & 23.1 \\
\hline 11 & 17.3 & 74.0 & 4.15 & 309 & 22.7 \\
\hline
\end{tabular}

The numerical simulation model used to simulate the operation of the two-stroke spark-ignition linear engine proved to be in agreement with the resulting experimental data of the linear engine [4].

The numerical simulation model for the spark-ignition two-stroke linear engine 
involved dynamic and thermodynamic analysis. The dynamic analysis consisted of evaluation of the frictional forces and the load over the complete operating cycle of the engine. The thermodynamic analysis involved the evaluation of each process that took place during each stroke including compression, combustion, and expansion. The thermodynamic model used was a single zone model. In the single zone model the cylinder composition, pressure, and temperature are considered to be uniform and the energy released by the fuel combustion is calculated from the calculated in-cylinder pressure. Figure 2.1 and Figure 2.2 [4] illustrate the in-cylinder pressure volume diagram obtained from experimental data and the in-cylinder pressure volume diagram obtained from the numerical simulation model of the two-stroke spark-ignited engine. It can be easily seen that the two diagrams show a very good agreement. The numerical simulating model was used to carry out a parametric study that varied many working parameters to estimate the performance of such engines over a wide range of operating conditions, the air to fuel ratio, the moving assembly mass, the ignition timing, combustion duration, frictional load, and the external electrical applied load were the variable input factors of the parametric study. Figure 2.3 and Figure 2.4 present some of the results obtained from the parametric study [4].

In this model the scavenging processes were assumed to be perfect. The experimental testing of the two-stroke spark-ignition linear engine showed that the linear alternator introduces a load that has a roughly sinusoidal shape throughout the stroke. This is why the parametric study considered a load with various exponential sinusoidal functions over the stroke. The resulting resistant force was considered to be the total of the friction force and the applied load by the linear alternator. The shape of the resulting 
load function was varied considering three different cases. The first case was constant force through the stroke; the second case considered a triangular shaped force keeping the same integrated area under the curve. The third case modeled a sinusoidal function with varying its exponential power [4].

Changing the moving assembly mass, the peak in-cylinder pressure and the maximum stroke were varying in a directly proportional way. The in-cylinder pressure and the maximum stroke increased with increased the moving assembly mass. The frequency of the two-stroke linear engine varied inversely with the moving assembly mass.

On increasing the load's exponential sine power the in-cylinder peak pressure increased while the frequency decreased as shown in Figure 2.5 and 2.6 [4]. Also, Increasing the moving assembly mass increased the compression ratio. The in-cylinder peak pressure increased, while the frequency decreased as shown in Figure 2.7 and 2.8 [4].

Figure 2.9 [4] presents different $\mathrm{P} / \mathrm{V}$ diagrams for different heat inputs. 


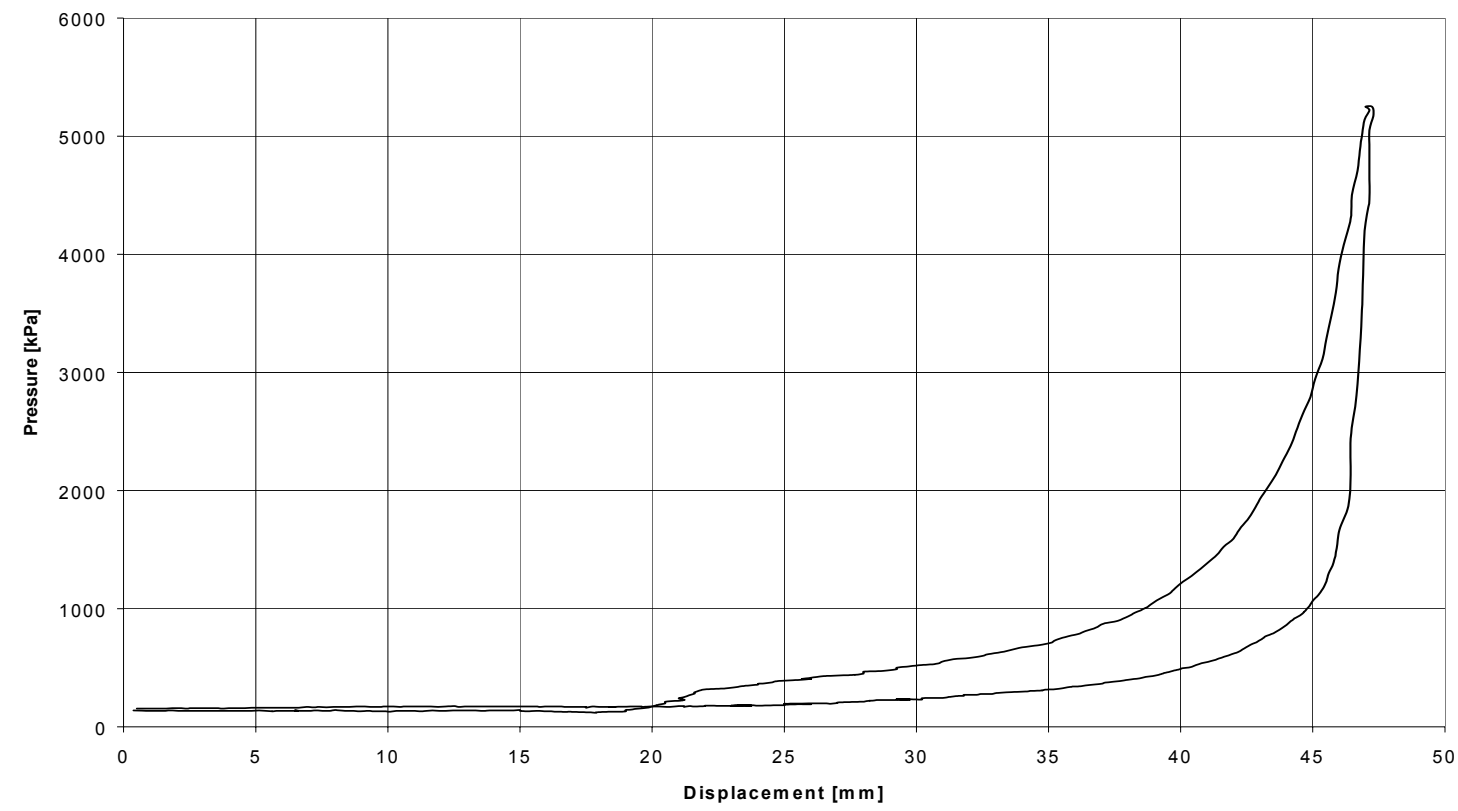

Figure 2.1. Experimental Data Obtained by the Prototype of the Two-Stroke Spark-Plug Linear Engine [4]

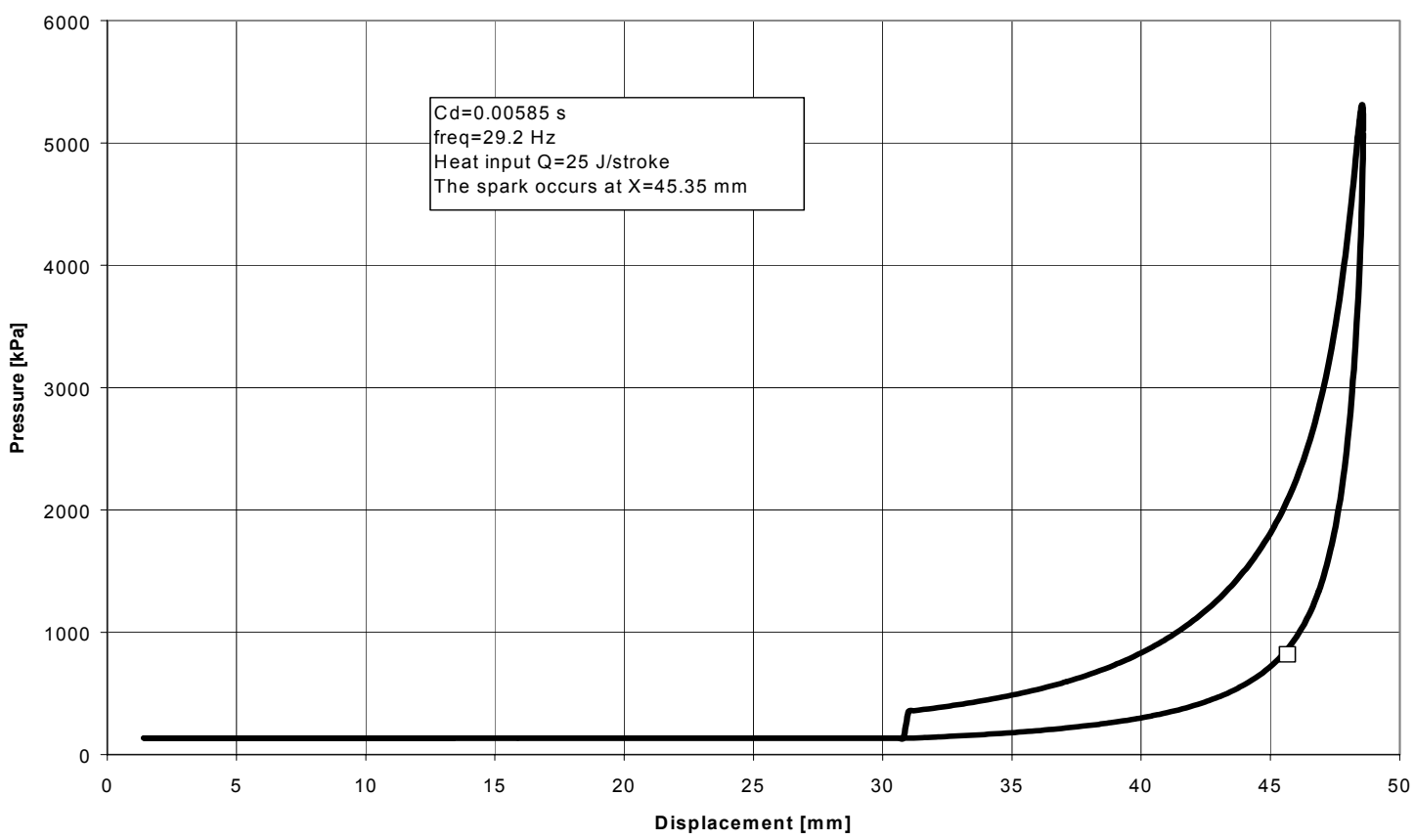

Figure 2.2. P/V Diagram Obtained by the Numerical Simulation of the Two-Stroke Spark-Plug Linear Engine Model [4] 


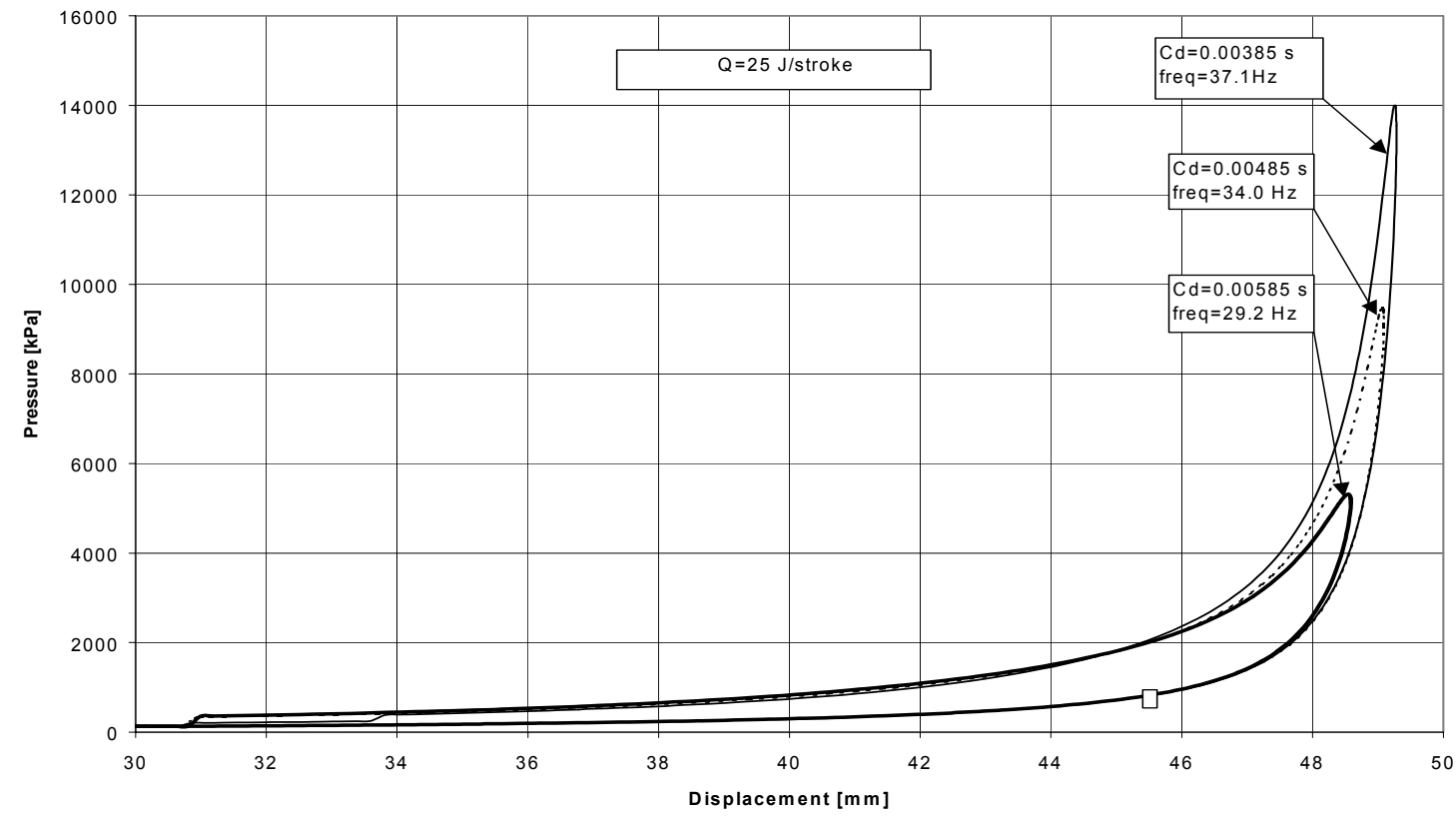

Figure 2.3. P/V Diagram Obtained by the Numerical Simulation of the Two-Stroke Spark-Plug Linear Engine Model for Different Combustion Duration Values and Same Heat Inputs [4] ${ }^{1}$

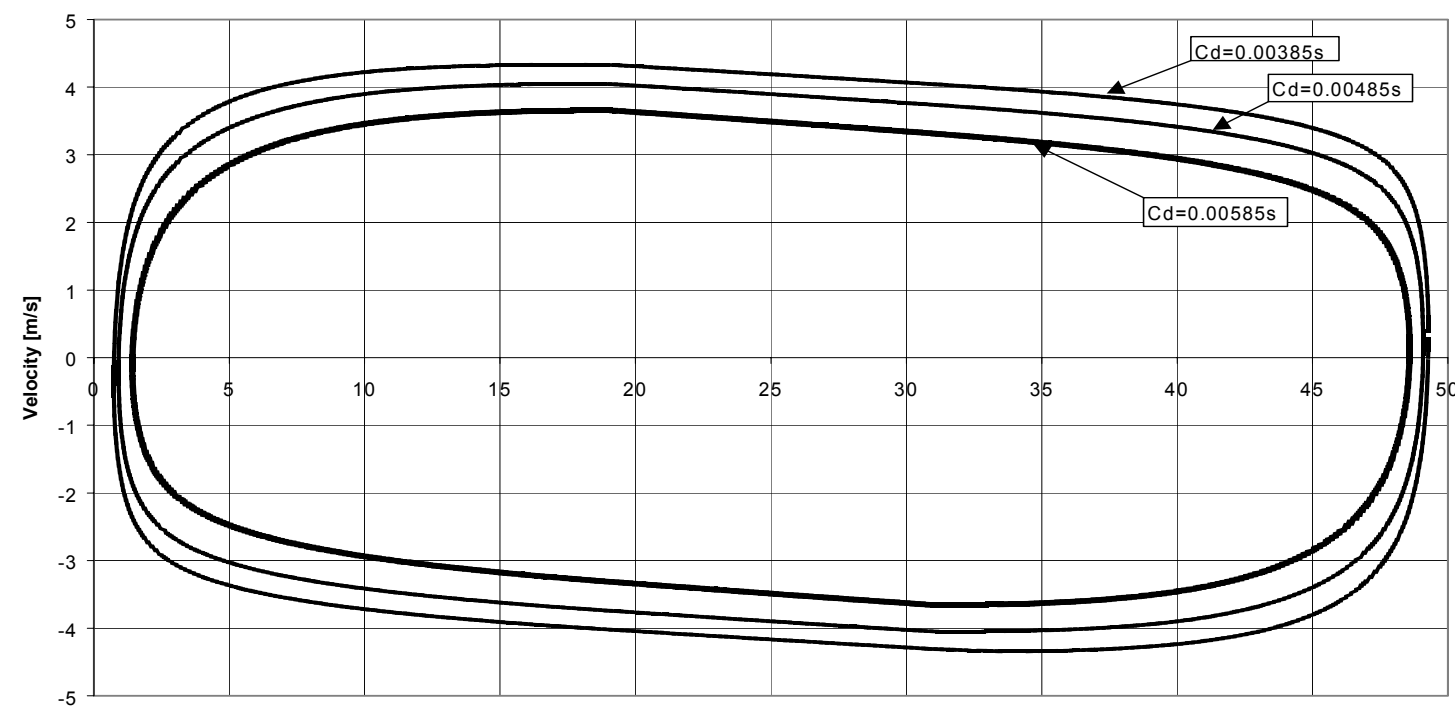

Displacement [mm]

Figure 2.4. Speed Versus Displacement Obtained by the Numerical Simulation of the Two-Stroke Spark-Plug Linear Engine Model for Different Combustion Duration Values and Same Heat Inputs

${ }^{1} \mathrm{C}_{\mathrm{d}}$ is combustion duration in sec. 


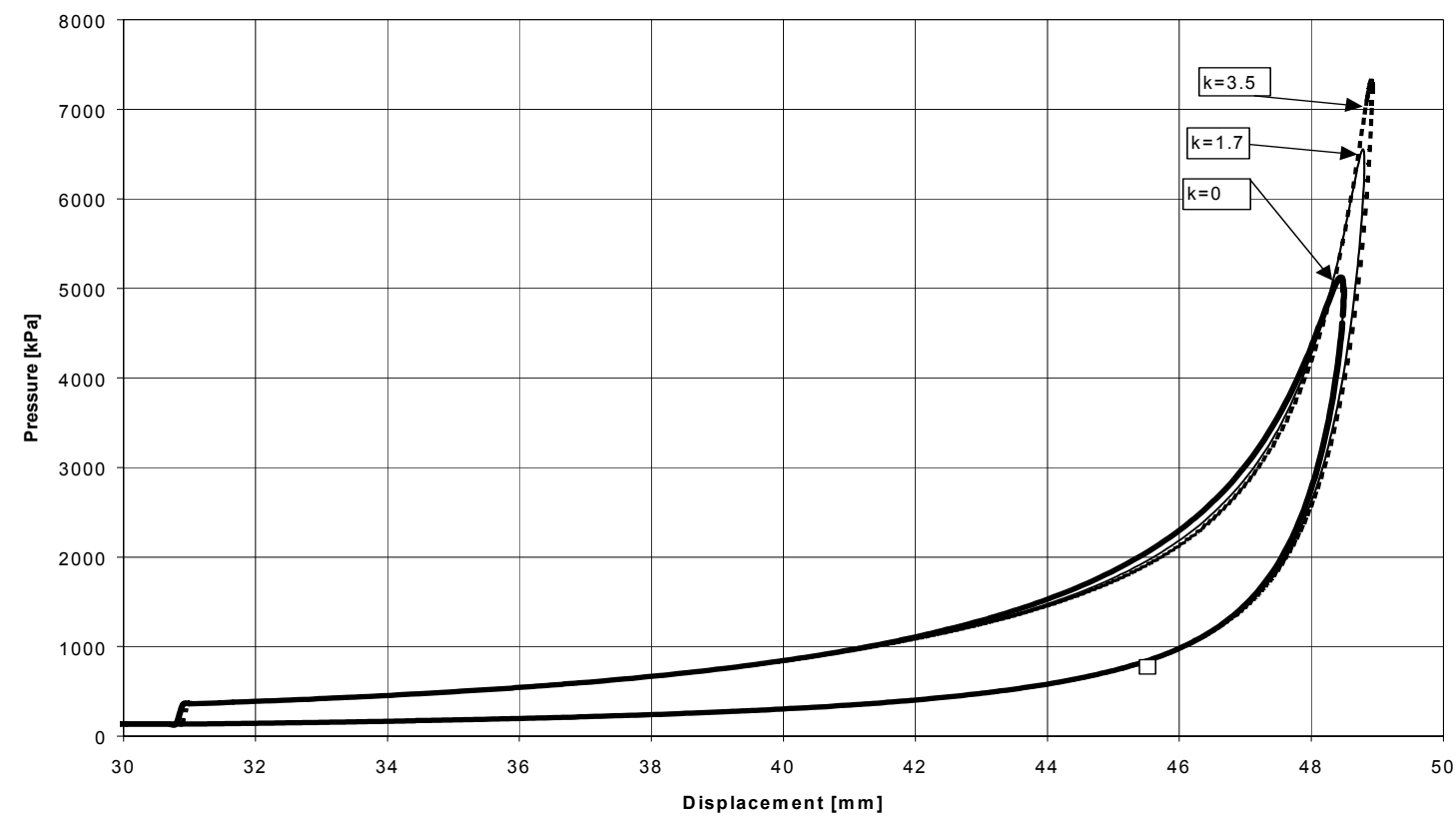

Figure 2.5. P/V Diagram Obtained by the Numerical Simulation of the Two-Stroke Spark-Plug Linear Engine Model for Different Profiles of Load [4] ${ }^{2}$

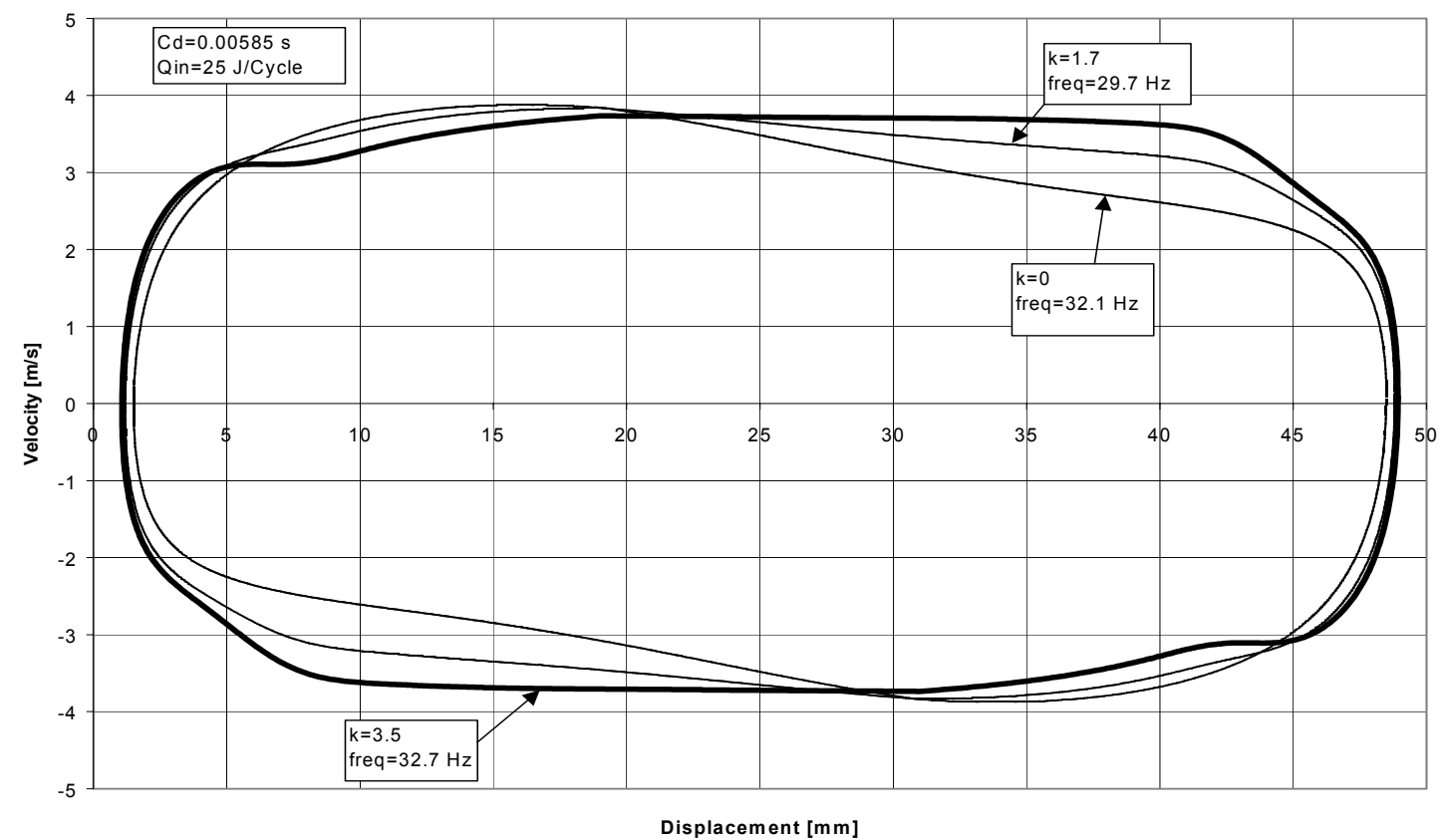

Figure 2.6. Piston Speed Versus Displacement Obtained by the Numerical Simulation of the TwoStroke Spark-Plug Linear Engine Model for Different Profiles of Load [4]

${ }^{2} \mathrm{~K}$ is exponential load factor 


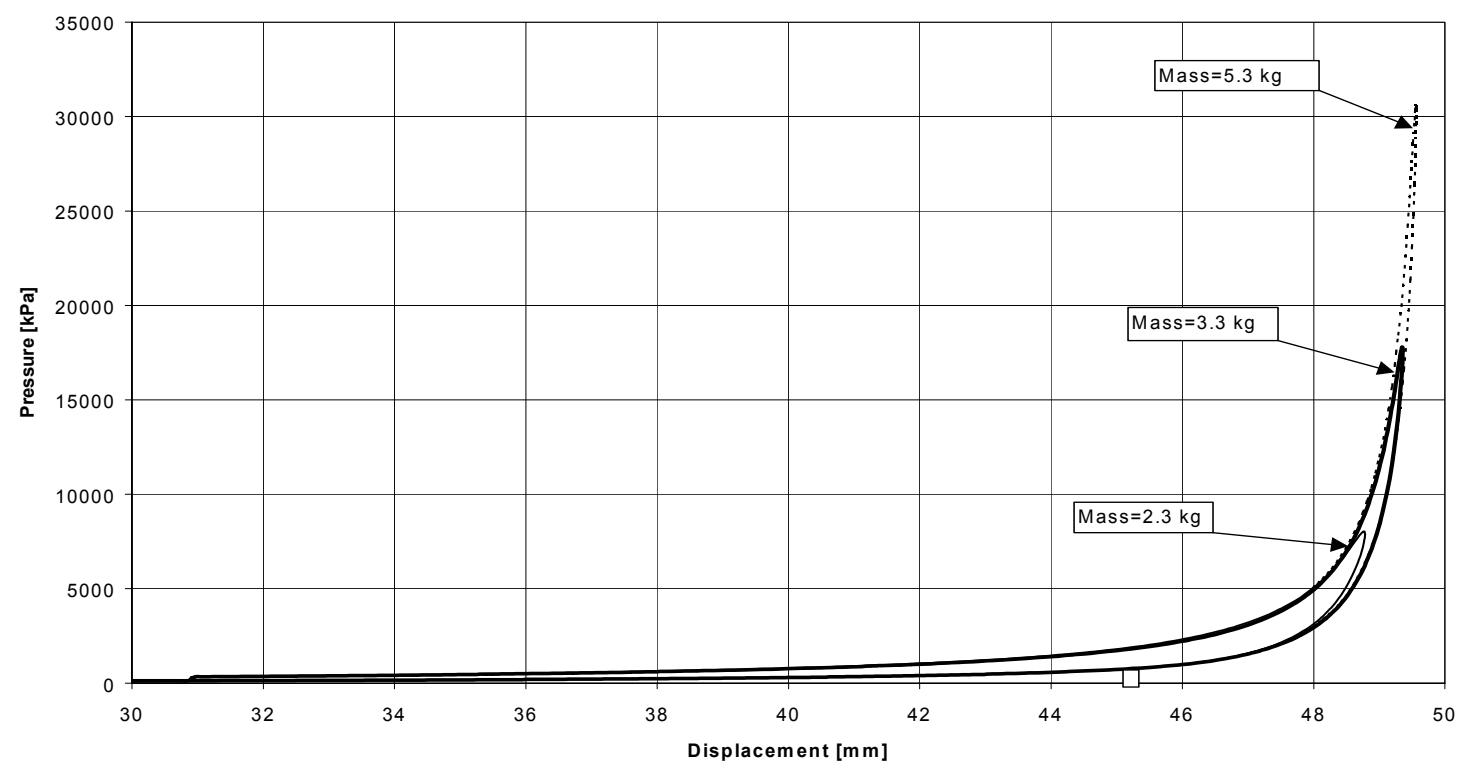

Figure 2.7. P/V Diagram Obtained by the Numerical Simulation of the Two-Stroke Spark-Plug Linear Engine Model for Different Moving Mass Assemblies [4]

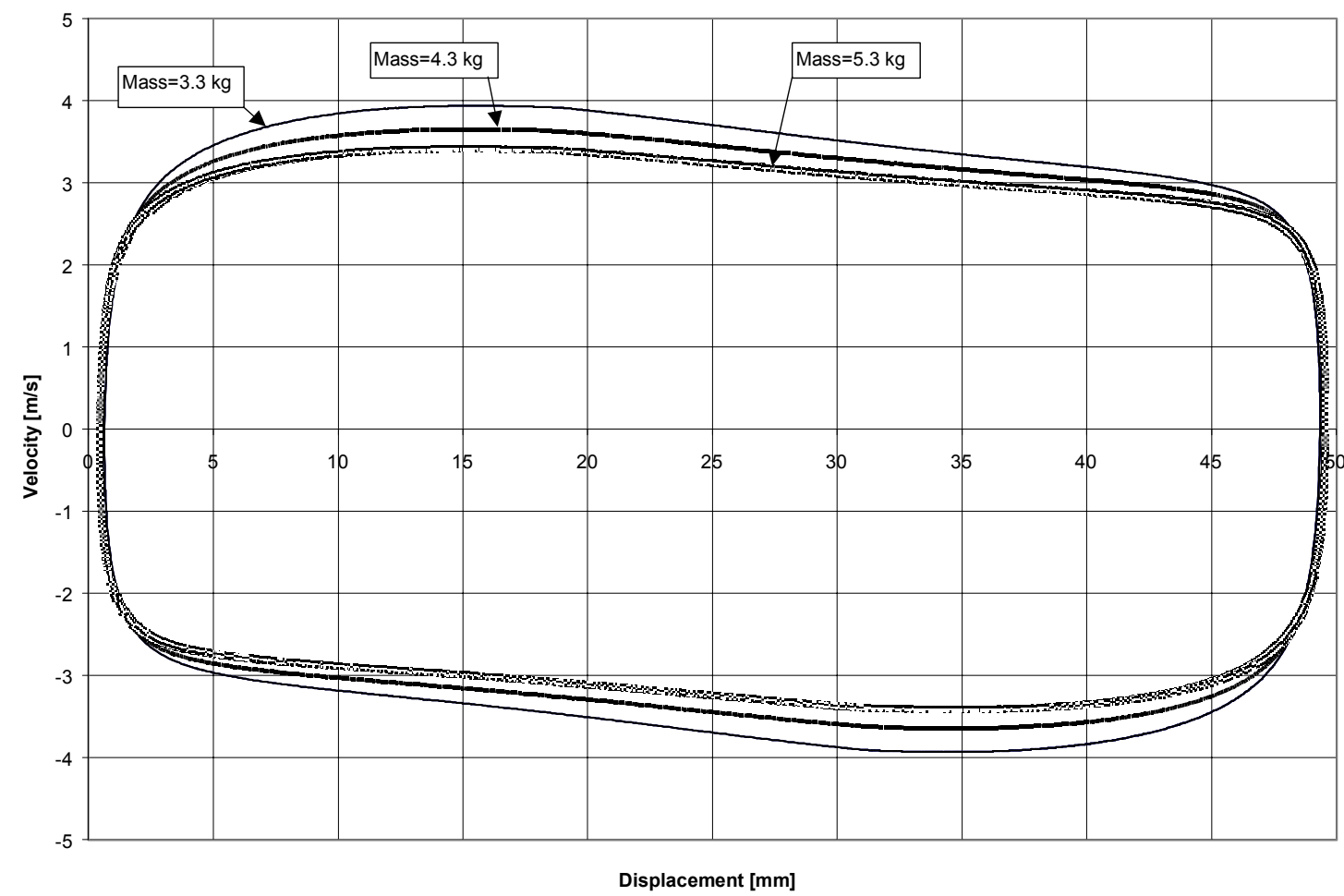

Figure 2.8. Piston Speed Versus Displacement Obtained by the Numerical Simulation of the TwoStroke Spark-Plug Linear Engine Model for Different Moving Mass Assemblies [4] 


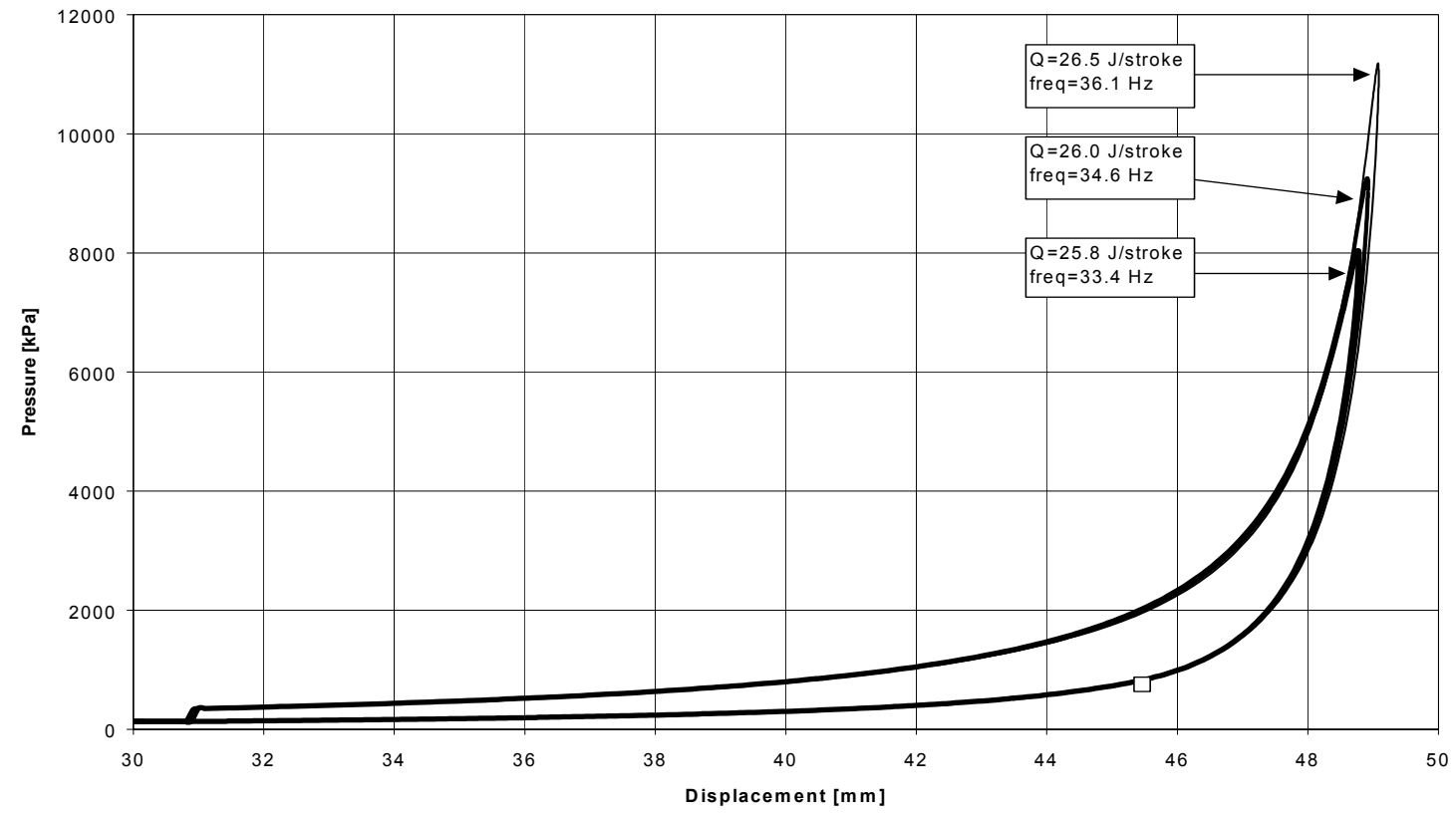

Figure 2.9. P/V Diagram Obtained by the Numerical Simulation of the Two-Stroke Spark-Plug Linear Engine Model for Different Heat Inputs [4]

Table 2.4 [4] summarizes some of the results of the modeling simulation program of the two-stroke spark-ignition linear engine ${ }^{3}$ :

\section{PARAMETER VARIED}

Effect Noticed Heat Input Combustion Duration Friction Force Mass

Frequency

In-Cylinder

Peak Pressure

Velocity

Displacement

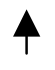

4

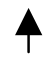

4

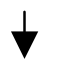

$\downarrow$

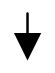

$\downarrow$

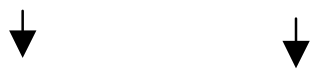

$\downarrow \quad 4$

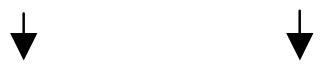

$\downarrow$

\footnotetext{
${ }^{3}$ Upper arrow indicates proportional dependence, and down arrow indicates inverse proportionality.
} 


\subsection{COMPRESSION IGNITION LINEAR ENGINE PROTOTYPE DEVELOPED AT WEST VIRGINIA UNIVERSITY}

A prototype of the compression-ignition linear engine was developed in the West Virginia University Engines Emission Research Center. Two Kawasaki Jetski 300sx cylinders were used in the prototype of $75 \mathrm{~mm}$ bore and $71 \mathrm{~mm}$ maximum stroke. Cylinder heads were manufactured to allow direct injection and cooling to the cylinders. Scavenging for the two Kawasaki cylinders was carried out by means of in house compressed air, for this purpose the two cylinders were machined to remove the lower portion of the piston skirt. This was done also, to prevent the skirt from contacting the bottom end. The two pistons were connected together with an aluminum rod that also had a provision for mounting the moving position sensor and the translator magnets for the linear alternator. An I-beam, connected to $600 \mathrm{lbs}$ steel plates supported the linear engine prototype and also minimized vibration [46].

The linear engine was lubricated by means of a single, manually operated, airregulating valve connected to a main compressed airline in the Engines Emission Research Center. The lubrication was done by means of in-line-air-tool lubricators. Lubricators provided the linear engine's rings with sufficient oil to keep it in good working condition. Also, the prototype linear engine's cylinder heads were connected to cooling water [46].

The alternator was used to start the linear engine by providing the needed force for cranking the engine. When the linear engine started and the speed increased to more than a certain preset value, the alternator was disengaged by means of the engine control unit [46].

Due to the fact that the prototype linear engine's stroke was not mechanically 
constrained the compression ratio of the engine was not fixed. An approximate maximum value, 50:1, was chosen for this particular prototype linear engine. This value was calculated based on different geometrical parameters like, the location of the exhaust port, the dimension of the cylinders, the maximum stroke of the pistons, and the clearance volume of the cylinders [46].

The linear engine prototype was provided with a direct fuel injection system. Fuel was supplied using a high-pressure pump that maintained the pressure at about 9000 psi. This pressure was maintained by using a pulse width modulated regulator. An automotive fuel pump was used to supply the high-pressure pump with fuel at a regulated pressure of 38 psi. The fuel flow rate to each cylinder was adjusted by a potentiometer connected to the electronic control unit. During cold starting of the linear engine and to ensure ignition during cranking when compression is low, glow plugs were installed in the linear engine prototype unit. Figure 2.10 shows the experimental model of the twostroke compression-ignition linear engine [46].

The linear engine control unit was used to operate the alternator as a motoring coil. Also, the pulse width, the start of injection position, and the rail pressure were completely controlled through the linear engine control unit. The linear engine control unit has been modified many times to match the high-induced voltage resulting from cranking the linear engine [46]. 


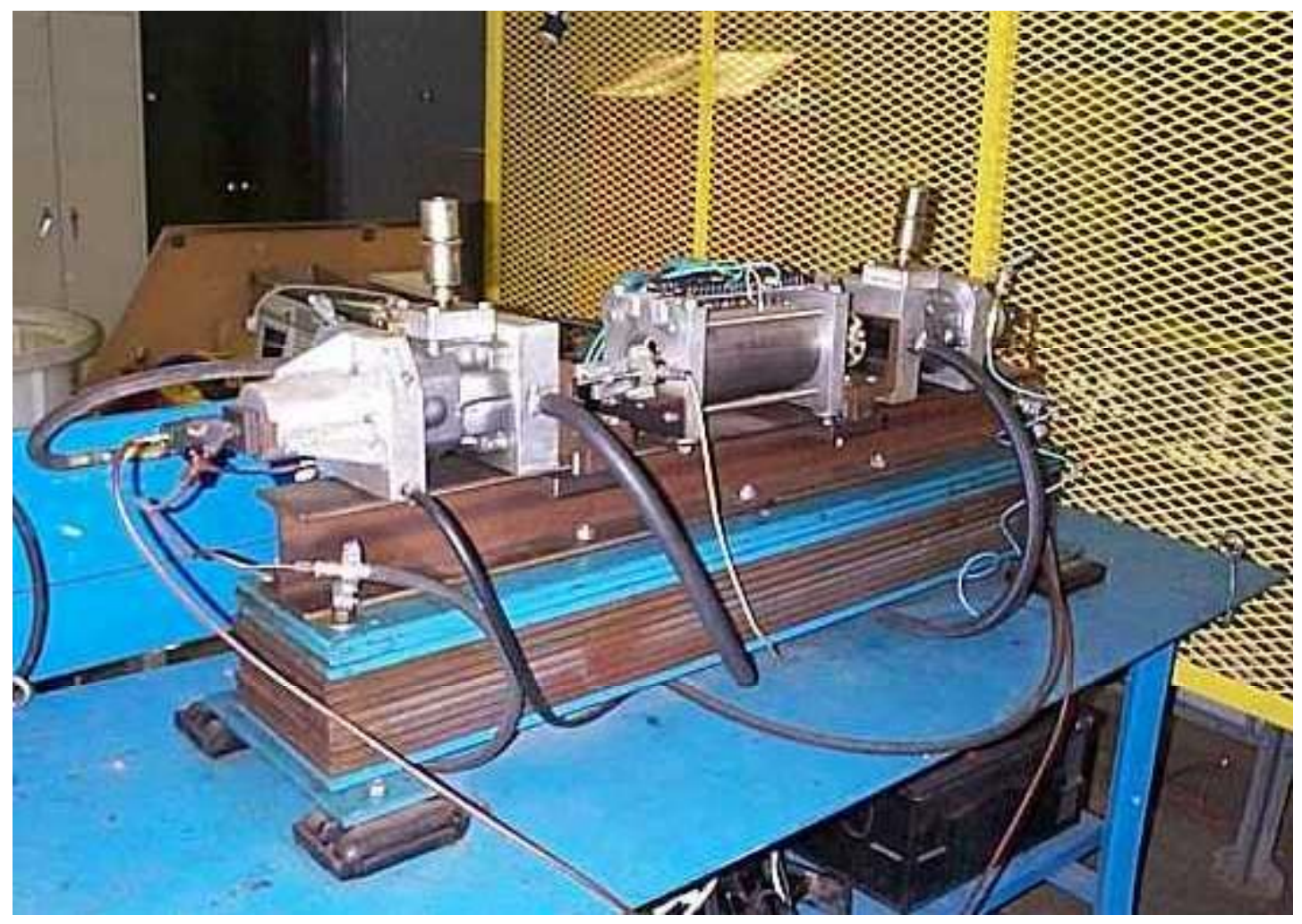

Figure 2.10. Experimental Prototype of Two-Stroke Compression-Ignition Linear Engine

Petreanu [47], in his dissertation, presented a conceptual design of a four-stroke compression-ignition linear engine based on a numerical simulation of the operation of this type of linear engine. Since the linear engine is a crankless engine the numerical simulation was carried out on a time-based analysis. The simulated four-stroke compression-ignition linear engine consisted of four opposed pistons linked by a connecting rod to a linear alternator. A series of numerical simulations were developed and used to investigate the characteristic operation and the performance of the four-stroke compression-ignition linear engine. Two numerical models were presented and used for this purpose. The first used direct injection mode while the second used homogeneous charge compression-ignition mode. The study showed that this engine had a limited 
range of operation. It also showed that this engine when working in a direct injecting mode had an efficiency that could reach up to $49 \%$, while with homogeneous charge compression-ignition mode the efficiency could go over $60 \%$.

Tor et al. [49] presented a dynamic mathematical model of a free piston, compression-ignition type engine. Controlling the timing controlled the motion of the piston via computer. The authors claimed that the computer controlled piston motion showed feasibility. 


\section{3-COMPUTATIONAL MODEL AND SYSTEM ANALYSIS}

The internal combustion engine represents both a thermodynamic and a dynamic device. Thus the approach that was used to model the two-stroke compression-ignition engine used a thermodynamic and dynamic series of equations to follow the different stroke events of the engine. The computational method was based on studies developed for the crankshaft internal combustion engines. This approach seemed to be logical and feasible as the linear engine has a lot of features in common with the conventional reciprocating internal combustion engine. Some of these equations are empirical. Moreover, this approach has been used by many researchers at West Virginia University in simulating the two-stroke spark-ignition linear engine and the four-stroke compression-ignition linear engine and gave satisfactory results [4, 47]. Also, in this model some of the experimental data that was developed from the two-stroke sparkignition linear engine will be used. The model that was designed followed the different operational steps of both of the cylinders at the same time.

\subsection{MODEL DESCRIPTION}

The model used a dynamic and thermodynamic series of equations, which accept input data describing the geometric configuration and the working conditions of the twostroke compression ignition linear engine and solve these equations simultaneously to predict the following [50]:

In-cylinder Pressure

Load and Power Output

Heat Released by Combustion

Piston Displacement and Acceleration
In-cylinder Temperature

Internal Friction

Instantaneous and Average Piston Speed 
The input variables and working conditions of the two-stroke linear engine fed to the computer simulating program include [50]:

Engine Bore and Stroke

Engine Reciprocating

External Load

Air/Fuel Ratio

Combustion Duration

Percentage of diffusive Combustion

Thickness of Piston Rings
Port Placement and Dimensions

Mass Injection Timing Position

Volumetric Efficiency

Heating Value of the Fuel

Percentage of Premixed Combustion

Number of Piston Rings

The inlet intake pressure and temperature were taken to be 1.0135 bars and $370 \mathrm{~K}$ respectively.

In the simulation model only one full stroke dimension will be used, from zero to full stroke in the arrow direction, Figure 3.1. At that time both cylinders events will be monitored by the program. In other words the program will describe mathematically the events that are happening in both cylinders at the same time along the full stroke. In this way the program will monitor the displacement up to the dimension of one stroke and observe the associated events that happen in the other cylinder [47].

\subsection{DYNAMIC MODELING}

Figure 3.1 shows a free body diagram showing the forces applied on the linear engine in the horizontal and vertical direction.

The displacement of the two-stroke linear engine is calculated after each time step using the following equations through a subroutine in the computer simulation program $[4,42,50]:$

$$
\begin{aligned}
& m \frac{d^{2} x}{d t^{2}}=(\Delta P)\left(A_{p}\right)-F_{l}-F_{f} \\
& \frac{d x}{d t}=\frac{d x_{0}}{d t}+\frac{d^{2} x}{d t^{2}} t
\end{aligned}
$$


$x=x_{0}+\frac{d x}{d t} t+\frac{\left(\frac{d^{2} x}{d t^{2}} t^{2}\right)}{2}$

Solving this equation results in finding the piston velocity and displacement [4, $42,50]$.

As the time increment is small the constant acceleration assumption is acceptable.

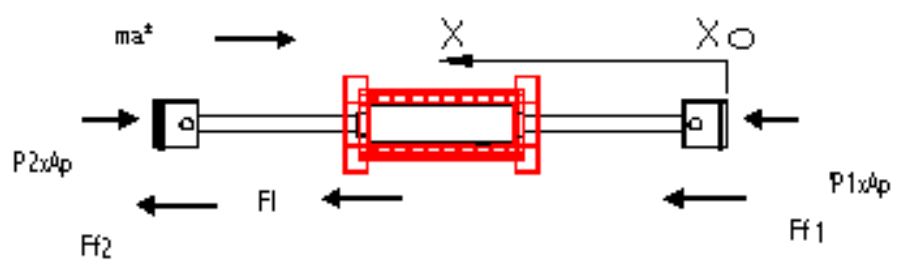

Figure 3.1 Free Body Diagram for Linear Engine 


\subsection{ALTERNATOR MODELING}

There was enough evidence through past experimental work carried out at West Virginia University suggesting that the alternator load possesses a sinusoidal shape [4]. This is why the alternator load was expressed by a sinusoidal function with different exponential power, and was based on a permanent magnet machine with resistive load [4, 42,50]. The following equation is one of the forms that were used to express the alternator's load [47].

$$
F_{l}=\left(C_{a}\right) \frac{d x}{d t} \sin ^{3}\left(\frac{\pi x}{L}\right)
$$

The equation shows a maximum load at the point for the highest product of velocity and load constant. Figure 3.2 shows a typical load shape modeled using equation 3.4.

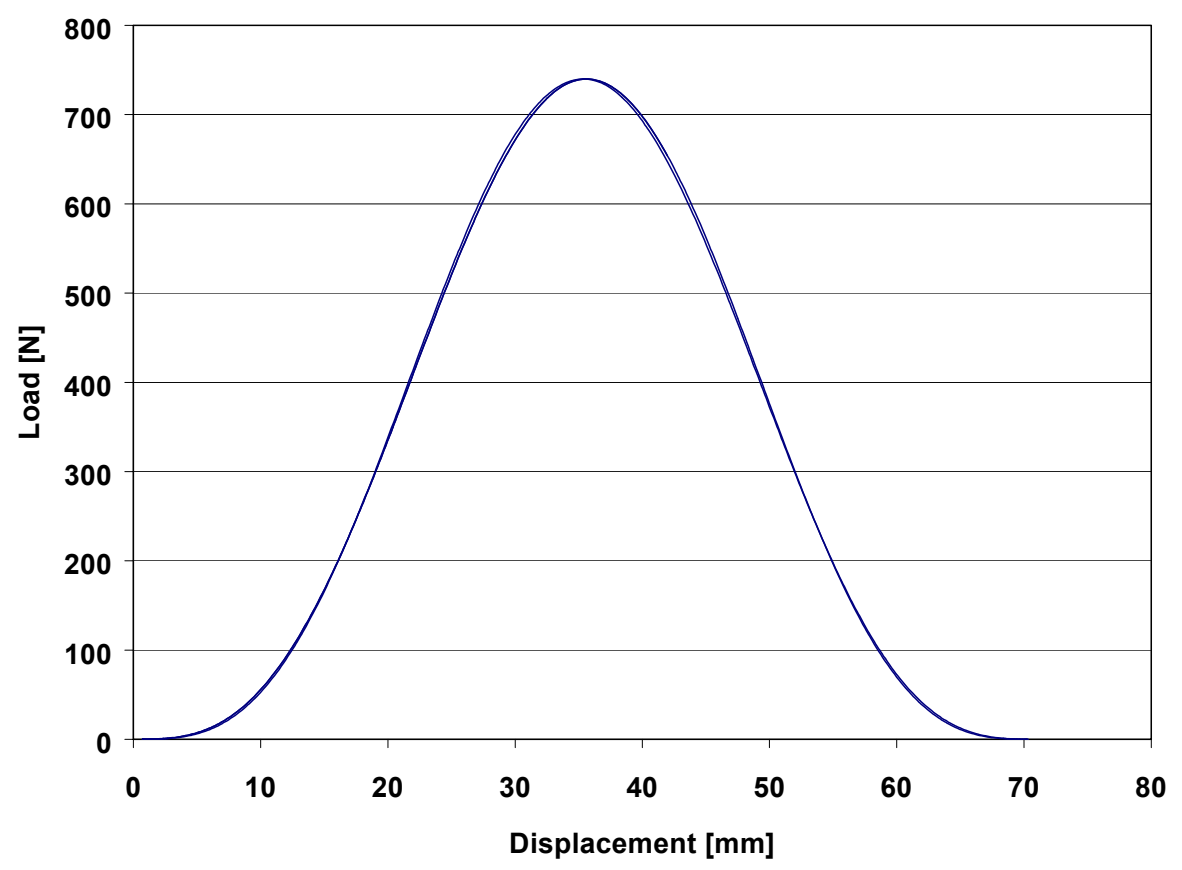

Figure 3.2. Load Shape Considered in the Analysis, $\mathrm{Ca}=60 \mathrm{~N} \mathrm{sec} / \mathrm{m}$ [50] 


\subsection{FRICTION MODELING}

Although the linear engine is crankless, the frictional force cannot be neglected. The friction in this case is attributed to the piston assembly only. Elements of the piston assembly that contribute to friction are the piston rings and the piston skirt. There is also friction in the wrist pin that should be noted even though it is small in comparison to the other friction forces previously mentioned. In traditional reciprocating engines the piston and connecting rod are virtually never perpendicular to each other, and as such the side loading forces on the piston skirt and rings are substantial. In linear engines, wrist pin and skirt forces will be negligible, due to the lack of side loading, and ring forces are primarily due to gravitational forces and asymmetrical forces generated by the alternator. Descriptions of the causes of friction for internal combustion engines and design solutions towards diminishing the effects of the frictional phenomena were researched. Rosenberg [48] states that the coefficient of friction of hydrodynamic lubricated engine components ranges from 0.2 to 0.001 depending on the lubrication.

The boundary lubrication regime the friction force is proportional to the normal load as per equation 3.5 and this is frequently referred to as Coulomb friction [48].

$F_{f l}=f m g$

The friction model consists of three terms. The first term is referred to as Coulomb friction force, which was discussed earlier. The second term correlates the fiction force to the friction radial force resulting from the deflection of the piston ring. The third term correlates the friction force to the in-cylinder pressure less the intake pressure.

The friction radial force that results from the piston ring can be calculated by considering the piston ring as a fixed uniformly loaded beam. This assumption was 
considered science the length of the piston ring is much longer than the thickness of the ring

Hence, $\delta=\frac{p s^{4}}{8 E I}$

where, E is Young's modulus of elasticity and taken to be $207 \mathrm{GPa}$, thickness and width of the piston ring were taken to be $0.0011 \mathrm{~m}$ and $0.003 \mathrm{~m}$ respectively, and $\delta$ was taken to be $0.0019 \mathrm{~m}$. In this case the friction force will be:

$F F=f(m g+p s)+\Psi \Delta P A_{R}$

where, f was taken to be 0.2 and three piston rings were used [48]. $\Psi$ was taken to be $0.001[48]$.

\subsection{THERMODYNAMIC MODELING}

Applying the first law of thermodynamics on the cylinder as a closed system

$d Q=d U+d w$

Applying the ideal gas relation to the gases in the cylinder:

$P V=m_{\text {in }} R T /(M W)_{\text {air }}$

where $\mathrm{R}$ is the universal gas constant $=8314 \mathrm{~J} / \mathrm{kmole} \mathrm{K}$.

Substitution and mathematical manipulation yields the following:

$\frac{d P}{d t}=-\gamma \frac{P}{V} \frac{d V}{d t}+\frac{\gamma-1}{V}\left(\frac{d Q_{h t}}{d t}\right)$

where, $\gamma$ is the specific heat ratio and is considered constant in the program and equal to1.37.

At each time step the heat transfer is calculated by

$\frac{d Q_{h t}}{d t}=h A_{c y l}\left(T-T_{W}\right)$ 
The heat transfer resulted by radiation was not considered

The temperature $\mathrm{T}$ is calculated by

$T=\frac{P V}{m_{\text {in }} R} \times(M W)_{\text {air }}$

where, $\mathrm{m}_{\mathrm{in}}$ is the inlet air mass in $\mathrm{kg}$. In the calculations the injected fuel mass is neglecled as compared to air mass.

The in-cylinder motoring pressure is calculated at each step by the following formula:

$\frac{d P_{m o t}}{d t}=-\gamma \frac{P_{m o t}}{V} \frac{d V}{d t}+\frac{\gamma-1}{V}\left(\frac{d Q_{m o t}}{d t}\right)$

where

$\frac{d Q_{m o t}}{d t}=h_{m o t} A_{c y l}\left(T_{m o t}-T_{W}\right)$

and $\mathrm{T}_{\mathrm{mot}}$ is found using

$T_{m o t}=\frac{P_{m o t} \times V \times(M W)_{a i r}}{m_{i n} R}$

The heat transfer model is based on Woschni's correlation that relates the heat transfer coefficient with $S_{\mathrm{P}}$, the average piston speed [44].

$W=\left(C_{1} \bar{S}_{p}+C_{2} \frac{V_{d} T_{r}}{P_{r} V_{r}}\left(P-P_{m o t}\right)\right)$

where, $\mathrm{C}_{1}$ and $\mathrm{C}_{2}$ are constants that are changing depending on the instantanous engine's process as follows [44]:

For the gas exchange period:

$\mathrm{C}_{1}=6.18$,

$\mathrm{C}_{2}=0$

For the compression period:

$\mathrm{C}_{1}=2.28$,

$\mathrm{C}_{2}=0$

For the combustion and expansion period:

$\mathrm{C}_{1}=2.28$,

$\mathrm{C}_{2}=.00324$ 
The Woschni's correlation then applied to calculate the heat transfer coefficient [44] as follows:

$h=3.26 B^{-0.2} P^{0.8} T^{-0.55} W^{0.8}$

The heat transfer rate from the cylinder was multiplied by a factor of $0.33^{1}$ to count for the constant low assumed wall temperature.

In a compression-ignition engine the combustion process is divided into distinct stages; premixed combustion, a period of rapid pressure change, followed by a period of continuous combustion and gradual pressure change called diffusive combustion. Diffusive combustion represents the phase of the combustion process in which the process itself is controlled by the rate at which the combustible mixture becomes available. Before these two stages take place a period of ignition delay occurs.

In this model ignition delay is taken into consideration. Time delay is the time that elapses from injecting the fuel till autoignition. Studies showed that the temperature and pressure of the air are the most important variables for a given fuel composition [44]. Ignition delay data from most studies has the form of :

$\tau_{\mathrm{id}}=\mathrm{AP}^{-\mathrm{n}} \exp \left(\mathrm{E}_{\mathrm{A}} / \mathrm{RT}\right)$

where, $\mathrm{A}$ and $\mathrm{n}$ are constants depend on the fuel, and are taken to be $4.0 \times 10^{-10}$ and 1 respectively [44]. $\mathrm{E}_{\mathrm{A}}$ is the apparent activation energy for the fuel autoignition and $\mathrm{E}_{\mathrm{A}} / \mathrm{R}$ is taken to be $20800 \mathrm{~K}$ [44]. The empirical formula developed showed good results for direct injection compression-ignition engines [44].

To account for the effect of changing conditions on the delay the following empirical integration is usually used:

${ }^{1}$ Appendix F 
tsi+rid

$\int(1 / \tau) d t=1$

tsi

In the program $\tau_{\mathrm{id}}$ was calculated just after injection, then the program keep adding $\tau_{\mathrm{id}}$ 's after each time step. When the value of the integration is equal to or greater than unity, iginition starts. Once the ignition delay period is over the first stage of the combustion process, which is the premixed combustion, takes place. The duration of this stage is dictated to a certain extent by the injection strategy adopted.

The heat release model is based on the two primary forms of compression-ignited combustion, the premixed combustion and the diffusive combustion. The Wiebe function represents empirical correlations and has the following form [44]. This equation was originally in terms of crank angle, $\theta$ but as the linear engines do not have crankcase this variable was replaced by $\mathrm{t}[42,44,50]$. For most engines $\theta \propto \mathrm{t}$, so for this exercise it has been converted to $t$, as shown below.

$$
X(t)=\frac{m_{b}}{m_{i n j}}=1-\exp \left(-a\left(\frac{t-t_{o}}{C_{d}}\right)^{b+1}\right)
$$

It is a common practice to use two Wiebe functions for the heat release in this type of application, one for premixed and one for diffusive combustion. This equation is usually represented by:

$$
\begin{gathered}
\frac{d Q}{d \vartheta}=a \frac{Q_{p}}{\vartheta_{p}}\left(M_{p}+1\right)\left(\frac{\vartheta}{\vartheta_{p}}\right)^{M_{p}} \exp \left(-a\left(\frac{\vartheta}{\vartheta_{p}}\right)^{M_{p}+1}\right)+ \\
a \frac{Q_{d}}{\vartheta_{d}}\left(M_{d}+1\right)\left(\frac{\vartheta}{\vartheta_{d}}\right)^{M_{d}} \exp \left(-a\left(\frac{\vartheta}{\vartheta_{d}}\right)^{M_{d}+1}\right)
\end{gathered}
$$

This equation is usually represented in terms of $\theta$, the crank angle. For slider-crank engines the equation has been converted to $t$, as shown below. 


$$
\begin{aligned}
\frac{d Q}{d t} & =a \frac{Q_{p}}{t_{p}}\left(M_{p}+1\right)\left(\frac{t}{t_{p}}\right)^{M_{p}} \exp \left(-a\left(\frac{t}{t_{p}}\right)^{M_{p}+1}\right)+ \\
& a \frac{Q_{d}}{t_{d}}\left(M_{d}+1\right)\left(\frac{t}{t_{d}}\right)^{M_{d}} \exp \left(-a\left(\frac{t}{t_{d}}\right)^{M_{d}+1}\right)
\end{aligned}
$$

where, $\mathrm{M}_{\mathrm{p}}$, and $\mathrm{M}_{\mathrm{d}}$, are shape factors are taken to be 3 and 0.5 respectively while constant a was taken to be 1.2 to allow near instantaneous heat release [50].

It should be noted that this model is only a single zone model, meaning that it considers the cylinder to be a homogenous mixture of ideal gases, and does not account for the presence of vaporizing liquid droplets, fluid flow, combustion chamber geometry or spatial variations of the mixture's composition and temperature.

In this model the scavenging processes will be assumed to be perfect. The cylinder pressure when the exhaust port closes will be assumed to have the same value as the applied intake pressure. The exhaust blow down process will also be considered to be perfect, so that the cylinder pressure will instantaneously drop to the value of the intake pressure when the exhaust ports open. 


\section{4-SOLUTION METHOD AND MODEL VALIDATION}

\subsection{SOLUTION METHOD}

On starting the program many values like the starting position, starting velocity, load, and in-cylinder pressure must be fed to the program as initial values. When the program is run these values are updated with new values that will be used in the subsequent time steps, i.e. replaced by calculated values.

The engine dimensions like bore, length of the cylinder, effective stroke length, exhaust port heights, and intake port heights must be fed to the program also. The geometric dimensions play an important role in the sequence of the program as they control all the major events of the engine, i.e. the gas exchange processes, starting the compression and the expansion processes.

Also, other boundary conditions must be fed to the program like the air to fuel ratio, the fuel heating value, injection position, manifold air pressure, manifold air temperature, the wall temperature, the specific heat ratio, the combustion duration, the premixed combustion percentage, the diffusive combustion percentage, number of piston rings, thickness of piston rings, and load constant.

The program in the beginning must be fed with initial values, which are load value, the initial pressure of one of the cylinders, initial frequency and velocity and the friction force. These values are not significantly different from the resulting calculated values and are only given for the purpose of starting the program.

The program has four subroutines which are:

- The load subroutine

- The heat transfer subroutine

- The dynamic subroutine 
- The graph subroutine

The program starts by calculating the load by calling the load subroutine, then it uses a starting module for one stroke and calculates in-cylinder pressure, in-cylinder temperature, displacement, velocity and acceleration. The starting module is not used anymore for the run.

The program then moves to stroke two it starts by calculating the heat transfer coefficient by calling the heat transfer subroutine. The program starts calculating using a group of mathematical equations the heat transfer rate, the in-cylinder pressure, the incylinder temperature, the motoring pressure, the motoring temperature, the fraction of the fuel burnt, the load, and the work done for each event that the cycle goes through for each process.

The program then goes to the next time step and does the same. Through balancing the forces that result from the combustion and the resulting increase of pressure, load and friction, the engine either keeps its direction of motion or reverses it.

At each time step the program calls the dynamic subroutine and updates the displacement, the velocity, and the acceleration.

No results are taken before the engine stabilizes. In other words, the program dose not change the resulted calculated values for compression ratio, frequency, indicated efficiency, and indicated power. It was found that it takes the engine about 50 cycles to stabilize.

After the engine finishes about 50-60 cycles the program calls the graph subroutine and calculates the engine frequency, the indicated power, and the compression ratio. The calculations of these values are based on the time taken for the engine to finish 
the stroke and the real stroke length ${ }^{1}$.

\subsection{ADIABATIC RELATION}

Before the study began a simple case was considered to compare the model's output results with theoretically calculated values to make sure that the major part of the program is correct. The heat transfer and friction modules were cancelled from the numerical simulating model, and a very high air to fuel ratio mixture was considered, lambda $=1000$, for three different cases with different manifold intake pressures. Figure 4.1 shows the pressure versus displacement diagrams of the three cases. The peak pressure and volume values were compared with the intake pressure and volume as per the adiabatic relation:-

$$
P_{1} V_{1}^{\gamma}=P_{2} V_{2}^{\gamma}
$$

where, 1 refers to initial pressure and volume values and 2 to the final values of pressure and volume at the end of the stroke for the same cylinder.

Figure 4.2 shows the results of the run. The small discrepancy was due to numerical error. However, error was in the range of $1.5 \%$. The model fairly well established.

\footnotetext{
${ }^{1}$ Program and flow chart are presented in appendix B.
} 


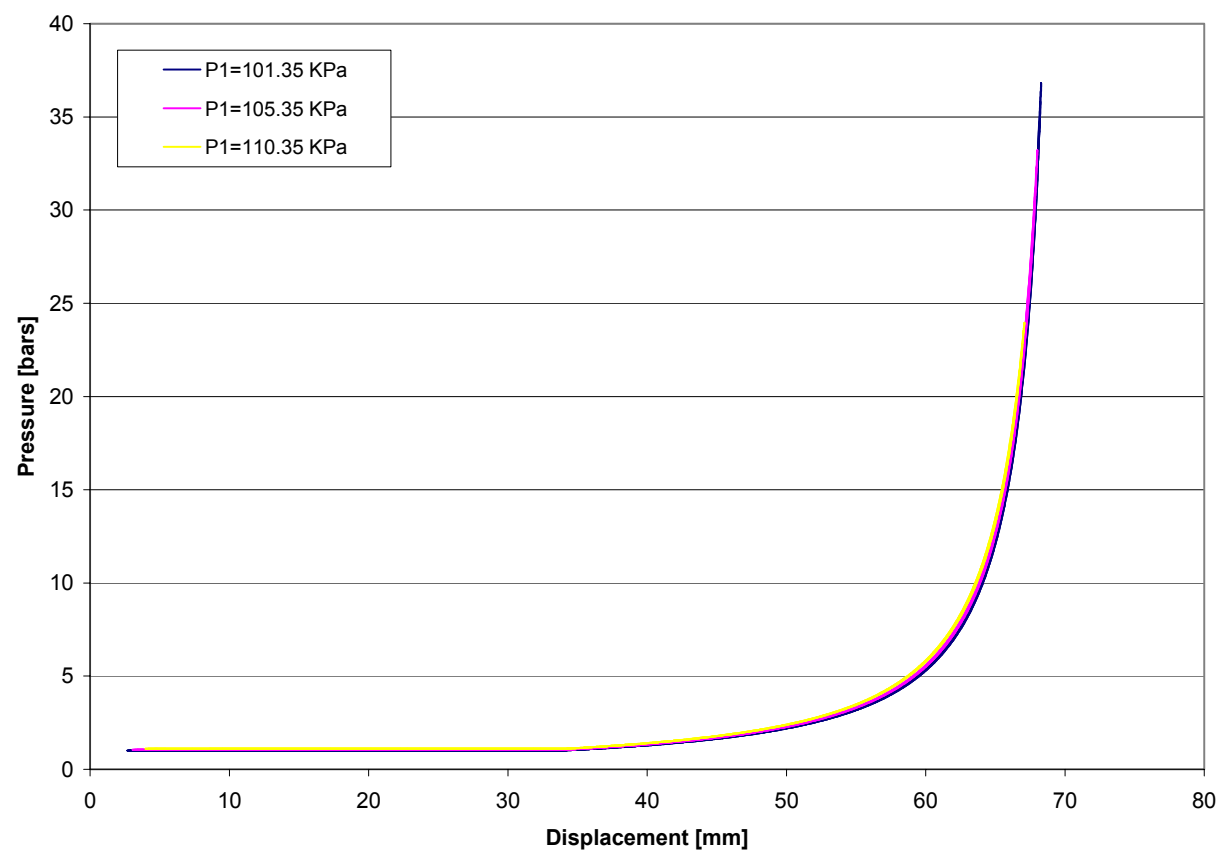

Figure 4.1. In-Cylinder Pressure/Displacement Diagrams for Different Manifold Pressures, Lambda $=1000$, no Friction, and no Heat Transfer

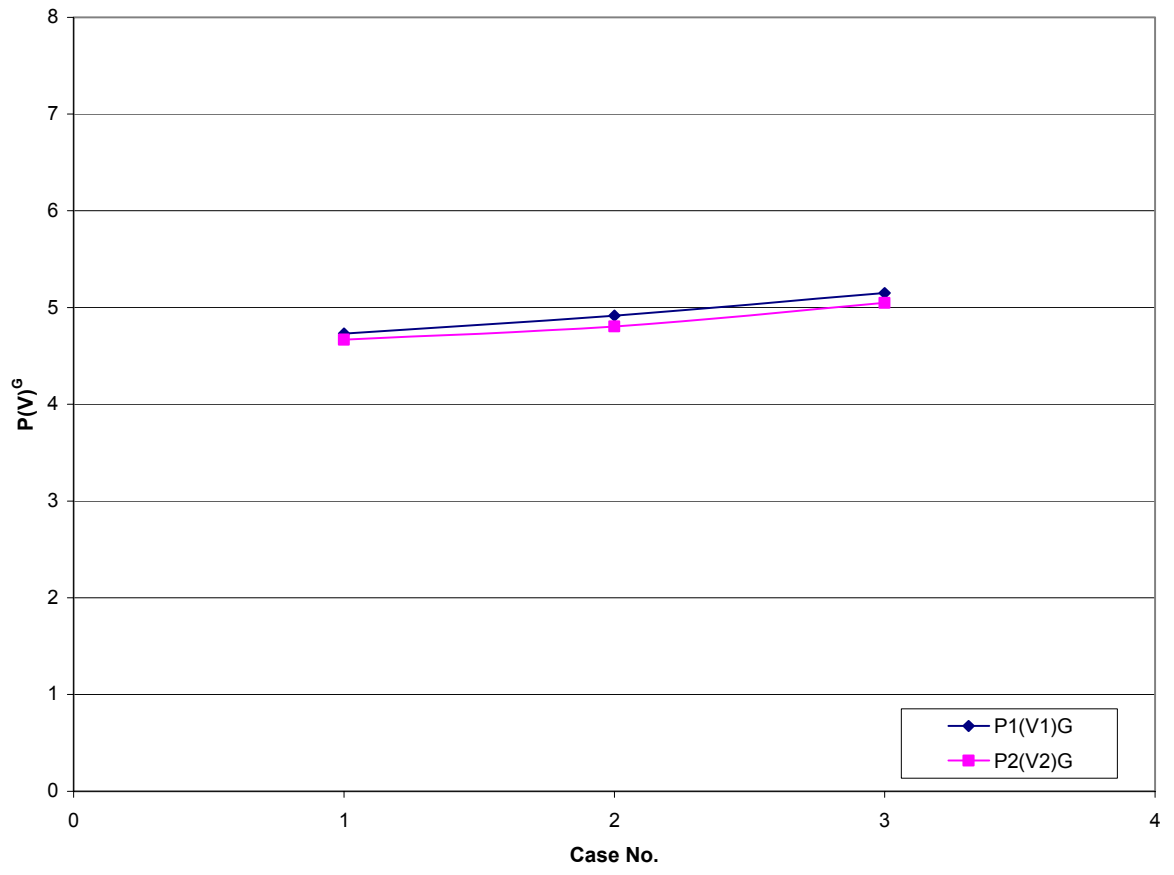

Figure 4.2. Comparison Adiabatic Relation Values for the Three Cases 


\subsection{THEORETICAL OTTO CYCLE}

To ensure the outputs of the model, a simple case was considered to compare the model's output results with theoretical values to validate the model. The model's resulted indicated efficiency was compared with the theoretical Otto cycle efficiency, as a special case. The program was altered to allow instantaneous heat release from an injection event occurring at less than $1 \mathrm{~mm}$ before cylinder head. The heat transfer losses and the friction loses were set to zero for the purpose of comparison. Figure 4.3 shows results from this exercise [50]. The small difference between theoretical Otto cycle and model results was due to the limits to add heat at the maximum stroke length instantaneously. In other words, the maximum accepted injection position that the program allowed was $0.0009 \mathrm{~m}$. However, the results have shown sufficient match to allow further investigation.

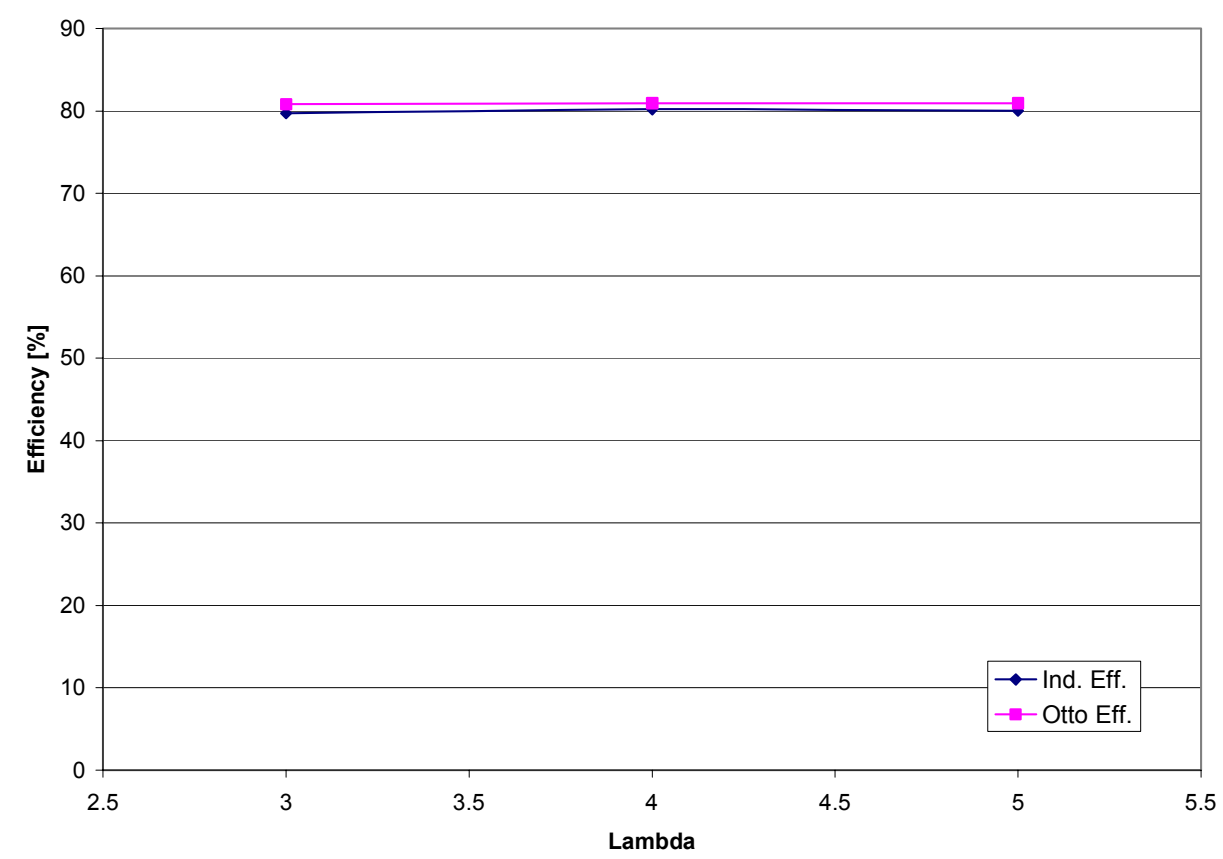

Figure 4.3. Efficiency Comparison Theoretical Otto Efficiency and Special Case Model Output. Translator $M=4 \mathrm{~kg}$ 


\subsection{HEAT TRANSFER MODEL}

On eliminating the heat transfer module the in-cylinder pressure and the velocity profile of the two-stroke compression ignition linear engine were also increased, Figures 4.4 and 4.5. The heat transfer was about 22 to $26 \%$ of the total power. Results were as expected, as higher percentage of the energy released by combusting the fuel was used to accelerate the engine and increase the compression ratio. Also, it can be seen that the resulted in-cylinder pressure was higher than normal standard commercial diesel engines.

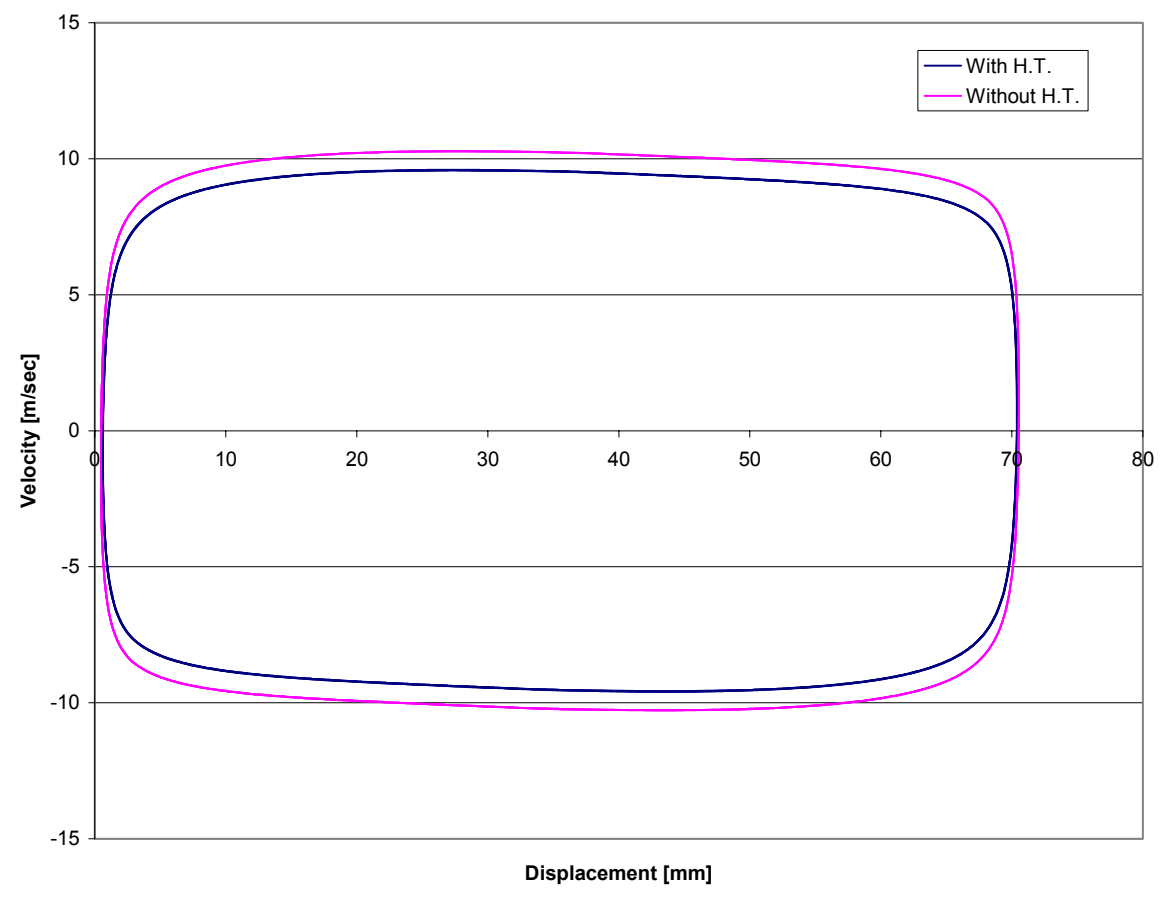

Figure 4.4. Velocity Profile Over the Stroke Versus Displacement for Lambda=3, Translator Mass=4 $\mathrm{kg}$, and $\mathrm{Ca}=25 \mathrm{~N} \mathrm{Sec} / \mathrm{m}$ 


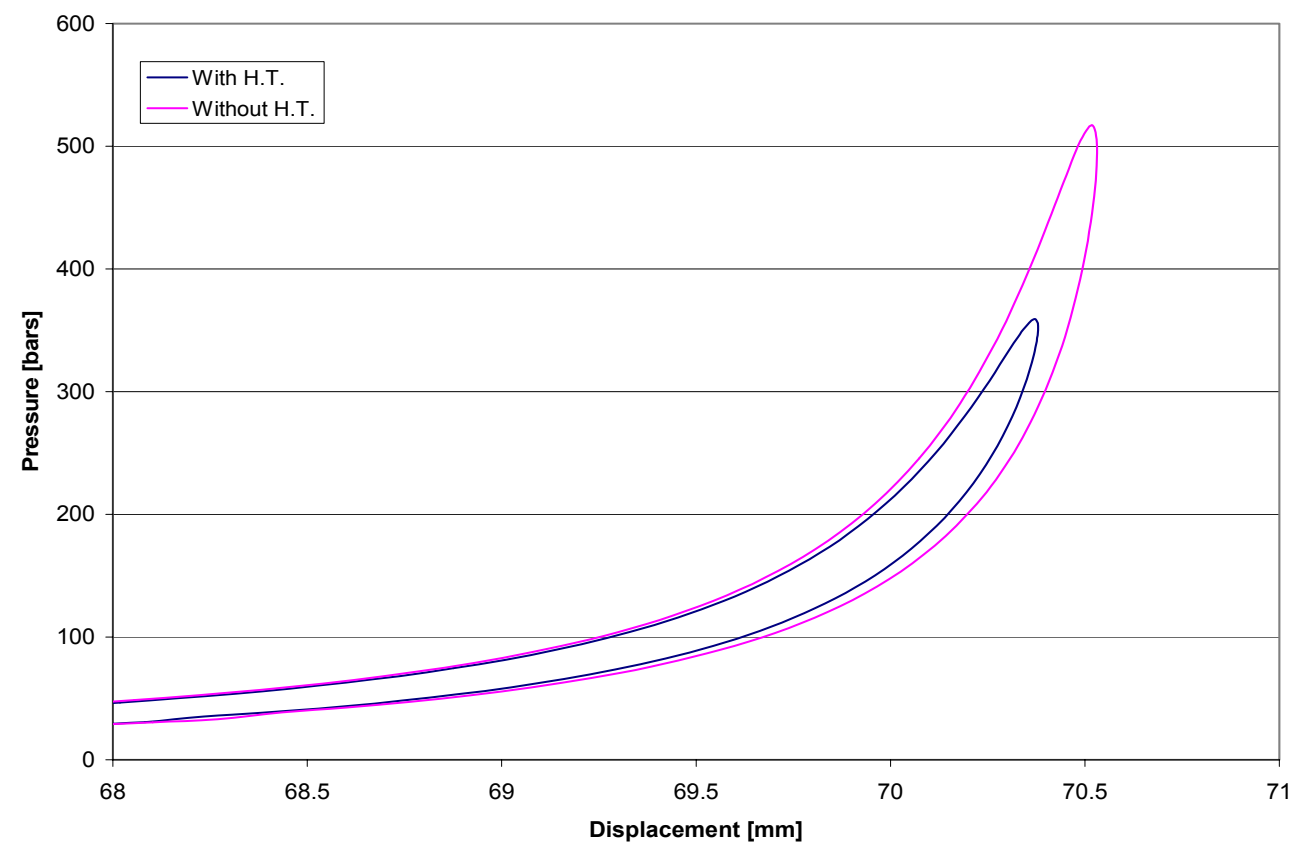

Figure 4.5. In-Cylinder Pressure Versus Displacement for $\operatorname{Lambda}=3$, Translator Mass $=4 \mathrm{~kg}$, and $\mathrm{Ca}=25 \mathrm{~N} \mathrm{Sec} / \mathrm{m}$

Figure 4.6 shows the difference between the compression ratio and the total output power of the two runs. As a result of eliminating the heat transfer module, the acceleration, the velocity, and the stroke length of the engine were increased. The increase of the stroke length was the reason for increasing the compression ratio, where the increase of speed resulted in a direct increase in the output power. 


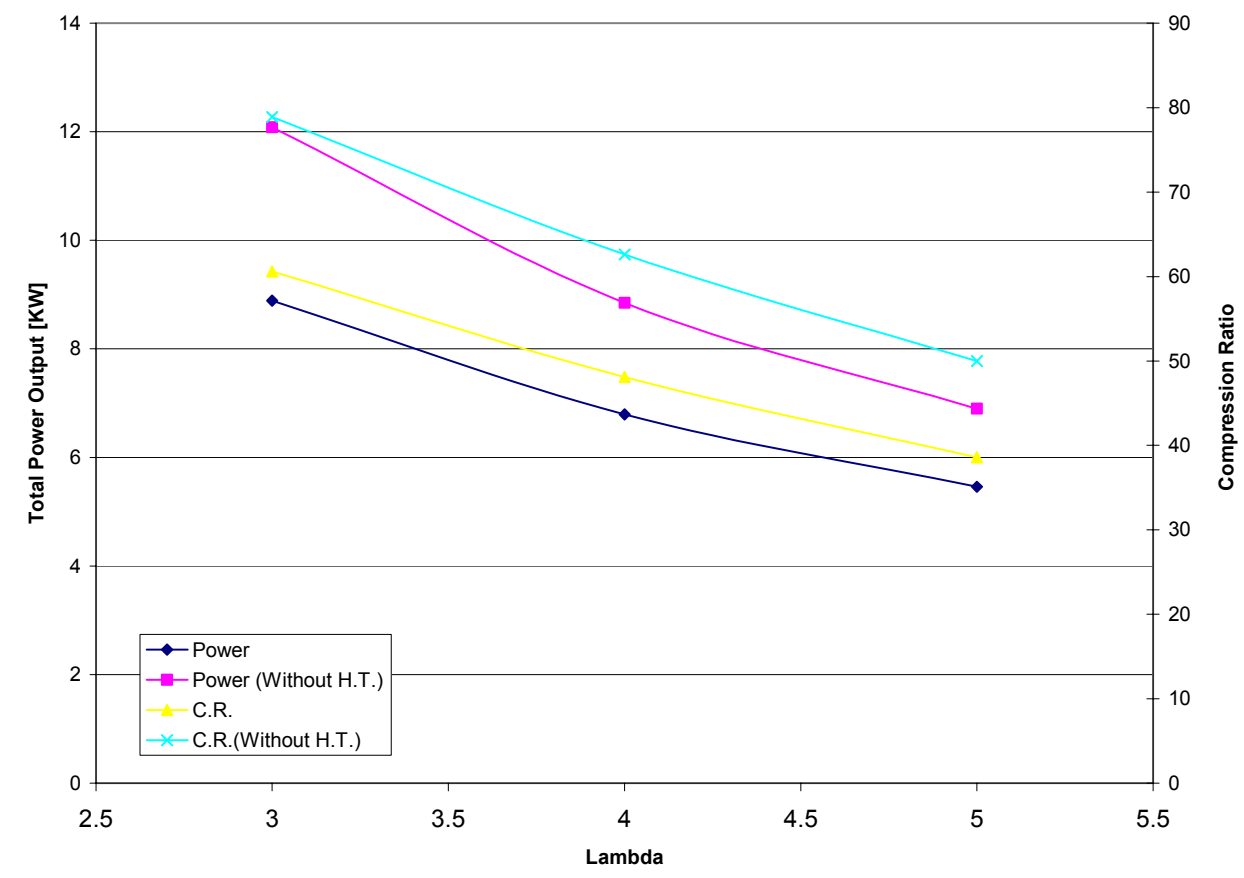

Figure 4.6. Output Power and Compression Ratio for Different Lambda, Translator Mass=4 kg, and $\mathrm{Ca}=25 \mathrm{~N} \mathrm{Sec} / \mathrm{m}$

\subsection{THERMODYNAMIC MODEL}

The last exercise to check the numerical simulating model was to replace the type of fuel and make sure that the model was responding accordingly. The US Army fuel, which was used in the previous runs, JP- $8^{2}$, was replaced with heavy diesel fuel ${ }^{3}$. Needless to say that, the stoichiometric air to fuel ratio for each fuel was altered in the program. Figure 4.7 illustrates the pressure/displacement diagram for the same air to fuel ratio. The in-cylinder pressure of the heavy diesel case was higher than that of the JP-8 case as the heating value of the heavy diesel fuel is higher than the heating value of the JP-8. Figure 4.8 confirmed the above-mentioned results.

\footnotetext{
${ }^{2} \mathrm{JP}-8$ fuel heating value is $35 \mathrm{MJ} / \mathrm{m}^{3}$

${ }^{3}$ Heavy diesel fuel heating value is $42.8 \mathrm{MJ} / \mathrm{m}^{3}$
} 


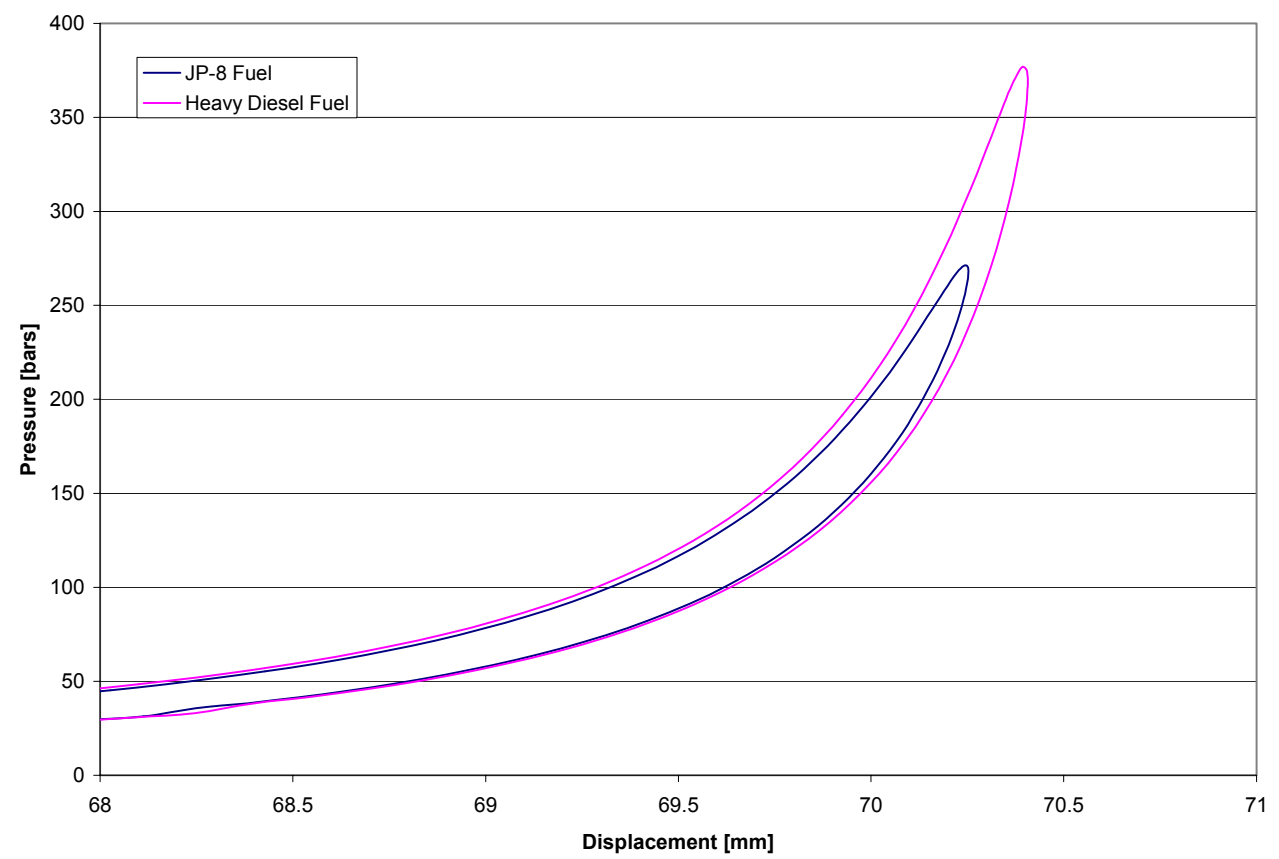

Figure 4.7. Pressure / Displacement Diagram for Two Different types of Fuels, Lambda=3, Translator Mass $=4 \mathrm{~kg}$, and $\mathrm{Ca}=25 \mathrm{~N} \mathrm{Sec} / \mathrm{m}$

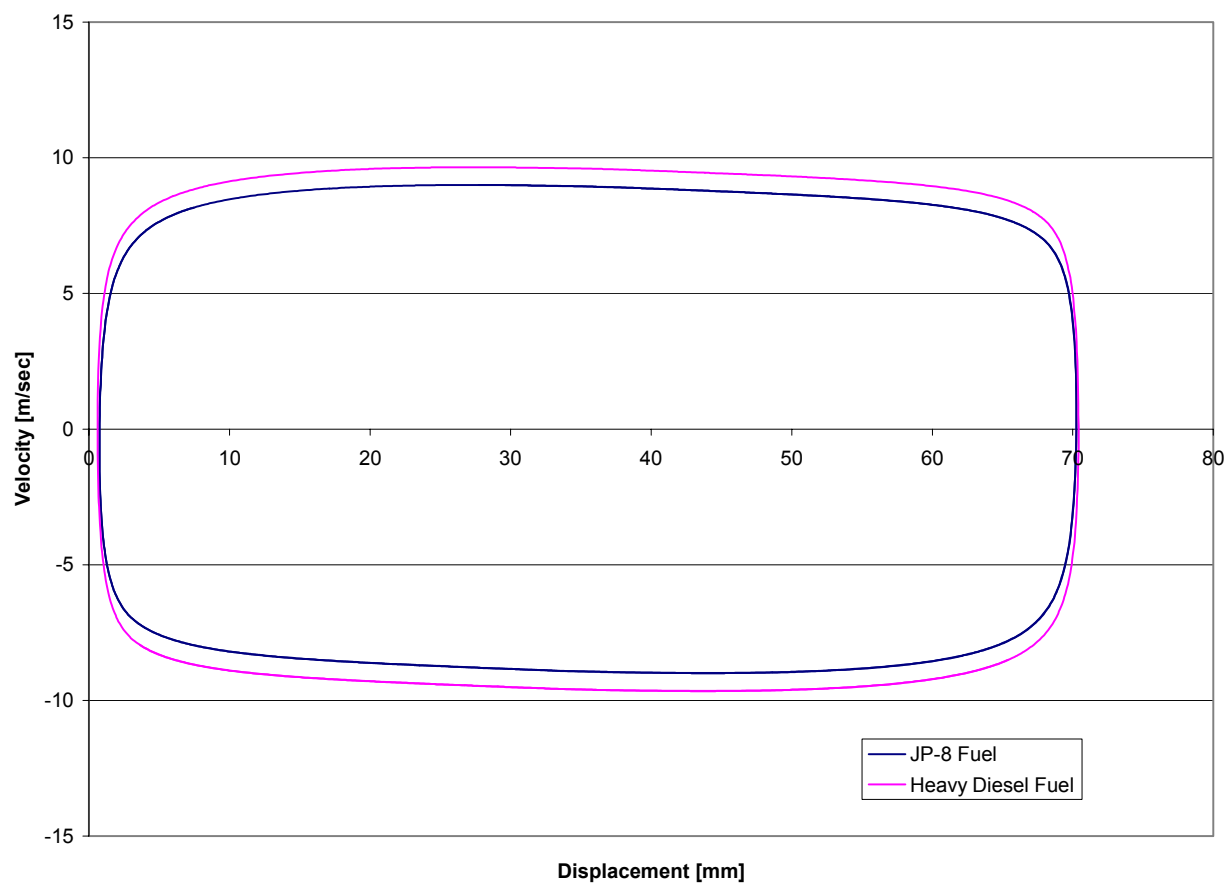

Figure 4.8. Velocity Profile Over the Stroke for Two Different Types of Fuels, Lambda=3, Translator Mass $=4 \mathrm{~kg}$, and $\mathrm{Ca}=25 \mathrm{~N} \mathrm{Sec} / \mathrm{m}$ 
It was decided to use for the rest of the study the JP-8 fuel, as this is the type of fuel that the US Army uses.

\subsection{ENGINE ANALYSIS}

To ensure that the simulating model was giving satisfactory results it was decided to analyze the output results by showing how the input energy divides, Figure 4.9.

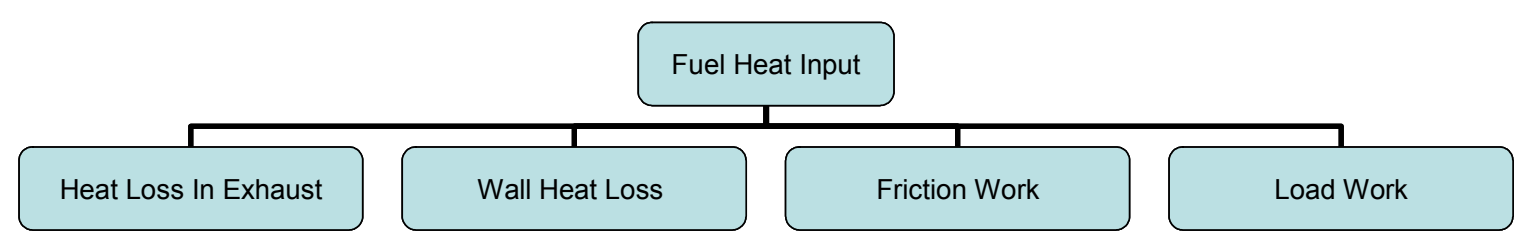

Figure 4.9. Fuel Input Energy and Its Dividing Channels

Figures 4.10 and 4.11 show two pie charts for the same load constant and different values of lambda illustrating results obtained by integrating the friction and load force over the cycle. 


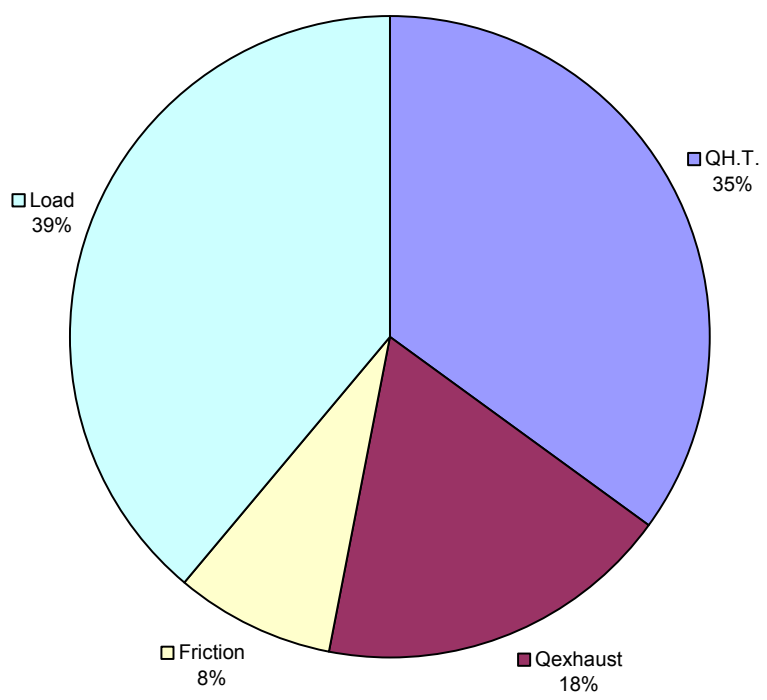

$$
\begin{aligned}
& \square \text { QH.T. } \\
& \square \text { Qexhaus } \\
& \text { 口Load }
\end{aligned}
$$

Figure 4.10. Pie Chart Showing How Input Energy Divides for Lambda=3, Translator Mass=4kg and $\mathrm{Ca}=25 \mathrm{~N} \mathrm{Sec} / \mathrm{m}$

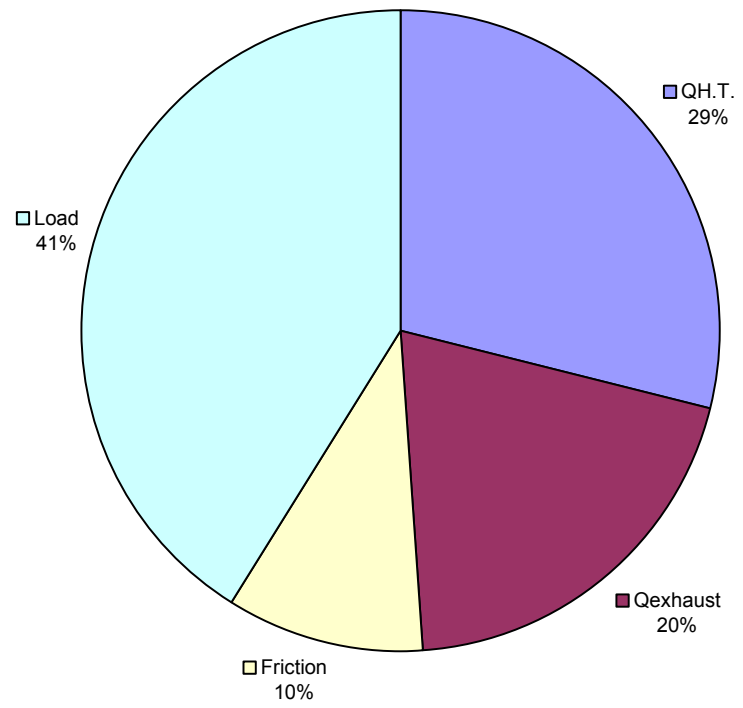

Figure 4.11. Pie Chart Showing How Input Energy Divides for Lambda=4, Translator Mass=4kg and $\mathrm{Ca}=25 \mathrm{~N} \mathrm{Sec} / \mathrm{m}$ 
It can be seen that increasing lambda increased the load work and the friction work as a percentage. In addition it decreased the heat transfer lost to cylinder wall as a result of the decreased in-cylinder pressure as a percentage also.

The mechanical efficiency ${ }^{4}$ for the first case of lambda $=3$ was $80 \%$ and for lambda $=4$ was $75.3 \%$.

\footnotetext{
${ }^{4}$ The mechanical efficiency is the ratio between load power and the indicated power
} 


\section{5-SPECIAL MOTORING CASES}

It was decided to study the dynamics of the two-stroke linear engine using motoring cases. Also, this study was coupled with studying the effect of the weight of the translator mass on the dynamics of the linear engine. In the motoring cases it was considered that the heat transfer and friction modules were cancelled and there was no heat added to the engine. The reason behind this was to study the dynamics of the engine without any influence of friction or heat transfer ${ }^{1}$. An initial starting force of $9700 \mathrm{~N}$ was applied to move the engine.

Figures 5.1, 5.2, and 5.3 illustrate the effect of increasing the translator mass. Figure 5.1 shows the displacement of the linear engine versus time for different translator masses. Figure 5.2 shows the velocity of the linear engine for different translator masses versus the displacement, the round shape of the velocity indicates that there was no heat transfer across the stroke. Figure 5.3 shows that increasing the translator mass decreased the engine the frequency $[47,50]$. Needless to say that, the engine frequency plays a vital role in increasing the unit power density.

This is why materials selected for linear engines should be of light materials to avoid the increase in compression ratio and the decrease of the engine frequency. Also, it can be seen that there was a dramatic effect of changing the translator mass on the engine velocity that affected the engine frequency as mentioned before.

\footnotetext{
${ }^{1}$ The friction force can be cancelled in the program by setting the friction force to zero in the dynamic subroutine. The heat transfer can be cancelled in the program by canceling calling the heat transfer subroutine.
} 


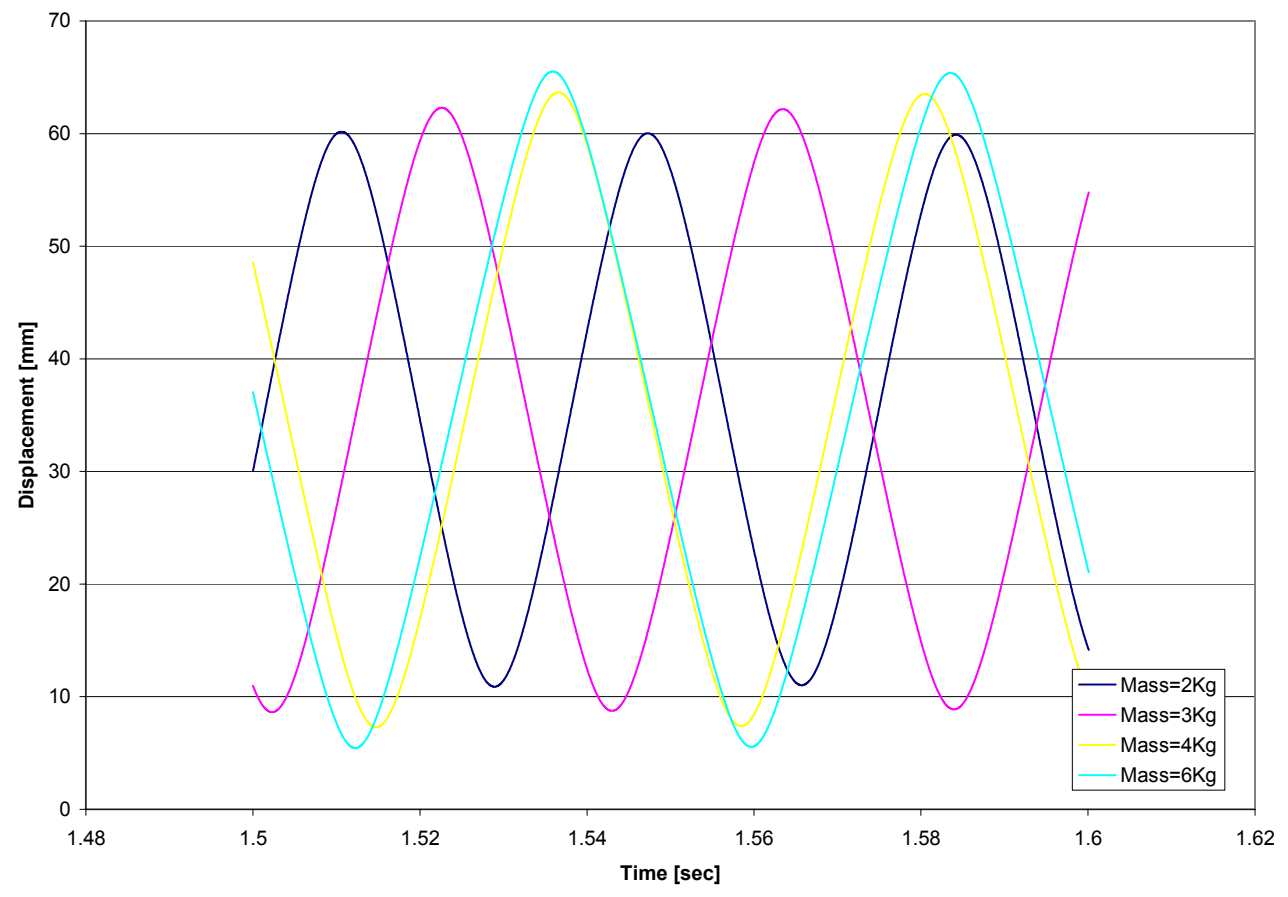

Figure 5.1. Displacement Versus Time for Different Translator Mass for Motoring Cases $^{2}$

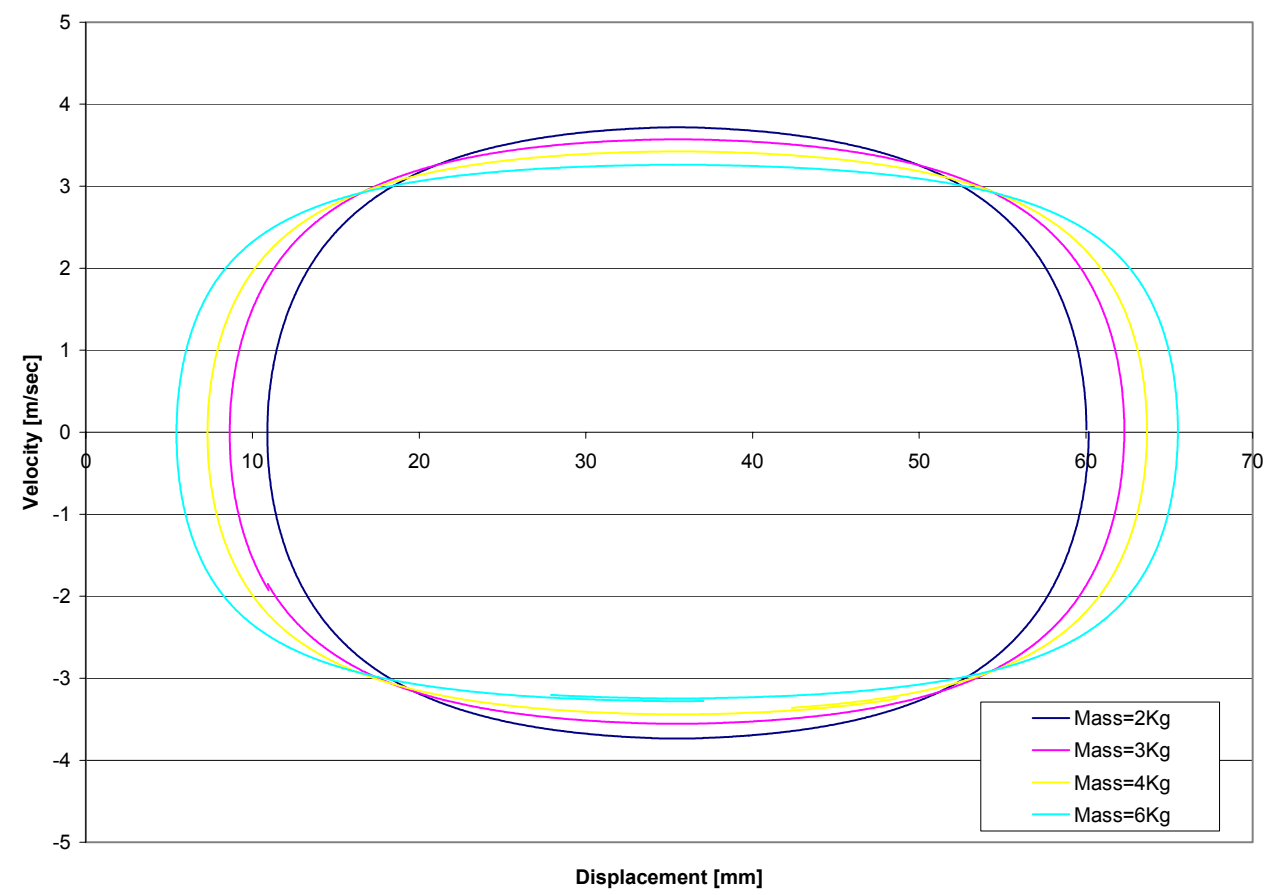

Figure 5.2. Velocity Versus Displacement for Different Translator Mass for Motoring Cases

${ }^{2}$ Initial starting pressure and starting piston position were held constant to produce these data 


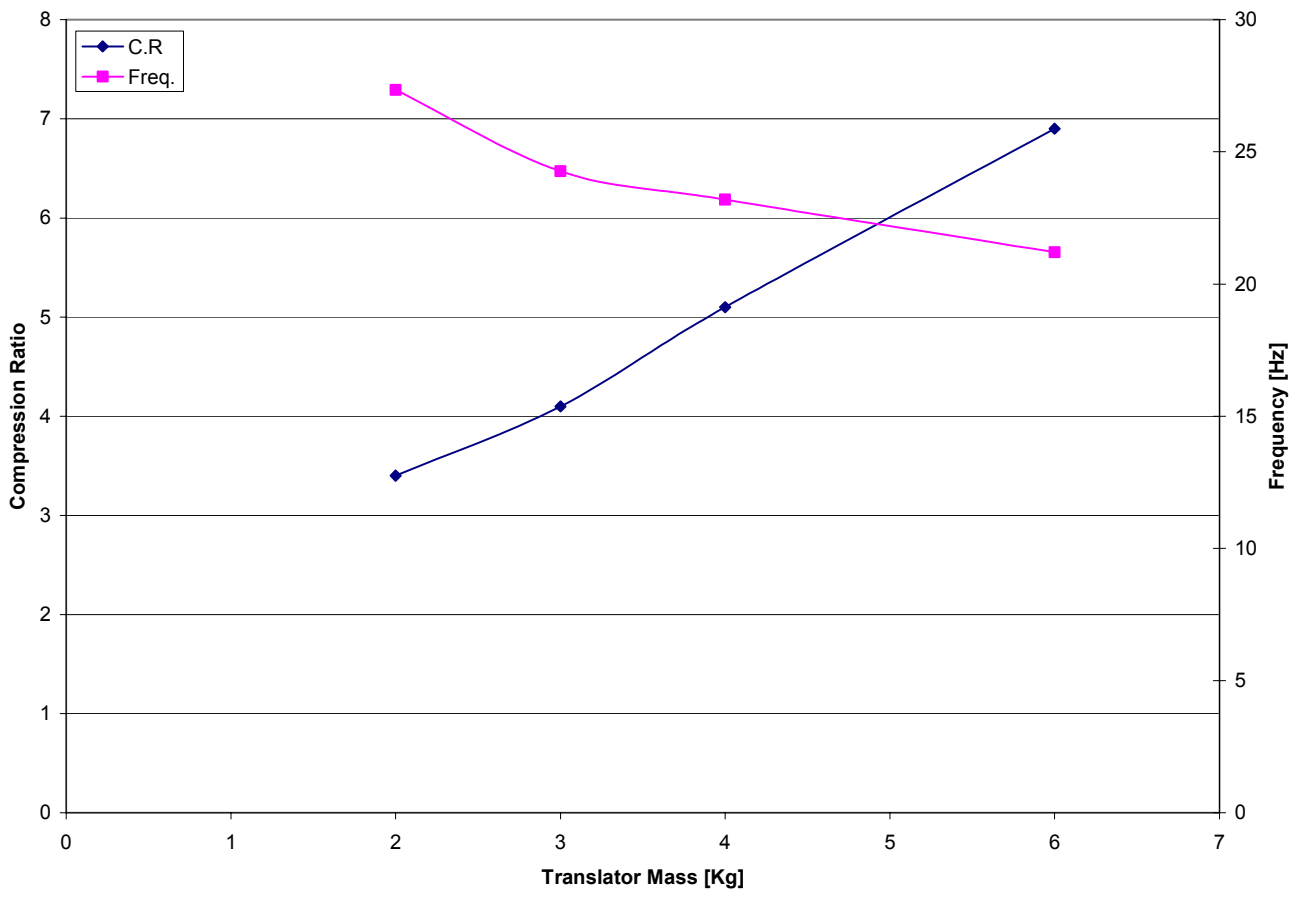

Figure 5.3. Compression Ratio and Frequency Versus Translator Mass for Motoring Cases 


\section{6- DIMENSIONLESS ANALYSIS}

It was decided to carry out a dimensionless analysis study for the two-stroke compression ignition direct injection linear engine coupled with linear alternator. The reason behind this was to generalize this study to a wide range of geometric designs of this type of internal combustion engines and hence find out the best geometric dimensions of the two-stroke compression ignition direct injection linear engine that corresponds to the most efficient performance for this type of internal combustion engines. Also, by using such a technique, engineers can reduce many parameters and still use the equations in a way that can help them to predict the performance of the tested object.

In the dimensionless study the dimensionless displacement $\mathrm{x}^{*}$, the dimensionless mass $\mathrm{M}^{*}$, and the dimensionless time $\mathrm{t}^{*}$ were chosen to be as follows:

$\mathrm{x}^{*}=\mathrm{x} / \mathrm{L}_{\mathrm{ste}}$

where, $\mathrm{L}_{\mathrm{ste}}$ is the effective stroke length in $\mathrm{m}$; i.e. the length from the closing of the exhaust port to the cylinder head, and $\mathrm{x}$ is the displacement in $\mathrm{m}$

$M^{*}=M / m$

where, $\mathrm{M}$ is the mass in $\mathrm{kg}$.

$\mathrm{t}^{*}=\mathrm{t} / \mathrm{t}_{\mathrm{r}}$

where, $\mathrm{t}$ is time in sec, $\mathrm{t}_{\mathrm{r}}=\sqrt{\frac{m}{p_{m p} L}}$.

The variables of the dimensionless analysis were chosen to cover the normal operating ranges of commercial diesel engines, and it was decided that the matrix would be extended to determine the operation conditions outside the assigned ranges, Table 6.1 . 
The base case was chosen to represent the experimental two-stroke linear engine prototype that was built in West Virginia University Engine Emission Research Center. All the variables listed in the matrix were converted to be dimensionless ${ }^{1}$.

The dimensionless analysis study was carried out as follows:

${ }^{1}$ Appendix A. 
TABLE 6.1 THE DIMENSIONLESS ANALYSIS MATRIX

Dimenssionless Parametric Study

\begin{tabular}{|c|c|c|c|c|c|c|}
\hline No. of Cases & & 4 & 4 & 3 & 2 & 2 \\
\hline Case Range & & $1.3-4$ & Load Cons & $3.0,4 \cdot 0,5.0$ & $0.081,0.19$ & $20 / 80,40 / 60$ \\
\hline Out put I & Case & B/Eff. St. & Dim. Lo. & Dim. Qin & Dim. Inj. Pos. & Com. \% \\
\hline$f^{*}$ & & $x$ & $x$ & $x$ & $x$ & $x$ \\
\hline $\mathrm{P}^{*}$ & & $x$ & $x$ & $x$ & $x$ & $x$ \\
\hline $\mathrm{Ff}^{*}$ & & $x$ & $x$ & $x$ & $x$ & $x$ \\
\hline $\mathrm{V}^{*}$ & & $x$ & $x$ & $x$ & $x$ & $x$ \\
\hline $\mathrm{AV}^{*}$ & & $x$ & $x$ & $x$ & $x$ & $x$ \\
\hline $\mathrm{IP}^{*}$ & & $x$ & $x$ & $x$ & $X$ & $x$ \\
\hline $\mathrm{IPM}^{*}$ & & $x$ & $x$ & $x$ & $x$ & $x$ \\
\hline $\mathrm{EM}^{*}$ & & $x$ & $x$ & $x$ & $x$ & $x$ \\
\hline $\mathrm{IPV}^{*}$ & & $x$ & $x$ & $x$ & $x$ & $x$ \\
\hline $\mathrm{EV}^{*}$ & & $x$ & $x$ & $x$ & $x$ & $x$ \\
\hline$\eta$ & & $x$ & $x$ & $x$ & $x$ & $x$ \\
\hline$r$ & & $x$ & $x$ & $x$ & $x$ & $x$ \\
\hline \multicolumn{7}{|c|}{ Dim. Base Case } \\
\hline B/St. & & 2 & & & & \\
\hline $\mathrm{C}_{\mathrm{a}}{ }^{*}$ & & 0.0049 & & & & \\
\hline$\lambda$ & & 4 & & & & \\
\hline$J^{*}$ & & 0.08108 & & & & \\
\hline $\mathrm{m}^{*}$ & & $4.8 \mathrm{E}-05$ & & & & \\
\hline $\operatorname{Dif}^{*}(\%)$ & & 80 & & & & \\
\hline $\operatorname{Pr}^{*}(\%)$ & & 20 & & & & \\
\hline
\end{tabular}

The generator mass in the above mentioned parametric study refers to the mass of the two-stroke compression ignition linear engine coupled with linear alternator and connected to a fuel tank. Of course four different values of masses for the four different designs of the two-stroke compression ignition linear engine linear alternator were suggested using weights of existing design commercial units of the same output power. 


\subsection{THE EFFECT OF DIMENSIONLESS LOAD CONSTANT}

Changing the dimensionless load constant can be considered as if the load of the two-stroke linear engine is changing. In other words increasing the dimensionless load constant means the load demand of the generator is increasing. It has been found that the dimensionless load constant can have a large impact on different parameters studied and can affect the operating conditions of the two-stroke compression ignition linear engine, as shown in Figure 6.2. However, four values for dimensionless load constant will be considered to study this effect. The four dimensionless constants will be referred to as $\mathrm{Ca} 1, \mathrm{Ca} 2, \mathrm{Ca} 3$ and $\mathrm{Ca} 4$. The values were assigned as follows, $\mathrm{Ca} 1=8.2 \times 10^{-4}, \mathrm{Ca} 2=$ $4.9 \times 10^{-3}, \mathrm{Ca} 3=7.4 \times 10^{-3}$, and $\mathrm{Ca} 4=1.6 \times 10^{-2}$. These values were typical expected operating dimensionless load constant for the smallest bore to effective stroke length of the two-stroke linear engine that was tested ${ }^{2}$.

Figures 6.1 and 6.2 show the change in the dimensionless indicated power versus bore to effective stroke length and dimensionless air mass for various dimensionless load constants. Increasing the bore to effective stroke length or the dimensionless air mass resulted in an increase in the dimensionless indicated power as a result of increasing the dimensionless input energy to the engine. It was also noticed that increasing the dimensionless load constant would increase the indicated efficiency as a result of increasing the load. In addition, the efficiency was slightly increased with the increase of the bore to effective stroke length and dimensionless air mass. The increase was a result of decreased dimensionless in-cylinder pressure, Figures 6.9 and 6.10. This also indicated that the dimensionless load constant has a small effect on indicated efficiency, Figure 6.3. It was also noticed that this increase in dimensionless indicated power was

${ }^{2}$ Appendix C. 
associated with an increase in dimensionless average piston speed as shown in Figure 6.4.

Also, as expected the dimensionless frequency increased as the frequency is synonymous to velocity. Figure 6.5 shows the change in dimensionless frequency with different bore to effective stroke length values.

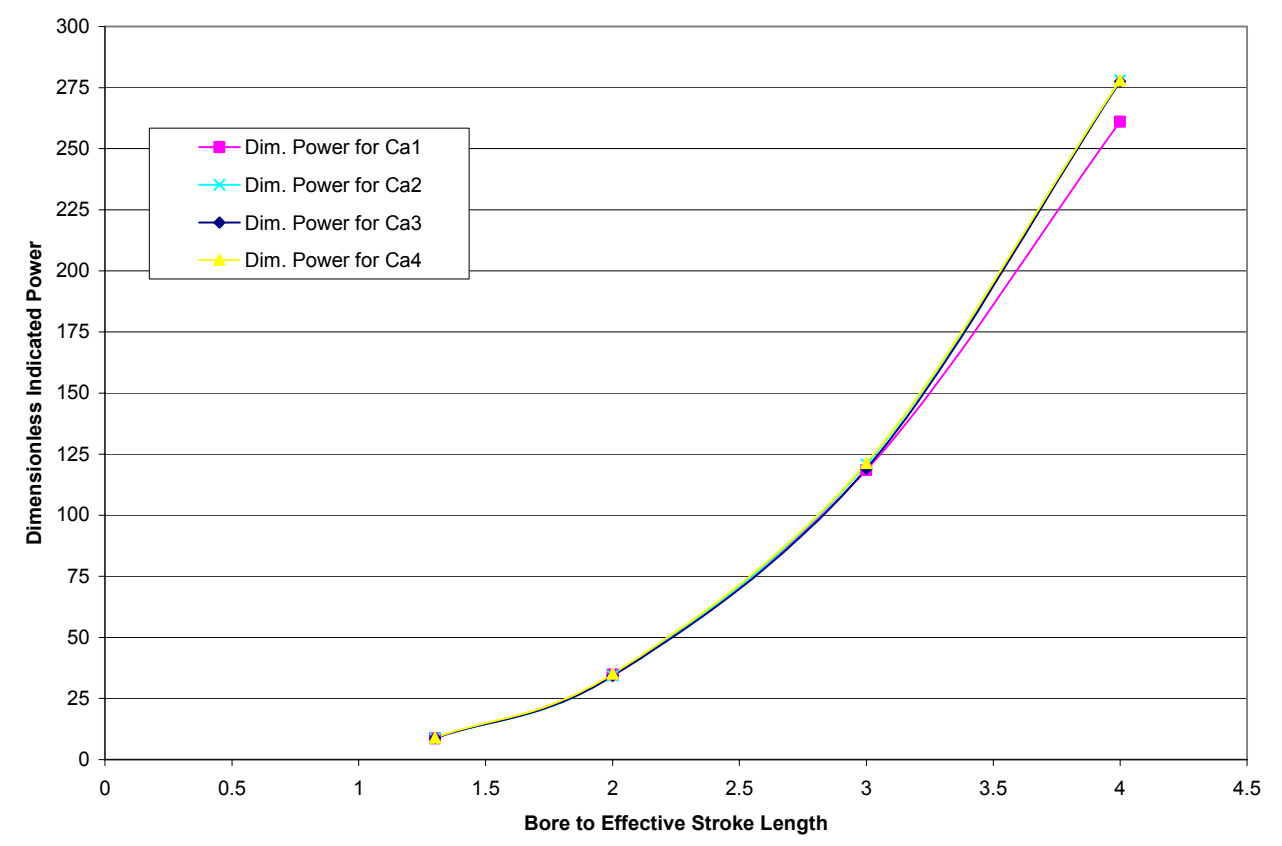

Figure 6.1. Dimensionless Indicated Power Versus Bore to Effective Stroke Length for Lambda = 3, and Dimensionless Injection Position $=\mathbf{0 . 0 8 1}$ 


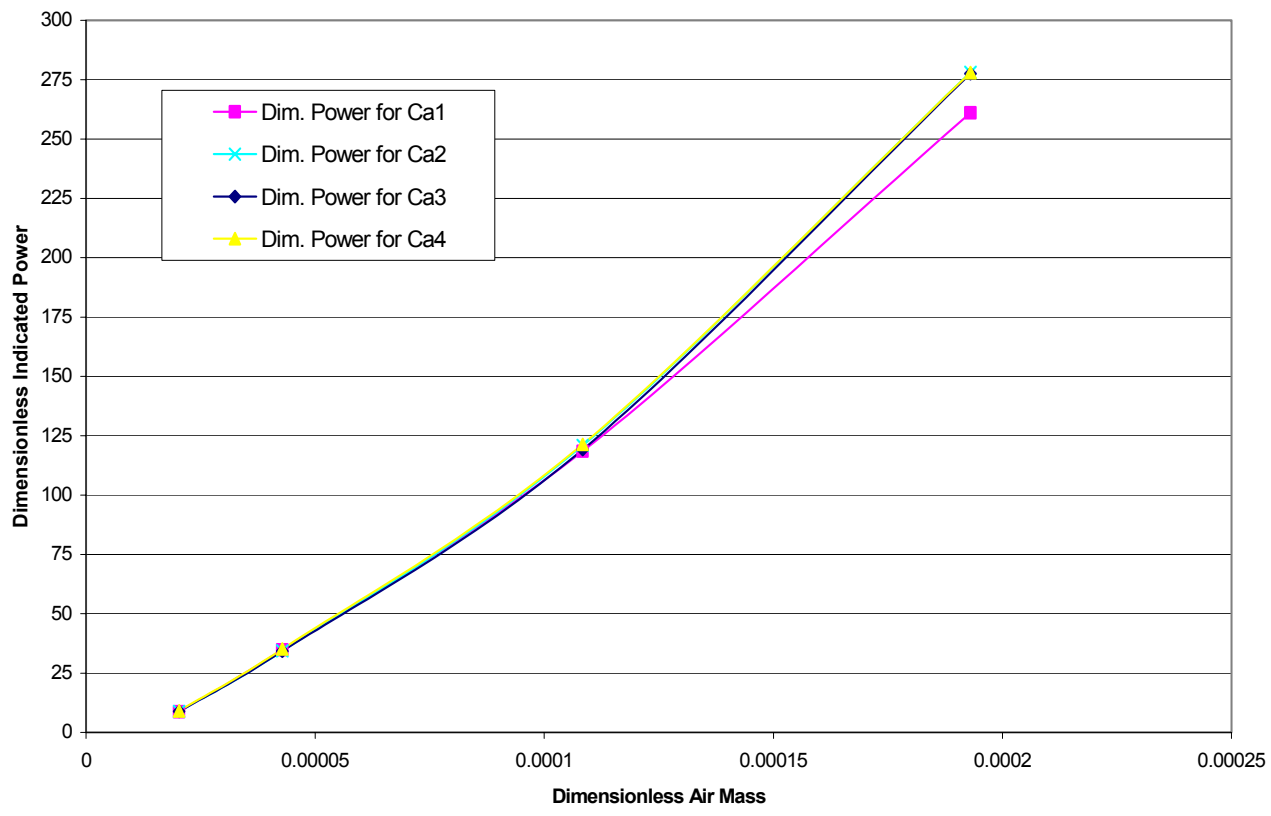

Figure 6.2. Dimensionless Indicated Power Versus Dimensionless Air Mass for Lambda $=3$, and Dimensionless Injection Position $=\mathbf{0 . 0 8 1}$

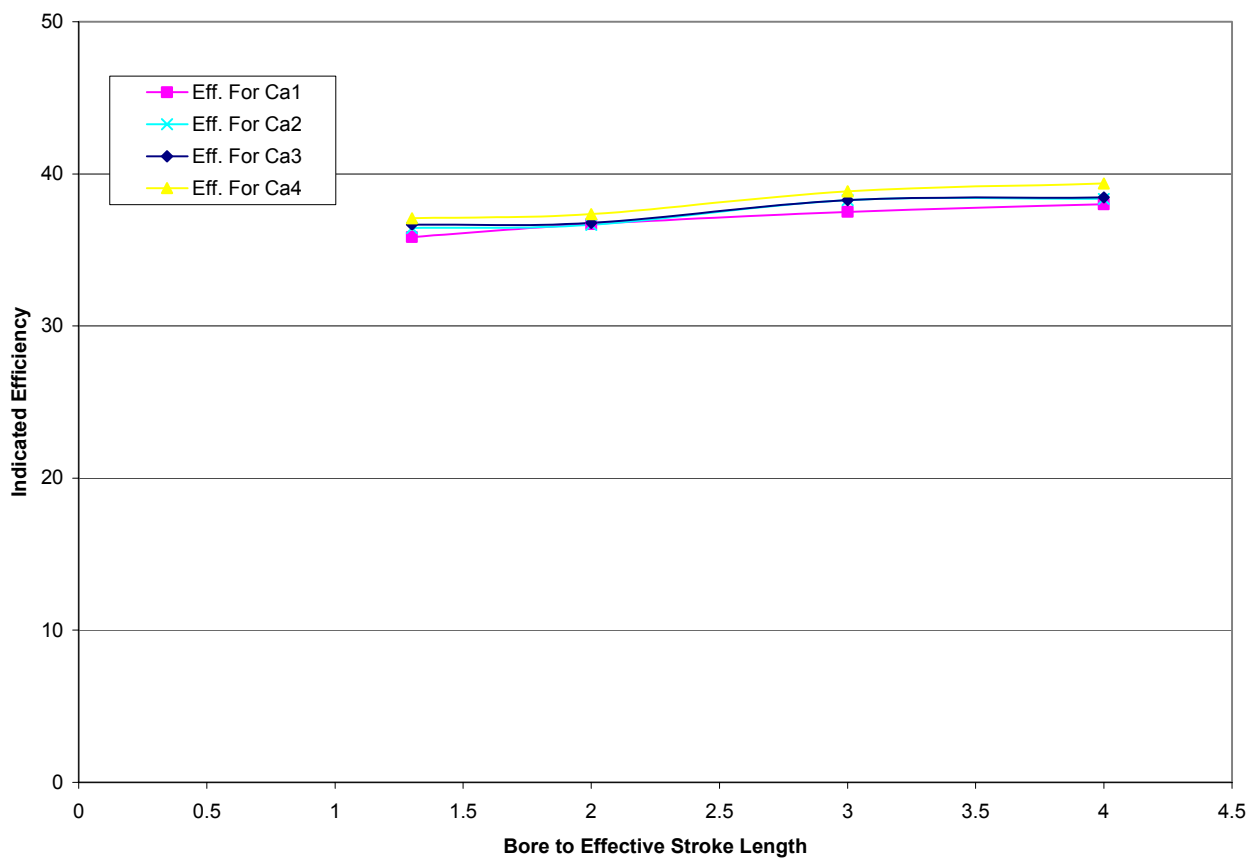

Figure 6.3. Indicated Efficiency Versus Bore to Effective Stroke Length for Lambda $=3$, and Dimensionless Injection Position=0.081 


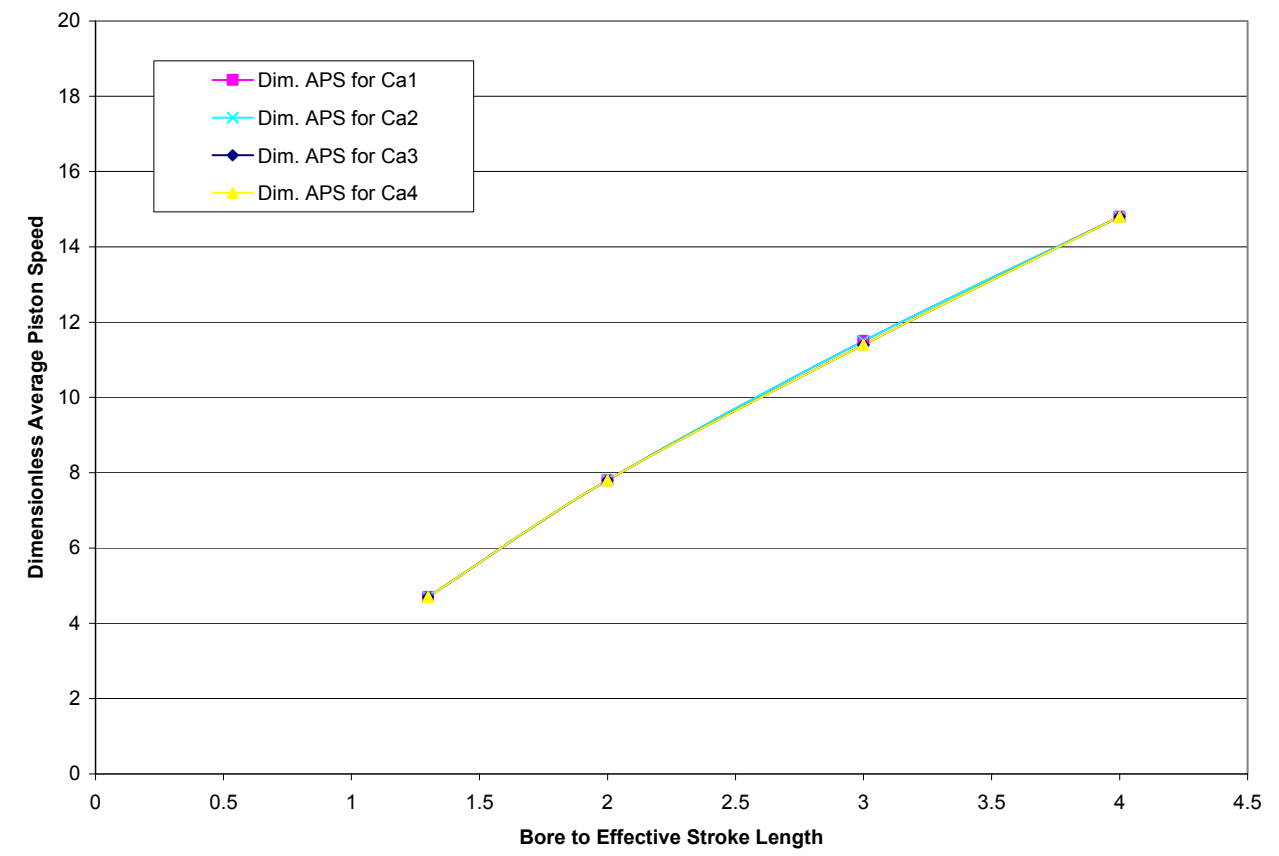

Figure 6.4. Dimensionless Average Piston Speed Versus Bore to Effective Stroke Length for Lambda $=3$, and Dimensionless Injection Position $=\mathbf{0 . 0 8 1}$

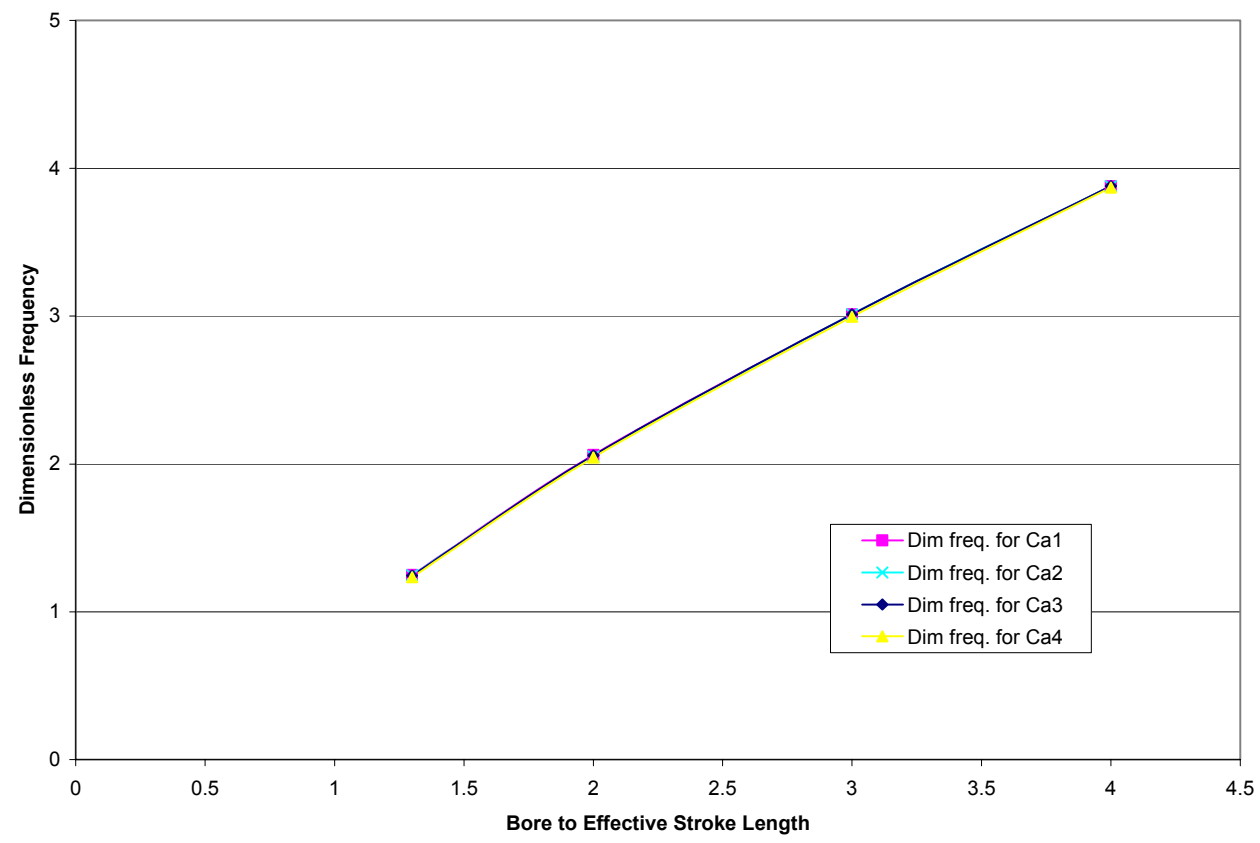

Figure 6.5. Dimensionless Frequency Versus Bore to Effective Stroke Length for Lambda $=3$, and Dimensionless Injection Position=0.081 
The close lines which are shown in Figures 6.4 and 6.5 were a direct result of using the dimensionless technique in studying the two-stroke compression ignition direct injection linear engine ${ }^{3}$.

Figure 6.6 illustrates the change of dimensionless velocity versus the dimensionless stroke length for different bore to effective stroke. It can be seen that the dimensionless speed increased with the increase of the bore to effective stroke length as a result of increasing the dimensionless input energy to the engine, as explained before. It was also noticed that changing the value of load constant had a negligible effect on the dimensionless velocity profile over the dimensionless position, Figures 6.6 and 6.7 .

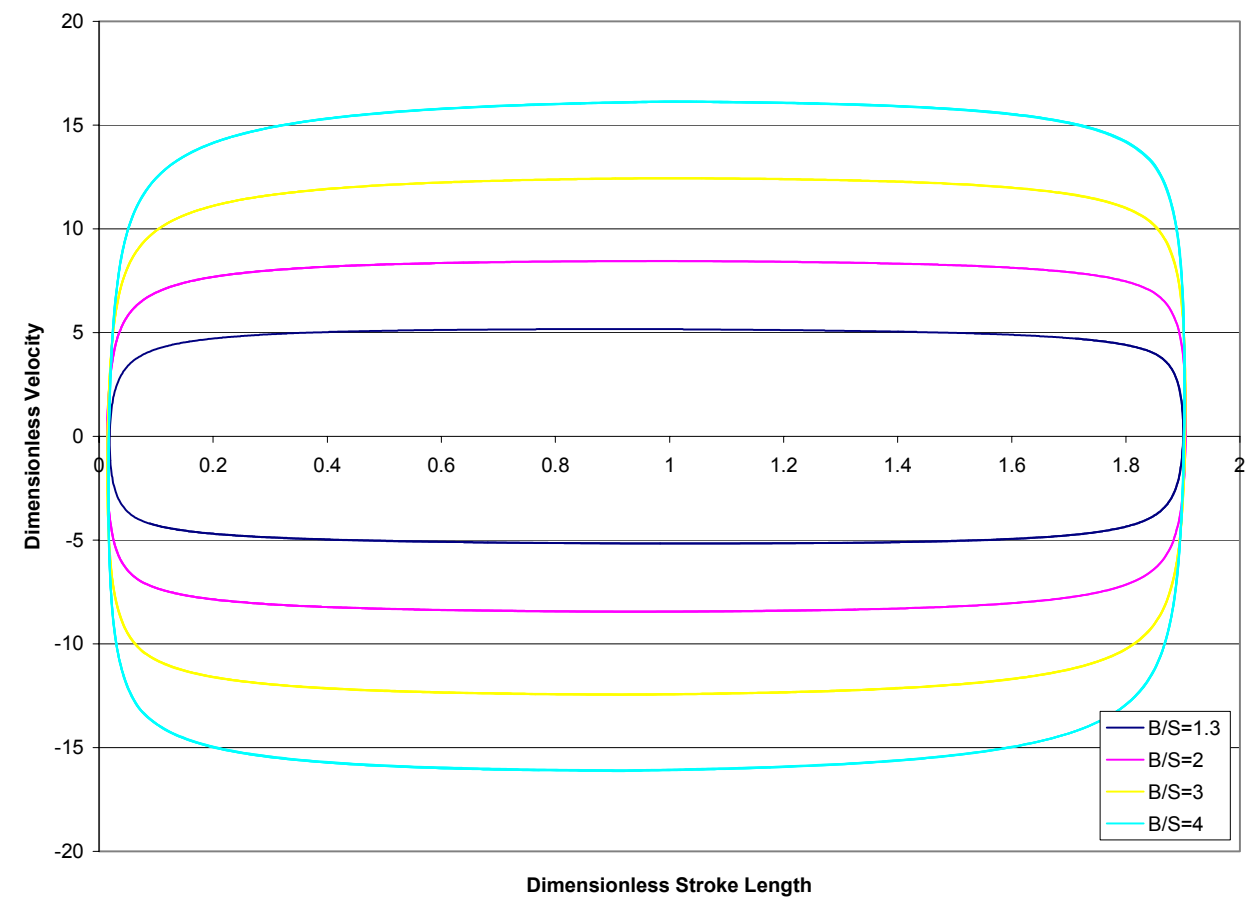

Figure 6.6. Dimensionless Velocity Versus Dimensionless Stroke Length for Lambda=3, Ca1, and Dimensionless Injection Position=0.081

\footnotetext{
${ }^{3}$ Multiplying the frequency by the relative time to make it in a dimensionless form resulted in having the dimensionless frequency almost the same value for each dimensionless load constant.
} 


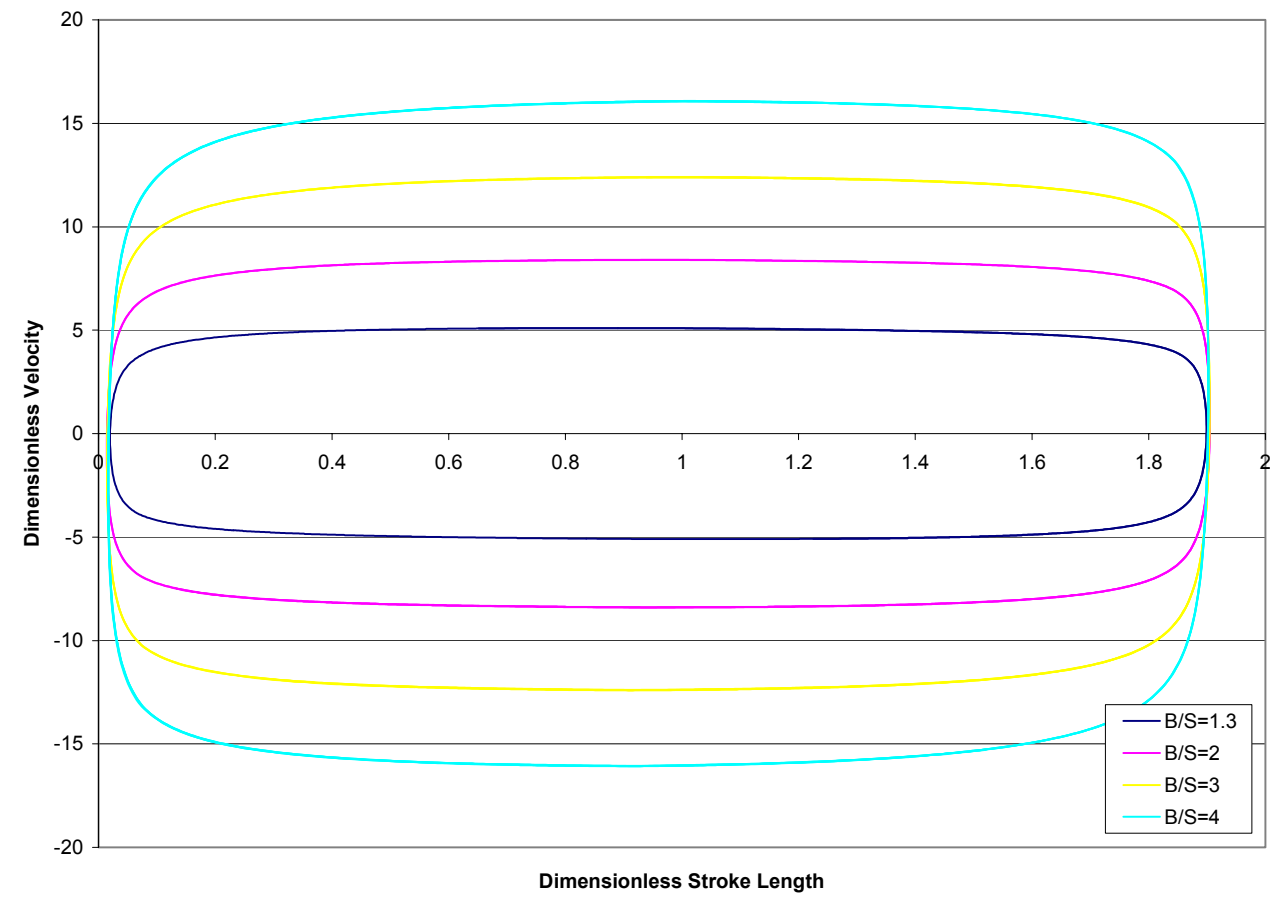

Figure 6.7. Dimensionless Velocity Versus Dimensionless Stroke Length for Lambda=3, Ca4, and Dimensionless Injection Position=0.081

Figure 6.8 illustrates the change of the compression ratio for different dimensionless load constants versus different bore to effective stroke length ratio. It can be seen that the highest compression ratio occurred with bore to effective stroke ratio of 2.2. It can also be seen that the compression ratio decreased by either the increase or the decrease of the bore to effective stroke length than this value. The lowest compression ratio in the figure took place with a bore to effective stroke length of 1.3 and Ca4. The increase in the compression ratio was due to the fact that the heat transfer factor is relatively low for small bore to effective stroke length, compared to larger bore to effective stroke length. On the other hand the compression ratio was low with bore to effective stroke length of 1.3 as a result of relatively low heat input. The high compression ratio was associated with high in-cylinder pressure; Figures 6.9 and 6.10 show this result. 


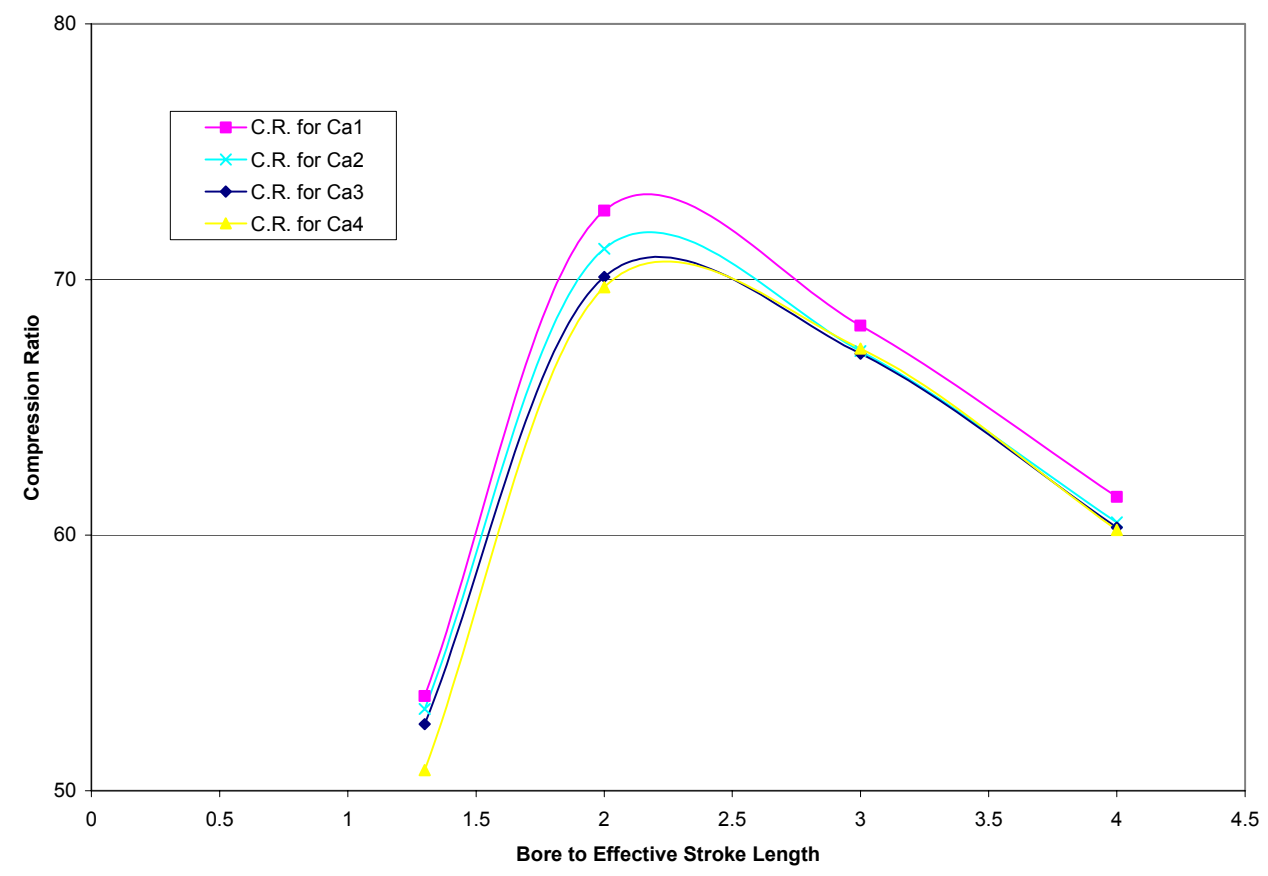

Figure 6.8. Compression Ratio Versus Bore to Effective Stroke Length for Lambda $=3$, and Dimensionless Injection Position=0.081

Figures 6.9 and 6.10 show the change in the dimensionless in-cylinder pressure with the dimensionless position for different dimensionless load constants, Ca1 and Ca4. It was noticed that the highest dimensionless in-cylinder pressure took place with bore to effective stroke length of two. In addition, it was also noticed that the dimensionless incylinder pressure was decreased with either the increase or decrease of bore to effective stroke, which confirmed results obtained in Figure 6.8. 


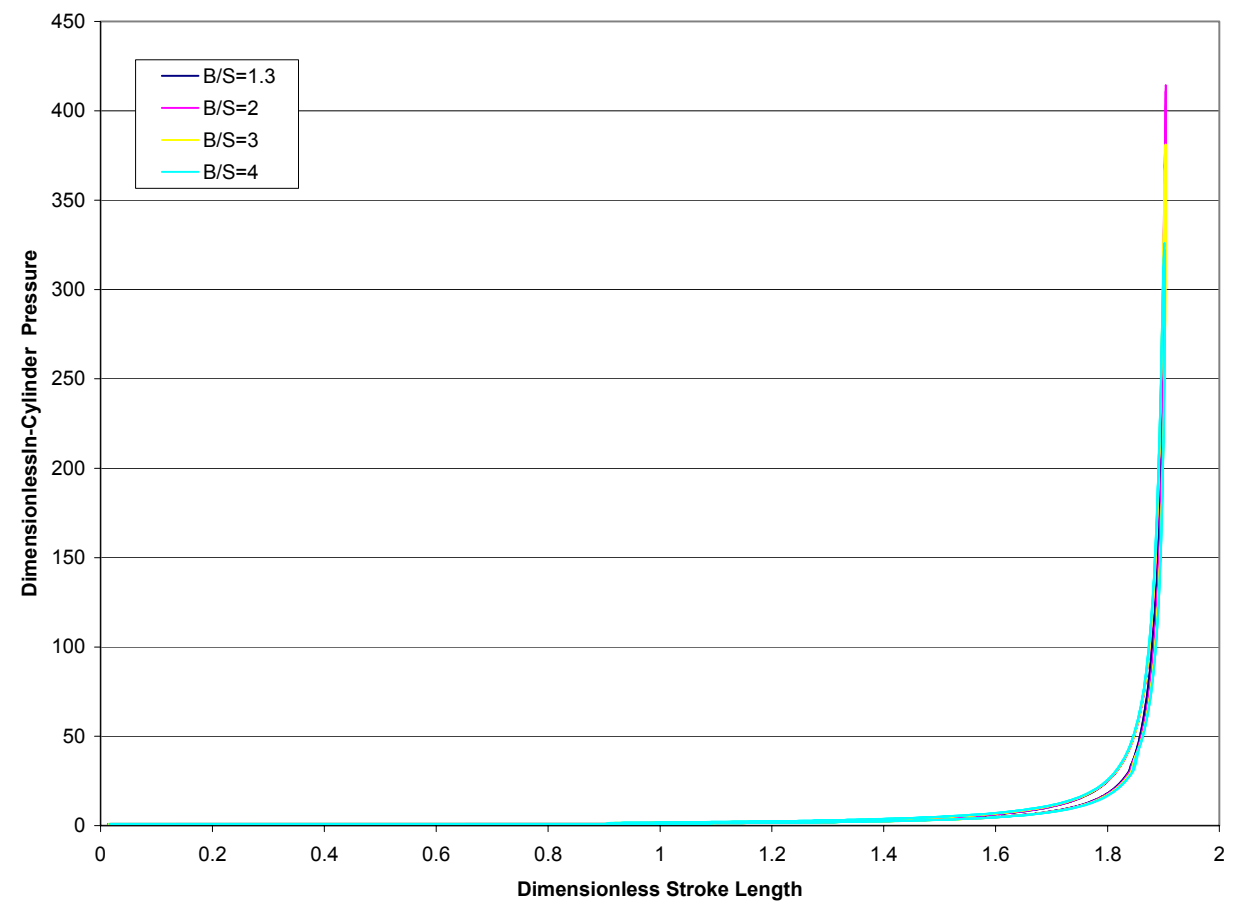

Figure 6.9. Dimensionless In-Cylinder Pressure Versus Dimensionless Stroke Length for Lambda=3, Ca1, and Dimensionless Injection Position $=0.081$

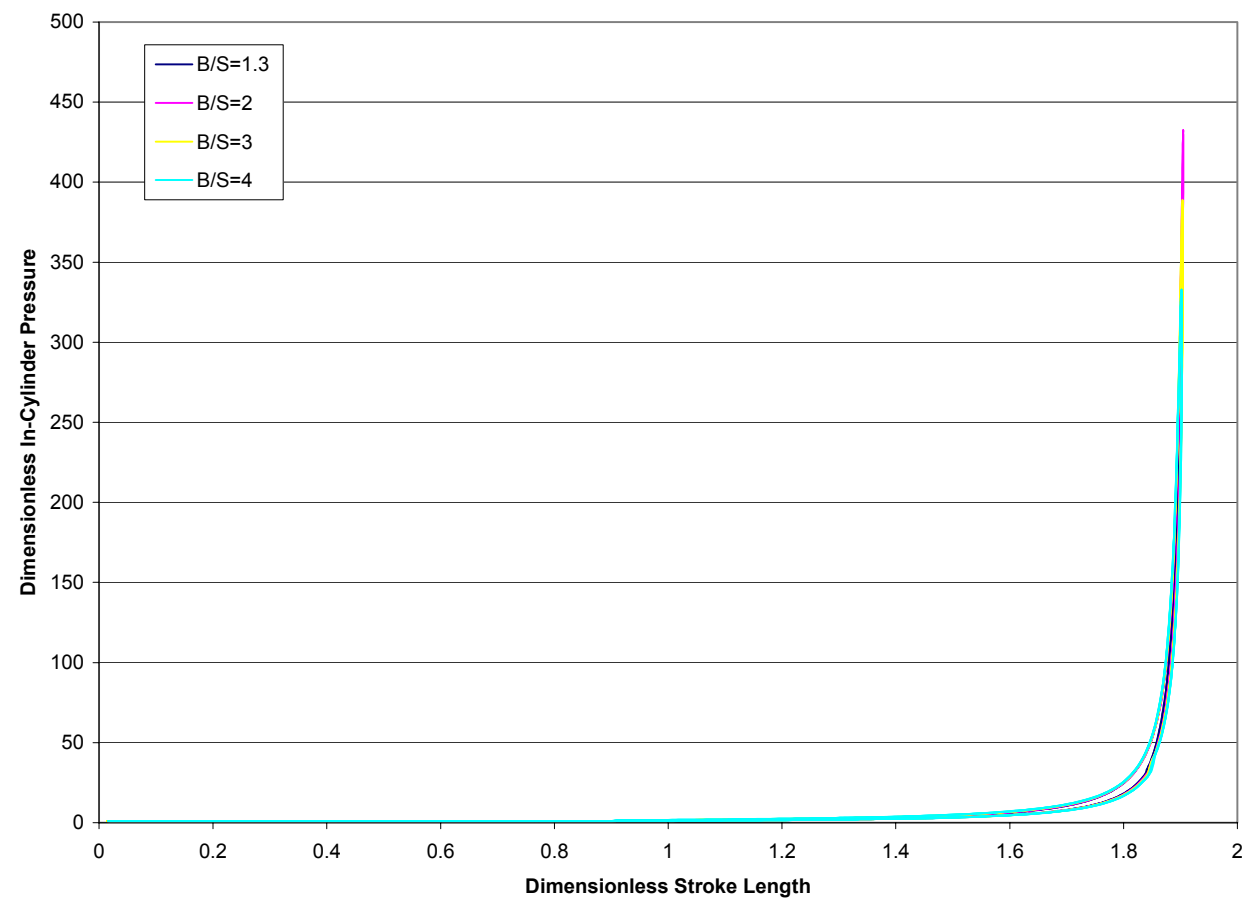

Figure 6.10. Dimensionless In-Cylinder Pressure Versus Dimensionless Stroke Length for Lambda $=3$, Ca4, and Injection Position $=0.081$ 
Figures $6.11,6.12$, and 6.13 illustrate the dimensionless friction force versus dimensionless stroke length for the full two strokes of the two-stroke compression ignition linear engine. It can be seen that the peak values of the dimensionless friction forces increased with increased bore to effective stroke as a result of increasing piston ring area contacting the piston skirt. In addition it was noticed that the peak values of the dimensionless friction forces were not greatly affected by increasing the dimensionless load constant. Increasing the dimensionless load constant resulted in a decrease in the dimensionless in-cylinder pressure which decreased the peak value of the dimensionless friction force. Figure 6.13 shows slight decrease in the peak dimensionless friction forces.

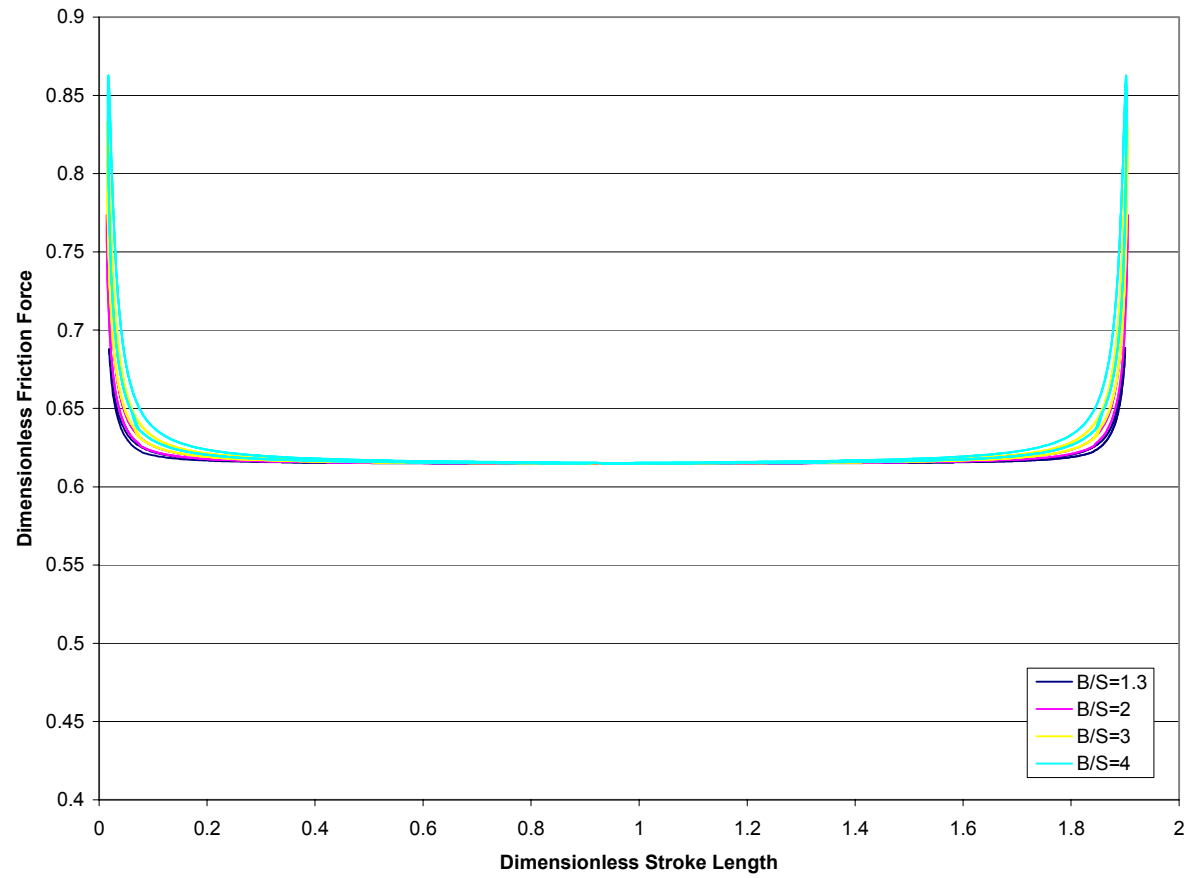

Figure 6.11. Dimensionless Friction Force Versus Dimensionless Stroke Length for Lambda=3, Ca2, and Dimensionless Injection Position $=\mathbf{0 . 0 8 1}$ 


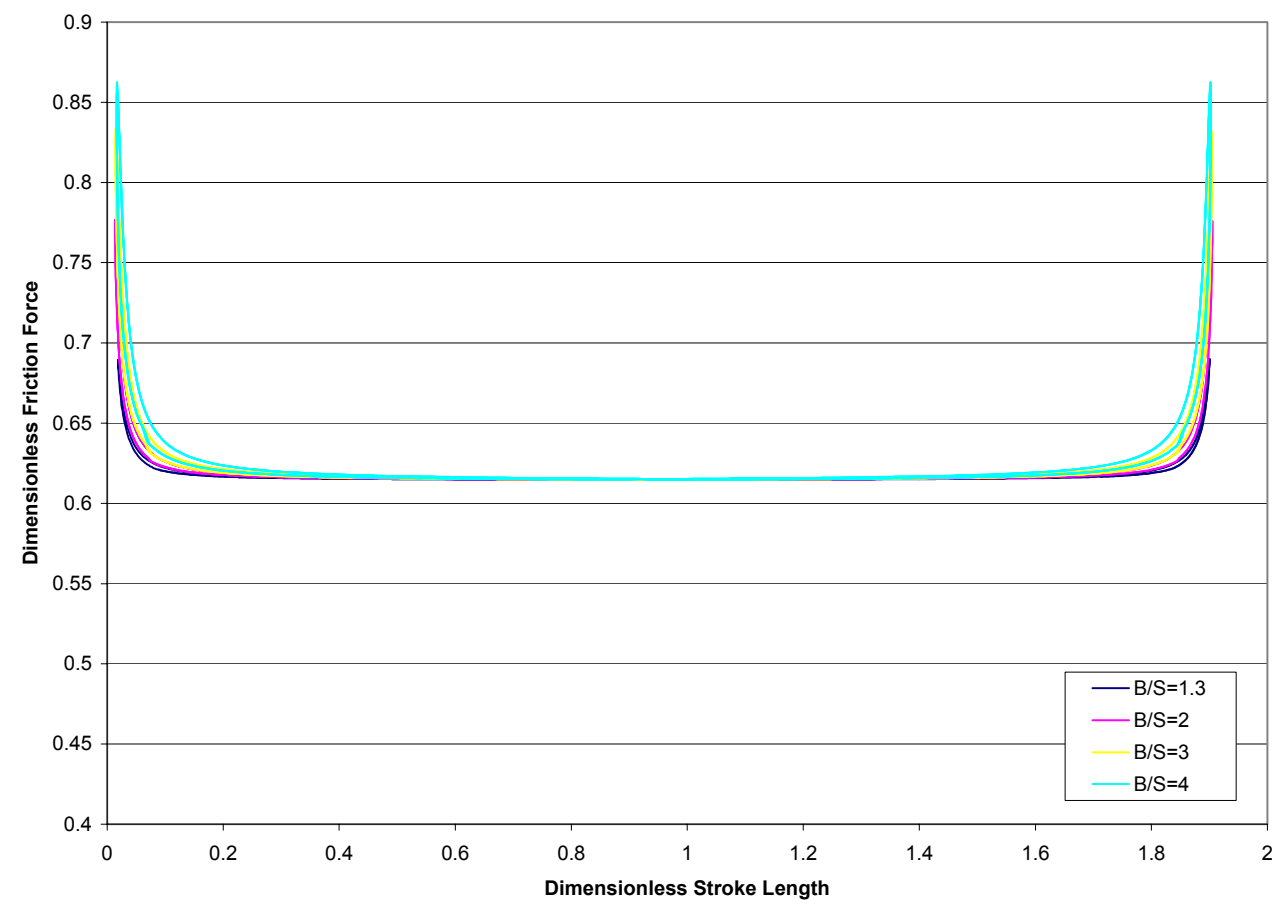

Figure 6.12. Dimensionless Friction Force Versus Dimensionless Stroke Length for Lambda=3, Ca2, and Dimensionless Injection Position $=\mathbf{0 . 0 8 1}$

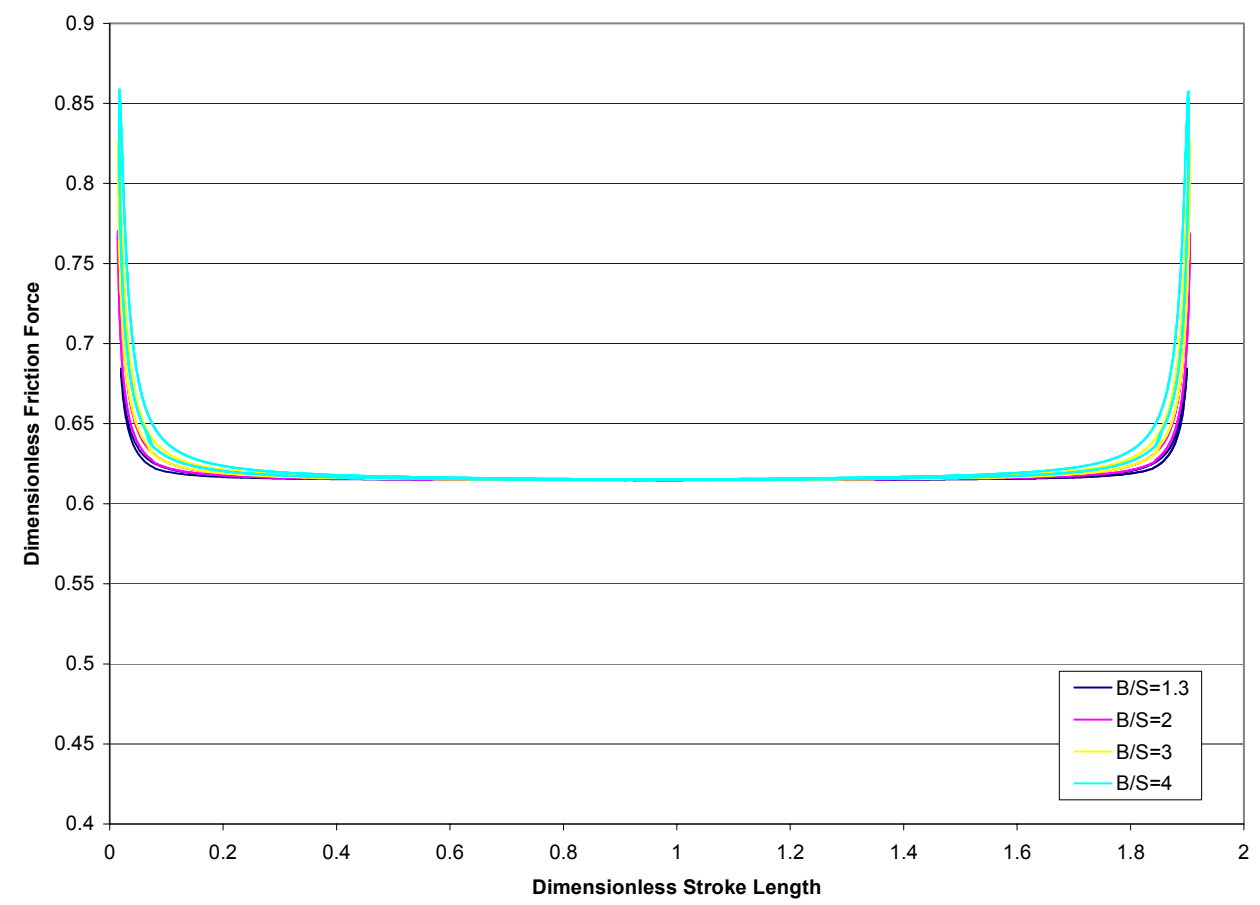

Figure 6.13. Dimensionless Friction Force Versus Dimensionless Stroke Length for Lambda=3, Ca4, and Dimensionless Injection Position $=\mathbf{0 . 0 1 8}$ 
Figure 6.14 shows the change in the dimensionless energy release per generator volume. It can be seen that the maximum dimensionless energy released per generator volume increased with the increase of the bore to effective stroke till it reached its maximum with bore to effective stroke length of three then it started to drop. This was a result of different factors affecting the performance. One of these factors is the volume of the generator, which is relatively large with a bore to effective stroke length of four compared with the generator volume of bore to effective stroke length of three. Another factor was the increased surface area of heat transfer, which increased the heat transfer rate.

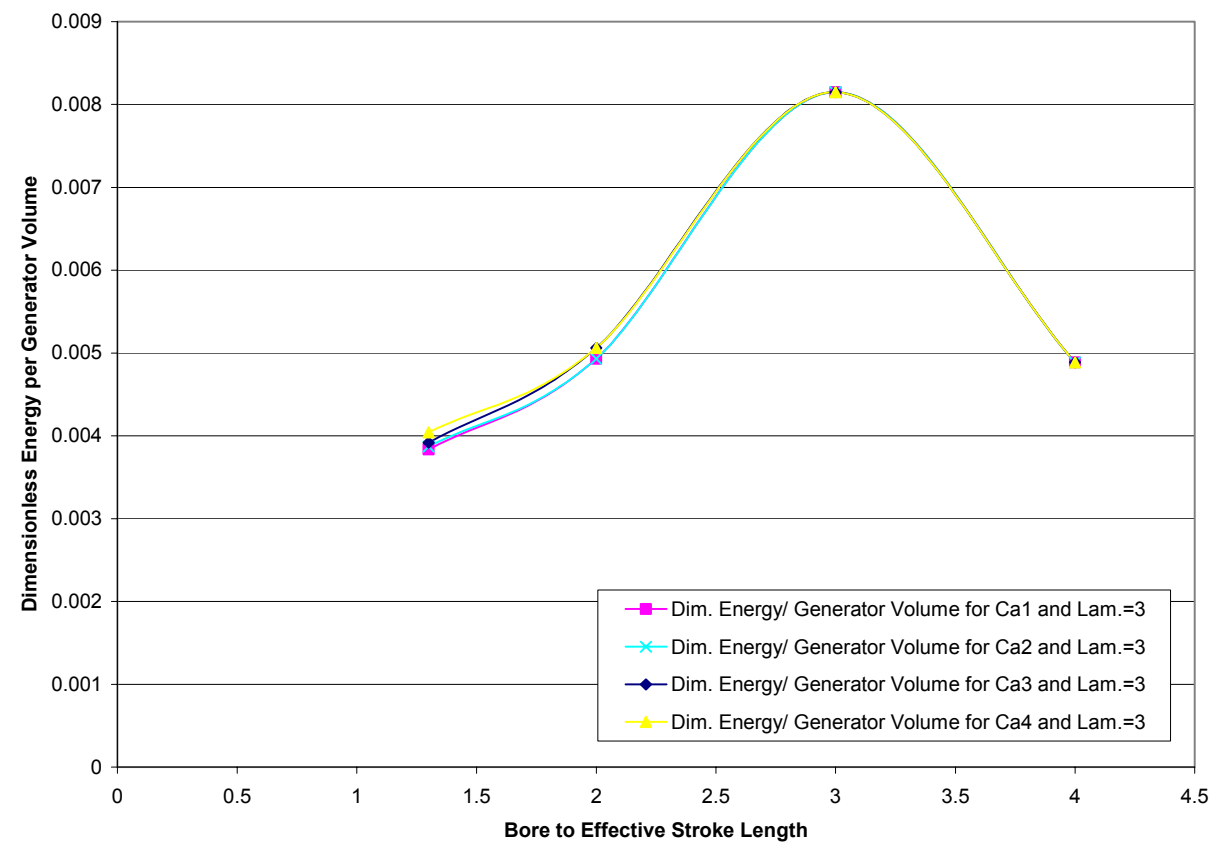

Figure 6.14. Dimensionless Energy per Generator Volume Versus Bore to Effective Stroke Length for Lambda $=3$, and Dimensionless Injection Position $=\mathbf{0 . 0 8 1}$ 
Figure 6.15 shows the change of dimensionless indicated power per cylinder volume with different bore to effective stroke length. It can be seen that increasing the bore to effective stroke length increased the dimensionless indicated power per cylinder volume as a result of increasing the input energy as a result of increasing the dimensionless air mass. It can also be seen that the highest increase took place with a bore to effective stroke ratio of four and dimensionless load constant Ca4. The increase took place as a result of increasing the heat input with larger bore. The small difference that took place with bore to effective stroke of four and dimensionless load constant $\mathrm{Ca} 4$ was due to the fact that the dimensionless indicated power was increased by increasing the dimensionless load constant.

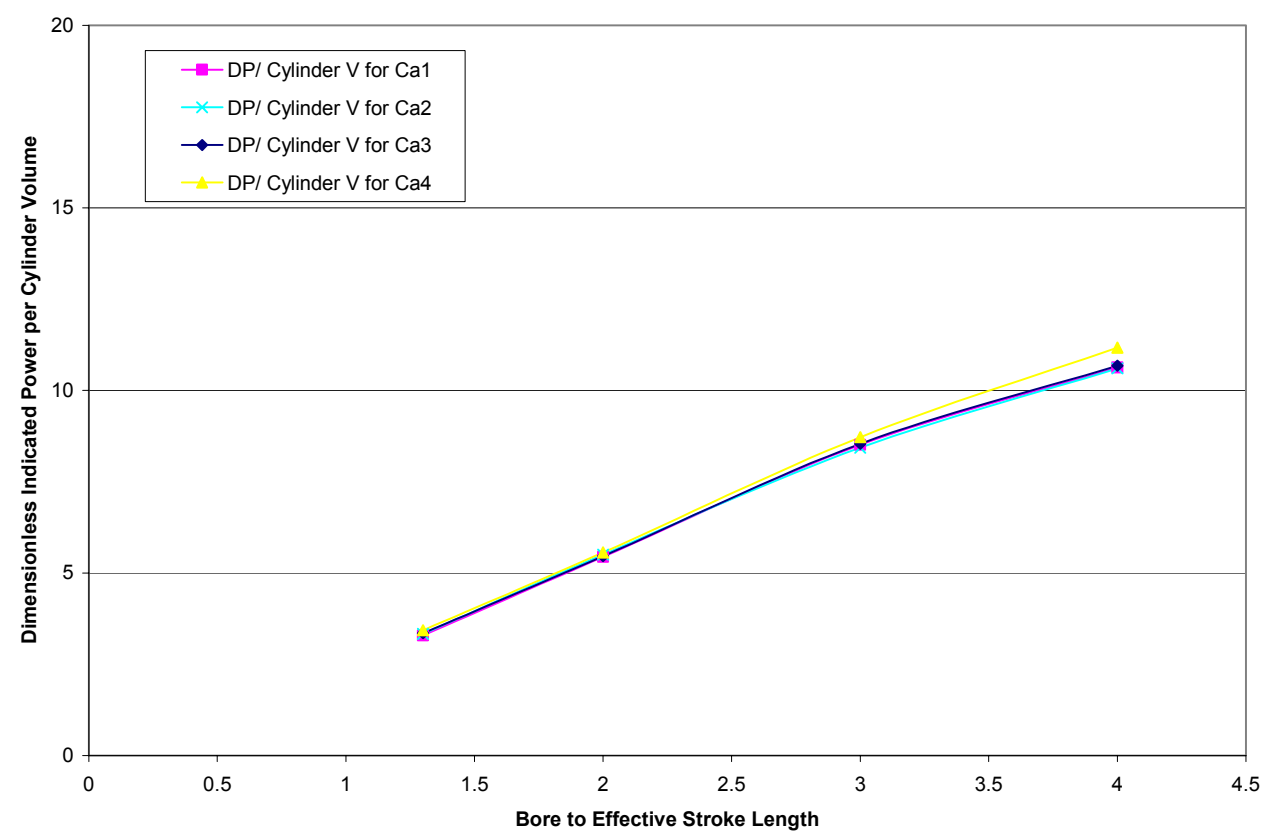

Figure 6.15. Dimensionless Indicated Power per Cylinder Volume Versus Bore to Effective Stroke Length for Lambda $=3$, and Dimensionless Injection Position $=0.081$ 
Figure 6.16 shows the change in the dimensionless indicated power per generator mass with bore to effective stroke length. The dimensionless indicated power per generator mass increased until it reached its peak when the bore to effective stroke reached a value of two, and then it decreased again. It reached its lower value when the bore to effective stroke was three then it started increasing again. The decrease that took place was a result of increasing the generator mass relative to its dimensionless indicated power output. This reason was not the major factor with increasing the bore to effective stroke length to four and the increase in the dimensionless indicated power output.

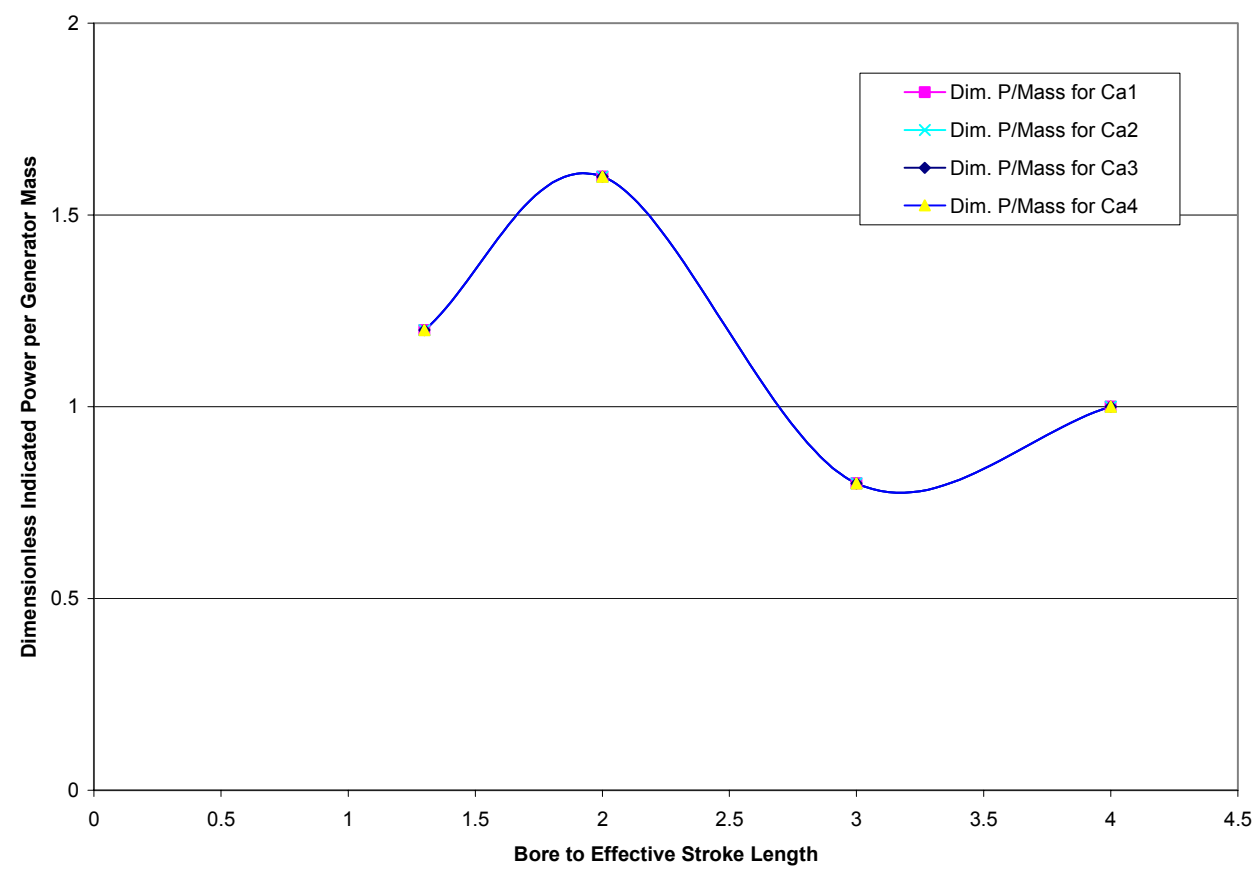

Figure 6.16. Dimensionless Indicated Power per Generator Mass Versus Bore to Effective Stroke Length for Lambda $=3$, and Dimensionless Injection Position $=0.081$ 
Figure 6.17 shows the change in dimensionless energy per generator mass versus bore to effective stroke length. The dimensionless energy per generator mass, for bore to effective stroke 1.3 to 3 , decreased continuously with the increase of bore to effective stroke length till it reached its lower value at bore to effective stroke ratio of three then it started increasing slightly again. It can be also seen that increasing the dimensionless load constant improves the dimensionless energy per generator mass. This was clear especially with bore to effective stroke value of 1.3. Increasing the dimensionless load constant resulted in decreasing the dimensionless in-cylinder pressure and increasing the dimensionless energy.

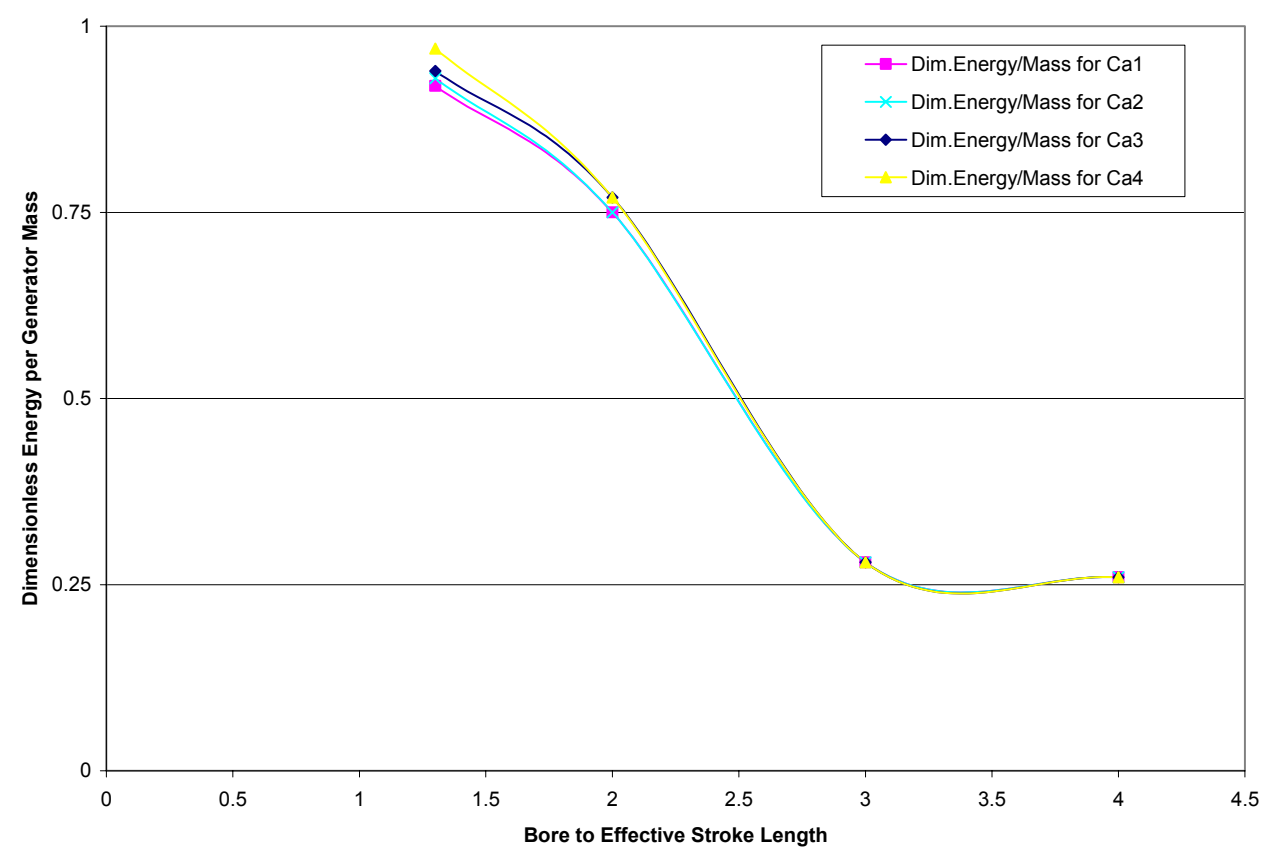

Figure 6.17. Dimensionless Energy per Generator Mass Versus Bore to Effective Stroke for Lambda $=3$, and Dimensionless Injection Position $=0.081$ 


\section{SUMMARY OF THE EFFECT OF DIMENSIONLESS LOAD CONSTANT:}

Increasing the dimensionless load constant for a bore to effective stroke length of

1.3 to 4 , lambda $=3$, and dimensionless injection position $=0.081$ resulted in:

- Increasing the indicated efficiency.

- Decreasing the compression ratio.

- Decreasing the dimensionless in-cylinder pressure.

- Increasing the dimensionless indicated power per cylinder volume.

- Increasing the dimensionless energy per generator volume for bore to effective stroke length 1.3 to 2.2 .

- Increasing the dimensionless energy per generator mass for bore to effective stroke length 1.3 to 2.2 . 


\subsection{THE EFFECT OF AIR TO FUEL RATIO}

Decreasing the amount of fuel injected to the engine resulted in decreasing the dimensionless indicated power, the dimensionless velocity, the dimensionless frequency, and the compression ratio as a result of decreasing the dimensionless heat input to the engine. Figures $6.18,6.20$ and 6.21 show dimensionless indicated power, dimensionless average piston speed, and dimensionless frequency versus bore to effective stroke length, while Figure 6.19 shows the change in dimensionless indicated power with dimensionless air mass for different air to fuel ratios and dimensionless load constants. It can be seen also that for different dimensionless load constants, bore to effective stroke length of 1.3 and dimensionless air mass of 0.00002 the values of dimensionless indicated power were almost the same for Figures 6.18 and 6.19 as the dimensionless heat input was almost the same.

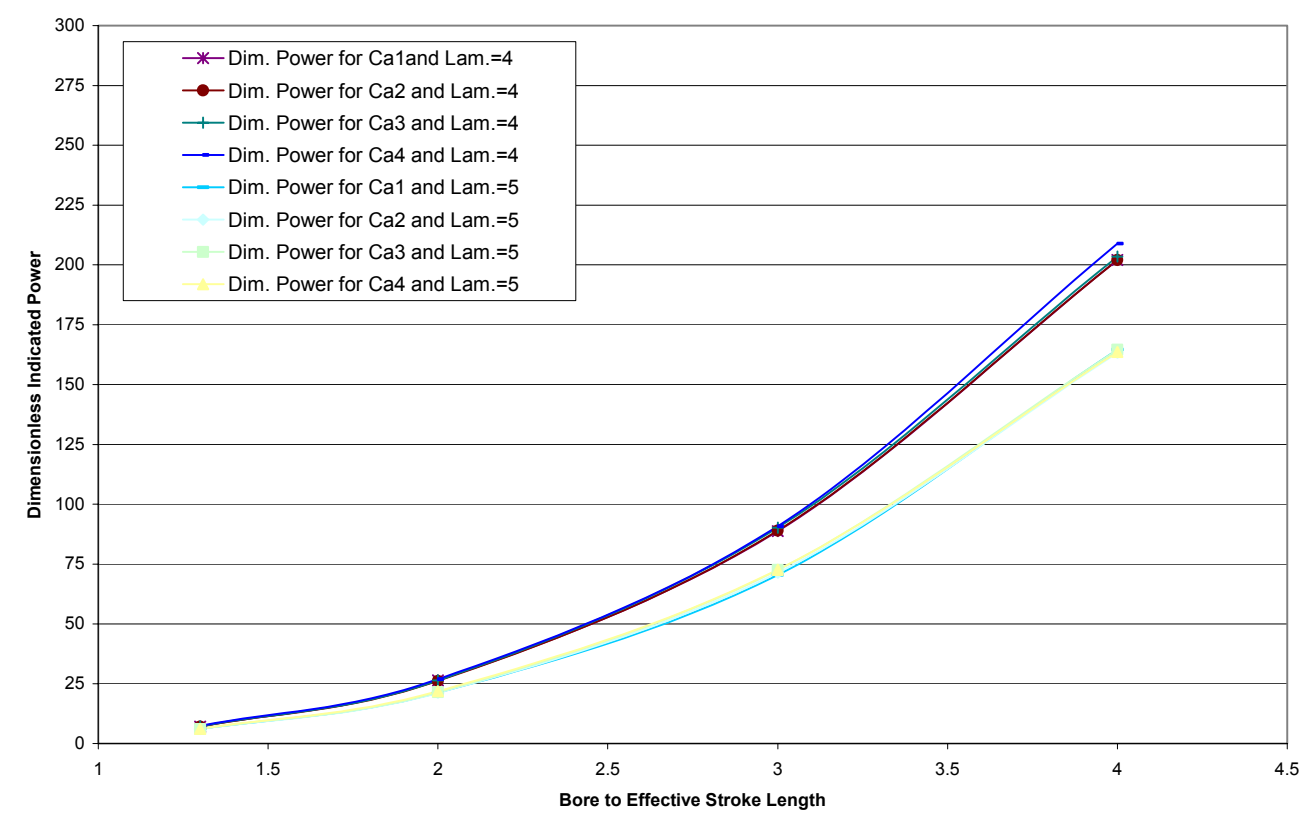

Figure 6.18. Dimensionless Indicated Power Versus Bore to Effective Stroke Length for Different Lambda, Different Dimensionless Load Constants, and Dimensionless Injection Position=0.081 


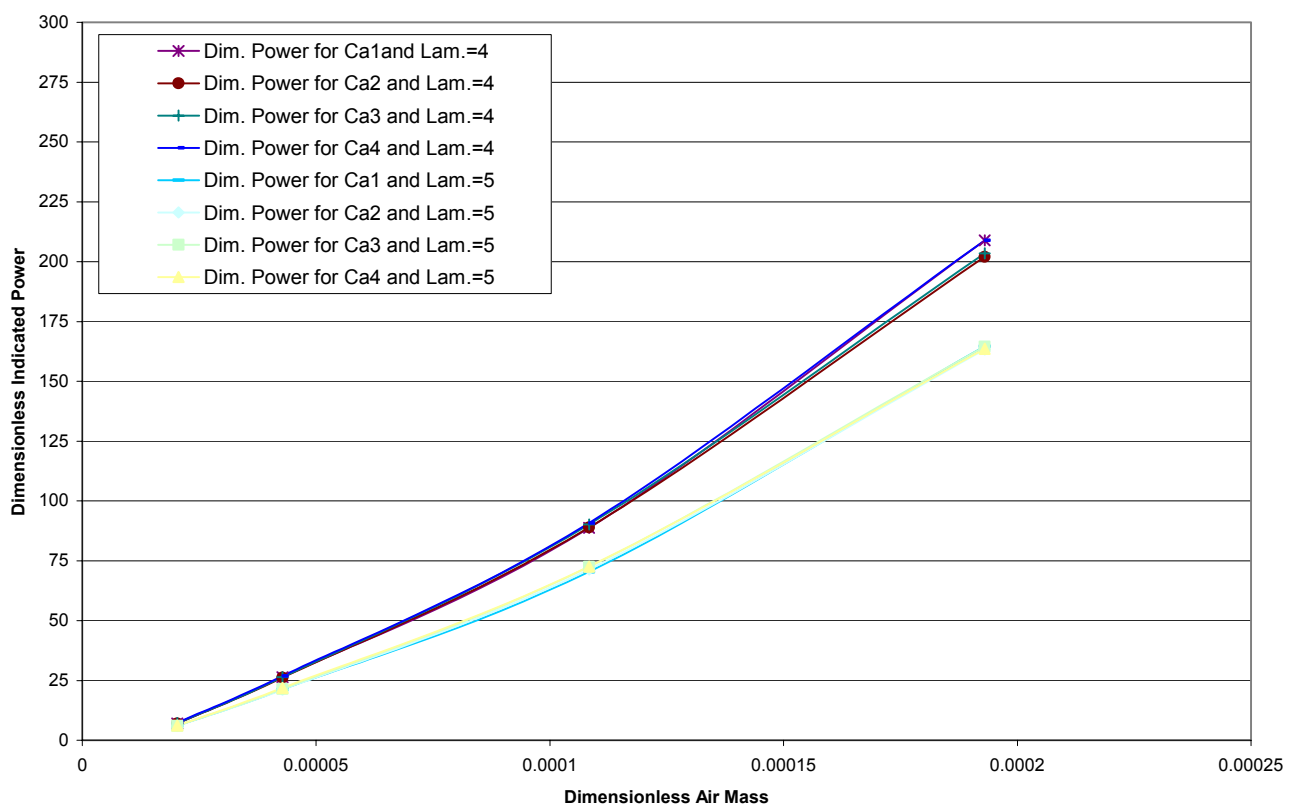

Figure 6.19. Dimensionless Indicated Power Versus Dimensionless Air Mass for Different Lambda, Different Dimensionless Load Constants, and Dimensionless Injection Position=0.081

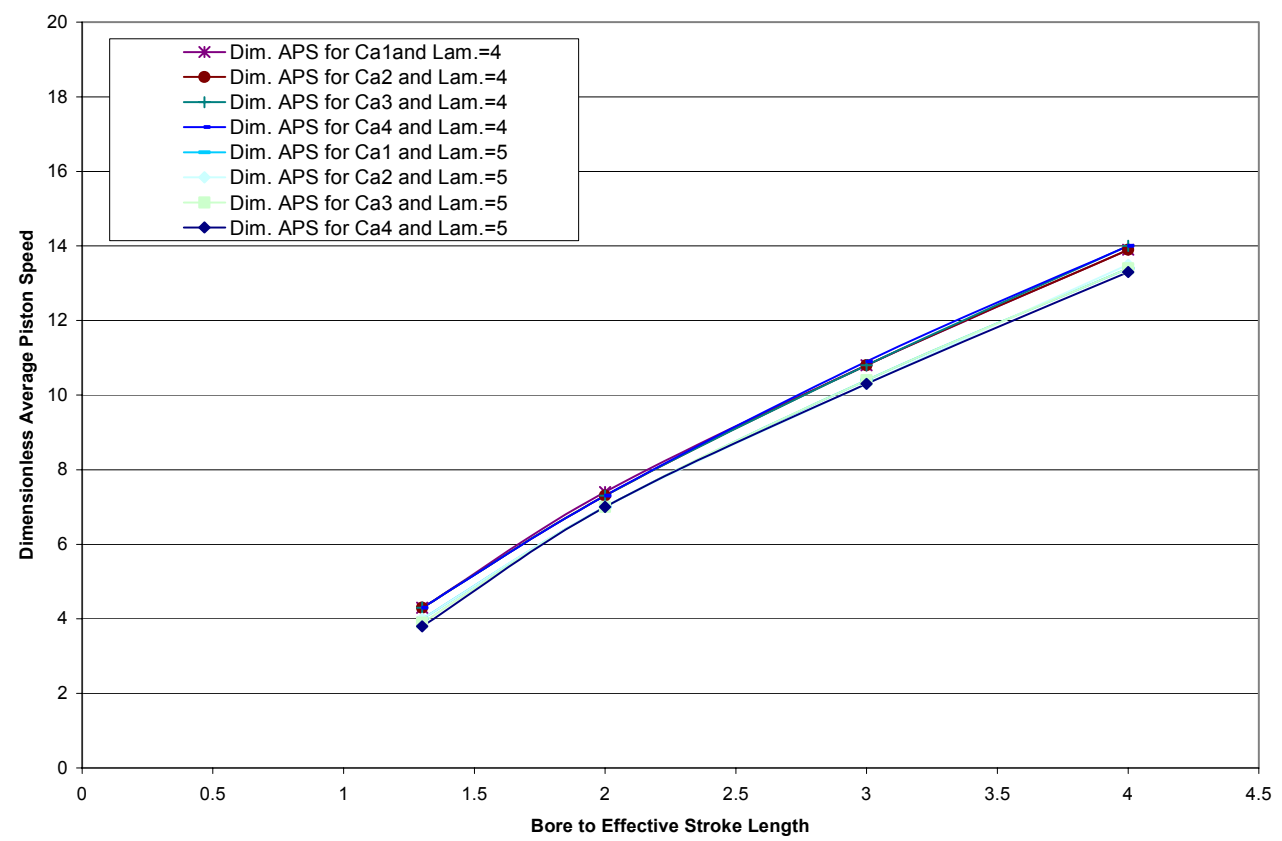

Figure 6.20. Dimensionless Average Piston Speed Versus Bore to Effective Stroke Length for Different Lambda, Different Dimensionless Load Constants and Dimensionless Injection Position $=\mathbf{0 . 0 8 1}$ 


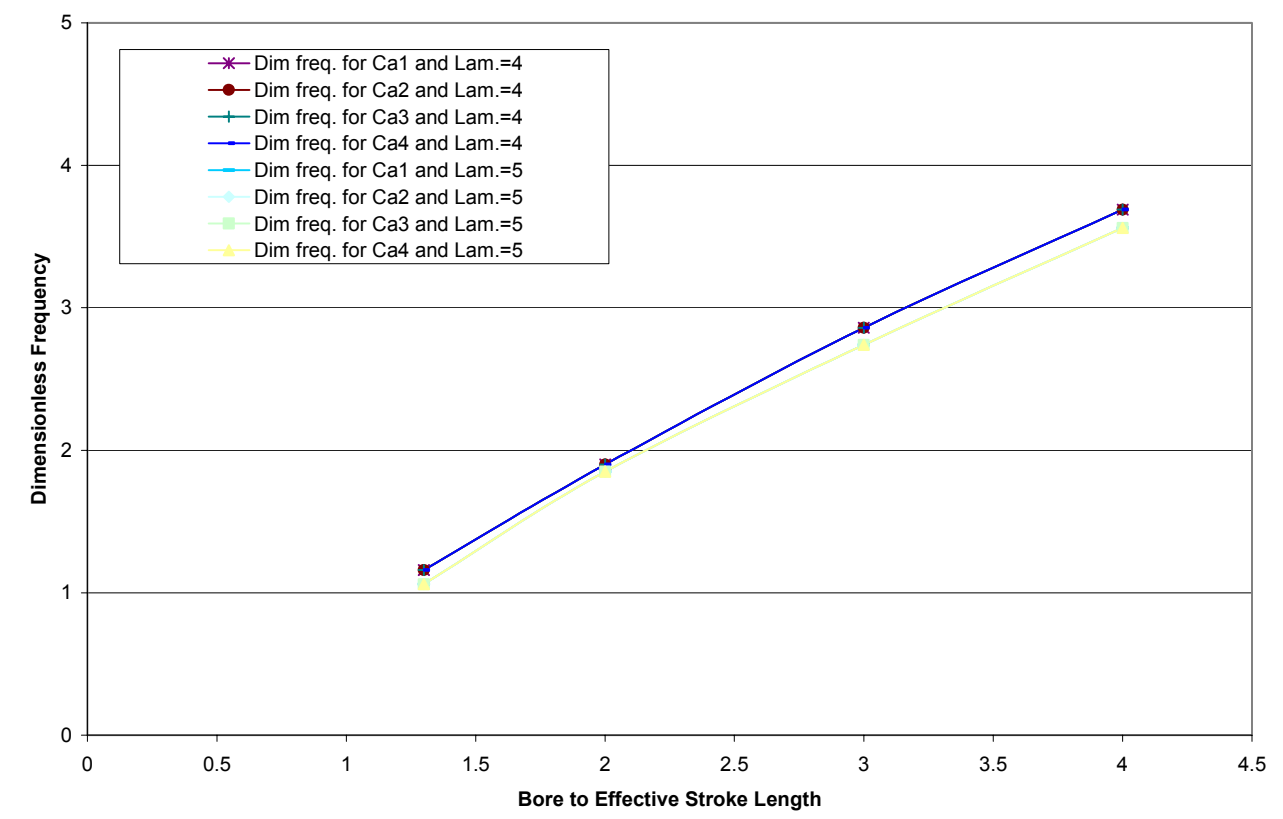

Figure 6.21. Dimensionless Frequency Versus Bore to Effective Stroke length for Different Lambda, Different Dimensionless Load Constants and Dimensionless Injection Position=0.081

Figure 6.22 illustrates the change in indicated efficiency with bore to effective stroke length and dimensionless air mass. It can be seen that there was an increase in the indicated efficiency occurred at bore to effective stroke length value of 1.3. The increase was a direct result of relatively smaller difference between the in-cylinder temperature and the wall temperature that resulted in a decrease in the wall heat loss and an increase the indicated efficiency. Figures 6.21 to 6.28 confirmed this result. The resulting indicated efficiency is very close to what has been reported about indicated efficiency of free piston diesel engines $[47,53]$.

Figures 6.23 and 6.24 show the dimensionless velocity over the stroke versus dimensionless stroke length. It can be seen that changing the dimensionless load constant had a negligible effect on dimensionless velocity. On the other hand the air to fuel had some effect on the dimensionless velocity as shown in Figure 6.25. 


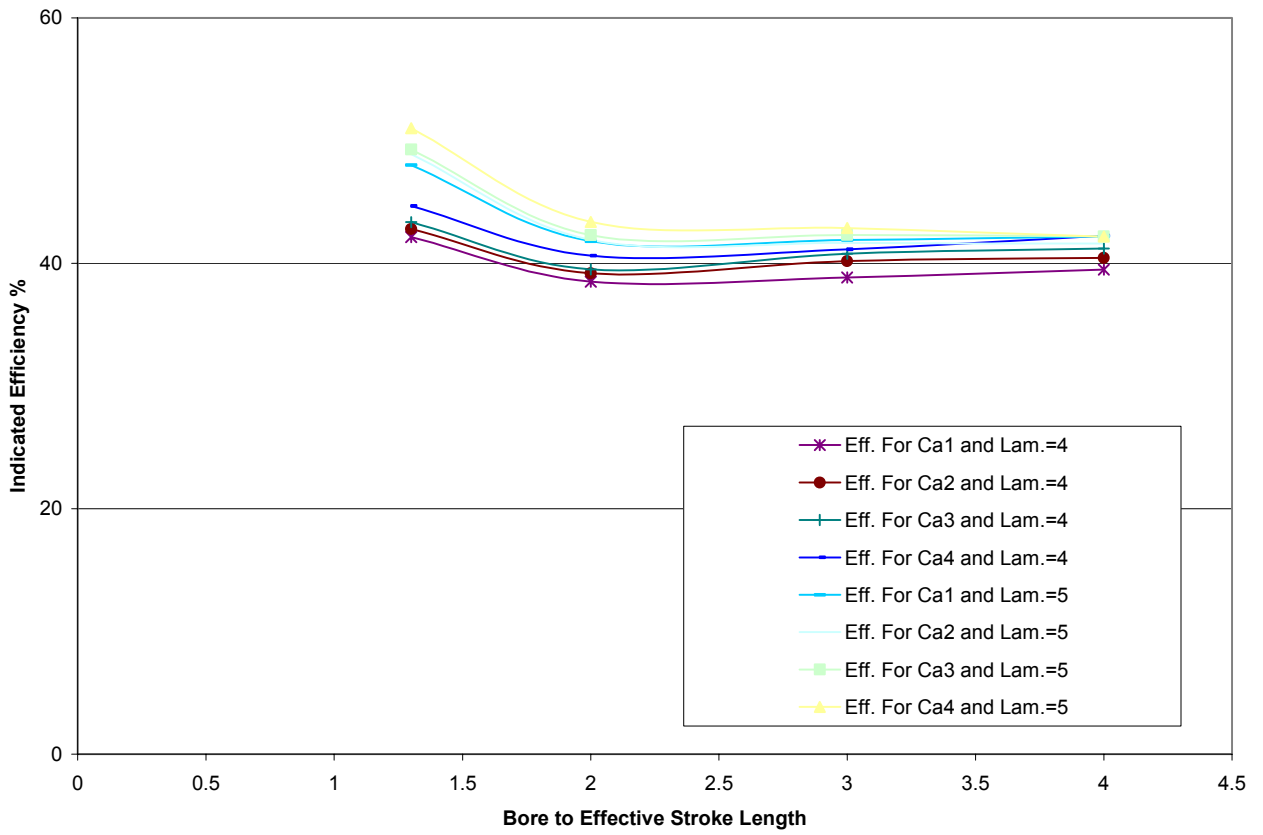

Figure 6.22. Indicated Efficiency Versus Bore to Effective Stroke Length for Different Lambda, Different Dimensionless Load Constants and Dimensionless Injection Position=0.081

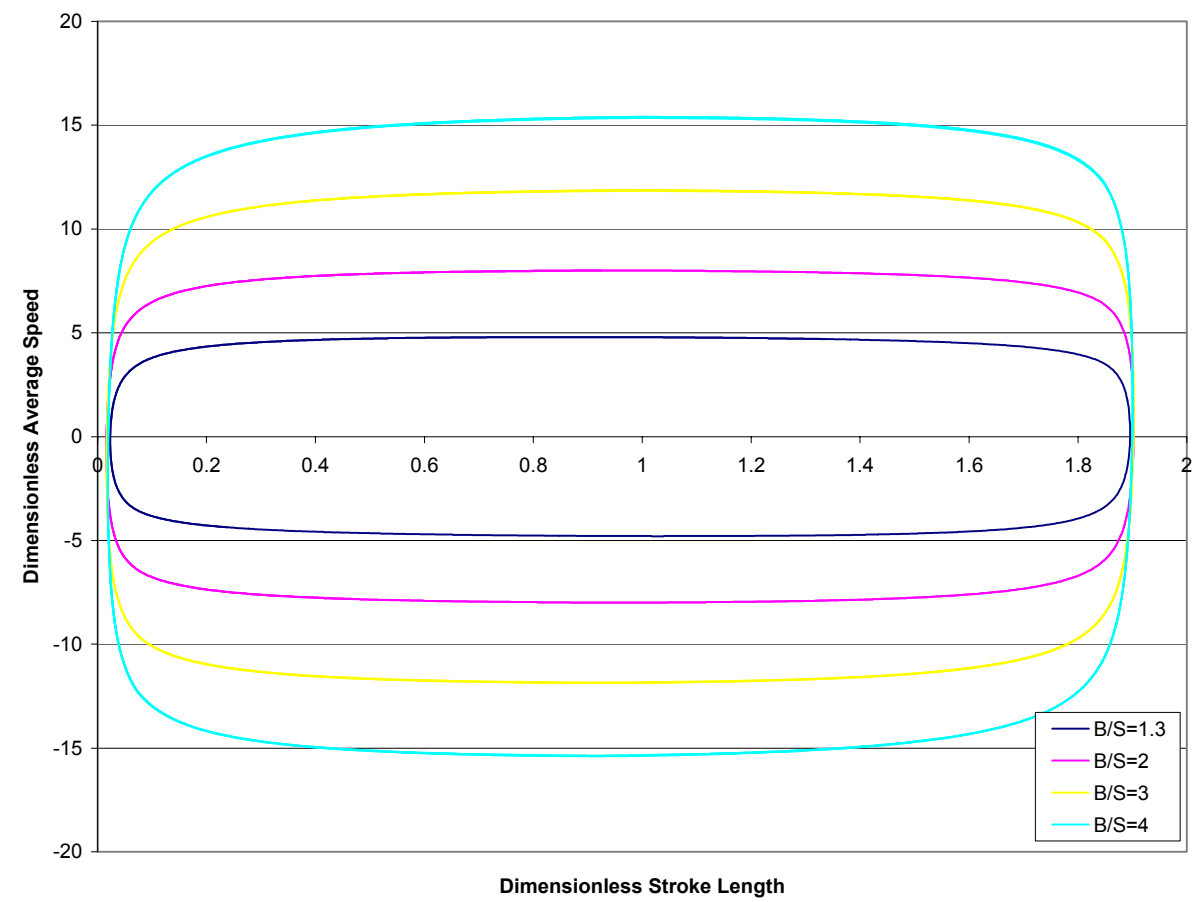

Figure 6.23. Dimensionless Velocity Versus Dimensionless Position for Lambda=4, Ca1, and Dimensionless Injection Position $=\mathbf{0 . 0 8 1}$ 


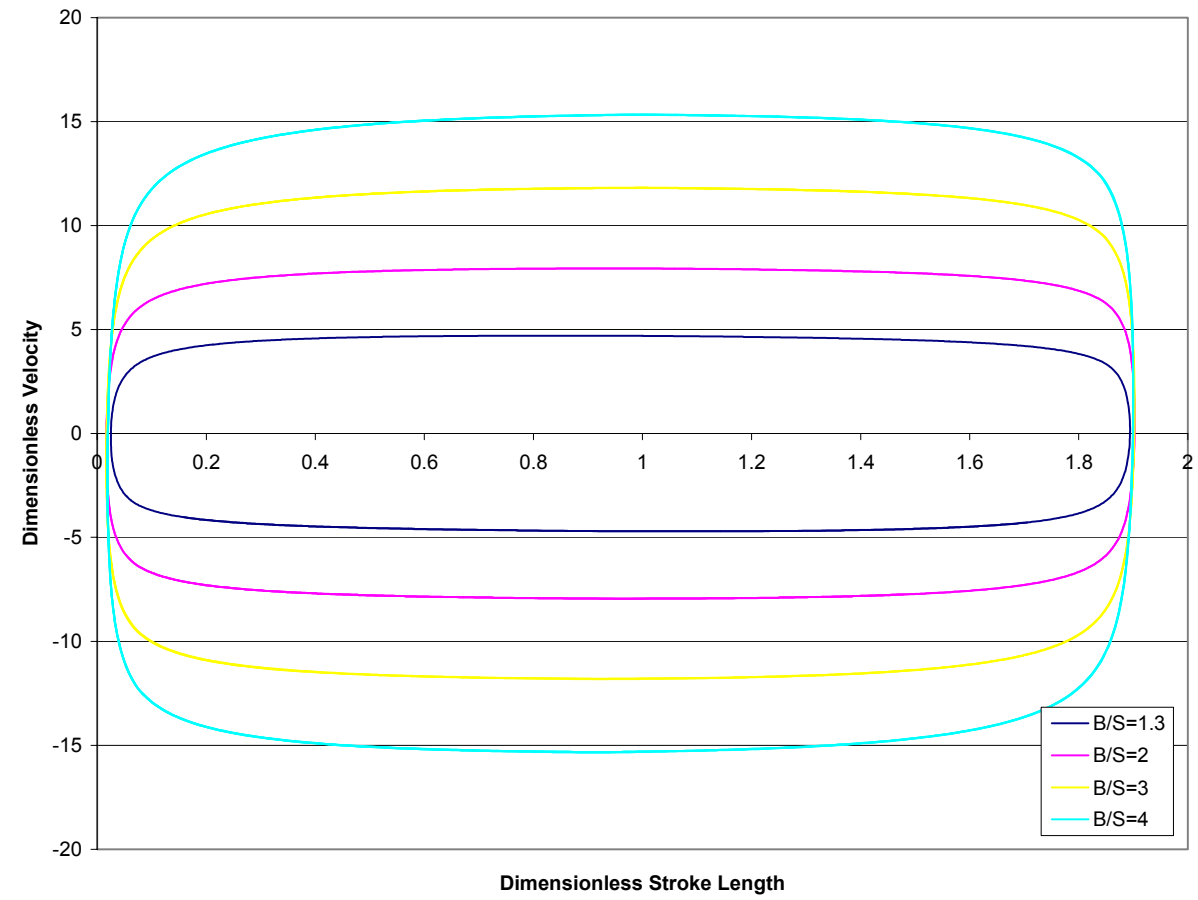

Figure 6.24. Dimensionless Velocity Versus Dimensionless Stroke Length for Lambda=4, Ca4, and Dimensionless Injection Position=0.081

Figure 6.25 illustrates the dimensionless velocity over the stroke versus dimensionless stroke length for lambda equal to five and different dimensionless load constants. It can be noticed that there was a further decrease in the dimensionless velocity, compared to the dimensionless velocity over the stroke for lambda equal to three, Figures 6.6 and 6.7, as the input energy to the engine was decreased. 


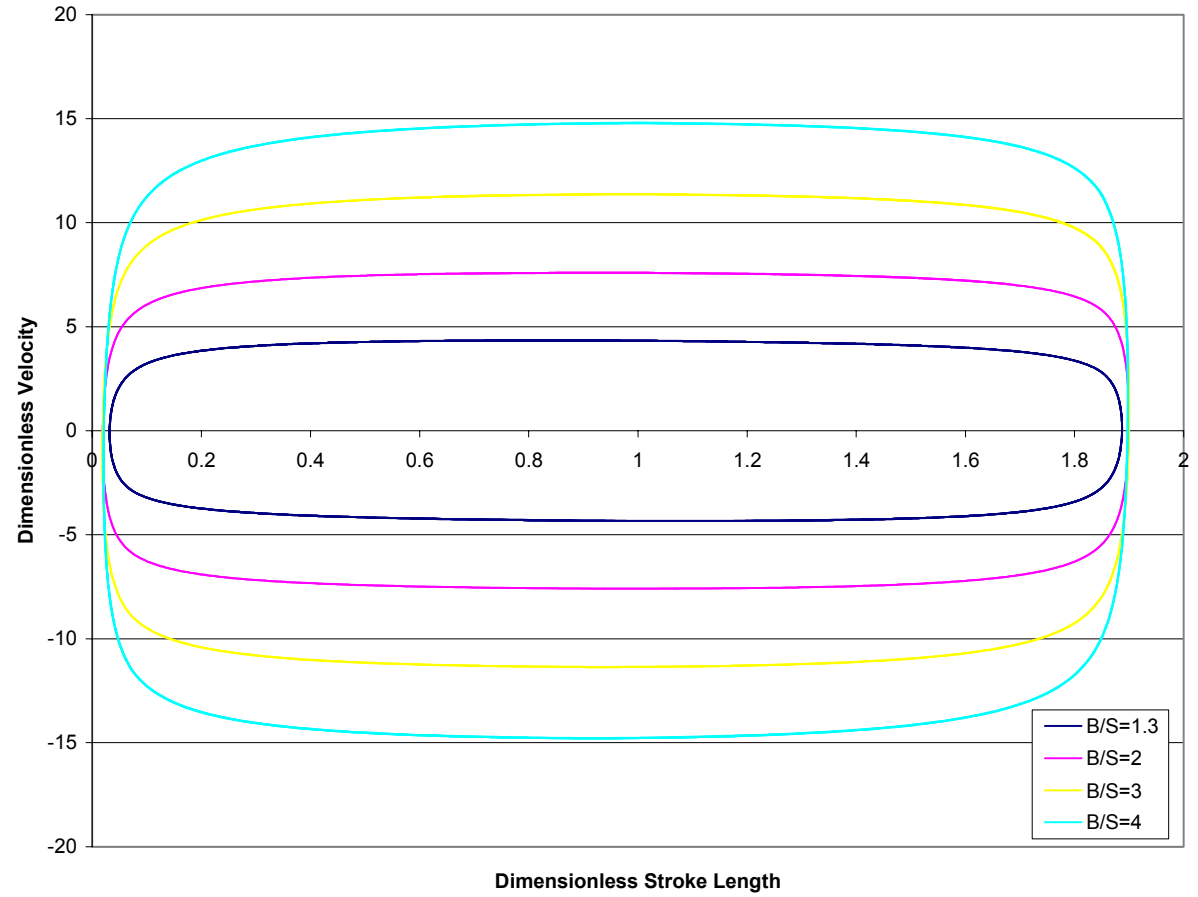

Figure 6.25. Dimensionless Velocity Versus Dimensionless Stroke Length for Lambda=5, Ca4, and Dimensionless Injection Position $=\mathbf{0 . 0 8 1}$ 
Figure 6.26 illustrates compression ratio versus bore to effective stroke length for different lambda and different dimensionless load constants. The figure confirmed the same result obtained previously in Figure 6.8. Also, it can be seen that there was a significant decrease in compression ratio with the increase of lambda. This can lead to the fact that two-stroke compression ignition linear engine compression ratio can be controlled by choosing a high lambda and a bore to effective stroke lower or higher than 2.2 .

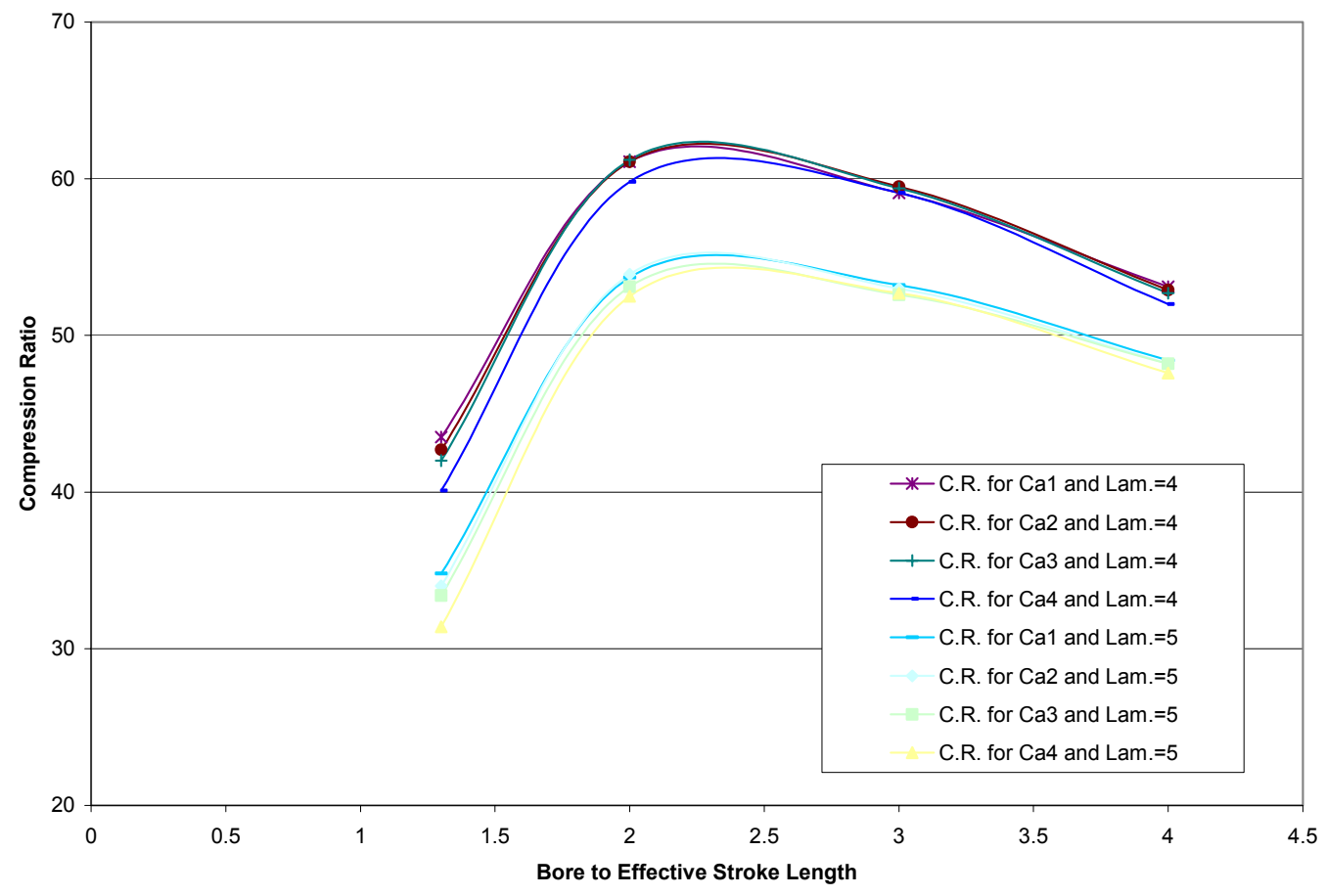

Figure 6.26. Compression Ratio Versus Bore to Effective Stroke for Different Lambda, Different Dimensionless Load Constants, and Dimensionless Injection Position $=0.081$ 
Figure 6.27 illustrates the change in the dimensionless in-cylinder pressure with dimensionless stroke length for lambda equal to four and dimensionless load constant equal to Ca1. The figure confirmed results obtained in previous figures, Figures 6.9 and 6.10 , the highest in-cylinder pressure occurred with bore to effective stroke length equal to two. Figure 6.28 also shows that increasing lambda considerably decreased the dimensionless in-cylinder pressure, which was a direct result of decreasing the compression ratio, Figure 6.26 .

Figure 6.29 shows that the dimensionless friction force versus dimensionless stroke length for two complete strokes. It can be seen that the dimensionless friction force was barely affected with the change of lambda, Figures 6.11 and 6.29 .

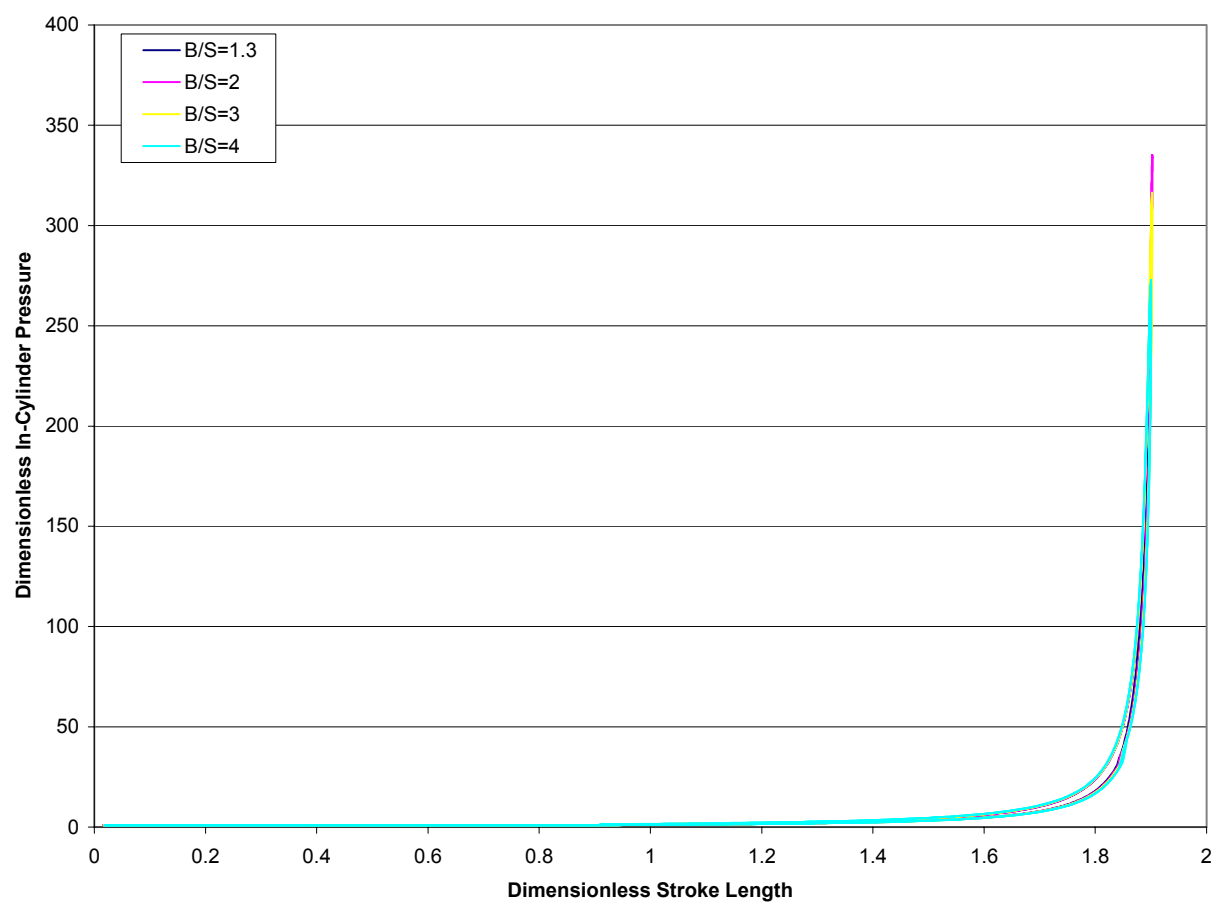

Figure 6.27. Dimensionless In-Cylinder Pressure Versus Dimensionless Stroke Length for Lambda $=4, \mathrm{Ca} 1$, and Dimensionless Injection Position $=0.081$ 


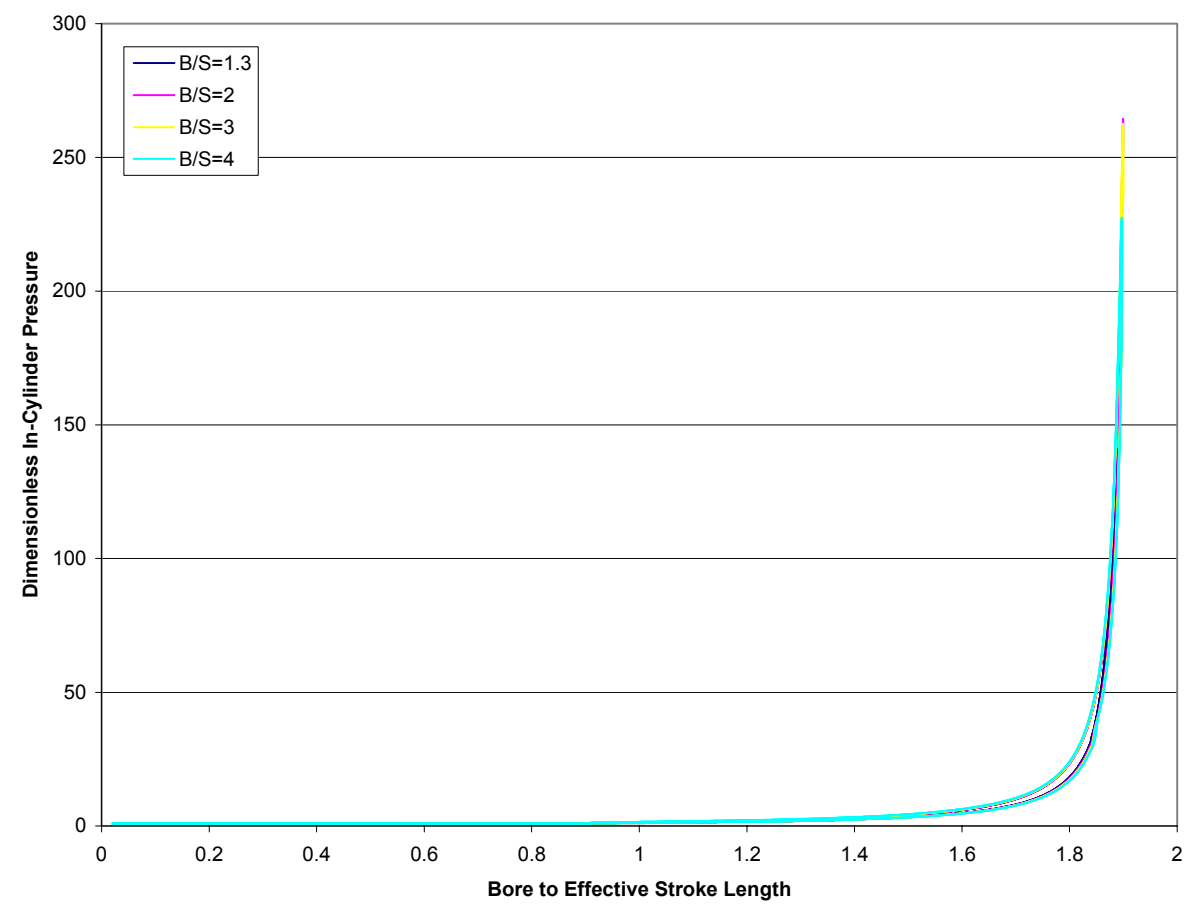

Figure 6.28. Dimensionless In-Cylinder Pressure Versus Dimensionless Stroke Length for Lambda $=5, \mathrm{Ca} 4$, and Dimensionless Injection Position $=0.081$

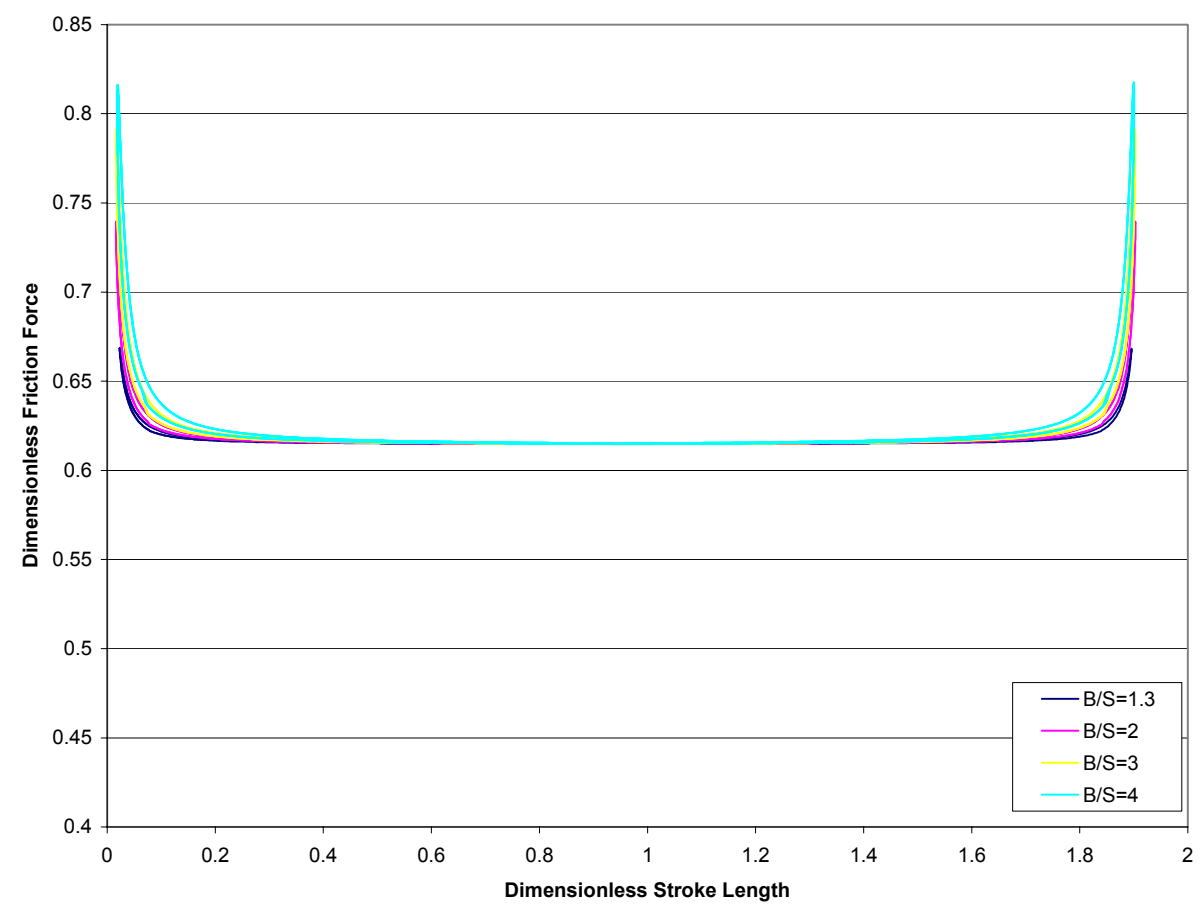

Figure 6.29. Dimensionless Friction Force Versus Dimensionless Stroke Length for Lambda=4, Ca1, and Dimensionless Injection Position $=\mathbf{0 . 0 8 1}$ 
Figure 6.30 shows the change in the dimensionless energy released per generator volume. The figure confirmed results previously obtained in Figure 6.14. Also it can be seen that there was an increase in the value of dimensionless energy per generator volume with lambda equal to four, dimensionless load constant $\mathrm{Ca} 4$ and bore to effective stroke length of three. This increase did not mean that the energy released from the engine was maximum at that point. It only meant that the dimensionless ratio of energy released per generator volume was maximum at that point.

Figure 6.31 confirmed the facts discussed in Figure 6.15. The figure also shows the drop in dimensionless indicated power per cylinder volume with the increase of lambda.

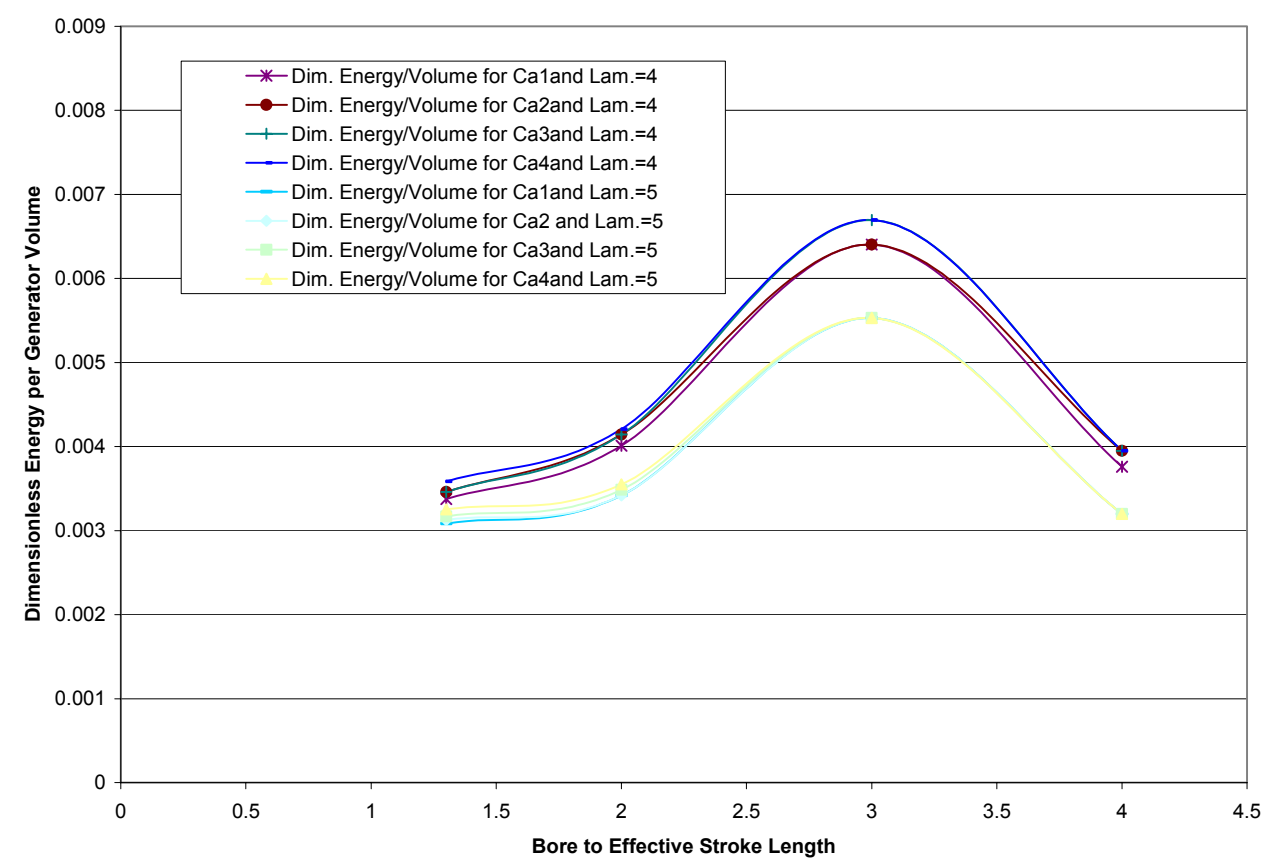

Figure 6.30. Dimensionless Energy per Generator Volume Versus Bore to Effective Stroke Length for Different Lambda, Different Dimensionless Load Constants, and Dimensionless Injection Position $=\mathbf{0 . 0 8 1}$ 


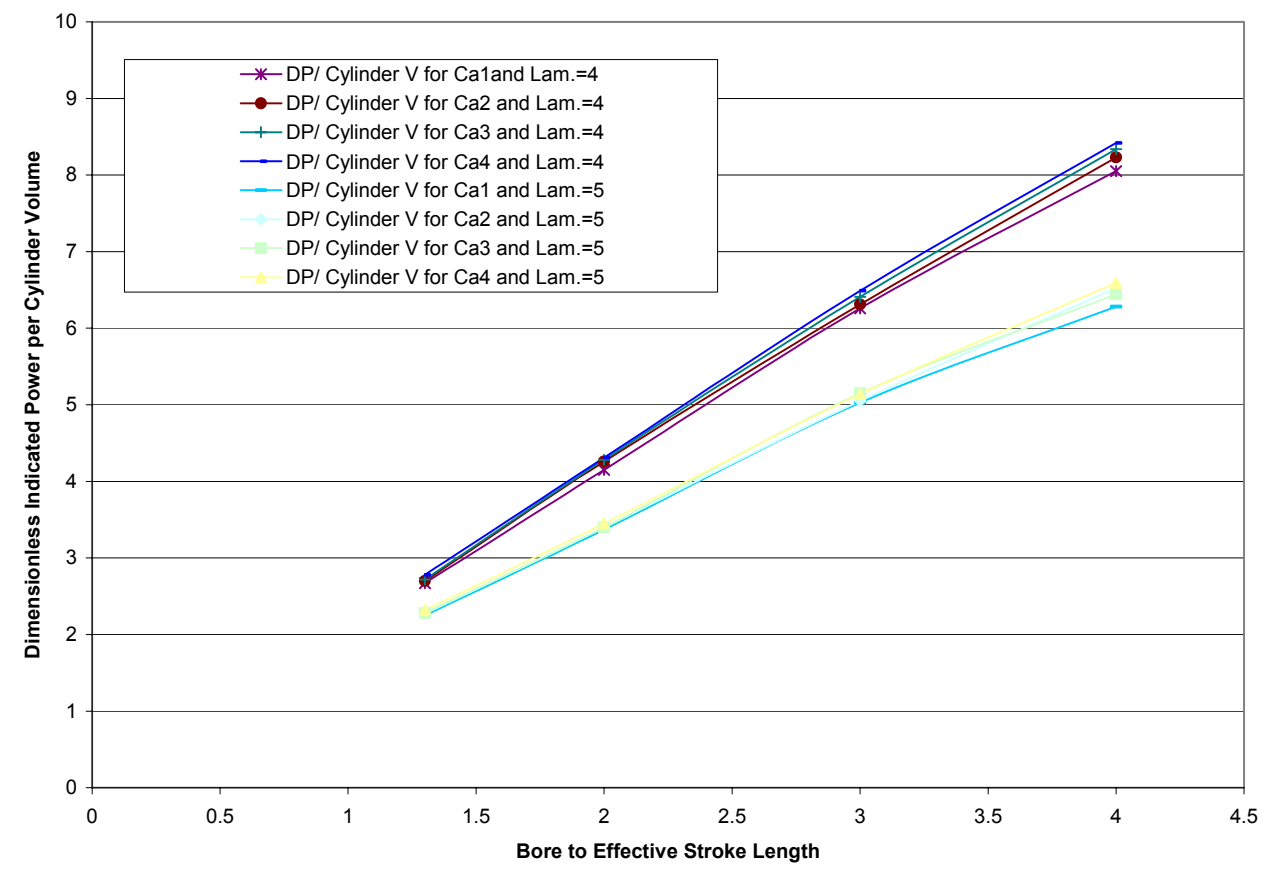

Figure 6.31. Dimensionless Indicated Power per Cylinder Volume Versus Bore to Effective Stroke Length for Different Lambda, Different Dimensionless Load Constants, and Dimensionless Injection Position $=0.081$

Figure 6.32 shows the change of dimensionless indicated power per generator mass with bore to effective stroke and dimensionless air mass. As in Figure 6.16 the dimensionless indicated power per generator mass increased with bore to effective stroke length. It reached its peak with bore to effective stroke equal to two then it decreased again. It was also noticed that there was a little decrease in the value of dimensionless indicated power per generator mass for lambda equal to four, load constant $\mathrm{Ca} 1$ and bore to effective stroke length of 1.3. This decrease was a result of the decrease in dimensionless indicated power per generator mass, as a ratio, for Ca1.

In addition it was noticed that the dimensionless power per generator mass decreased with the increase of lambda. The figure also shows an increase in dimensionless indicated power per generator mass with bore to effective stroke increase 
more than three. This increase was a result of the increased dimensionless indicated power for the case of bore to effective stroke length 4 .

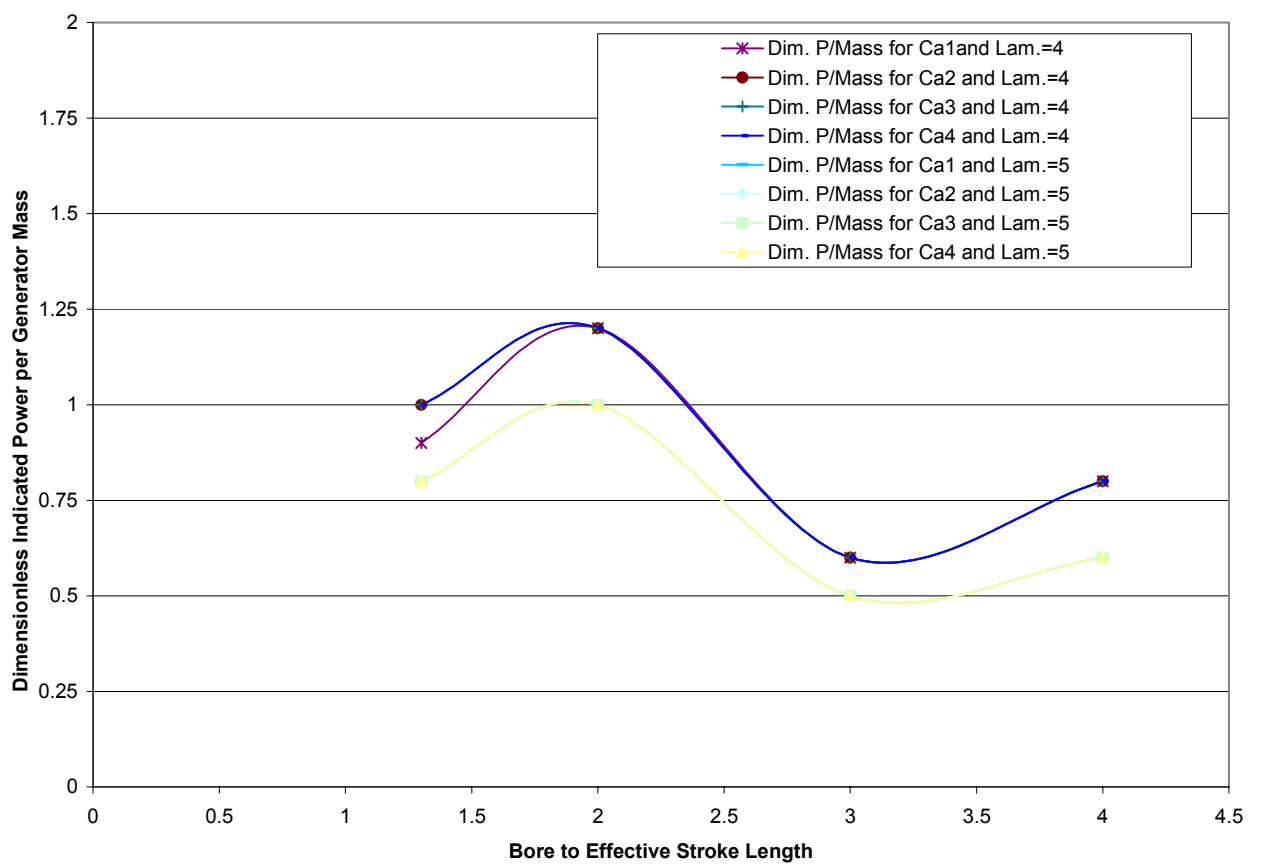

Figure 6.32. Dimensionless Indicated Power per Generator Mass Versus Bore to Effective Stroke Length for Different Lambda, Different Dimensionless Load Constants, and Dimensionless Injection Position $=0.081$

Figures 6.33 shows that there was a slight increase in the dimensionless energy per generator mass with bore to effective stroke length between three and four. The same results were obtained in Figure 6.32. It was also noticed that there was a considerable decrease when the bore to effective stroke length was increased from 1.3 to three. In addition it can be seen that, the dimensionless power per generator mass decreased with the increase of lambda. 


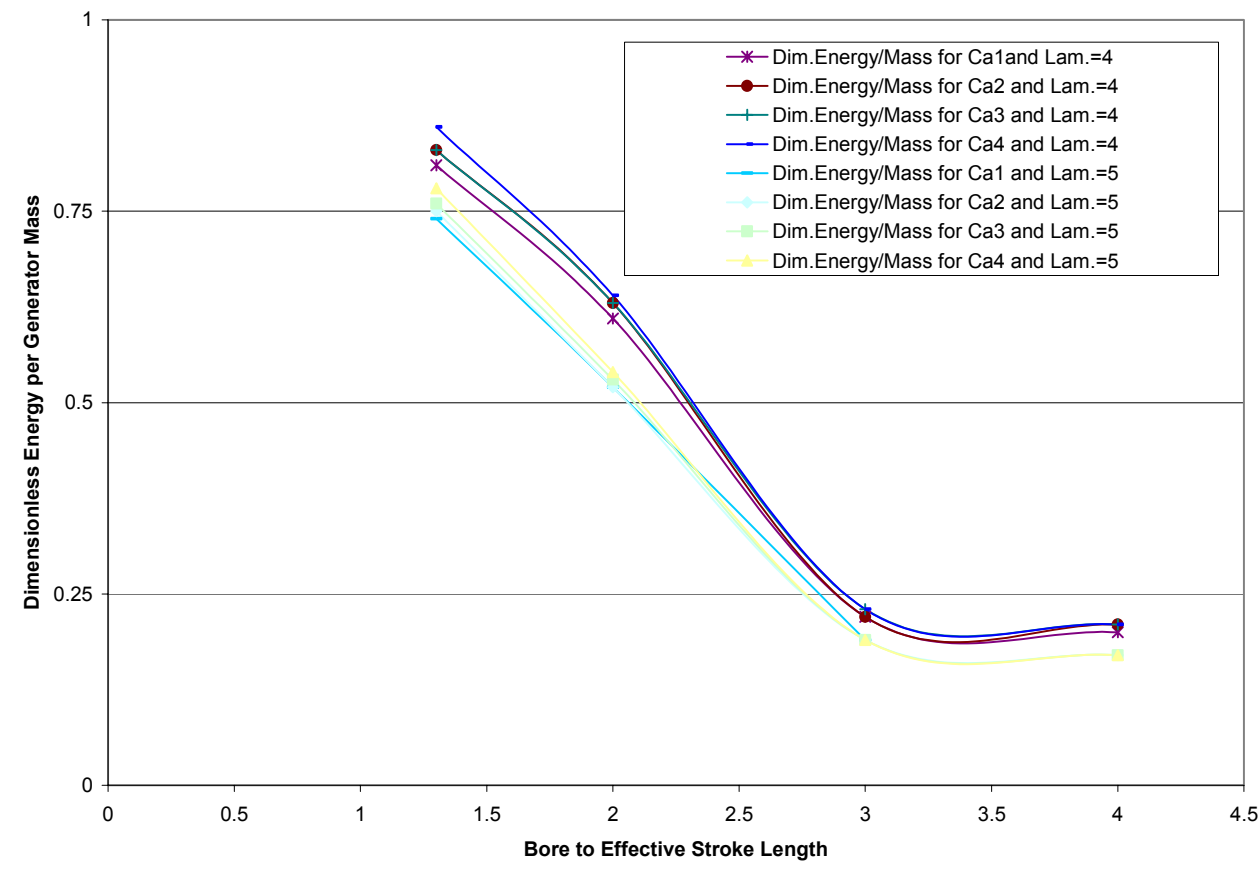

Figure 6.33. Dimensionless Energy per Generator Mass Versus Bore to Effective Stroke Length for Different Lambda, Different Dimensionless Load Constants, and Dimensionless Injection Position $=0.081$ 


\section{SUMMARY OF THE EFFECT OF AIR TO FUEL RATIO:}

Increasing the air to fuel ratio, lambda, for a bore to effective stroke length of 1.3

to 4 , and dimensionless injection position $=0.081$ resulted in:

- Decreasing the dimensionless indicated power.

- Decreasing the dimensionless average piston speed.

- Decreasing the dimensionless frequency.

- Increasing the indicated efficiency.

- Decreasing the compression ratio.

- Decreasing the dimensionless in-cylinder pressure.

- Decreasing the dimensionless friction force.

- Decreasing the dimensionless energy per generator volume.

- Decreasing the dimensionless indicated power per cylinder volume.

- Decreasing the dimensionless indicated power per generator mass.

- Decreasing the dimensionless energy per generator mass. 


\subsection{THE EFFECT OF INJECTION TIMING}

Injecting timing or injection position is one of the major factors that controls the engine operating condition. Injecting the fuel while the piston far from the cylinder head during compression stroke resulted in decreasing dimensionless indicated power, indicated efficiency, dimensionless average velocity, and dimensionless frequency Figures 6.34, to 6.38. Even though it seemed to be a drawback, it was one of the ways to control the compression ratio of the two-stroke compression ignition linear engine as shown in Figure 6.39.

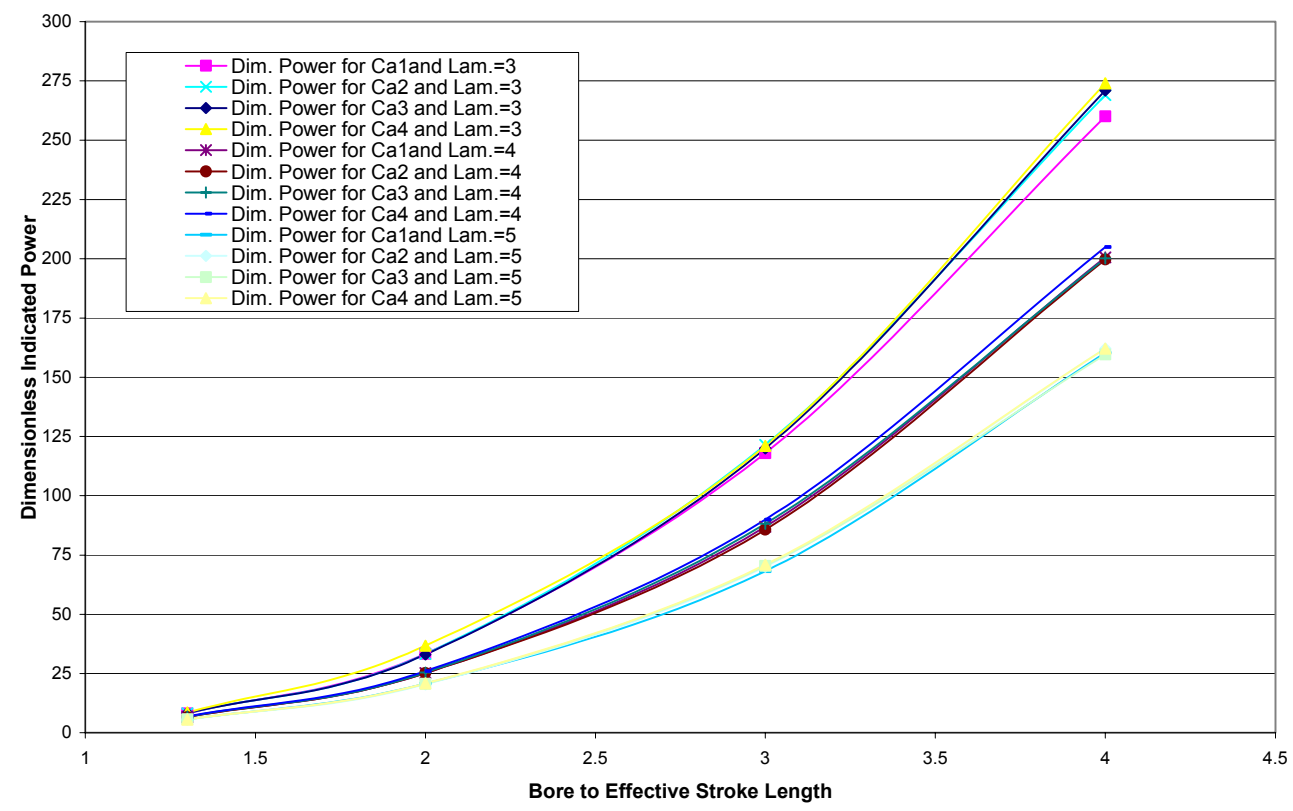

Figure 6.34. Dimensionless Indicated Power Versus Bore to Effective Stroke Length for Different Lambda, Different Dimensionless Load Constants, and Dimensionless Injection Position=0.19 


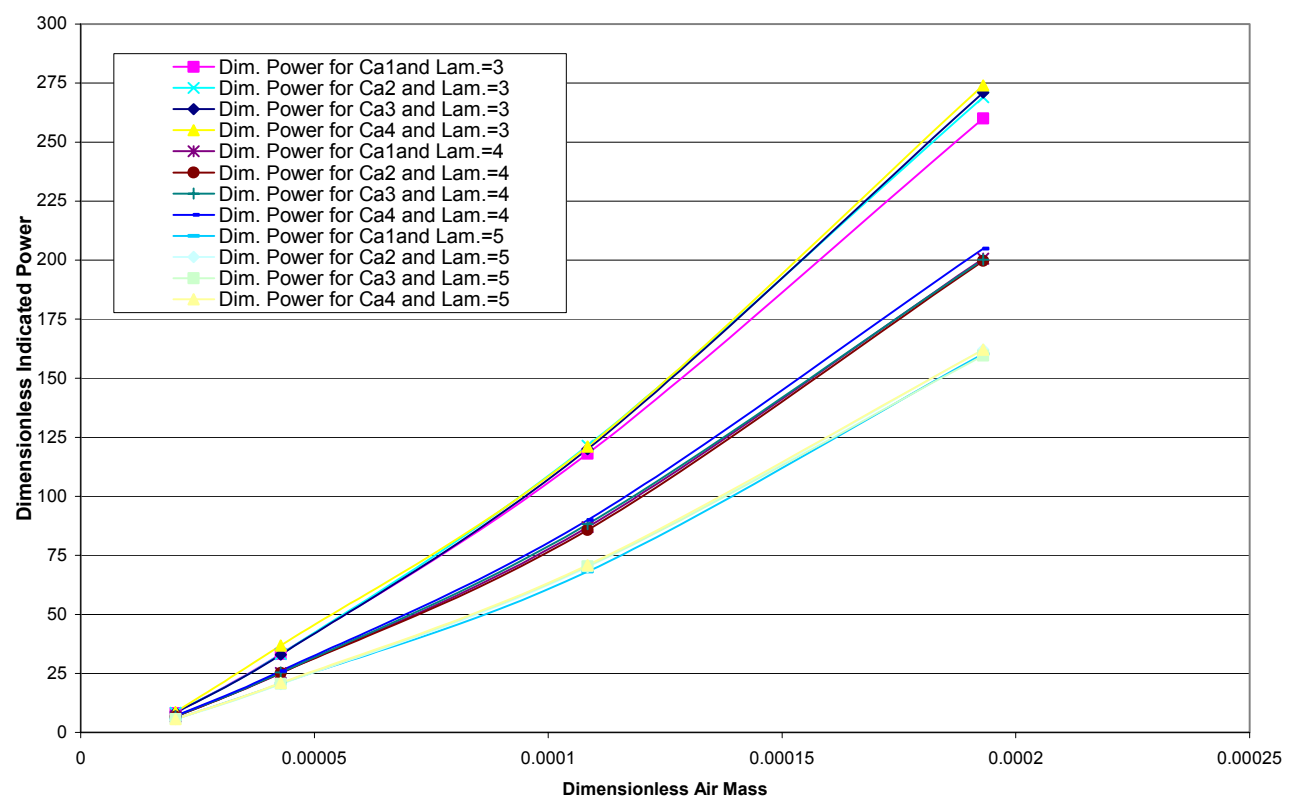

Figure 6.35 Dimensionless Indicated Power Versus Dimensionless Air Mass for Different Lambda, Different Dimensionless Load Constants, and Dimensionless Injection Position=0.19

Figure 6.36 shows the indicated efficiency versus bore to effective stroke length and dimensionless air mass for different dimensionless load constants and lambda. Compared to Figures 6.22, it was clear that the indicated efficiency deteriorated with injecting the fuel during compression stroke while the piston far from the cylinder head during compression stroke ${ }^{4}$.

For different dimensionless load constants, bore to effective stroke length of 1.3 and dimensionless air mass of 0.00002 the values of dimensionless indicated power, and dimensionless average velocity were almost the same as shown in Figures 6.34, 6.35, and 6.37 .

\footnotetext{
${ }^{4}$ Injecting the fuel in a position relative to the piston position.
} 


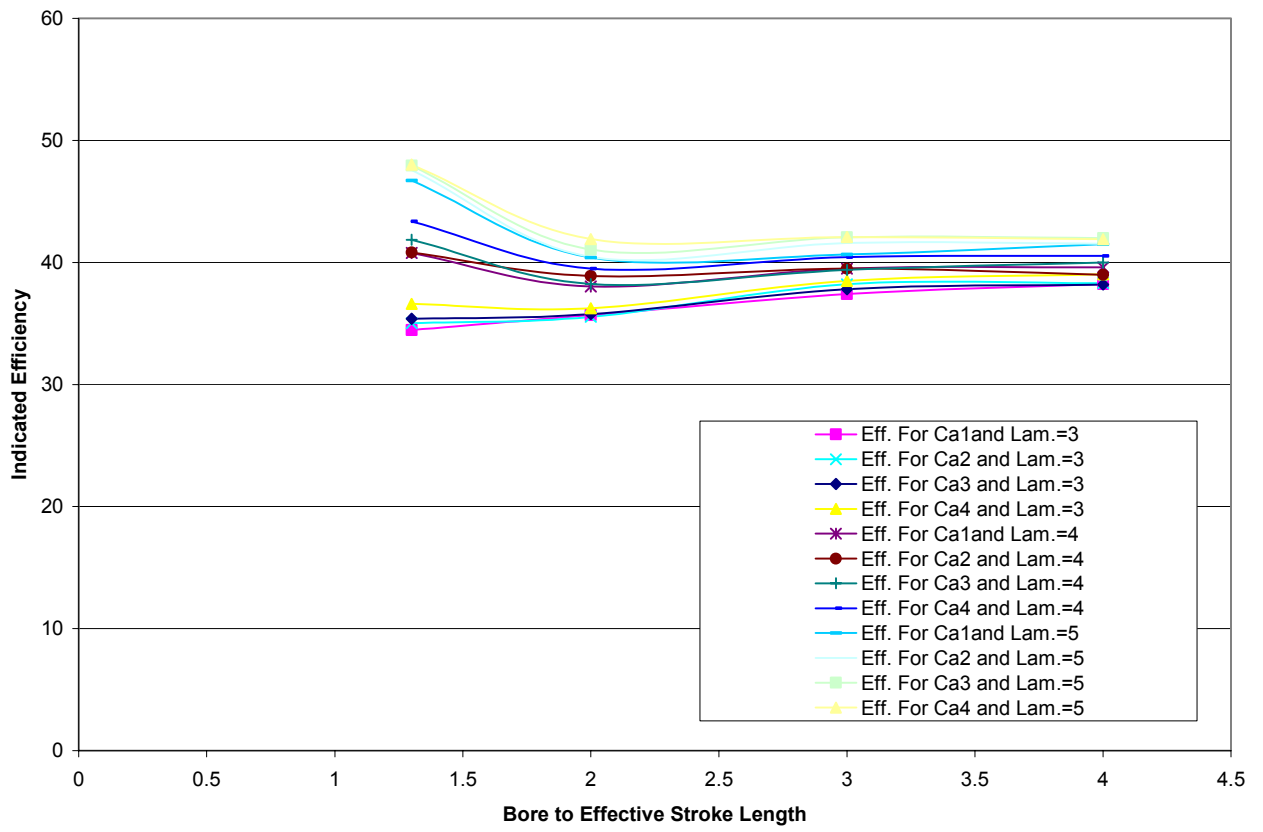

Figure 6.36. Indicated Efficiency Versus Bore to Effective Stroke Length for Different Lambda, Different Dimensionless Load Constants, and Dimensionless Injection Position=0.19

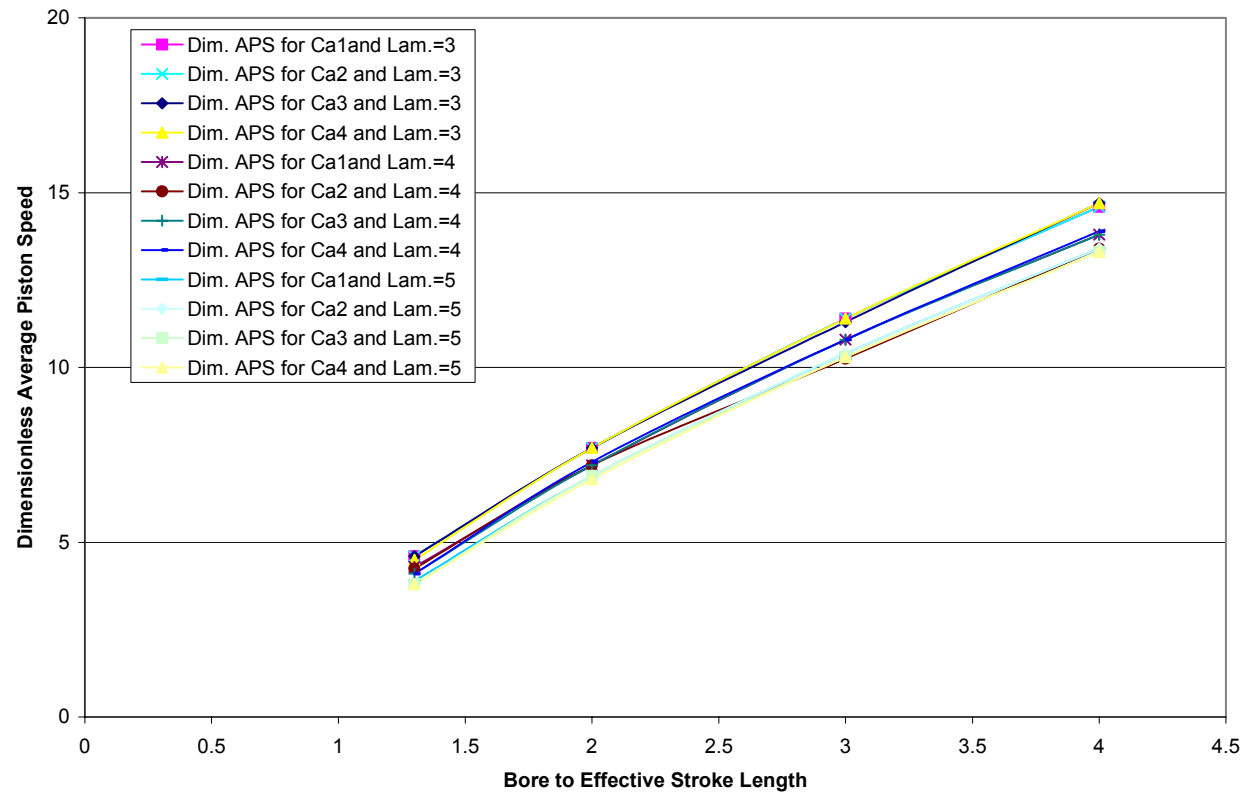

Figure 6.37. Dimensionless Average Piston Speed Versus Bore to Effective Stroke Length for Different Lambda, Different Dimensionless Load Constants, and Dimensionless Injection Position=0.19 


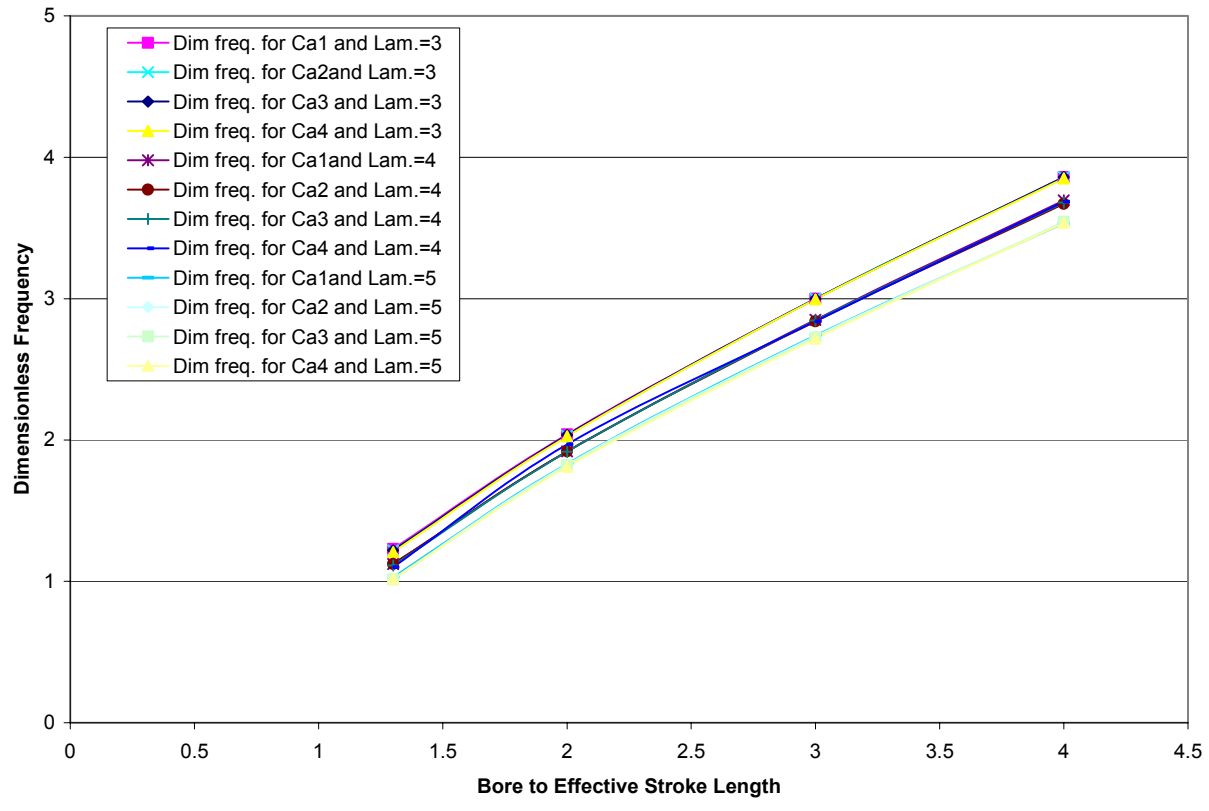

Figure 6.38. Dimensionless Frequency Versus Bore to Effective Stroke Length for Different Lambda, Different Dimensionless Load Constants, and Dimensionless Injection Position=0.19 
Figure 6.39 shows the compression ratio versus bore to effective stroke length for different dimensionless load constants and lambda. The figure confirmed the fact that the highest compression ratios occurred with bore to effective stroke length of 2.2, Figures 6.8 and 6.26. Increasing or decreasing bore to effective stroke length resulted in decreasing the compression ratio. Also it can be seen that injecting a lean fuel to air mixture of lambda equals five and injecting the fuel at a dimensionless injection position of 0.19 resulted in a compression ratio close to normal operating compression ratio of commercial diesel engines. In addition, the indicated efficiency for such an operating condition was relatively high as shown in Figure 6.36.

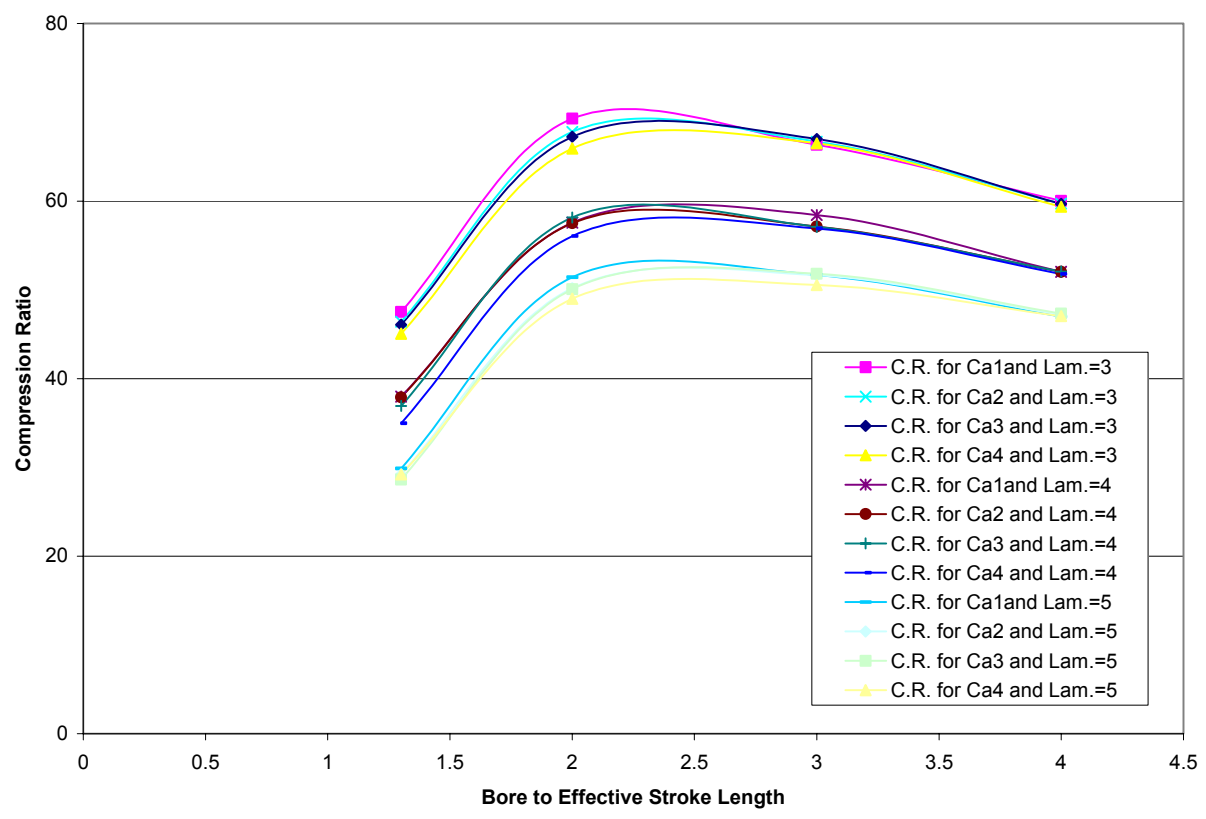

Figure 6.39. Compression Ratio Versus Bore to Effective Stroke for Different Lambda, Different Dimensionless Load Constants, and Dimensionless Injection Position=0.19 
Figure 6.40 and 6.41 show dimensionless in-cylinder pressure for different dimensionless load constants and lambda. Figure 6.41 show that the peak value of dimensionless in-cylinder pressure for bore to effective stroke length of two was almost the same as the peak value of dimensionless in-cylinder pressure of bore to effective stroke length of three. The reason behind this was that the compression ratio was almost the same for both cases as shown in Figure 6.39.

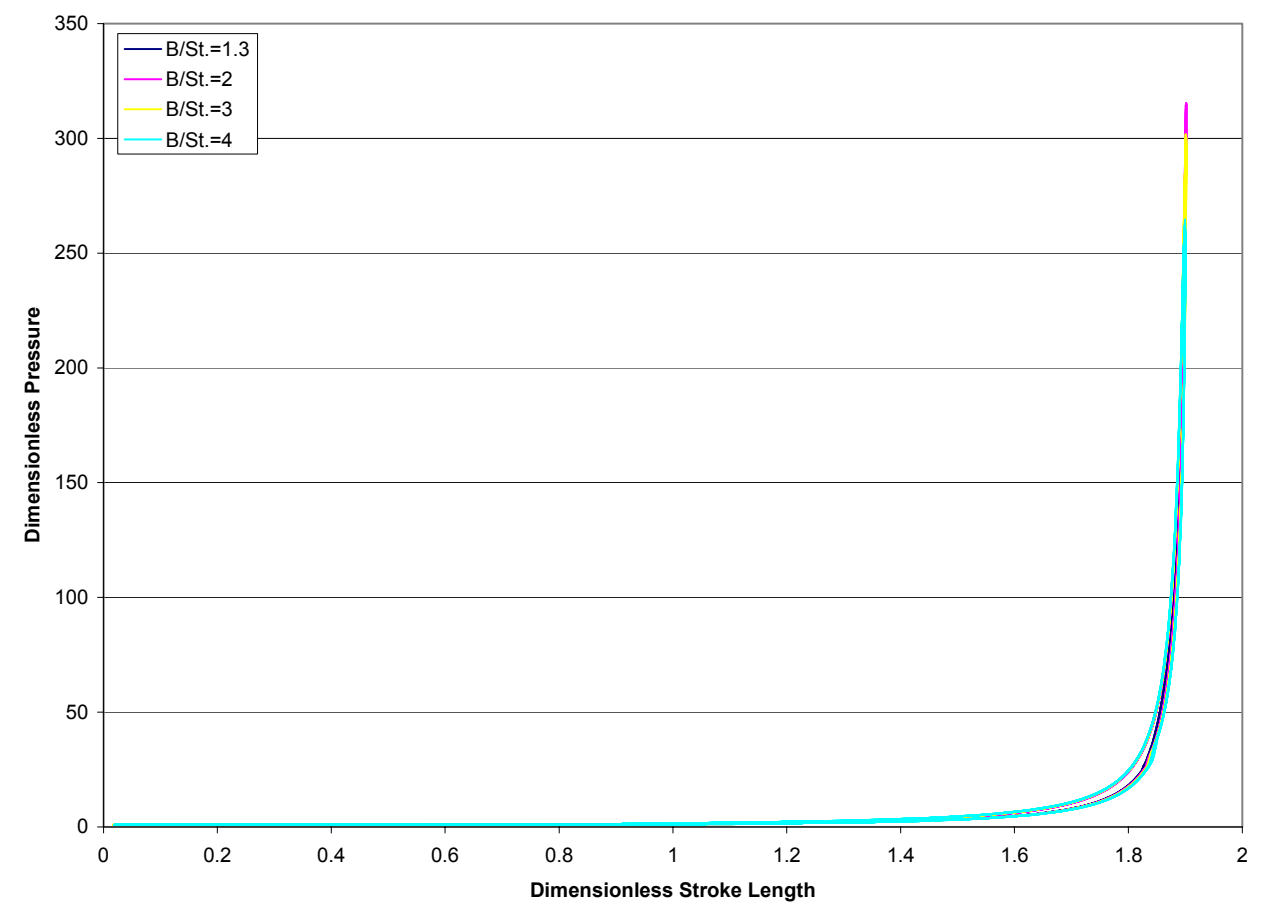

Figure 6.40. Dimensionless In-Cylinder Pressure Versus Dimensionless Stroke Length for Lambda $=4, \mathrm{Ca} 3$, and Injection Position $=0.19$ 


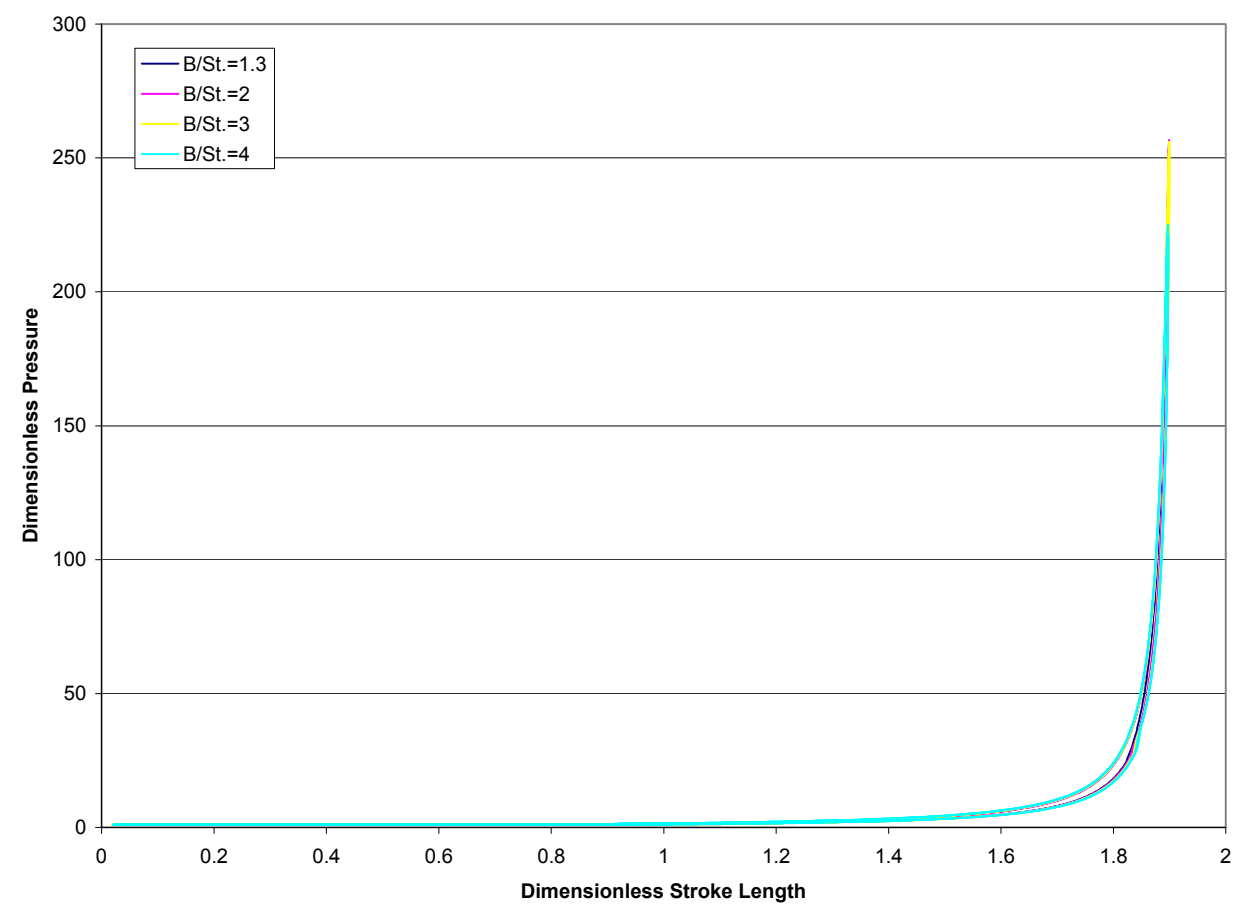

Figure 6.41. Dimensionless In-Cylinder Pressure Versus Dimensionless Stroke Length for Lambda $=5$, Ca3, and Injection Position $=0.19$

Figures 6.42 and 6.43 show dimensionless friction force versus dimensionless stroke length. It can be seen that injecting the fuel at a dimensionless injection position of 0.19 decreased the peak values of the dimensionless friction force as a result of decreasing the dimensionless in-cylinder pressure. However, the change in the dimensionless friction force peaks was insignificant.

As expected there was a decrease in the dimensionless velocity over the dimensionless, Figures 6.44 and 6.45 . 


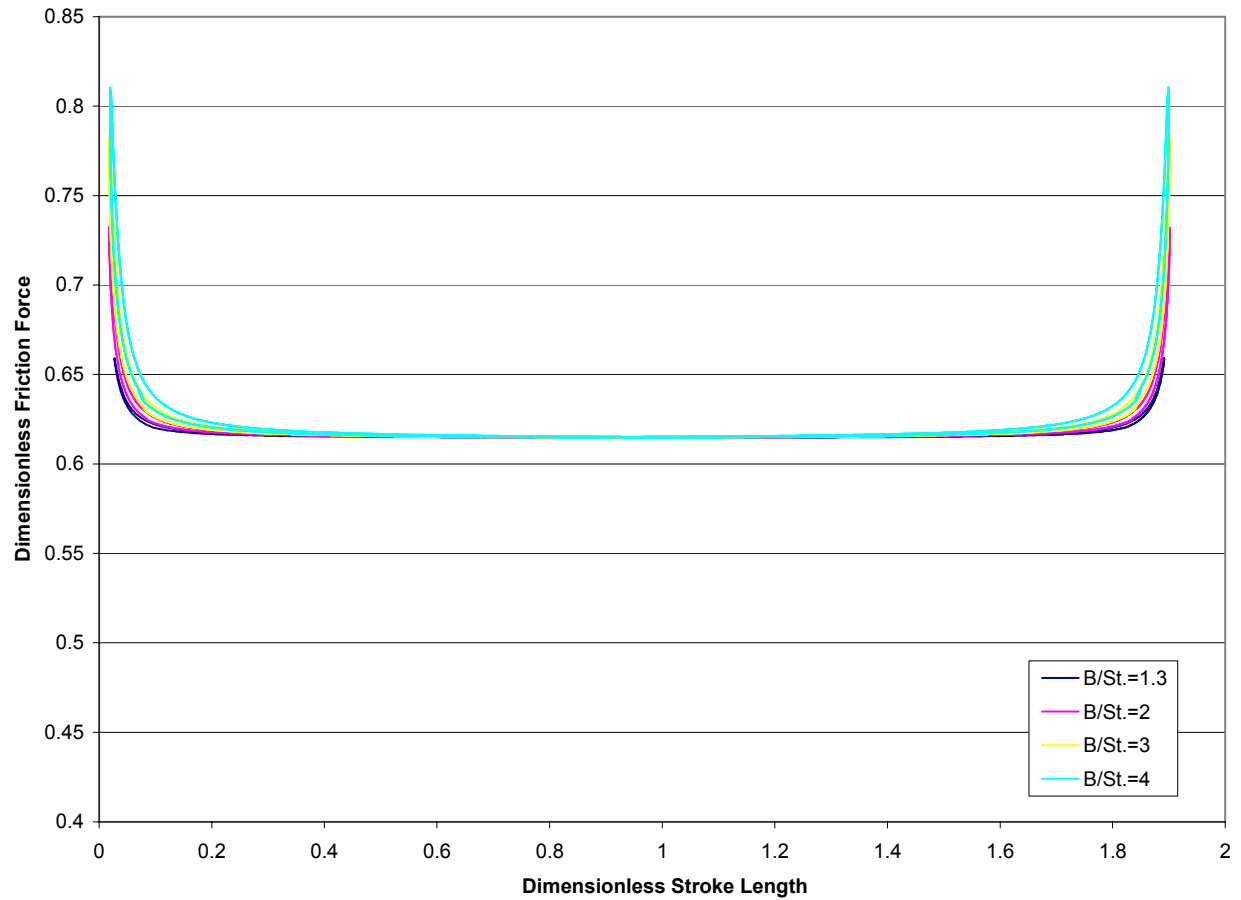

Figure 6.42. Dimensionless Friction Force Versus Dimensionless Stroke Length for Lambda=4, Ca3, and Dimensionless Injection Position $=0.19$

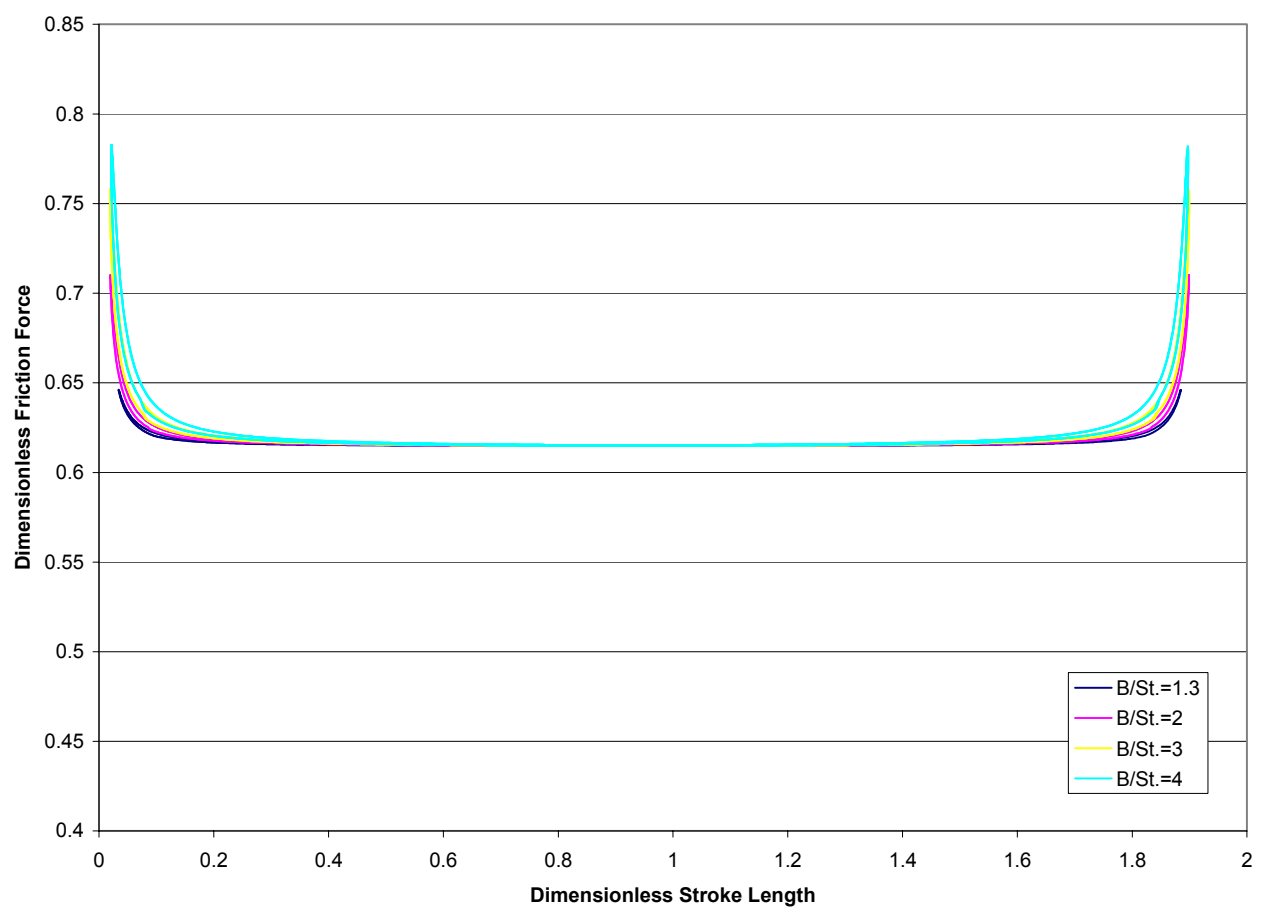

Figure 6.43. Dimensionless Friction Force Versus Dimensionless Stroke Length for Lambda=5, Ca3, and Dimensionless Injection Position $=0.19$ 


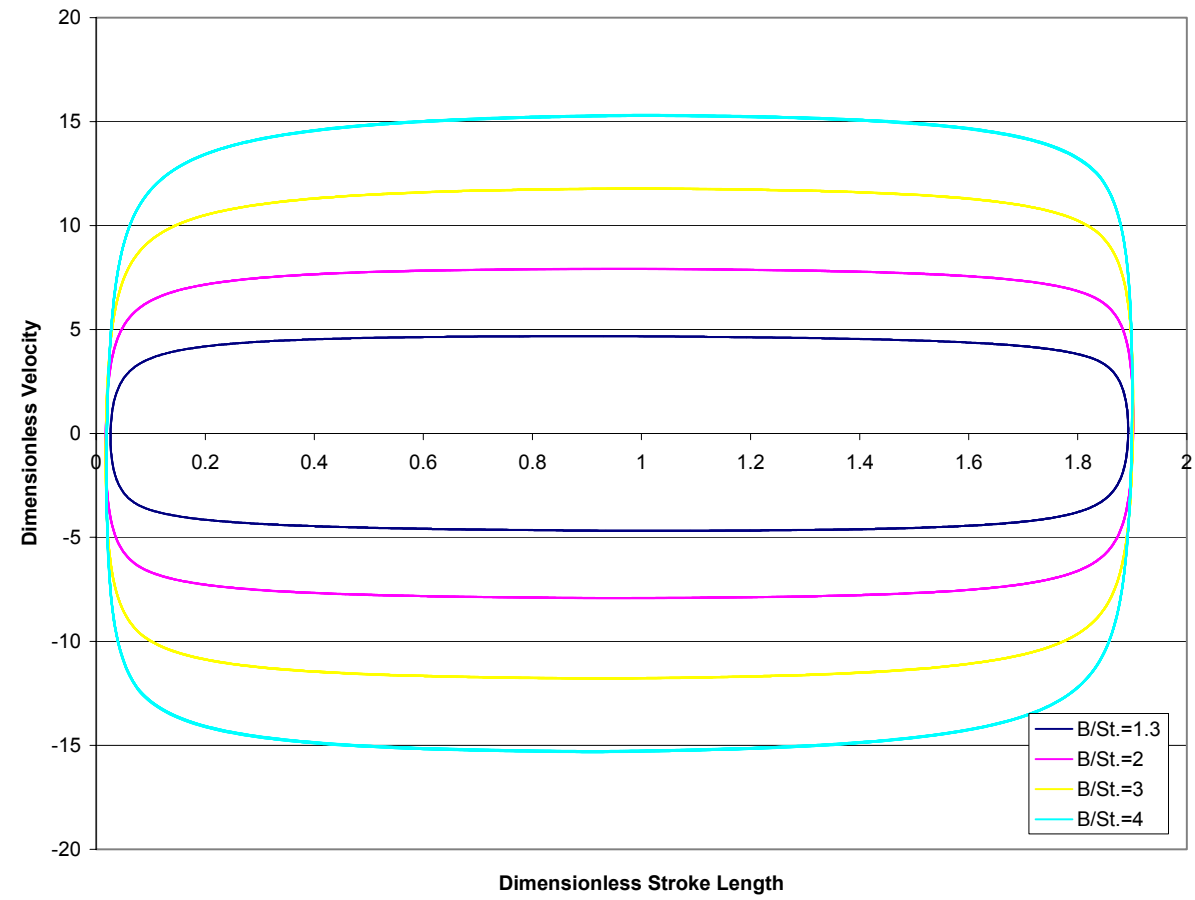

Figure 6.44. Dimensionless Velocity Versus Dimensionless Stroke Length for Lambda=4, Ca3, and Dimensionless Injection Position $=\mathbf{0 . 1 9}$

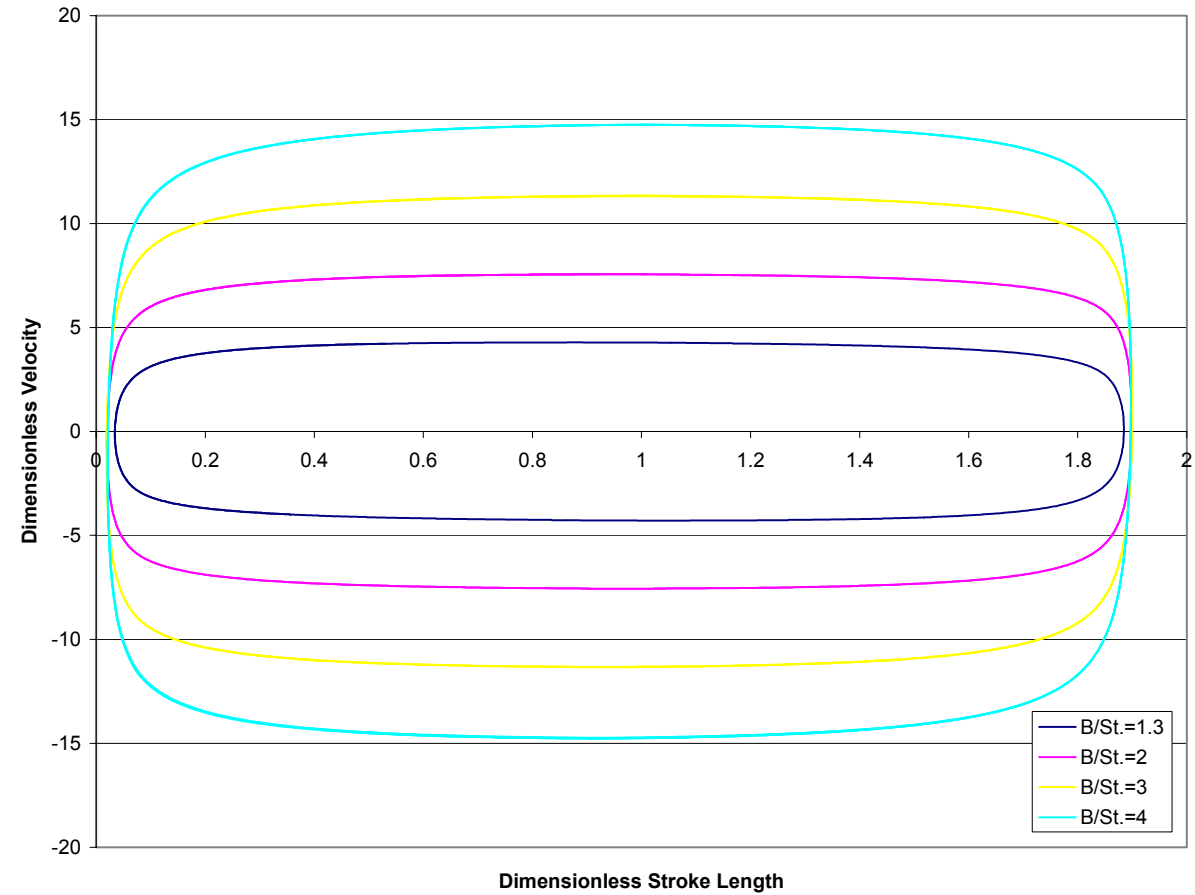

Figure 6.45. Dimensionless Velocity Dimensionless Stroke Length for Lambda=5, Ca3, and Dimensionless Injection Position $=\mathbf{0 . 1 9}$ 
Figure 6.46 illustrates the change in dimensionless energy per generator volume. The figure confirmed results previously obtained in Figures 6.14 and 6.30. Also it can be seen that there was an increase in the value of dimensionless energy per generator volume with dimensionless load constant $\mathrm{Ca} 4$, lambda equal to five and bore to effective stroke length of three.

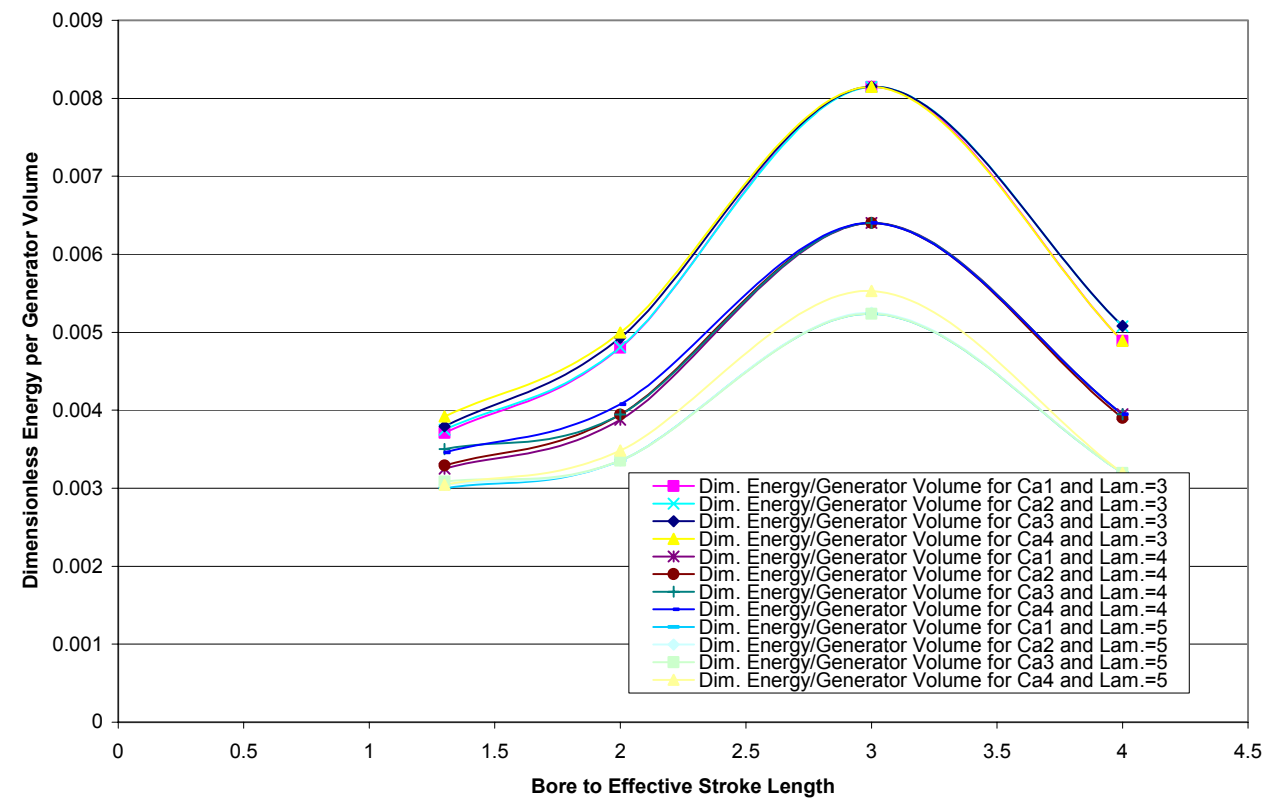

Figure 6.46. Dimensionless Energy per Generator Volume Versus Bore to Effective Stroke Length for Different Lambda, Different Dimensionless Load Constants, and Dimensionless Injection Position=0.19 
Figure 6.47 shows the change in dimensionless indicated power per cylinder volume. The figure confirmed results obtained in Figures 6.15 and 6.31 that increasing the bore to effective stroke increased the dimensionless indicated power.

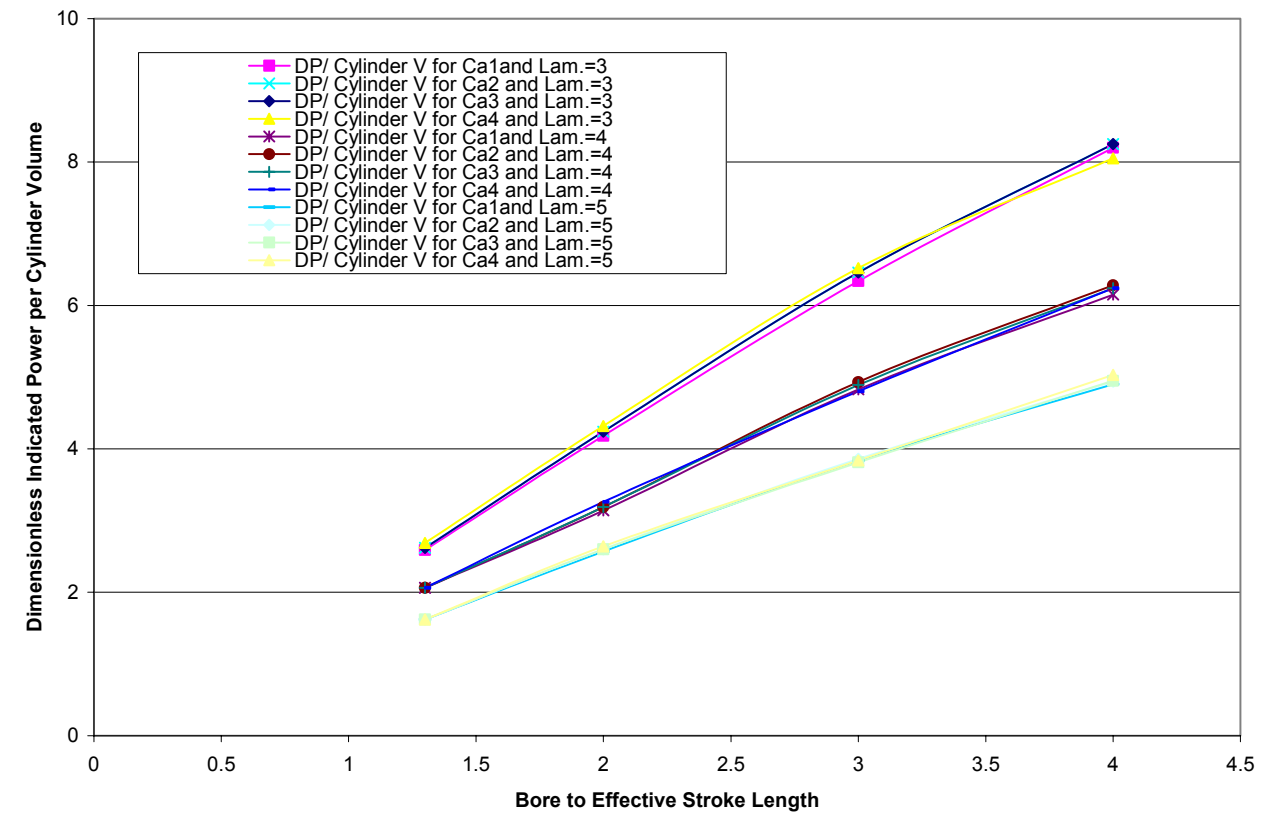

Figure 6.47. Dimensionless Indicated Power per Cylinder Volume Versus Bore to Effective Stroke Length for Different Lambda, Different Dimensionless Load Constants, and Dimensionless Injection Position=0.19 
Figures 6.48 and 6.49 show the change in dimensionless energy per generator mass and dimensionless indicated power per generator mass versus bore to effective stroke length. The four figures showed a decrease in values compared to dimensionless injection position of 0.081 . Also, Figure 6.48 confirmed results obtained earlier in Figures 6.16, and 6.32. These figures confirmed also that the highest value of dimensionless indicated power occurred with bore to effective stroke length of two.

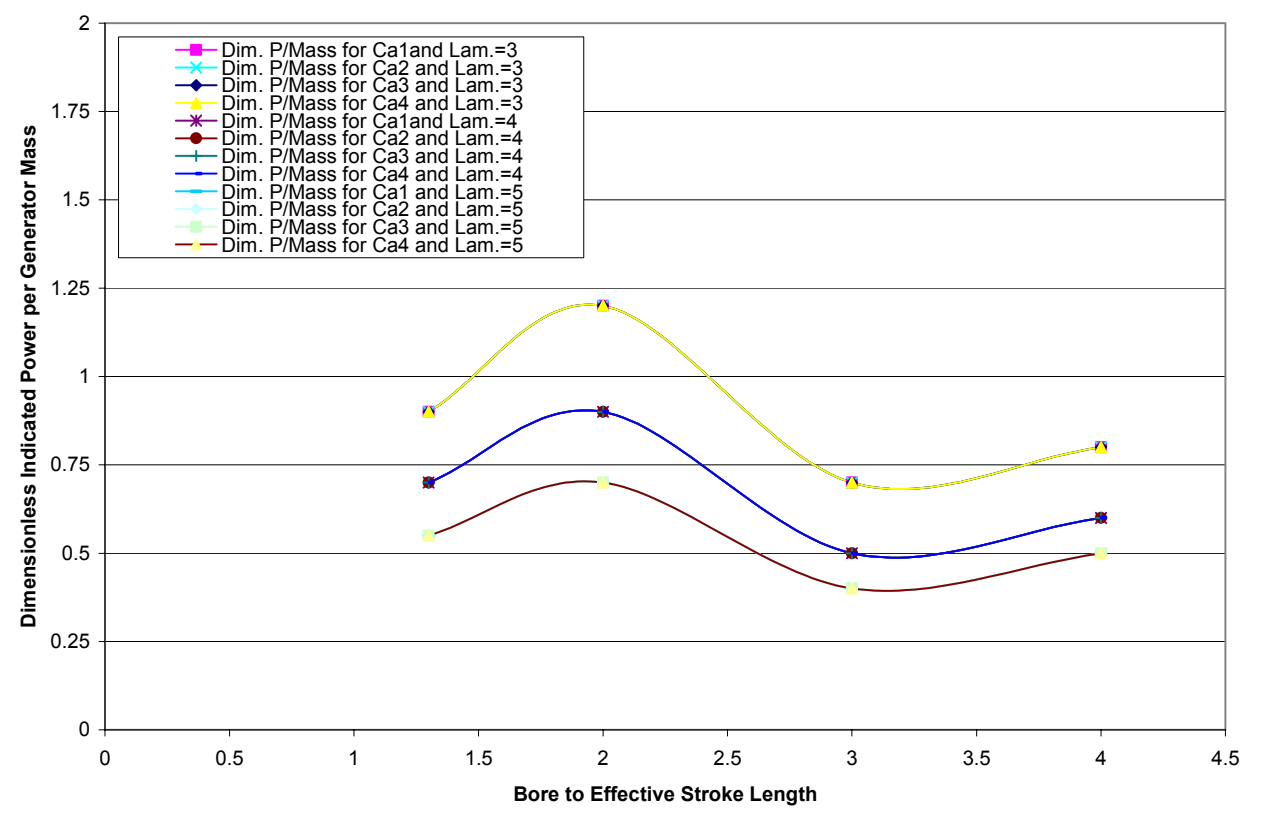

Figure 6.48. Dimensionless Indicated Power per Generator Mass Versus Bore to Effective Stroke Length for Different Lambda, Different Dimensionless Load Constants, and Dimensionless Injection Position=0.19 


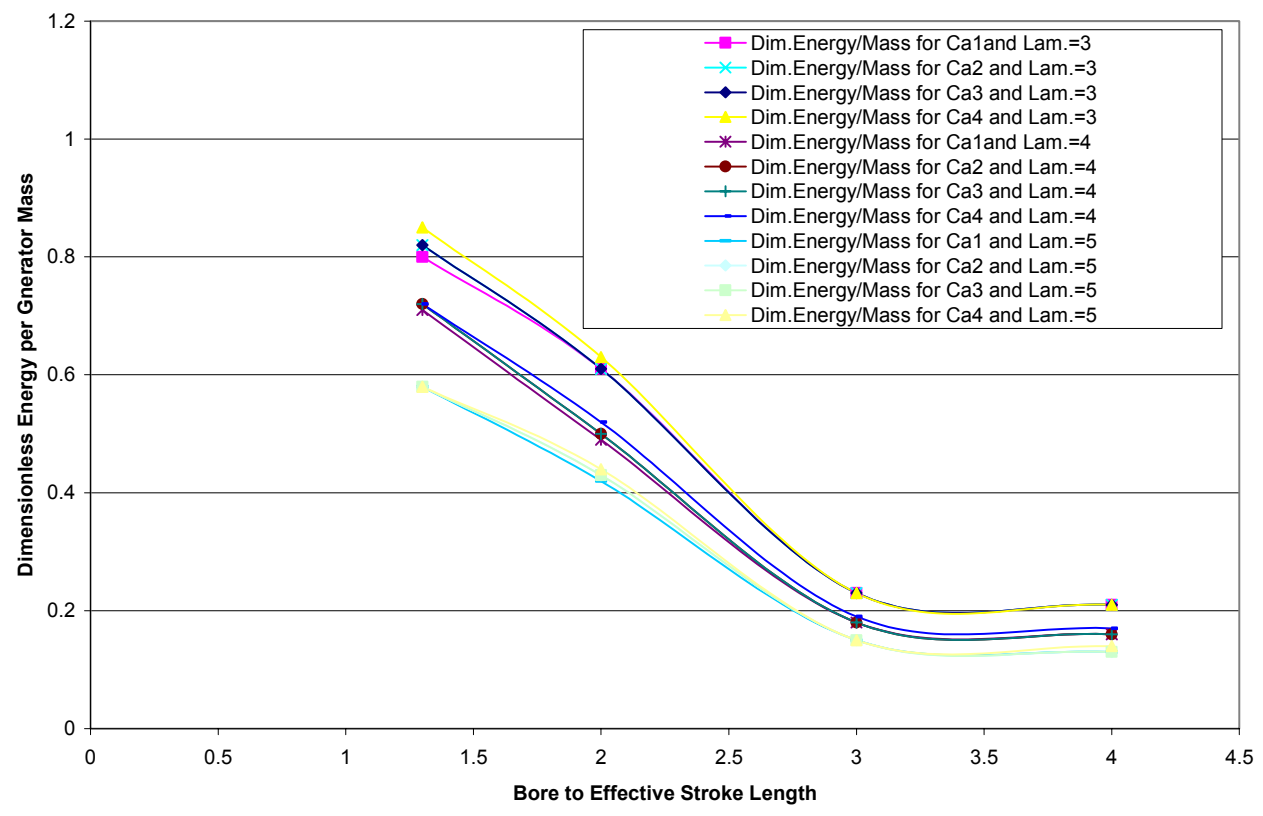

Figure 6.49. Dimensionless Energy per Generator Mass Versus Bore to Effective Stroke Length for Different Lambda, Different Dimensionless Load Constants, and Dimensionless Injection

Position=0.19 


\section{SUMMARY OF THE EFFECT OF INJECTION TIMING:}

Advancing the injection timing or injection position to be far from cylinder head during compression stroke for a bore to effective stroke length of 1.3 to 4 , and lambda $=3$, 4 and 5 resulted in:

- Decreasing the dimensionless indicated power.

- Decreasing the dimensionless average piston speed.

- Decreasing the dimensionless frequency.

- Decreasing the indicated efficiency.

- Decreasing the compression ratio.

- Decreasing the dimensionless in-cylinder pressure.

- Decreasing the dimensionless friction force.

- Decreasing the dimensionless energy per generator volume.

- Decreasing the dimensionless indicated power per cylinder volume.

- Decreasing the dimensionless indicated power per generator mass.

- Decreasing the dimensionless energy per generator mass. 


\subsection{EFFECT OF COMBUSTION DISTRIBUTION}

The change in the combustion distribution for premixed combustion to diffusion combustion ratios had a dramatic effect on the performance of the two-stroke compression ignition linear engine. It was found that decreasing the percentage of the diffusive combustion ratio to $60 \%$ and increasing the percentage of the premixed combustion to $40 \%$ resulted in decreasing the dimensionless indicated power and indicated efficiency as a result of decreasing the dimensionless in-cylinder pressure. In the first case, $20 \%$ premixed combustion and $80 \%$ diffusive combustion; the combustion process was close to homogeneous charge combustion case [50]. In other words, allowing instantaneous heat release. Also, increasing the rate of energy release with premixed combustion resulted in partially rapid increase in the dimensionless in-cylinder pressure during the premixed domain that resulted in an increase in the power lost in heat transfer. Figures 6.50 to 6.53 show the dimensionless indicated power and indicated efficiency versus bore to effective stroke length for different dimensionless load constants, different lambda and different dimensionless injection positions ${ }^{5}$. The dimensionless indicated power versus bore to effective stroke length of 1.3 did not vary with changing dimensionless load constant or lambda as shown in Figures 6.50 and 6.51. Also, it can be seen that the indicated efficiency for lambda equal to three, bore to effective stroke length 1.3 compared to other values of effective bore to effective stroke length as shown in Figures 6.52 and 6.53. However, these values were less than the corresponding values in Figures 6.3, 6.22, and 6.36.

\footnotetext{
${ }^{5}$ All figures presented in this section are for $40 \%$ premixed combustion and $60 \%$ diffusive combustion.
} 


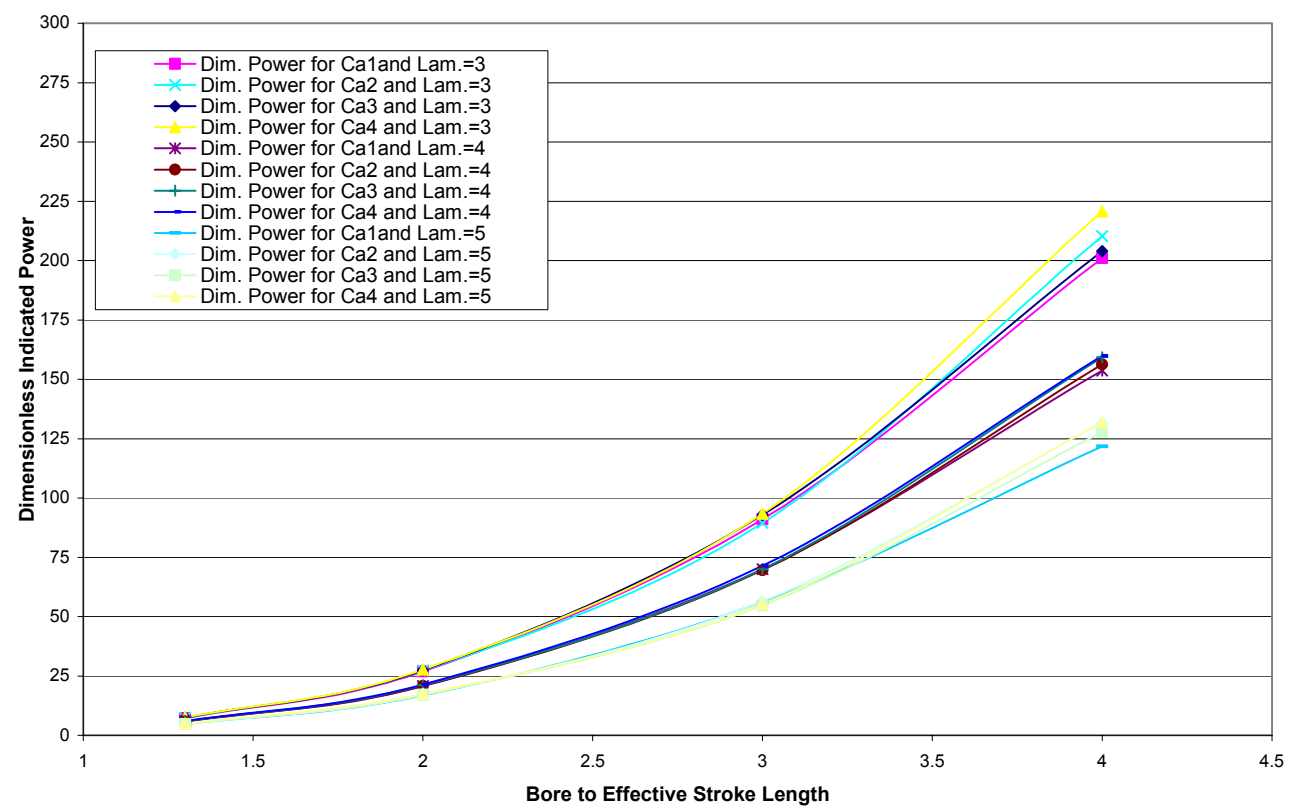

Figure 6.50. Dimensionless Indicated Power Versus Bore to Effective Stroke Length for Different Lambda, Different Dimensionless Load Constants, and Dimensionless Injection Position $=0.081$

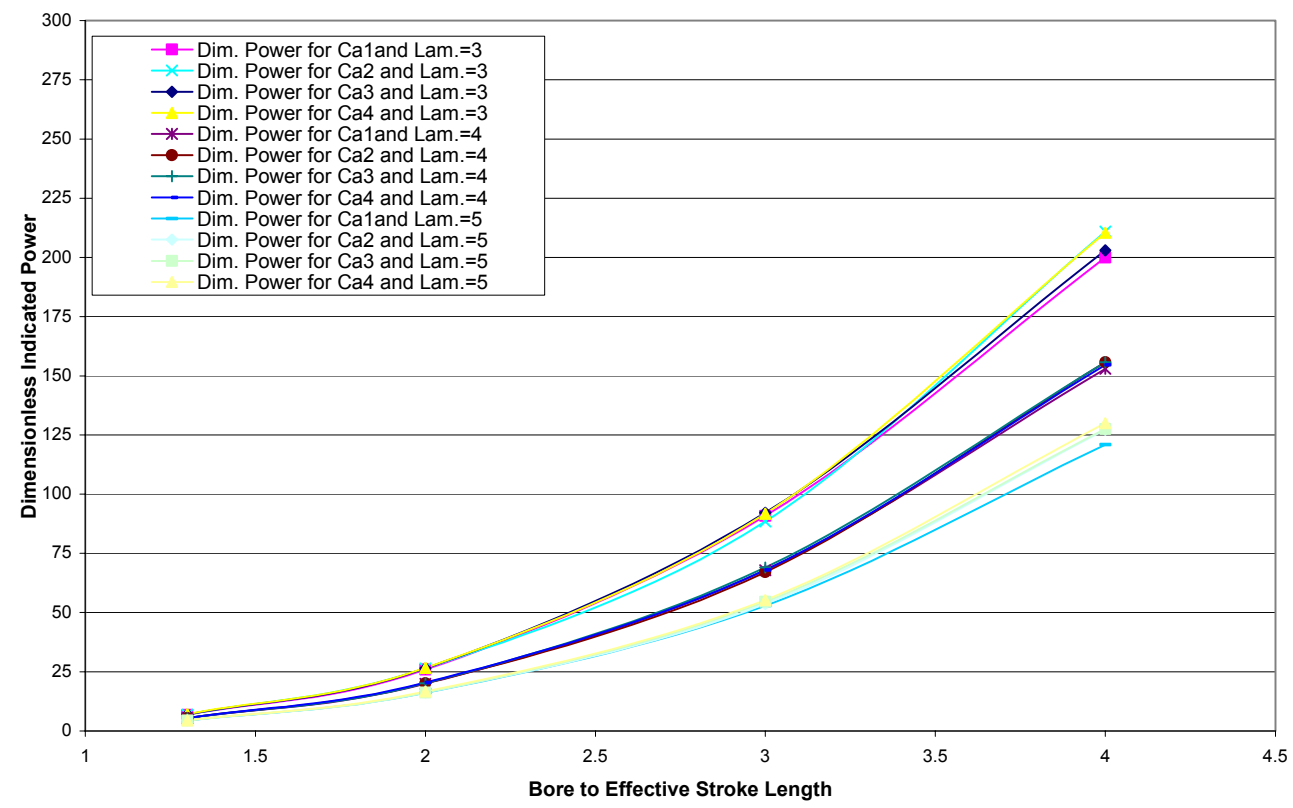

Figure 6.51. Dimensionless Indicated Power Versus Bore to Effective Stroke Length for Different Lambda, Different Dimensionless Load Constants, and Dimensionless Injection Position=0.19 


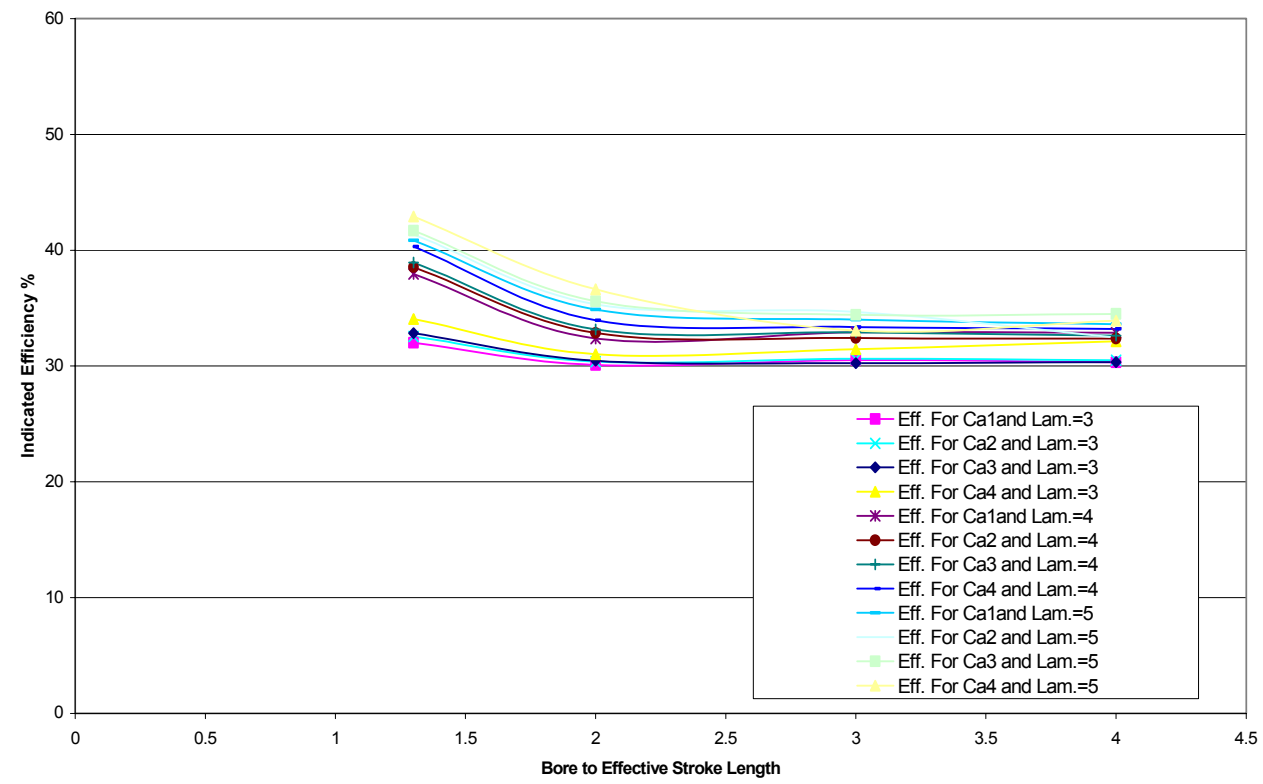

Figure 6.52. Dimensionless Indicated Power Versus Bore to Effective Stroke Length for Different Lambda, Different Dimensionless Load Constants, and Dimensionless Injection Position=0.018

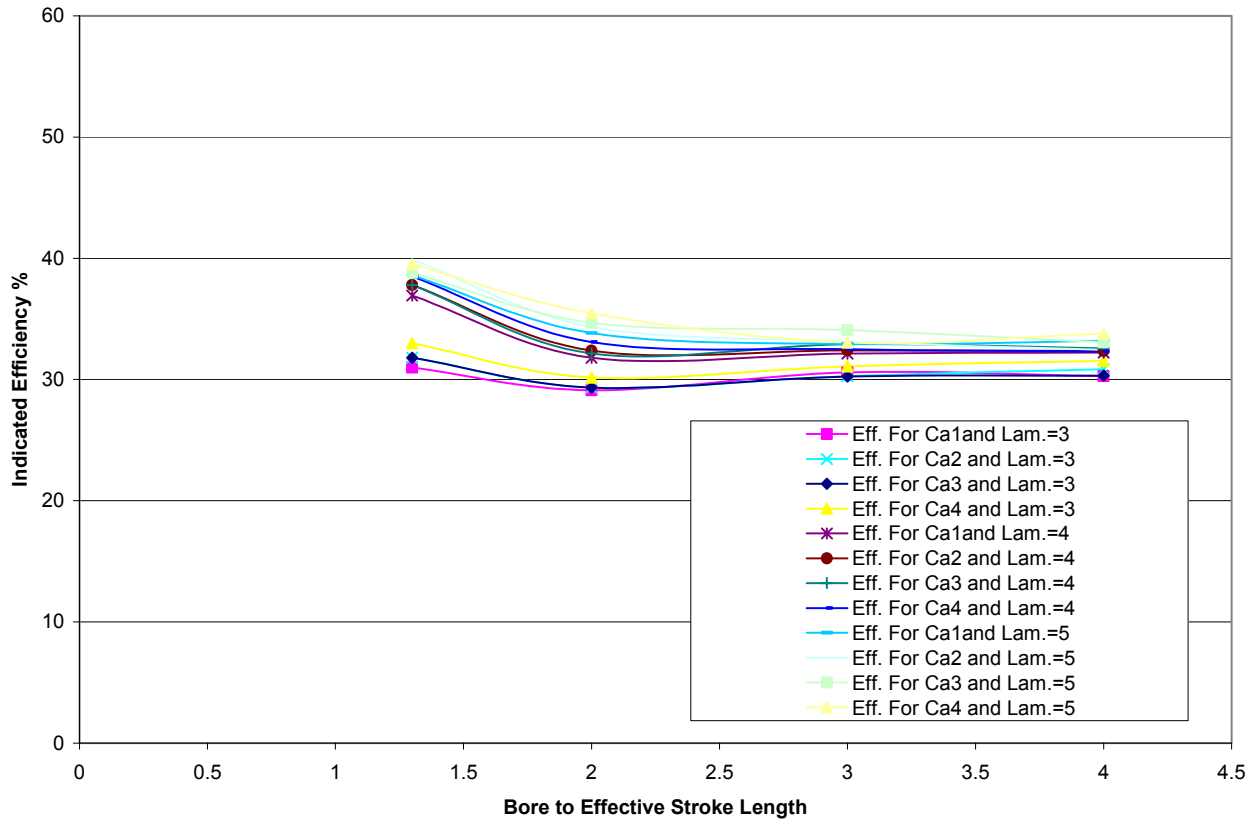

Figure 6.53. Indicated Efficiency Versus Bore to Effective Stroke Length for Different Lambda, Different Dimensionless Load Constants, and Dimensionless Injection Position=0.19 
Also, as a result of decreasing the diffusion combustion ratio the dimensionless average piston speed, the dimensionless frequency, the dimensionless in-cylinder pressure, the dimensionless friction force and the dimensionless velocity over the stroke length decreased. Figures 6.54 to 6.63 show these results for different dimensionless load constants, different lambda and different dimensionless injection positions.

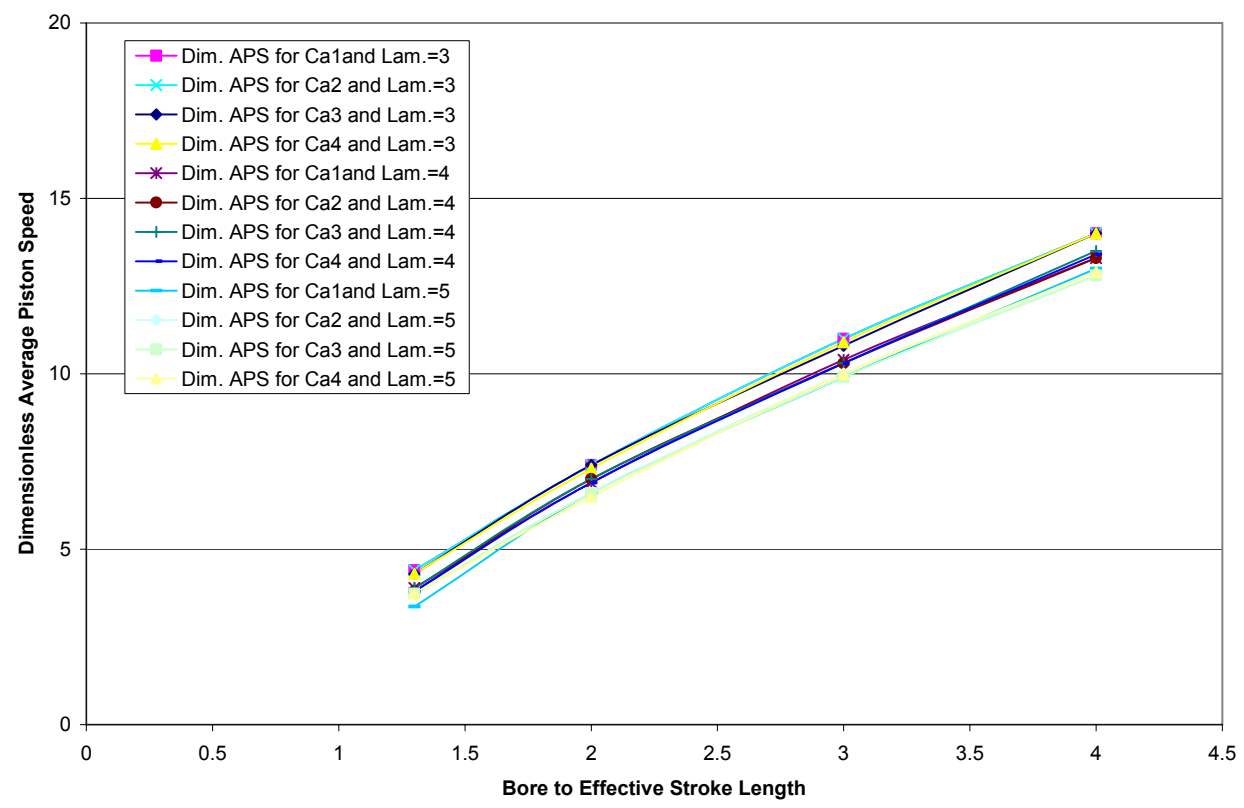

Figure 6.54. Dimensionless Average Piston Speed Versus Bore to Effective Stroke Length for Different Lambda, Different Dimensionless Load Constants, and Dimensionless Injection Position $=0.018$ 


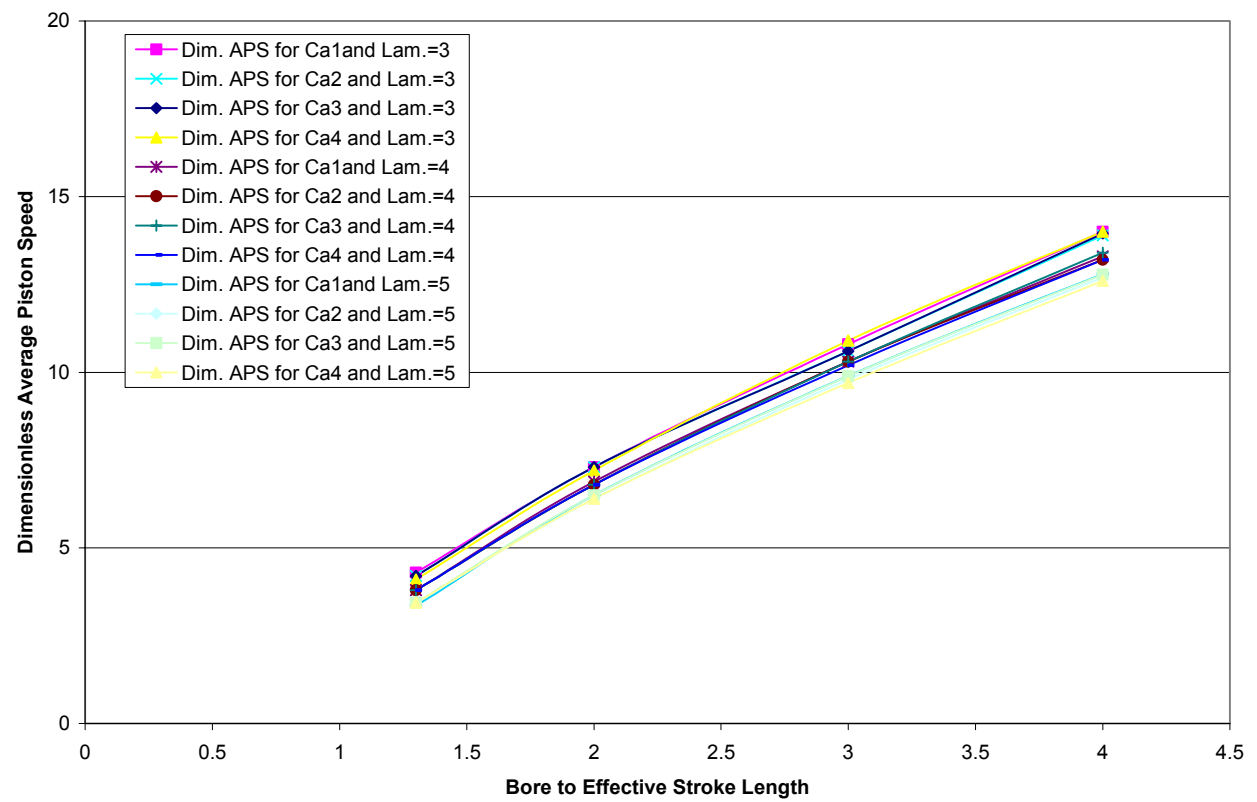

Figure 6.55. Dimensionless Average Piston Speed Versus Bore to Effective Stroke Length for Different Lambda, Different Dimensionless Load Constants, and Dimensionless Injection Position=0.19

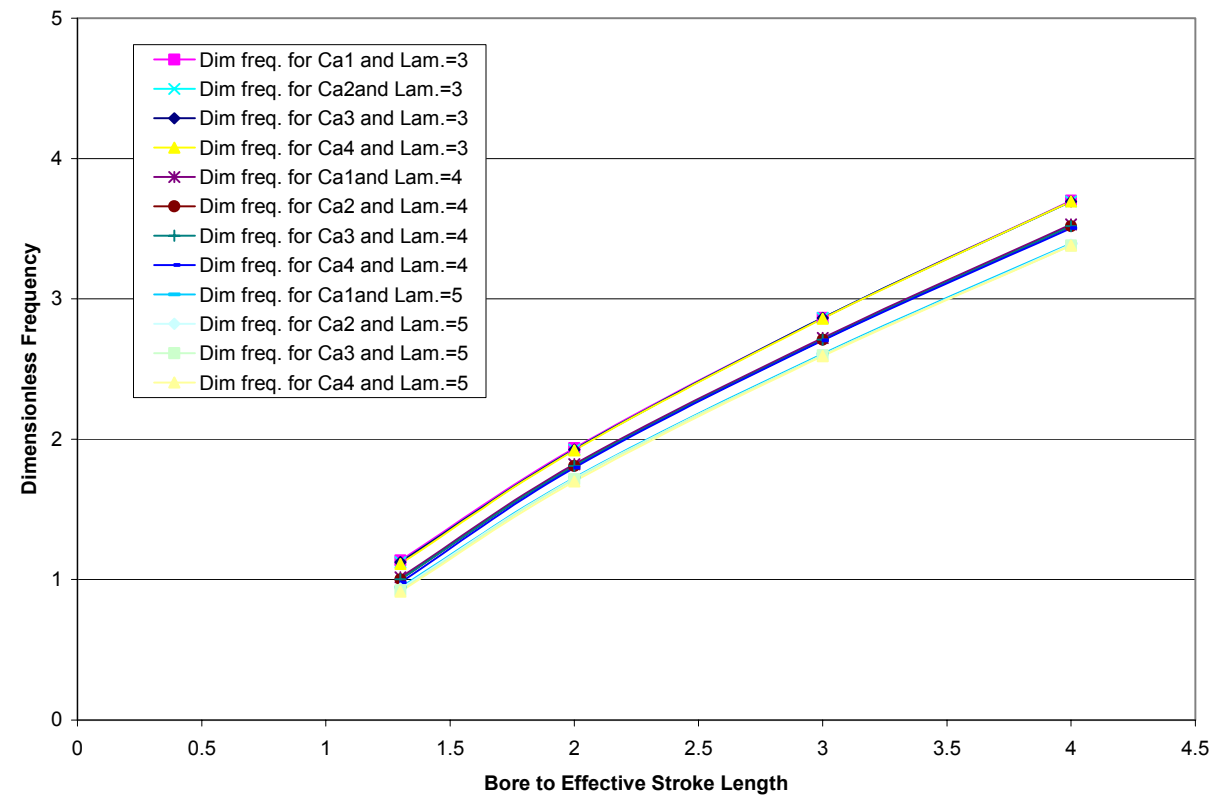

Figure 6.56. Dimensionless Frequency Versus Bore to Effective Stroke Length for Different Lambda, Different Dimensionless Load Constants, and Dimensionless Injection Position=0.018 


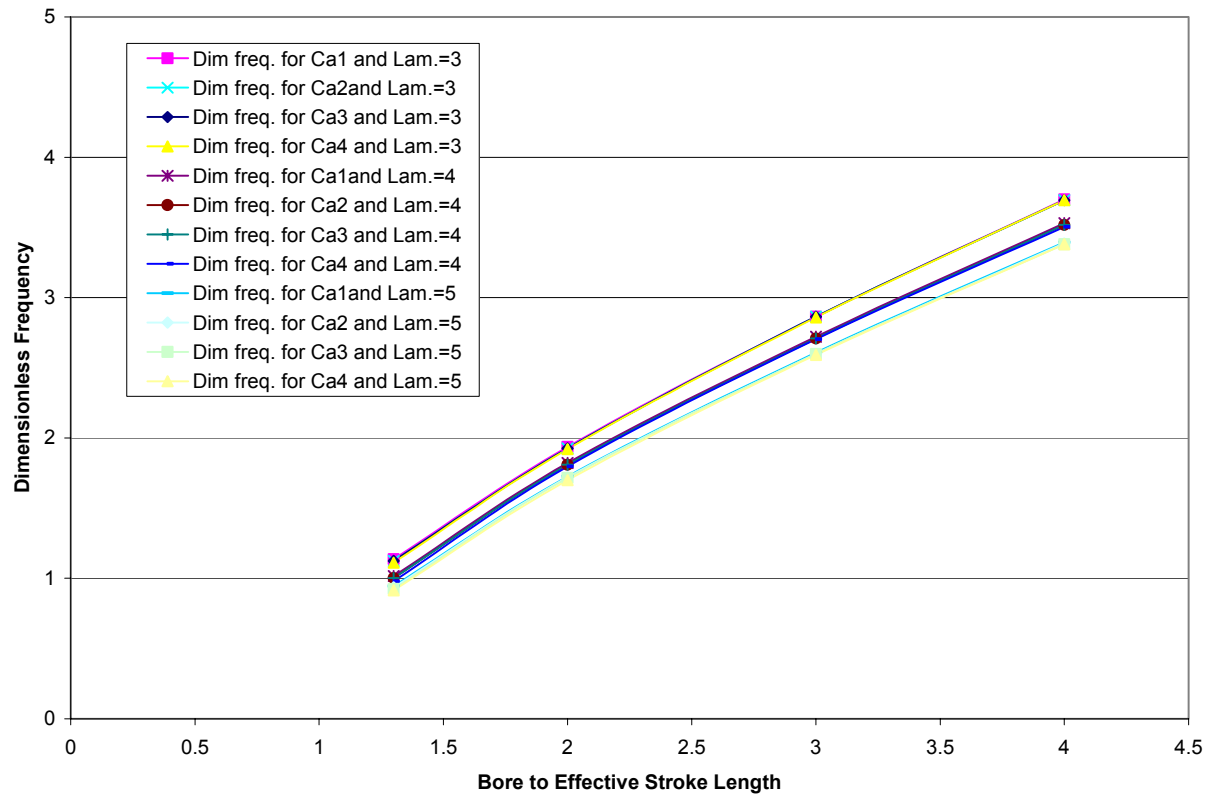

Figure 6.57. Dimensionless Frequency Versus Bore to Effective Stroke Length for Different Lambda, Different Dimensionless Load Constants, and Dimensionless Injection Position=0.19

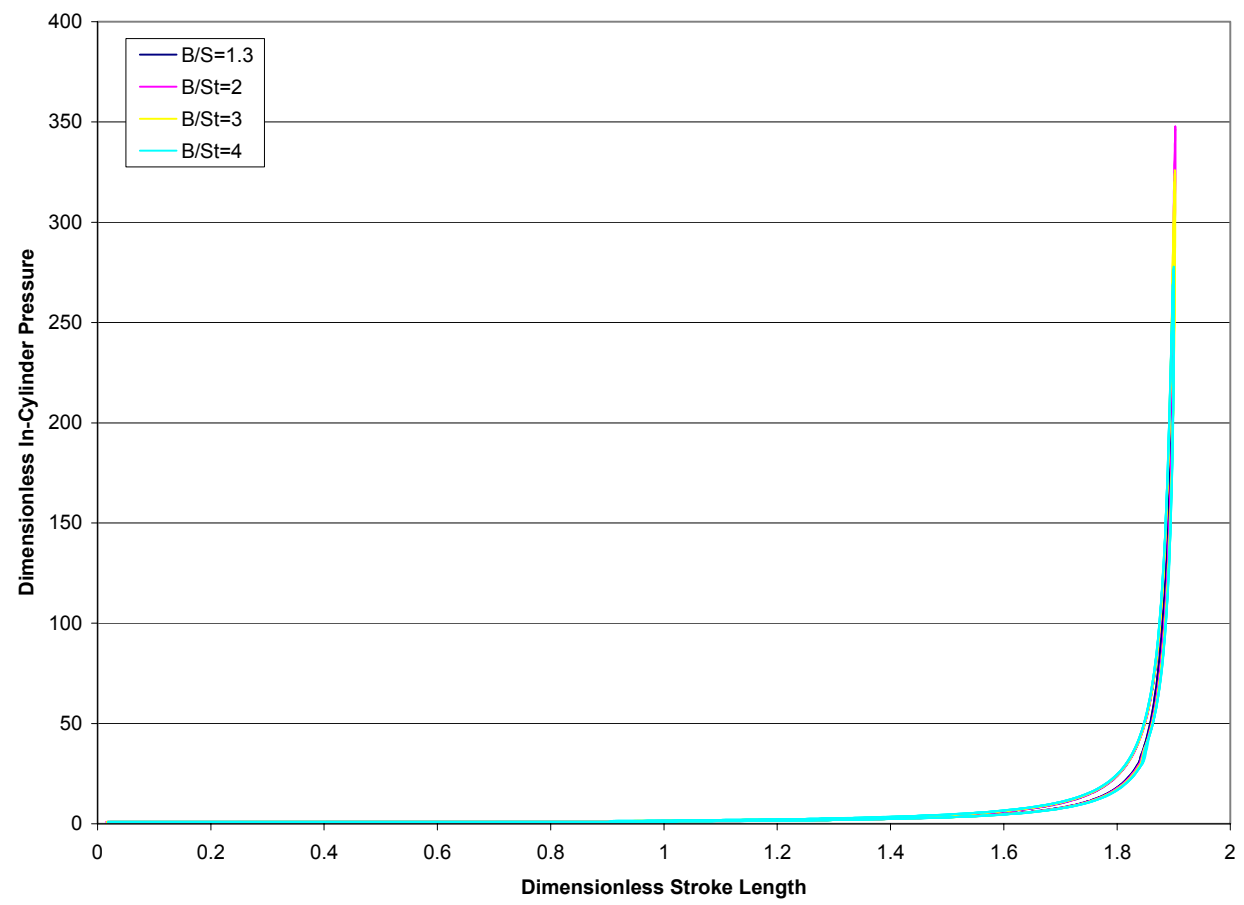

Figure 6.58. Dimensionless In-Cylinder Pressure Versus Dimensionless Stroke Length for Lambda $=3$, Ca1, and Injection Position $=0.018$ 


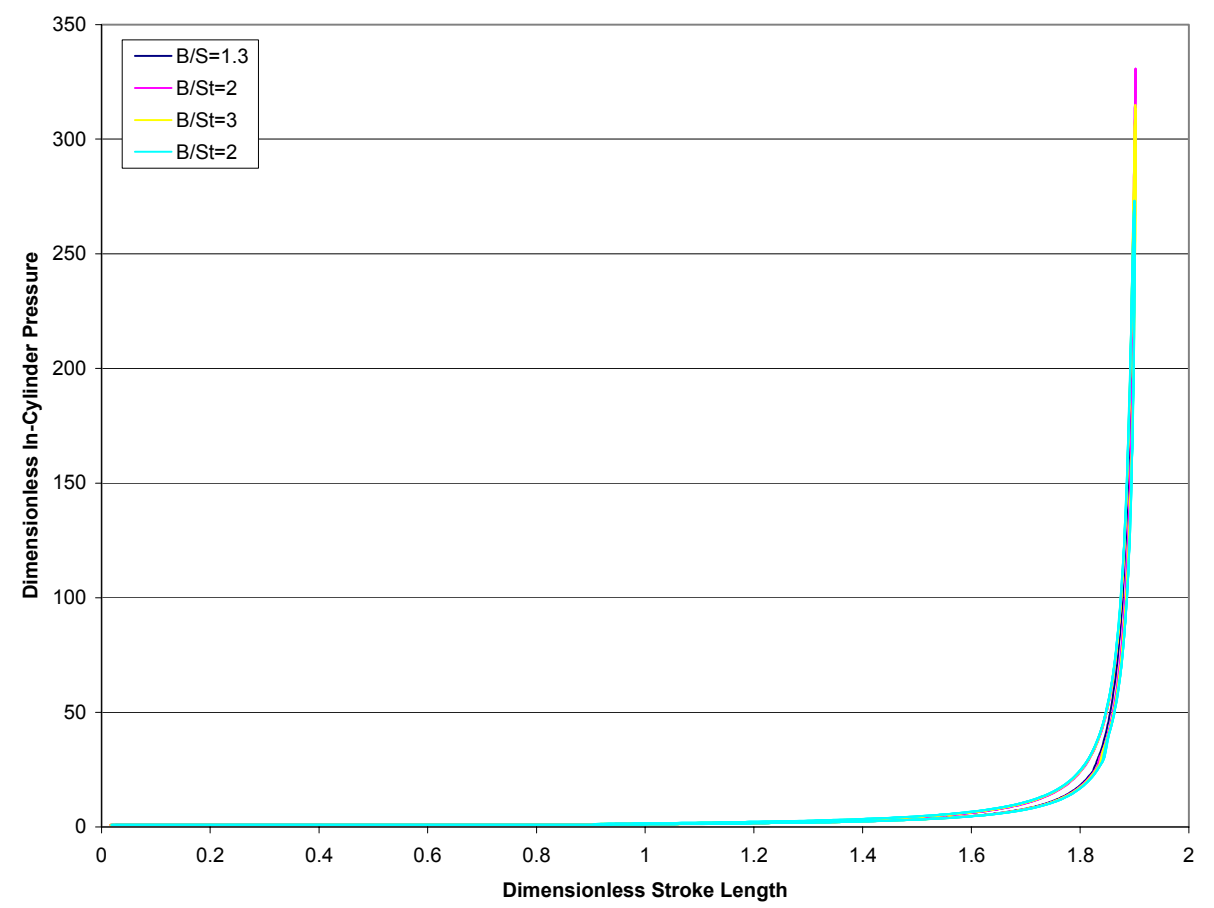

Figure 6.59. Dimensionless In-Cylinder Pressure Versus Dimensionless Stroke Length for Lambda=3, Ca1, and Injection Position=0.19

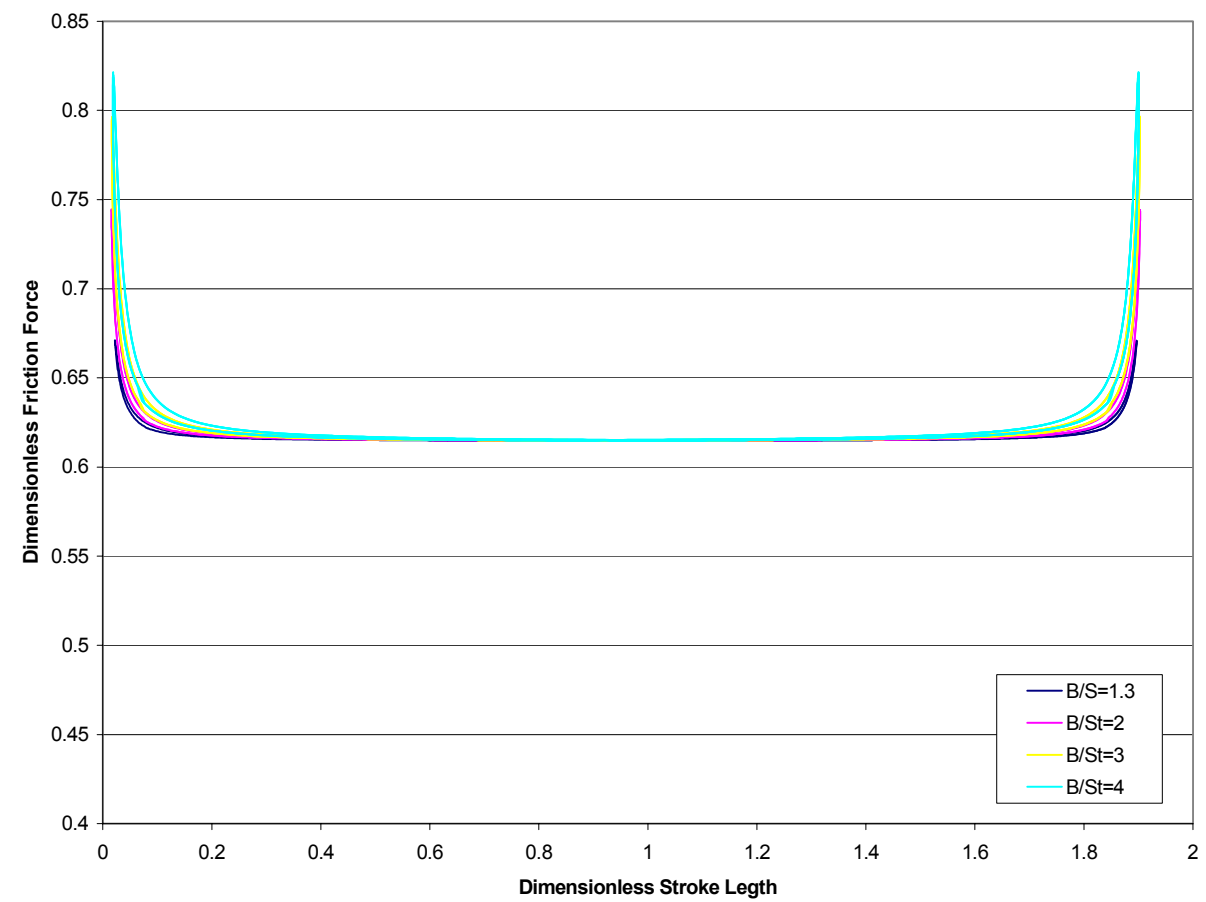

Figure 6.60. Dimensionless Friction Force Versus Dimensionless Stroke Length for Lambda=3, Ca1, and Dimensionless Injection Position $=\mathbf{0 . 0 1 8}$ 


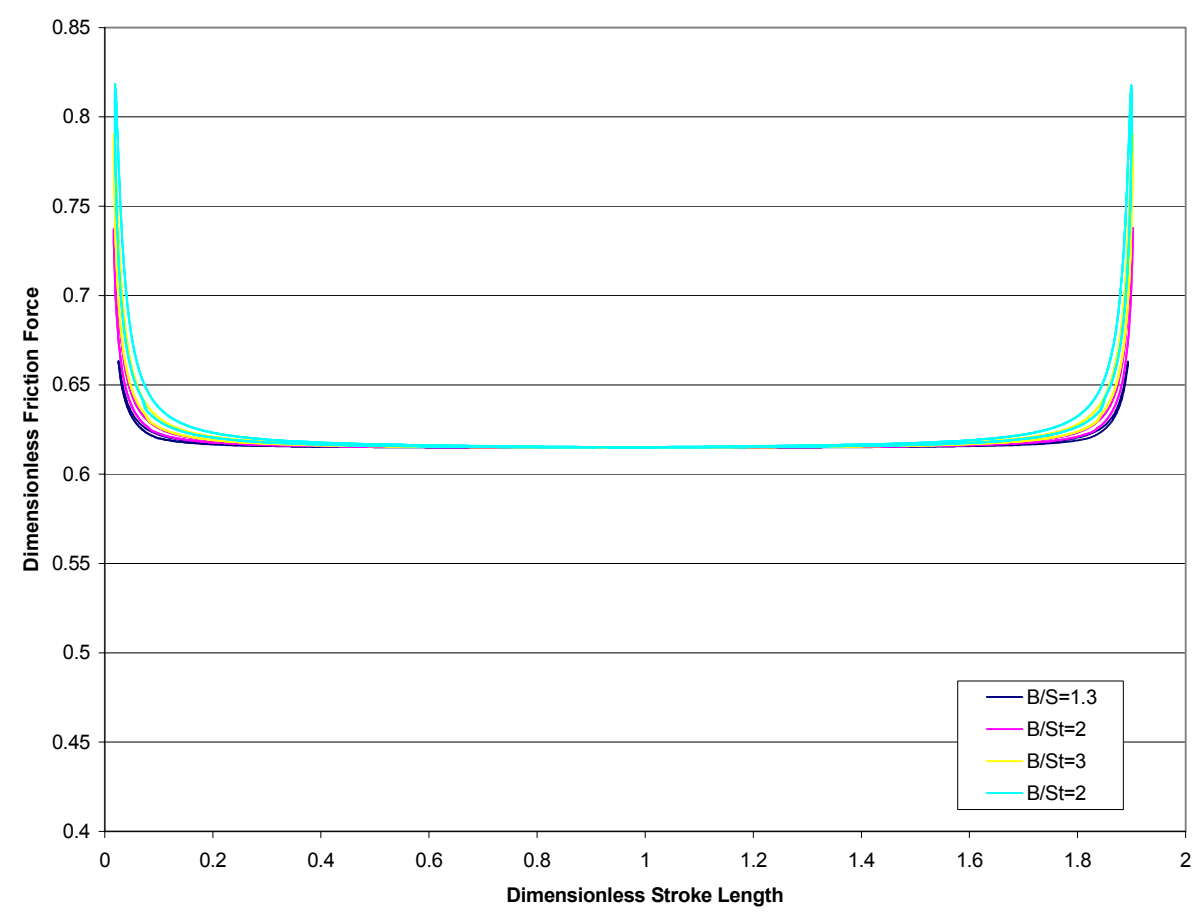

Figure 6.61. Dimensionless Friction Force Versus Dimensionless Stroke Length for Lambda=3, Ca1, and Dimensionless Injection Position $=\mathbf{0 . 1 9}$

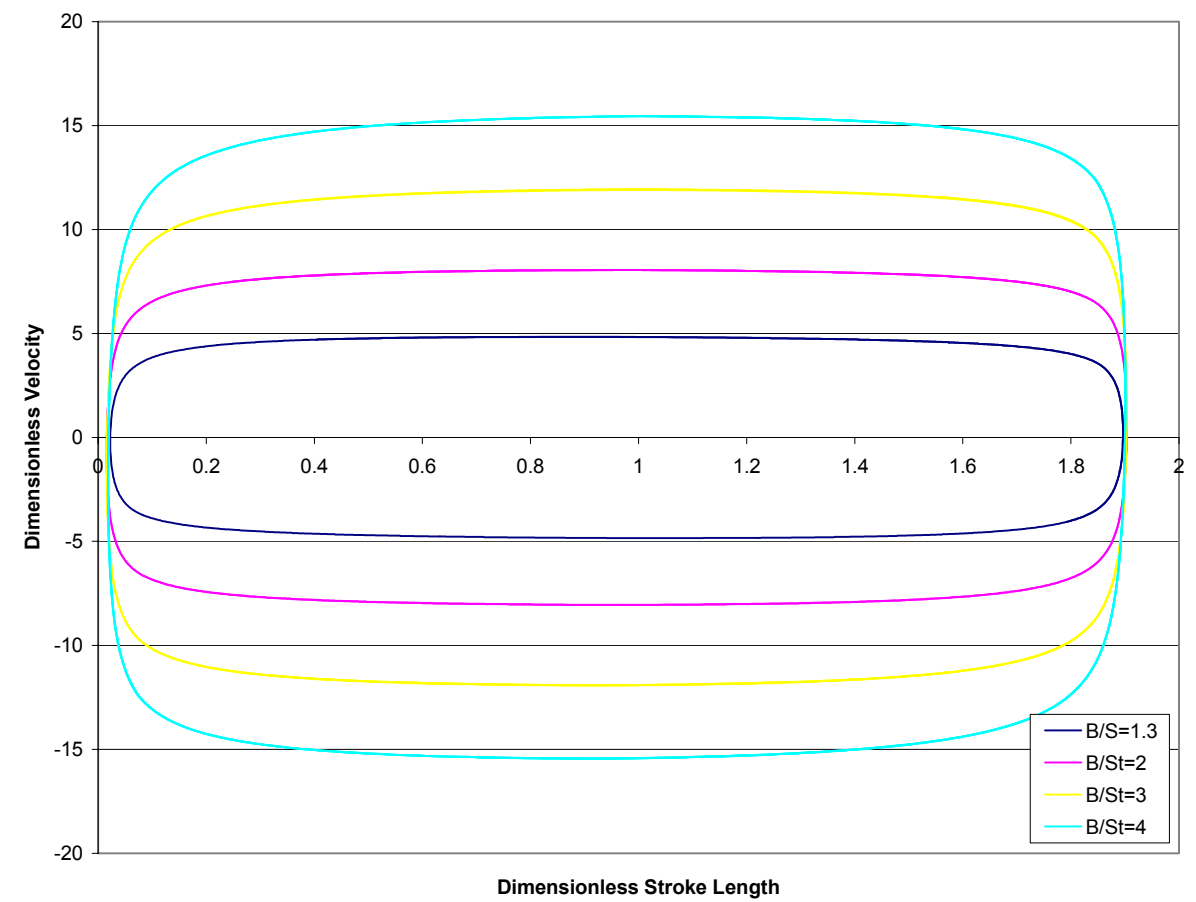

Figure 6.62. Dimensionless Velocity Versus Dimensionless Stroke Length for Lambda=3, Ca1, and Dimensionless Injection Position $=\mathbf{0 . 0 1 8}$ 


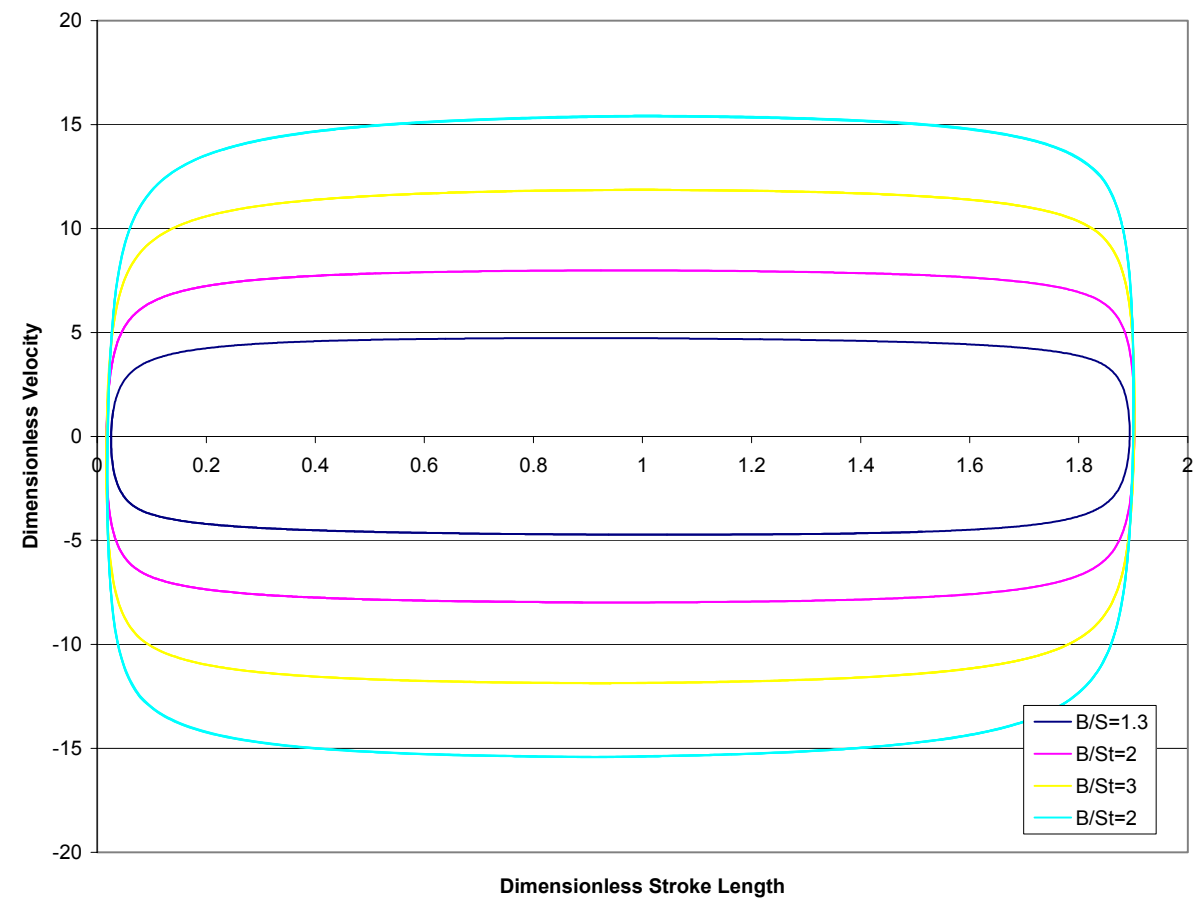

Figure 6.63. Dimensionless Velocity Versus Dimensionless Stroke Length for Lambda=3, Ca1, and Dimensionless Injection Position =0.19

Figures 6.64 and 6.65 show the compression ratio versus bore to effective stroke length. It can be seen that for dimensionless injection position of 0.19 the corresponding compression ratios of lambda four and five with effective bore to stroke length of 1.3 were dropped significantly compared to previous runs shown in Figures 6.8 and 6.26. In addition, it was noticed that for bore to effective stroke length equal to 1.3 compression ratio values for lambda equal to four were almost the same as the values of lambda equal to five as shown in Figure $6.65^{6}$.

\footnotetext{
${ }^{6}$ For more runs see appendix D
} 


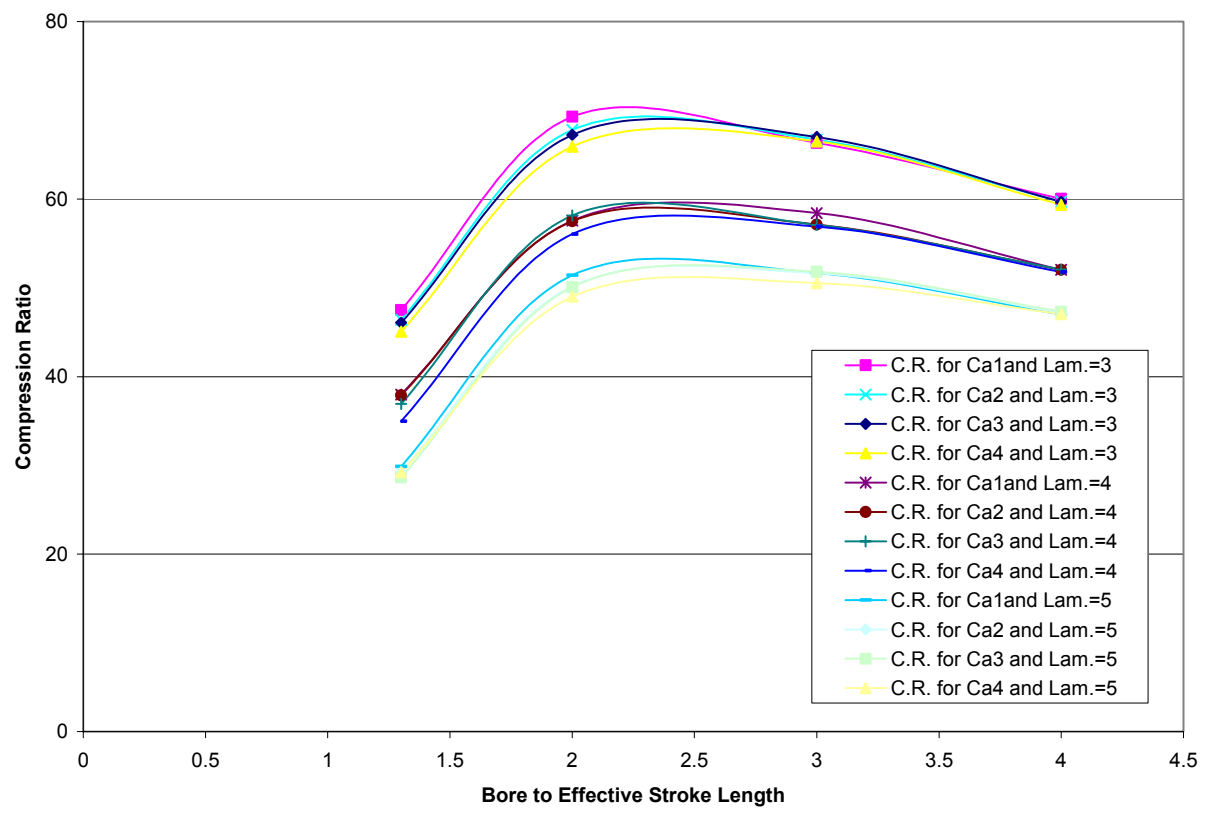

Figure 6.64. Compression Ratio Versus Bore to Effective Stroke for Different Lambda, Different Dimensionless Load Constants, and Dimensionless Injection Position=0.081

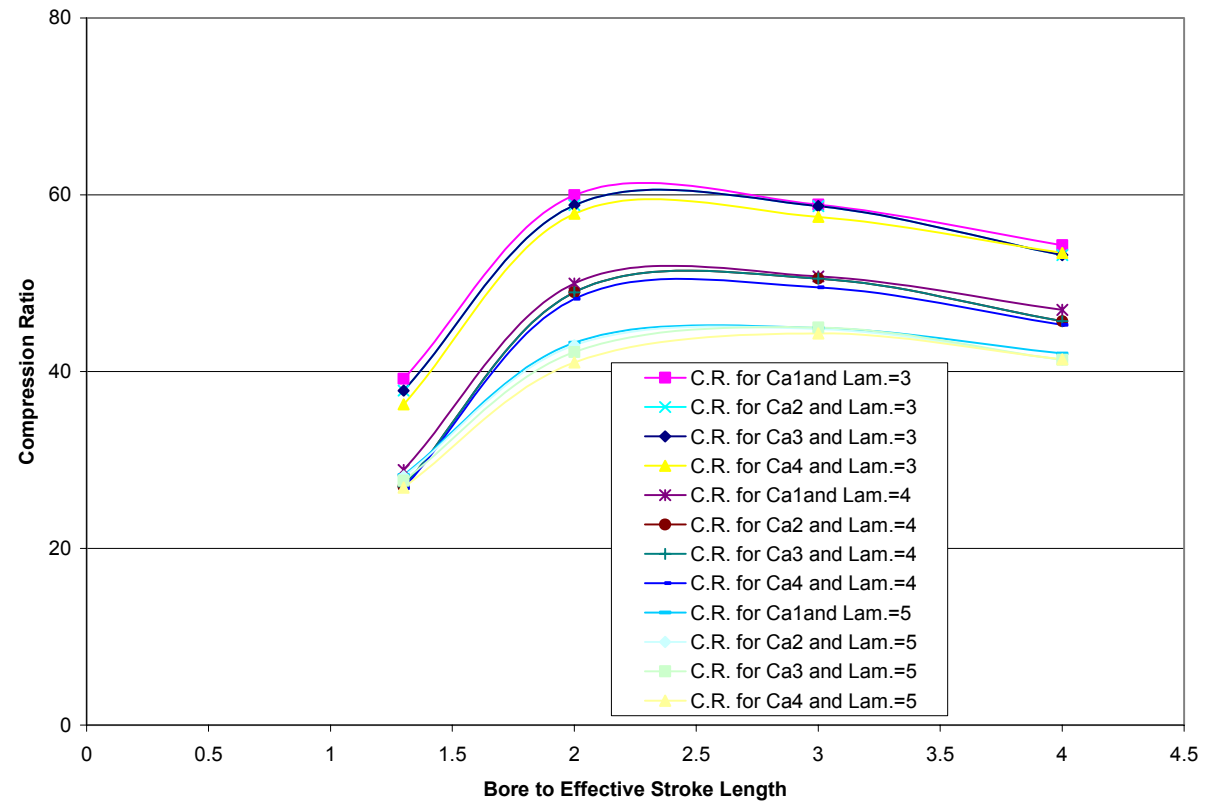

Figure 6.65. Compression Ratio Versus Bore to Effective Stroke for Different Lambda, Different Dimensionless Load Constants, and Dimensionless Injection Position=0.19 


\section{SUMMARY OF THE EFFECT OF COMBUSTION DISTRIBUTION:}

Changing the percentage of combustion distribution of premixed combustion and diffusive combustion from $20 \%$ and $80 \%$ to be $40 \%$ and $60 \%$ respectively for a bore to effective stroke length of 1.3 to 4 , lambda $=3,4$, and 5 , and dimensionless injection position $=0.081$ resulted in:

- Decreasing the dimensionless indicated power.

- Decreasing the dimensionless average piston speed.

- Decreasing the dimensionless frequency.

- Decreasing the indicated efficiency.

- Decreasing the compression ratio.

- Decreasing the dimensionless in-cylinder pressure.

- Decreasing the dimensionless friction force.

- Decreasing the dimensionless energy per generator volume.

- Decreasing the dimensionless indicated power per cylinder volume.

- Decreasing the dimensionless indicated power per generator mass.

- Decreasing the dimensionless energy per generator mass. 


\subsection{EXPLORING OUTSIDE THE DIMENSIONLESS ANALYSIS MATRIX}

It was decided to explore the performance of the two-stroke compression ignition linear engine outside the matrix illustrated in Table 6.1 using the same dimensionless technique used in this study. Figure 6.66 shows the indicated efficiency and the compression ratio versus bore to effective stroke for lambda equal to 3 , Ca1, premixed combustion to diffusive combustion $20 \%$ to $80 \%$, and dimensionless injection position equal to 0.081 . The reason behind using extreme design figures, like bore to effective stroke length of five, even though these ratios are not used for commercial diesel engines, was to explore the performance of the two-stroke compression ignition linear engine and to find out the best design value for bore to effective stroke length. Also, small increment increase was used to make sure that there were not hidden peaks along the bore to effective stroke length range that had been used for testing the two-stroke compression ignition linear engine. The reason behind choosing lambda equal to three to explore outside the parametric study matrix was that it was hard to start up the two-stroke compression ignition linear engine with higher lambda and a bore to effective stroke length less than 1.3. In addition, choosing the dimensionless injection position of 0.081 and premixed combustion to diffusive combustion $20 \%$ to $80 \%$, was because injecting the fuel while the piston is far from cylinder head during compression stroke and using a higher premixed combustion ratio resulted in deteriorating the two-stroke compression ignition linear engine performance as explained before.

Figure 6.66 shows that the maximum value of the efficiency occurred with bore to effective stroke length of one. Also, it can be seen that the compression ratio dropped for this particular design value to be almost thirty. In addition it can be seen that there were not any peaks, sudden increase or decrease for the indicated efficiency or the 
compression values inside investigated matrix, which means that the curves that were presented earlier in this chapter were correct and there were not hidden peaks, sudden increase or decrease along the range of bore to effective stroke length presented in this study $^{7}$.

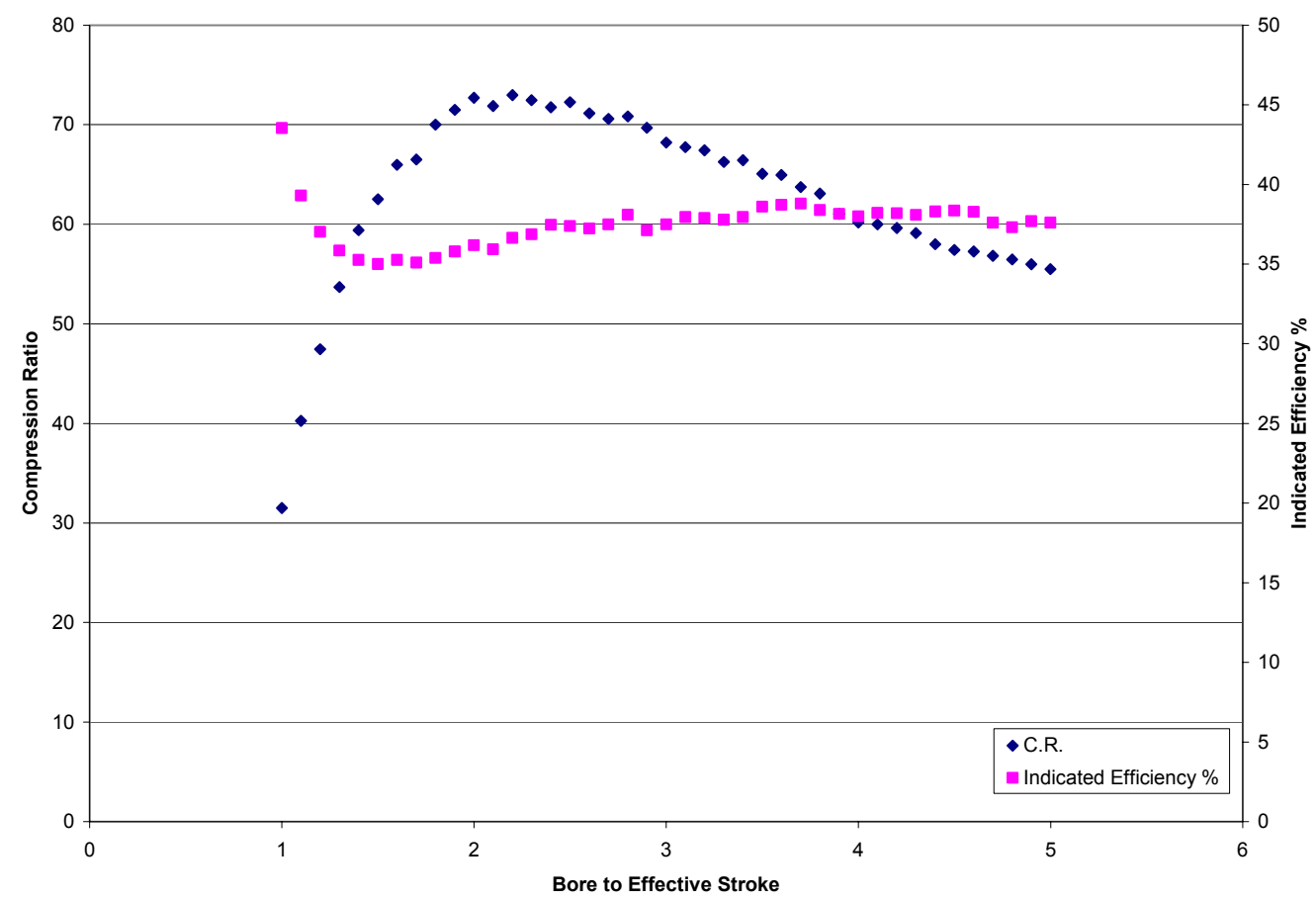

Figure 6.66 Compression Ratio and Indicated Efficiency Versus Bore to Effective Stroke Length for Lambda $=3$, Ca1, and Dimensionless Injection Position $=0.081$

\footnotetext{
${ }^{7}$ For more runs see appendix $\mathrm{E}$
} 


\subsection{GLOBAL OPTIMUM RELATIONSHIP BETWEEN DIMENSIONLESS INDICATED POWER PER GENERATOR MASS AND INDICATED EFFICIENCY}

It was decided to correlate the dimensionless indicated power per generator mass with the indicated efficiency. The idea behind this was to study what are the parameters affecting such a relationship. The injection timing and combustion distribution factors in this case were not included as variables. The reason behind this was that we know that injecting the fuel while the piston is far from cylinder head during compression stroke and increasing premixed combustion to be $40 \%$ would deteriorate the two-stroke linear engine performance. The runs with closer injection to cylinder head and lower premixed combustion percentage were considered only ${ }^{8}$. In other words, dimensionless injection timing was kept at 0.081 . The premixed combustion and diffusive combustion ratio were $20 \%$ and $80 \%$ respectively.

The data previously obtained were used to correlate the dimensionless indicated power per generator mass with indicated efficiency. Figures 6.67 and 6.68 show the relation between them dimensionless load constant $\mathrm{Ca} 1$ and $\mathrm{Ca} 4$, different lambda, and different bore to effective stroke length.

The figures show that increasing the dimensionless load constant and lambda result in higher indicated efficiency. The figures also show that maximum indicted efficiency took place with dimensionless indicated power per generator mass of an average of 0.83 and lambda $=5$. Needless to say the bore to effective stroke effect is within the dimensionless mass term of dimensionless indicated power per generator mass.

\footnotetext{
${ }^{8}$ Sections 6.3 .1 and 6.4 .1
} 


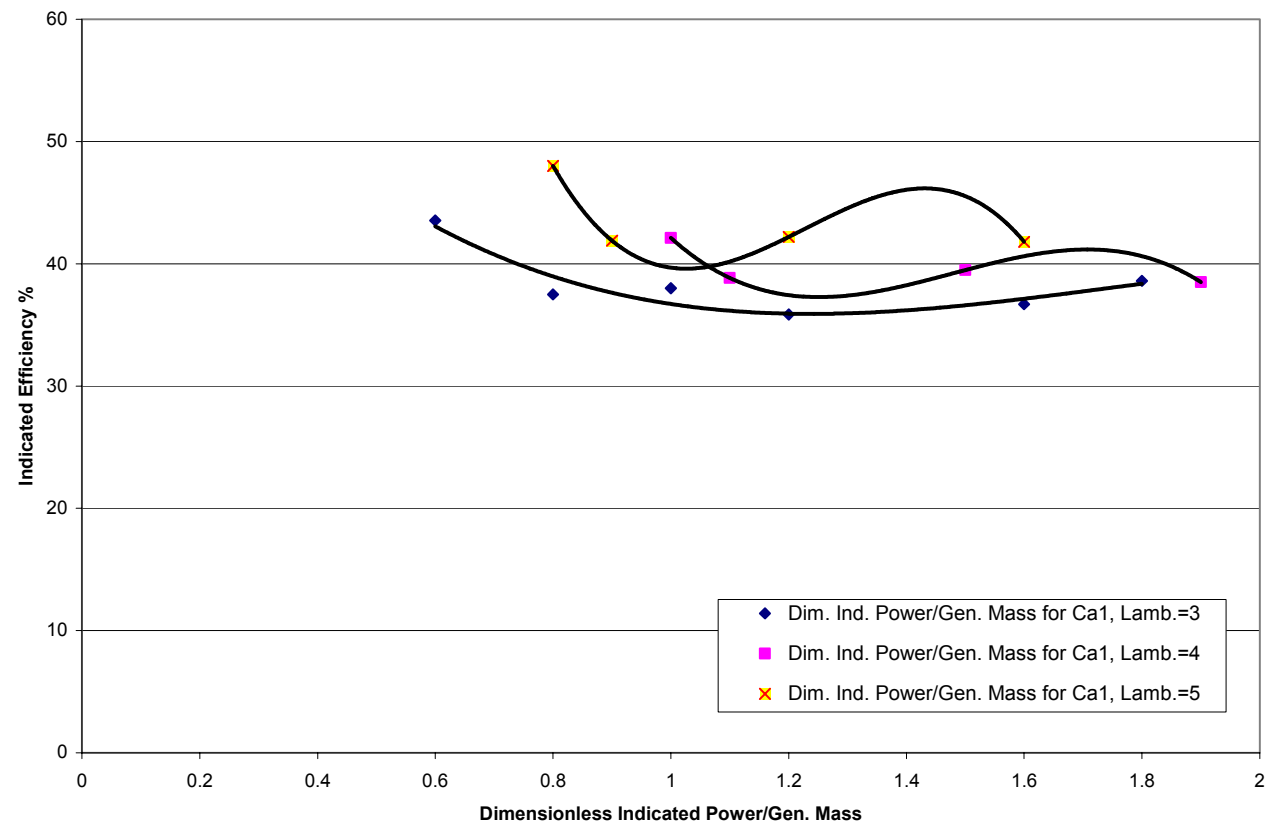

Figure 6.67 Indicated Efficiency Versus Dimensionless Indicted Power per Generator Mass for Ca1, Different Lambda and Different Bore to Effective Stroke Length

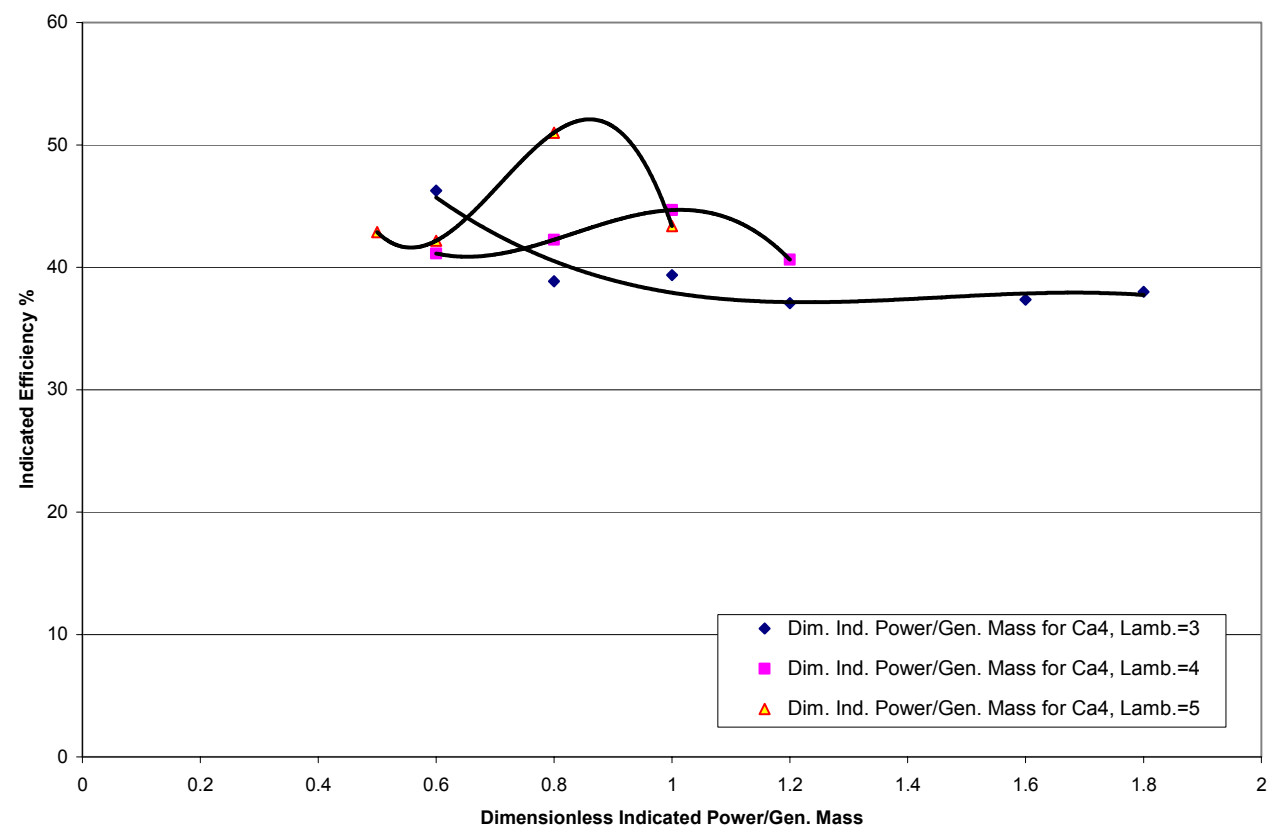

Figure 6.68 Indicated Efficiency Versus Dimensionless Indicted Power per Generator Mass for Ca4, Different Lambda and Different Bore to Effective Stroke Length 


\subsection{DIMENSIONLESS ANALYSIS CHECK}

As a check for the dimensionless analysis technique used in the dissertation, it was decided to check the output results by changing some values like moving assembly mass and stroke effective length and compare the new output results with the obtained ones. Of course related dimensionless numbers like dimensionless time number was changed for each case to be used with the new study. For both cases dimensionless input energy was kept constant. The first case the moving mass assembly was changed to be 2 $\mathrm{kg}$, while in the second case the effective stroke length was changed to be $50 \mathrm{~mm}$.

Figures 6.69 and 6.70 show the dimensionless frequency versus bore to effective stroke length. It can be seen that both trials showed agreement with previously obtained results in Figure 6.21.

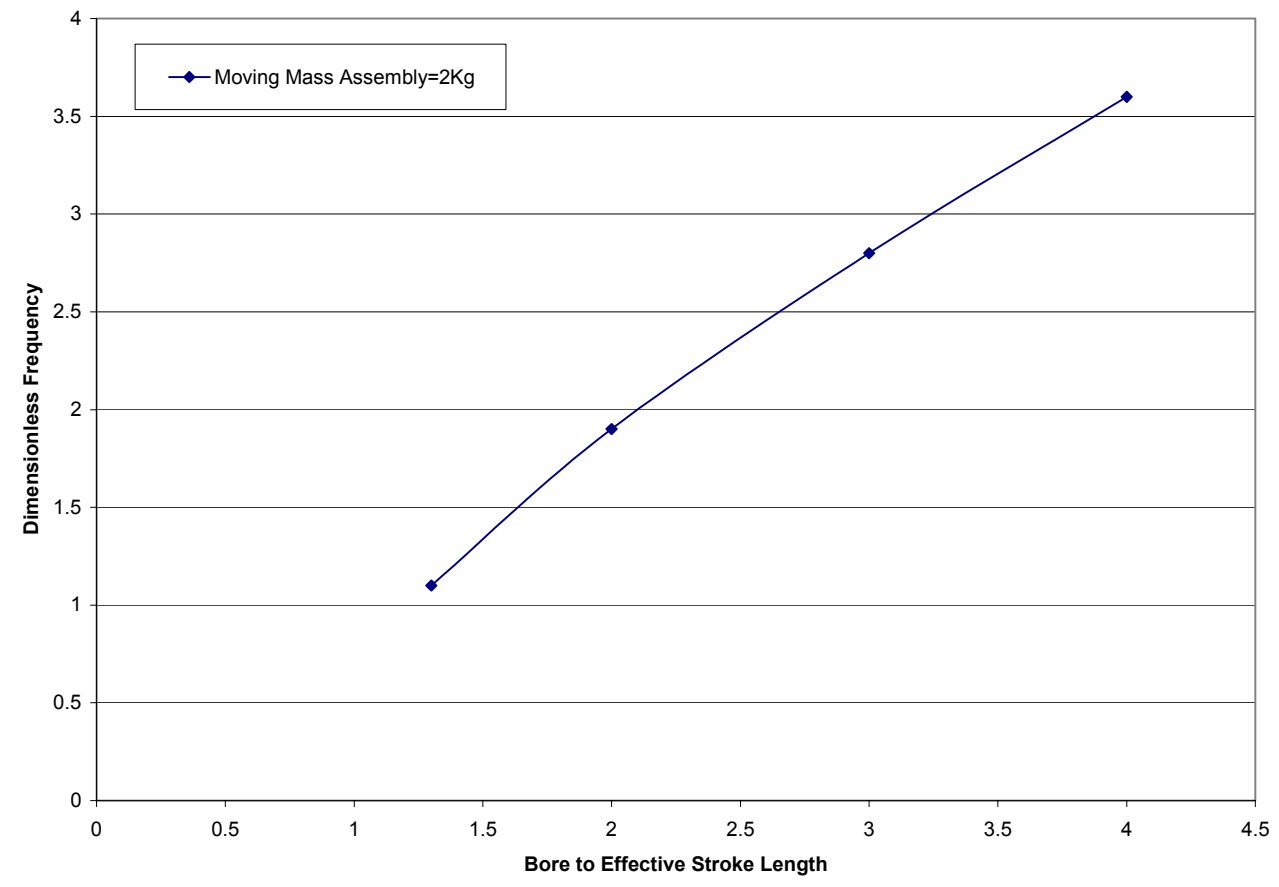

Figure 6.69. Dimensionless Frequency Versus Bore to Effective Stroke Length for Ca1, Lambda=5, and Dimensionless Injection Position $=\mathbf{0 . 0 8 1}$ 


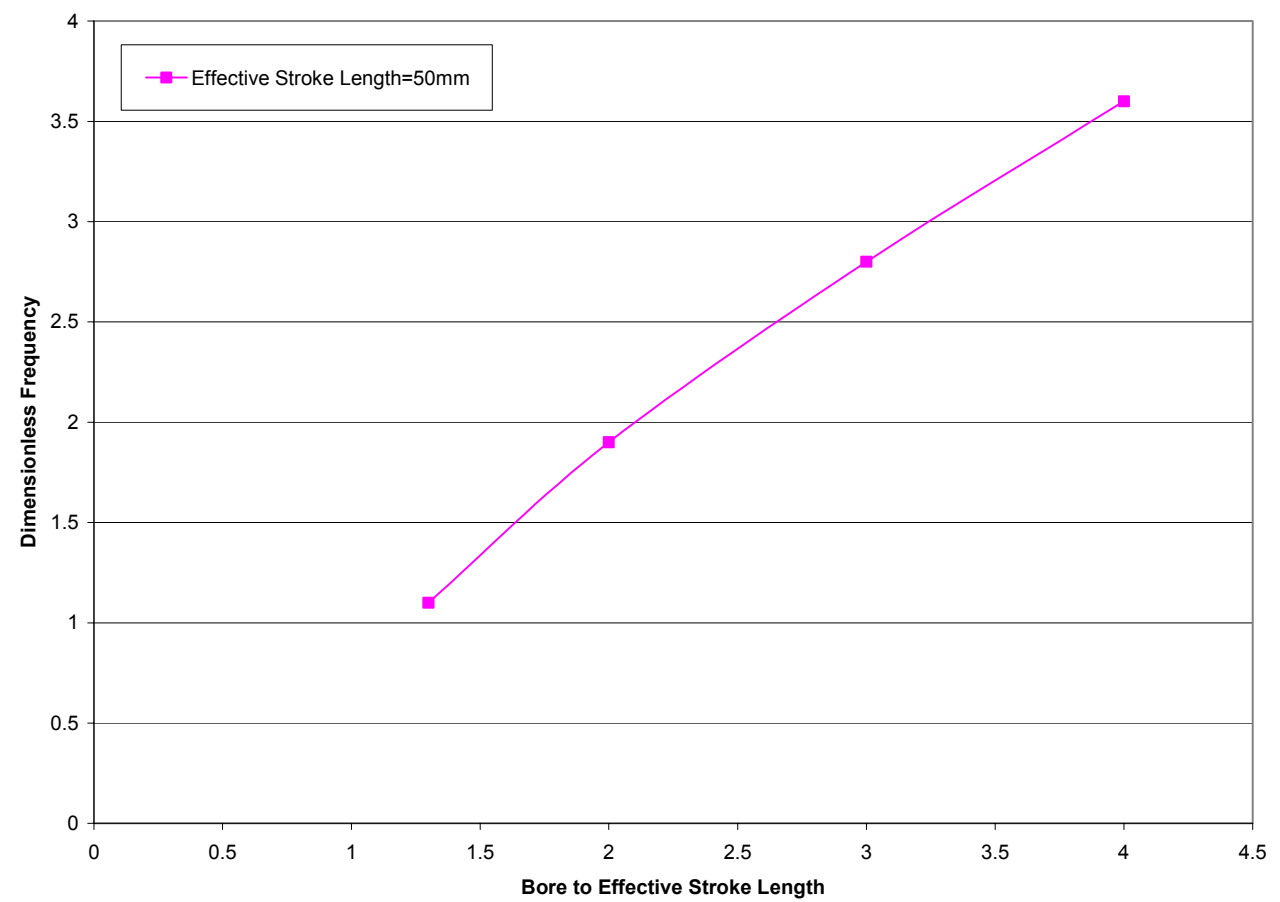

Figure 6.70. Dimensionless Frequency Versus Bore to Effective Stroke Length for Ca1, and Dimensionless Injection Position=0.081 


\subsection{COMPARISON BETWEEN THE MASSES OF TWO-STROKE COMPRESSION IGNITION LINEAR ENGINE/ALTERNATOR WITH THE MASS OF LEAD ACID BATTERIES}

It was decided to compare the output power related to the mass of a two-stroke compression ignition linear engine generator with the mass of commercial lead acid batteries. A commercial lead acid battery mass is about 63.1 pounds, $28.4 \mathrm{~kg}$, and would give a $1.1 \mathrm{~kW}, 12$ volts at $92 \mathrm{Amp}$ [51]. The battery would work continuously for 20 hrs. The battery output power was compared with the output power of different twostroke compression ignition linear engine with bore to effective stroke of two and dimensionless load constant Ca4. Bore to effective stroke of two was chosen, as this was the best case for dimensionless indicated power per generator mass as shown in Figure 6.16 .

Figure 6.71 shows the result that after 7.5 operation hours it was better to use a generator rather than acid lead batteries.

Figure 6.72 shows the comparison between a battery of 12 volts and 55 Amp. with a diesel engine of $0.7 \mathrm{~kW}$ indicated power, bore to effective stroke of one. The battery weight was 39 pounds, $17.6 \mathrm{~kg}$, and it would work continuously for 20 hours [51]. The ratio of bore to effective stroke of one was chosen as this was the lowest value of dimensionless indicated power per generator mass. The figure shows that it was more convenient to use batteries for up to 47.5 hours continuous operation. In other word in case of need for a longer operation time than 47.5 hours it was more convenient to use a two-stroke compression ignition linear engine. 


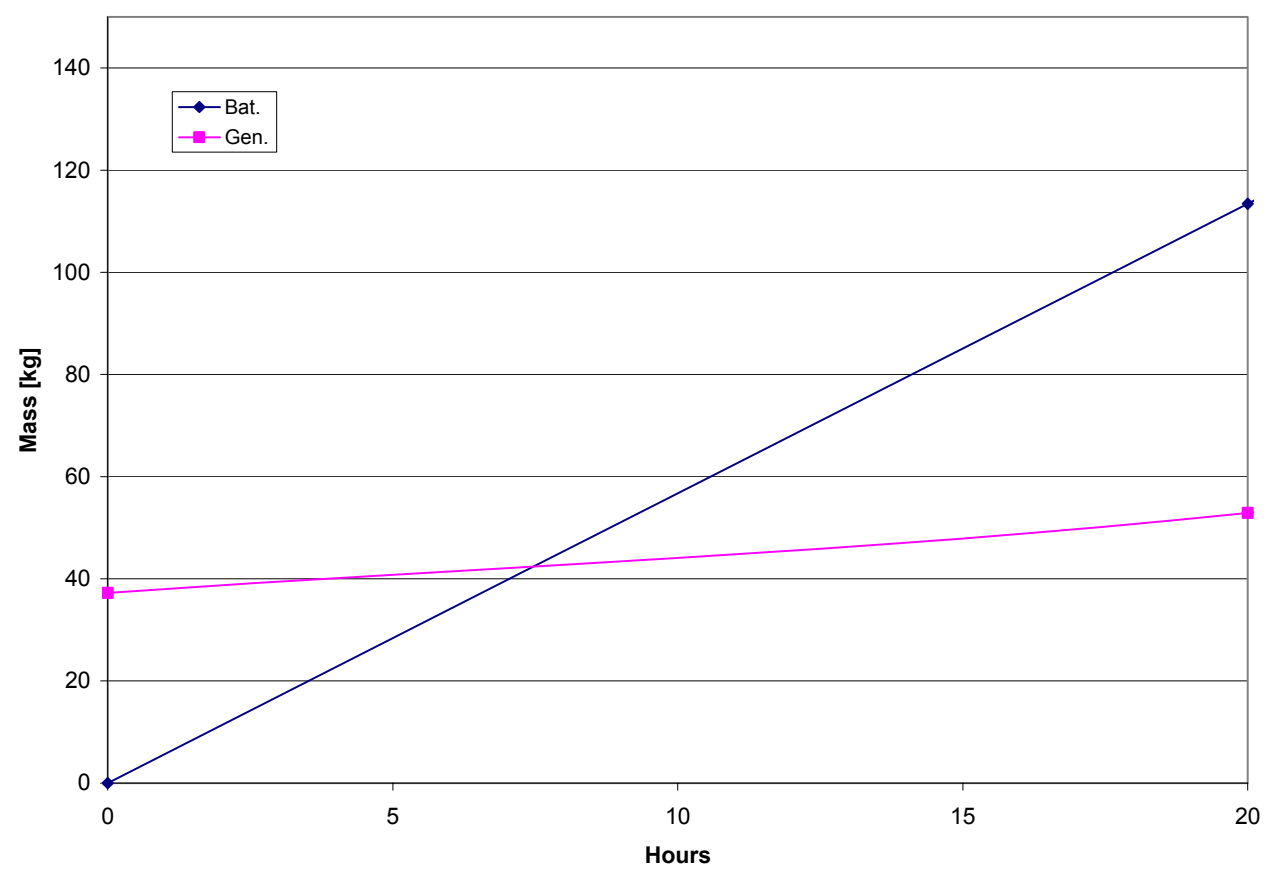

Figure 6.71. Comparison Between the Mass of $4.4 \mathrm{~kW}$ Two-Stroke Compression Ignition Linear Engine and the Mass of Lead Acid Batteries

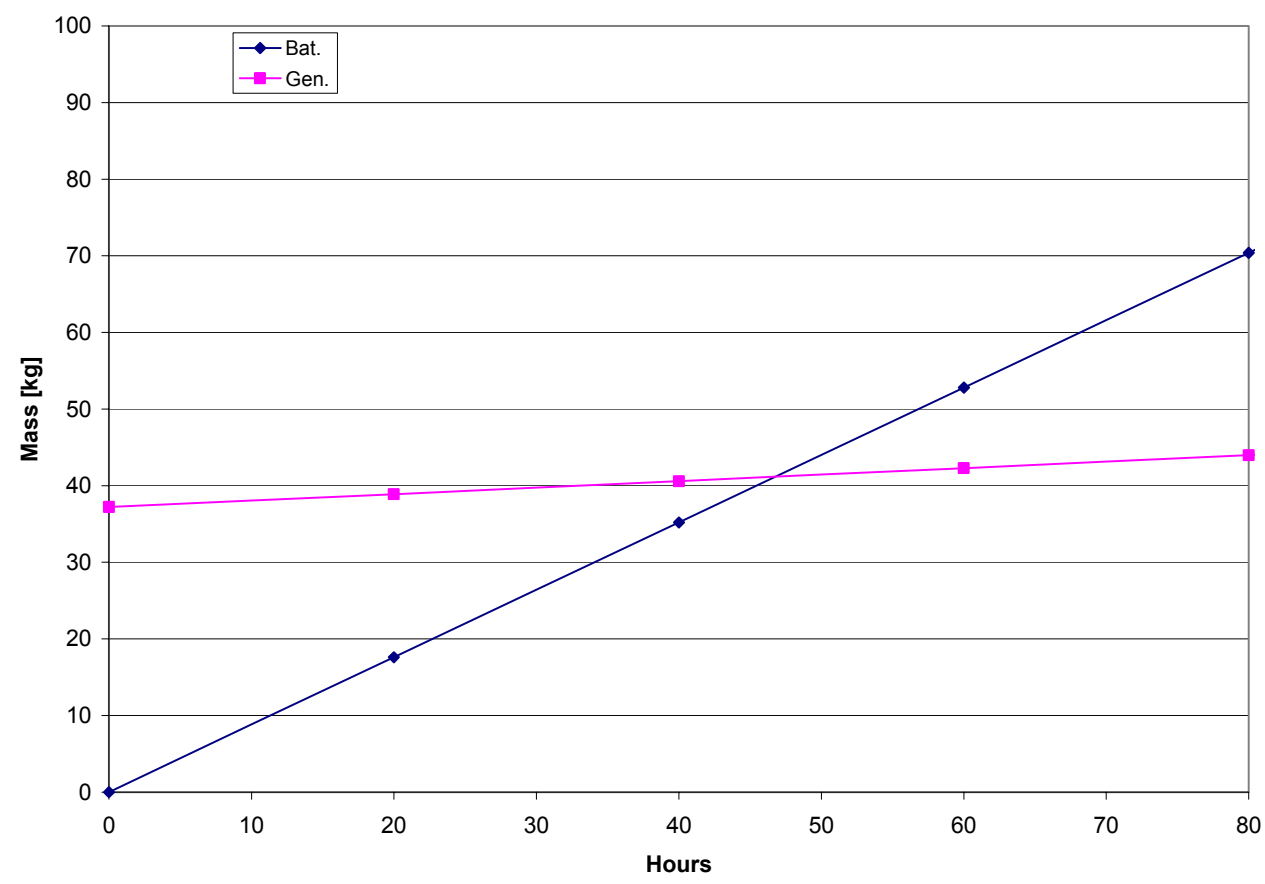

Figure 6.72. Comparison Between the Mass of $0.7 \mathrm{~kW}$ Two-Stroke Compression Ignition Linear Engine and the Mass of Lead Acid Batteries 


\section{7-CONCLUSIONS}

The objective of this dissertation was to explore the benefits of the two-stroke compression ignition linear engine coupled with a linear alternator and find out its best operating conditions using the dimensionless analysis technique. A numerical simulating model was built for this purpose.

It has been found that the moving assembly mass has a great affect on engine frequency and compression ratio. It is highly recommended to use a lighter material in designing the moving assembly mass.

Also, it has been found that there was not a case that combined highest power output and highest indicated efficiency per stroke. This was because the major factor that controlled the highest power output was the frequency or the engine speed, which resulted in high output power. On the other hand the cases of lower frequency or lower speed resulted in higher indicated efficiency per stroke. For the purpose of stationary power generation a bore to effective stroke length of 1.3, and a high air to fuel ratio, lambda equal to five, would be used. This would result in a high-indicated efficiency up to $52 \%$ and a relatively low dimensionless indicated power per generator mass, which for a stationary power generation application sometimes does not matter. The highest industrial recorded indicated efficiency is just over $50 \%$ for, $50 \mathrm{MW}$ unit, two-stroke stationary power stations manufactured by Man B\&W [52], or as reported about the marine two-stroke diesel engine which is called "cathedral engine" [2].

For another application like transportation or mobile power generation application, a bore to effective stroke length of three or four and a low air to fuel ratio, like lambda equal to three would be used. This would result in a high dimensionless 
indicated power, a high dimensionless indicated power per cylinder volume, and a low dimensionless energy released per generator mass. Even though, a bore to effective stroke length of 2.2 resulted in highest indicated power per generator mass this engine dimension resulted in highest compression ratio that made such a design limited to special application and not for commercial one.

The study also revealed that the two-stroke linear engine is a type of internal combustion engines that has a tendency to build up compression ratio, which can result in complicating the engine design and high heat transfer rate. However, the air to fuel ratio is a major factor that can be used not only to operate the two-stroke linear engine with a high indicated efficiency, over $50 \%$ but with a low compression ratio as well, close to the normal operating conditions of the commercial two-stroke diesel engine. It has also been found that the increasing indicated efficiency depends on increasing the air to fuel ratio, lambda, and the dimensionless alternator load.

In general, the two-stroke compression ignition direct injection linear engine offered a high indicated efficiency of $42 \%$ as an average over a wide range of air to fuel ratio. In addition, a high indicated power per cylinder volume of an average of 23 $\mathrm{kW} /$ liter for air to fuel ratio, lambda equal to three. This gives the two-stroke compression ignition linear engine the credibility to work efficiently over a wide range of air to fuel ratio.

Also, it has been discovered that the indicated efficiency is increasing with the increase of the dimensionless load constant and lambda. Highest indicated efficiency occurred with dimensionless indicated power per generator mass of about 0.83 .

For all application purposes injecting the fuel close to the cylinder head during 
compression stroke and increase the premixed combustion ratio to be as close as to $20 \%$ would result in enhancing the indicated efficiency and the indicated power of the twostroke compression ignition direct injection linear engine relative to injecting the fuel far from the cylinder head during compression stroke and increase the premixed combustion to diffusive combustion ratio to be $40 \%$ to $60 \%$ respectively. 


\section{8-RECOMMENDATION FOR FUTURE WORK}

A prototype model of a two-stroke compression ignition linear engine of bore equal to effective stroke length, could be an interesting subject to investigate experimentally. Results taken from the experimental model could be compared with the numerical simulating model for verification. Further research on the electrical side for the linear generator can be used coupled with the numerical simulation program of the two-stroke compression ignition direct injection linear engine for further improvement of the indicated efficiency of this novel type of compression ignition linear engines. 


\section{REFERENCES}

[1] Blair, G., "The Basic Design of Two-Stroke Engines," Society of Automotive Engineers, Inc., Warrendale, PA, 1990.

[2] Cleveland Diesel Engine Division, "History and Description of the Free Piston Engine-Gas Turbine Power," (author unknown to GM), 1957.

[3] Goldsborough, S., "A Numerical Investigation of a Two-Stroke Cycle, HydrogenFueled, Free Piston Internal Combustion Engine," Thesis, Colorado State University, 1998.

[4] Atkinson, C., Petreanu, S., Clark, N., Atkinson, R., McDaniel, T., Nandkumar, S., and Famouri, P., "Numerical Simulation of a Two-Stroke Linear Engine-Alternator Combination," SAE 990921, 1999.

[5] Underwood, A., “GMR 4-4 Hyprex Free-Piston Turbine Engine,” SAE Paper, Volume 64, pp. 60-66, 1956.

[6] Frey, D., Klotsch, P., and Egli, A., "The Automotive Free Piston-Turbine Engine," SAE Paper, Volume 65, pp. 628-634, 1957.

[7] Galitello, K., “Two Stroke Cycle Engine,” U.S. Patent No. 4,876,991, 1989.

[8] Bock, R., "Gas Cushioned Free Piston Type Engine," U.S. Patent No. 4,128,083, 1978.

[9] Reitz, D., “Bourke Type Engine,” U.S. Patent No. 4,103,048, 1977.

[10] Cinquegrani, V., "Self-Supercharging Dual Piston Engine Apparatus," U.S. Patent No. $4,185,597,1980$. 
[11] Rittmaster, P. and Booth, J., "Hydraulic Engine,” U.S. Patent No. 4,326,380, 1982.

[12] Hientz, R., “Free Piston Engine Pump,” U.S. Patent No. 4,369,021, 1983.

[13] Allais, E., "Free Piston Engine with Operatively Independent Cam," U.S. Patent No. 4,480,599, 1984.

[14] Nerstorm, J., "Two-Cycle Internal Combustion Engine Including Means Varying Port Timing,” U.S Patent No. 4,516,540, 1985.

[15] Deng, Y. and Deng, K., "Free Piston Engine without Compressor," U.S. Patent No. 4,924,956, 1990.

[16] Iliev, M., Kervanbashiev, S., and Makednski, F., "Method and Apparatus for Producing Electrical Energy from a Cyclic Combustion Process Utilizing Coupled Pistons which Reciprocate in Unison,” U.S. Patent No. 4,532,431,1985.

[17] Kos, J., “Free Piston Engine Without Compressor,” U.S. Patent No. 4,924,956, 1990.

[18] Ramos, J., "Internal Combustion Engine Modeling,” Hemisphere Publishing Corporation, Pittsburgh, PA, 1989.

[19] Singh, T. and Surakomol, K., "Mathematical Modeling of Combustion Process in a Spark-Ignition Engine,” SAE Paper 790354, 1979.

[20] Reynolds, C., "Modeling of Fluid Motions in Engines-An Introductory Overview," Seventeen Symposium on Combustion Modeling in Reciprocating Engines, The Combustion Institute, pp. 41-68, 1980.

[21] Westbrook, K. and Dryer, L., "Chemical Kinetic Modeling of Combustion Processes," Eighteenth Symposium (international) on Combustion, The Combustion Institute, pp. 749-767, 1981. 
[22] Westbrook, K. and Dryer, L., "Chemical Kinetic Modeling of Hydrocarbon Combustion," Progress in Energy and Combustion Science, 10, pp. 1-57, 1984.

[23] Borman, G. and Nishiwaki, K., "Internal-Combustion Engine Heat Transfer," Progress in Energy and Combustion Science, 13, pp. 1-46, 1987.

[24] Pope, S.,"Computations of Turbulent Combustion: Progress and Challenges," Twenty-Third Symposium (International) on Combustion, The Combustion Institute, pp. 591-612, 1990.

[25] Raine, R., Stone, R., and Gould, J., "Modeling of Nitric Oxide Formation in SparkIgnition Engines with a Multizone Burned Gas," Combustion and Flame, 102, pp. $241-255,1995$.

[26] Olson, R., "Simulation of a Free Piston Engine,” SAE Paper 580267, 1958.

[27] Streit, E., and Borman, L., "Mathematical Simulation of Spark-Ignition Engine,"SAE Paper 730053, 1973.

[28] Lucas, G. and James, H., “A Computer Simulation of a Spark-Ignition Engine,” SAE Paper 730053, 1973.

[29] Benson, S. and Baruah, C., "Simulation Model for a Crankcase-Compression TwoStroke Spark-Ignition Engine Including Intake and Exhaust Systems," Proceedings of the Institution of Mechanical Engineers, 189, pp. 167-175, 1975.

[30] Heywood, J., "Parametric studies of Fuel Consumption and NO Emissions of Dilute Spark-Ignition Engine Operation Using a Cycle Simulation," Institute of Mechanical Engineers Conference Publication C98/79, pp. 117-127, 1979.

[31] Heywood, J., Higgins, J., Watts, P., and Tabaczynski,R., "Development and Use of a 
Cycle Simulation to Predict SI engine Efficiency and $\mathrm{NO}_{\mathrm{X}}$ Emission," SAE Paper 790291, 1979.

[32] Natarajan, B. and Bracco, F., "On Multidimensional Modeling of Auto-Ignition In Spark-Ignition Engines," Combustion and Flame, 57, pp. 179-197, 1984.

[33] Leppard, R., "A Detailed Chemical Kinetics Simulation of Engine Knock," Combustion Science and Technology," 43, pp. 1-20, 1985.

[34] Schapertons, H. and Lee, W., "Multidimensional Modeling of Knocking Combustion in SI Engines," SAE Paper 850502, 1985.

[35] Kishan, S., Bell, S., and Caton, J., "Numerical Simulations of Two-Stroke Cycle Engines Using Coal Fuels," Translations of the ASME, 108, pp. 661-668, 1986.

[36] Baruah, P., “A Free Piston Engine Hydraulic Pump for an Automotive Propulsion System,” SAE Paper 880658, 1988.

[37] Cowart, S., Keck, C., Heywwod, B., Westbrook, K., and Pitz, W., "Engine Knock Predictions Using a Fully Detailed and a Reduced Chemical Kinetic Mechanism,” Twenty-Third Symposium (International) on Combustion, The Combustion Institute, pp. 1055-1062, 1990.

[38] Crawford, B., Celik, I., and Lyons, D., "Modeling of a Spark-Ignition Engine to Predict Hydrocarbon Emissions," ASME ICE Division, Alternative Fuels, Engine Performance and Emissions, 20, pp. 167-174, 1993.

[39] Korematsu, K. and Hasegawa, M., "Total-System Simulation Model of Two-Stroke Cycle, Crank Case Compression-Type, Spark-Ignition Engines," Transactions of the JSME, 59, 1421-1426, 1993.

[40] Widener, S. and Ingram, K., "Free Piston Engine Linear Generator Technology 
Development," Final report, Under Contact to US. Army TARDEC, Mobility

Technology Center-Belvoir, Fort Belvoir, Virginia, January 1995.

[41] Clark, N., Nandkumar, S., and Famouri, P., "Operation of a Small Bore Two-Stroke Linear Engine," ASME 98-ICE-120, 1998.

[42] Clark, N., McDaniel, T., Atkinson, R., Nandkumar, S., Atkinson, C., Petreanu, S., Tennant, C., and Famouri, R., "Modeling and Development of a Linear Engine," 1998 Spring Technical Conference, ASME Ice Division, Front [35] Lauderdale, FL, ICE-Vol.30-2.

[43] Nandkumar, S., "Modeling of a Linear Engine," Master Thesis, West Virginia University, 1998.

[44] Heywood, J., "Internal Combustion Engine Fundamentals," McGraw-Hill, New York, 1988.

[45] Cawthorne, W., Famouri, R., Chen, J., Clark, N., McDanial, T., Atkinson, R., Nandkumar, S., Atkinson, C., and Petreanu, S., "Development of a LinearAlternator-Engine for Hybrid Electric Vehicle Applications," IEEE Translations on Vehicular Technology, Vol.48, No. 6, November, 1999.

[46] Houdyschell, D., “A Diesel Two-Stroke Linear Engine," Master Thesis, West Virginia University, 2000.

[47] Petreanu, S., "Conceptual Analysis of a Four-Stroke Linear Engine," Dissertation, West Virginia University, 2000.

[48] Rosenberg, R., “General Friction Considerations for Engine Design,” SAE Paper $821576,1982$.

[49] Tor, A., Johansen, O., Egeland, E., Johannessen, A., and Kvamsdal, R., "Free Piston 
Diesel Engine Dynamics and Control,” IEEE Trans. Control Systems Technology, accepted, 2002.

[50] Taylor, S., Shoukry, E., Clark, N., and Famouri, P., "Numerical Simulation for Parametric Study of a Two-Stroke Direct Injection Linear Engine," SAE Paper 2002-01-1739, 2002.

[51] Web Site, www.BatteryStuff.com, Hamburg, Germany, 2003.

[52] Web Site, www.mandw.dk, OR, USA, 2003.

[53] Somhorst, J. and Achten, P., "The Combustion Process in a DI Diesel Hydraulic Free Piston Engine," SAE Paper 960032, 1996. 


\section{Appendix A}

DIMENSIONLESS ANALYSIS PARAMETERS EQUATIONS:

$$
\begin{aligned}
& f^{*}=f q \times t_{r} \\
& C a^{*}=C a \times \frac{t_{r}}{M} \\
& V^{*}=v \times t_{r} / L s t e \\
& F f^{*}=F_{f} \times \frac{t_{r}{ }^{2}}{M \times L s t e} \\
& I P^{*}=P \times \frac{t_{r}{ }^{2} \times L s t e}{M} \\
& P^{*}=P W \times \frac{t_{r}{ }^{3}}{M \times L^{2} s t e} \\
& I P M^{*}=P W \times \frac{t_{r}{ }^{3}}{M \times L^{2} s t e} \times \frac{M}{G M} \\
& E V^{*}=E R \times \frac{t_{r}{ }^{2}}{M \times L^{2} \text { ste }} \times \frac{L^{3} s t e}{G V} \\
& I P V^{*}=P W \times \frac{t_{r}{ }^{3}}{M \times L^{2} s t e} \times \frac{t_{r}{ }^{3} s t e}{C V}
\end{aligned}
$$




\section{Appendix B}

\section{COMMENTED PROGRAM AND CODE FLOW CHART}

\section{B.1 COMMENTED CODE}

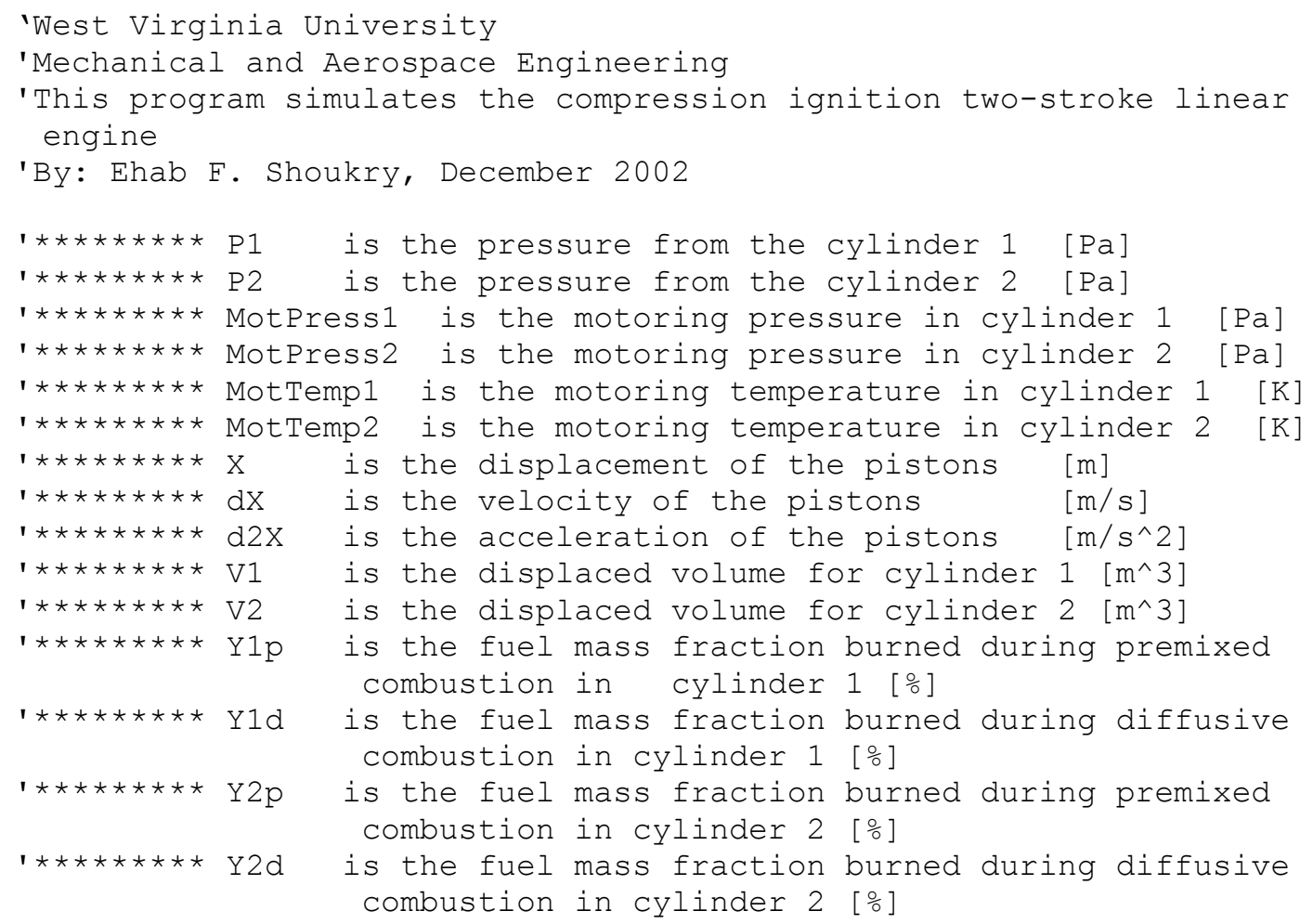




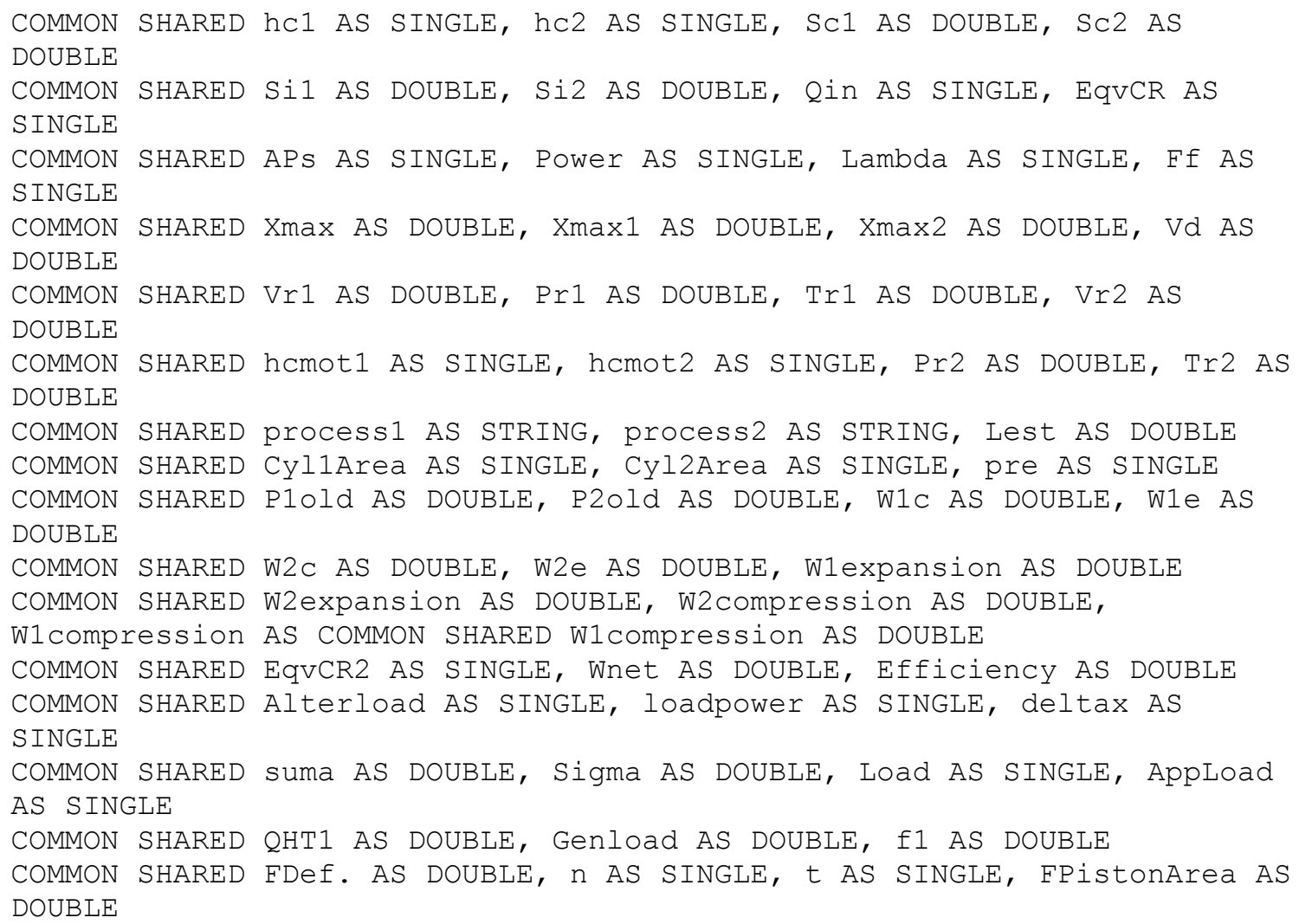




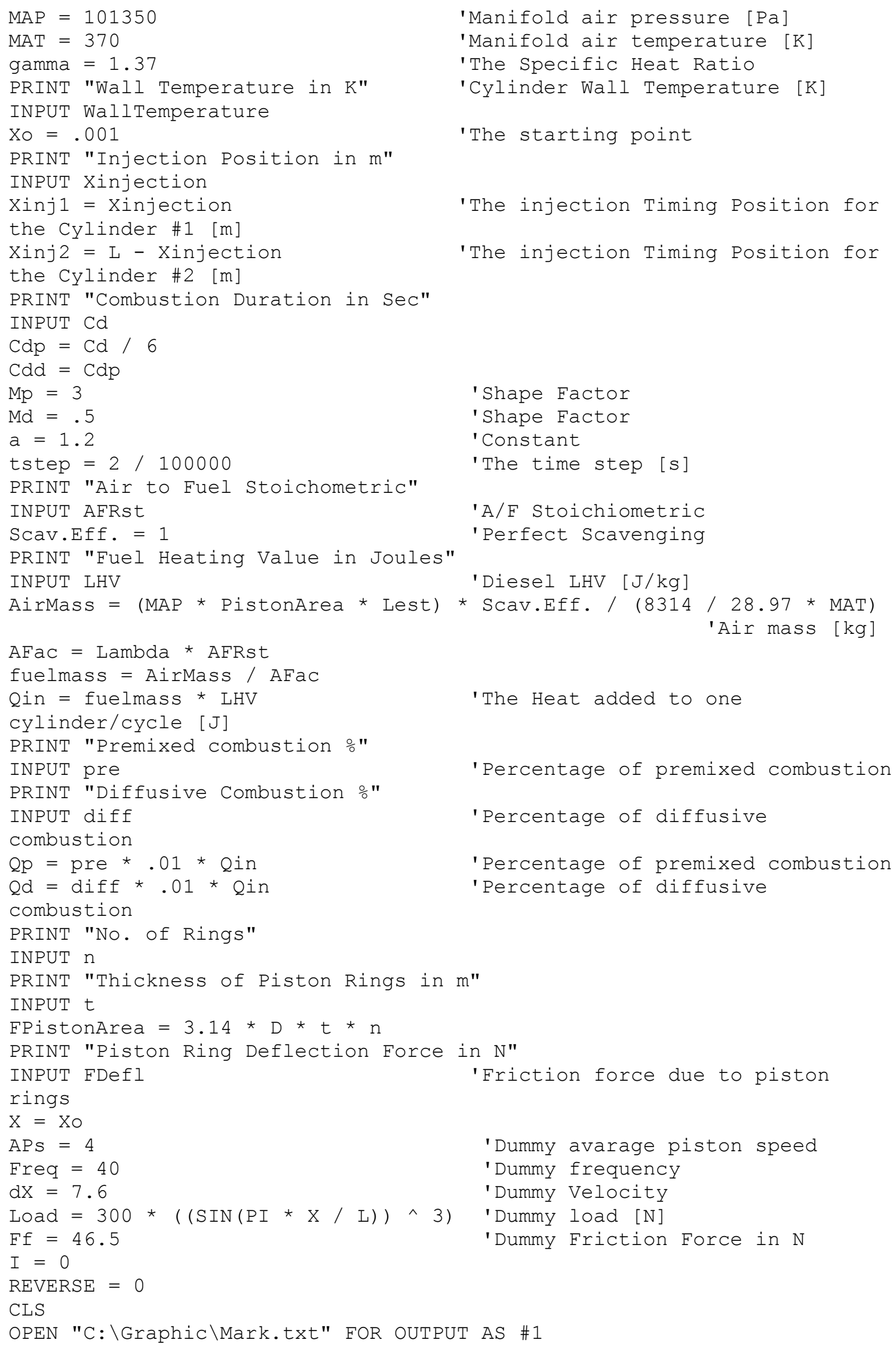


CALL Loadshape

FOR I $=0 \mathrm{TO} 10000000$

time $=I *$ tstep

IF $\mathrm{X}-\mathrm{Xold}>=0$ THEN

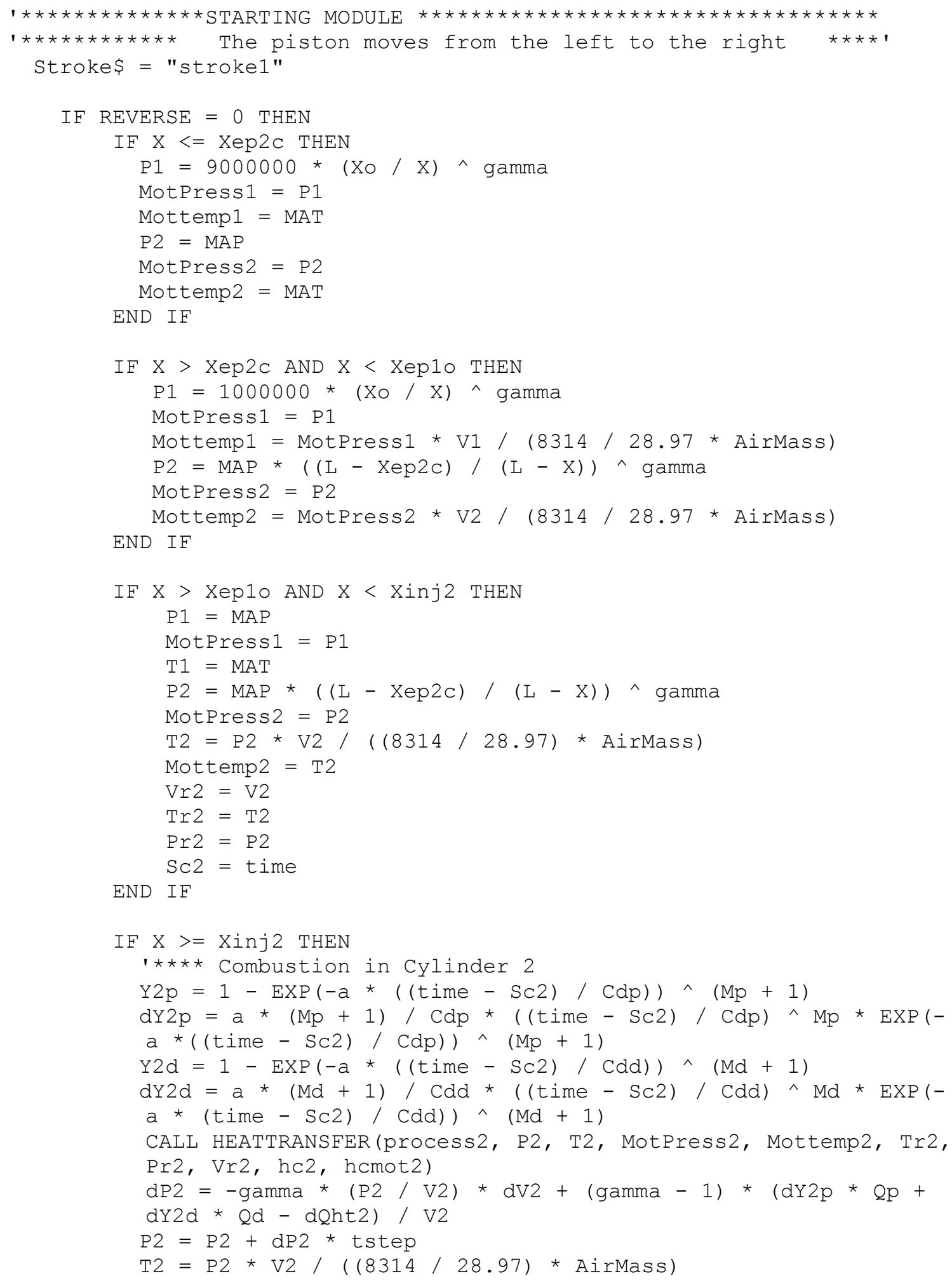




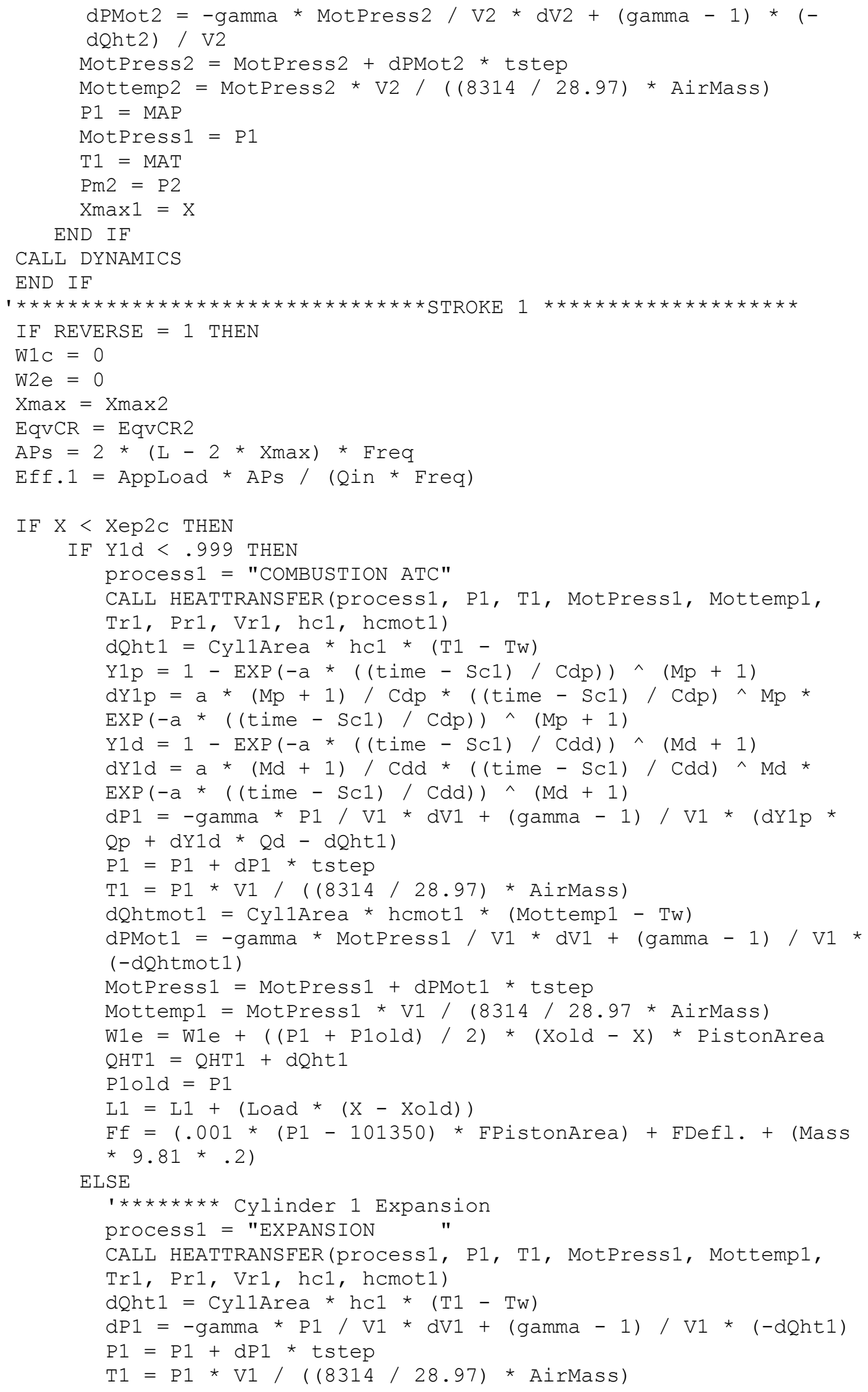




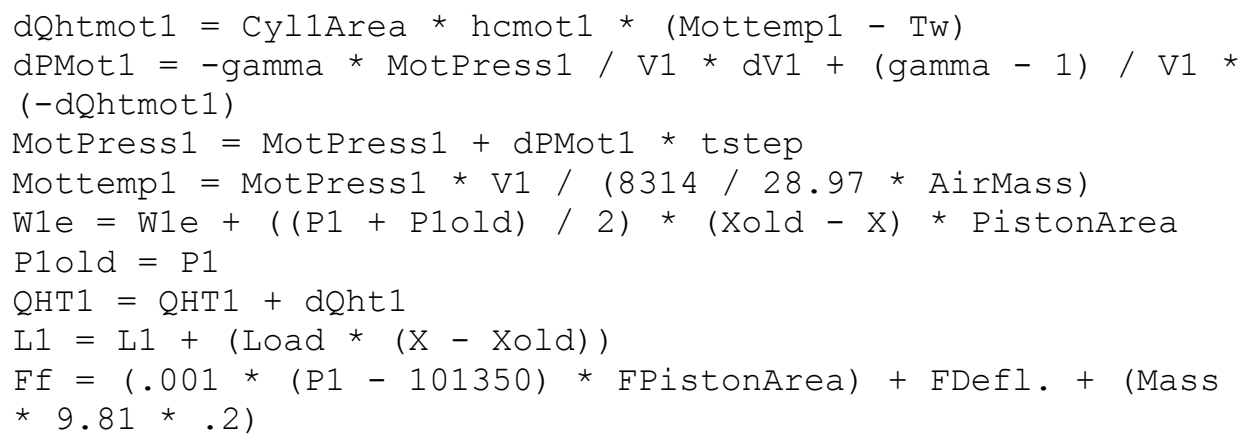




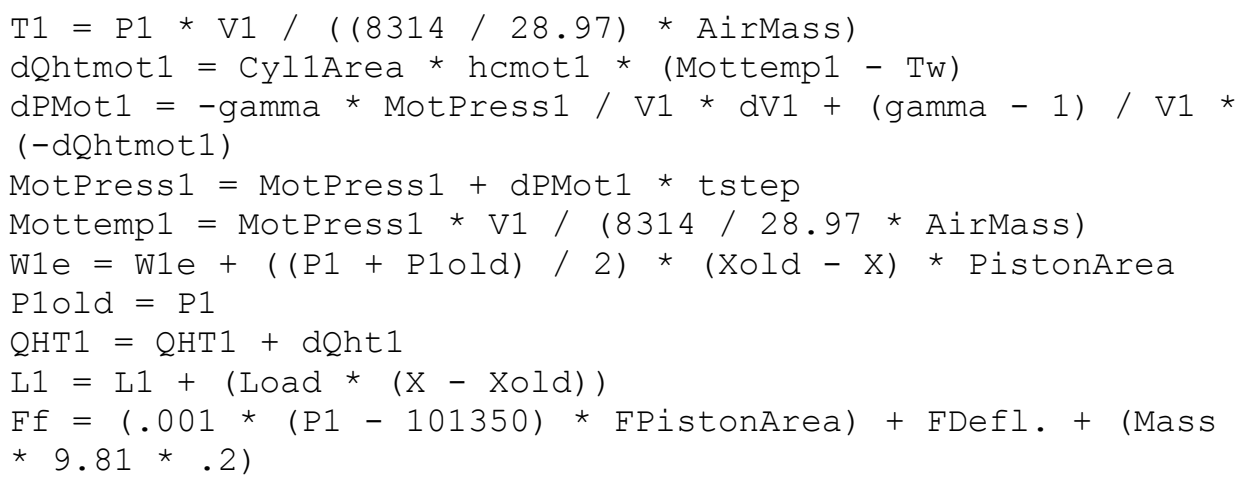




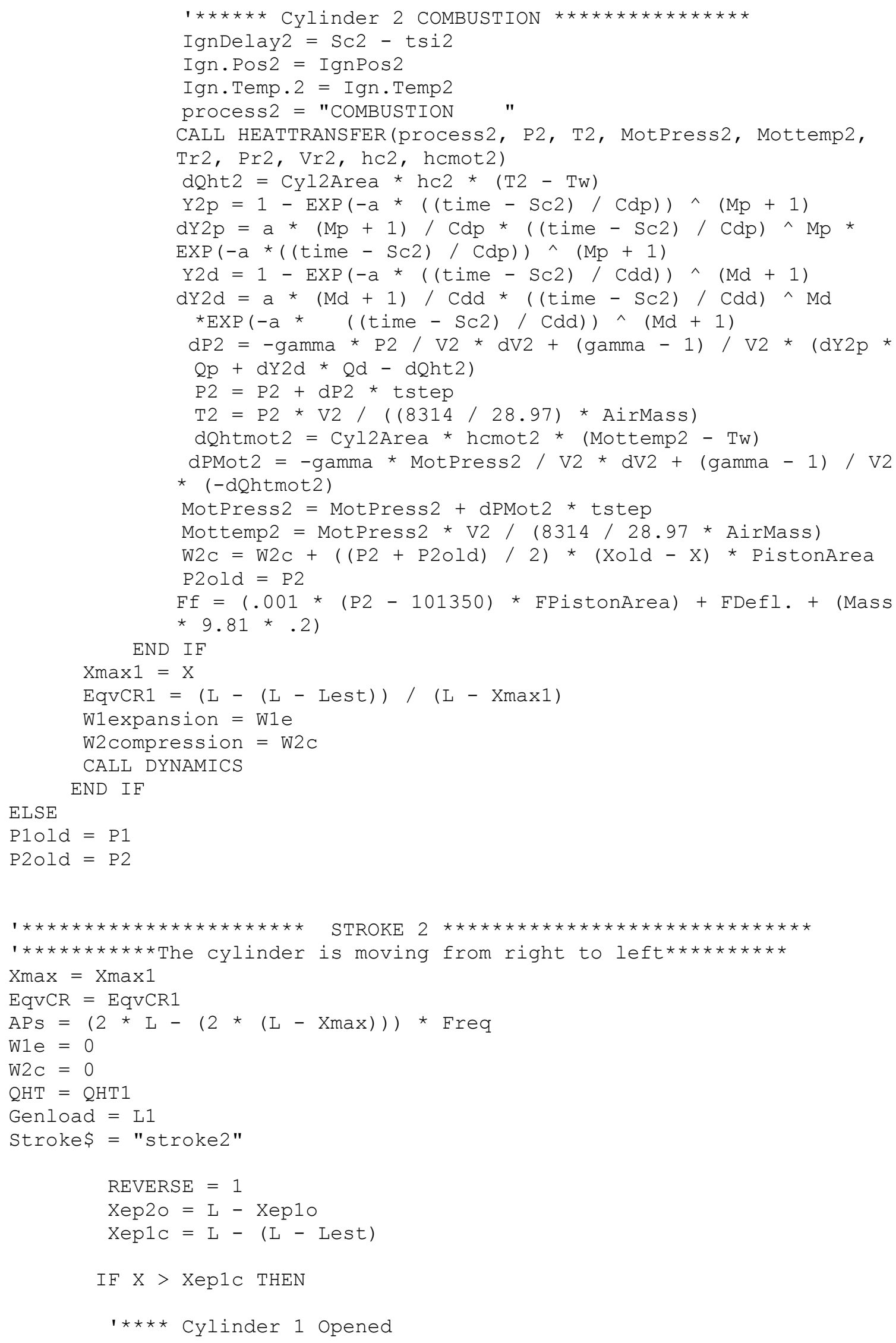




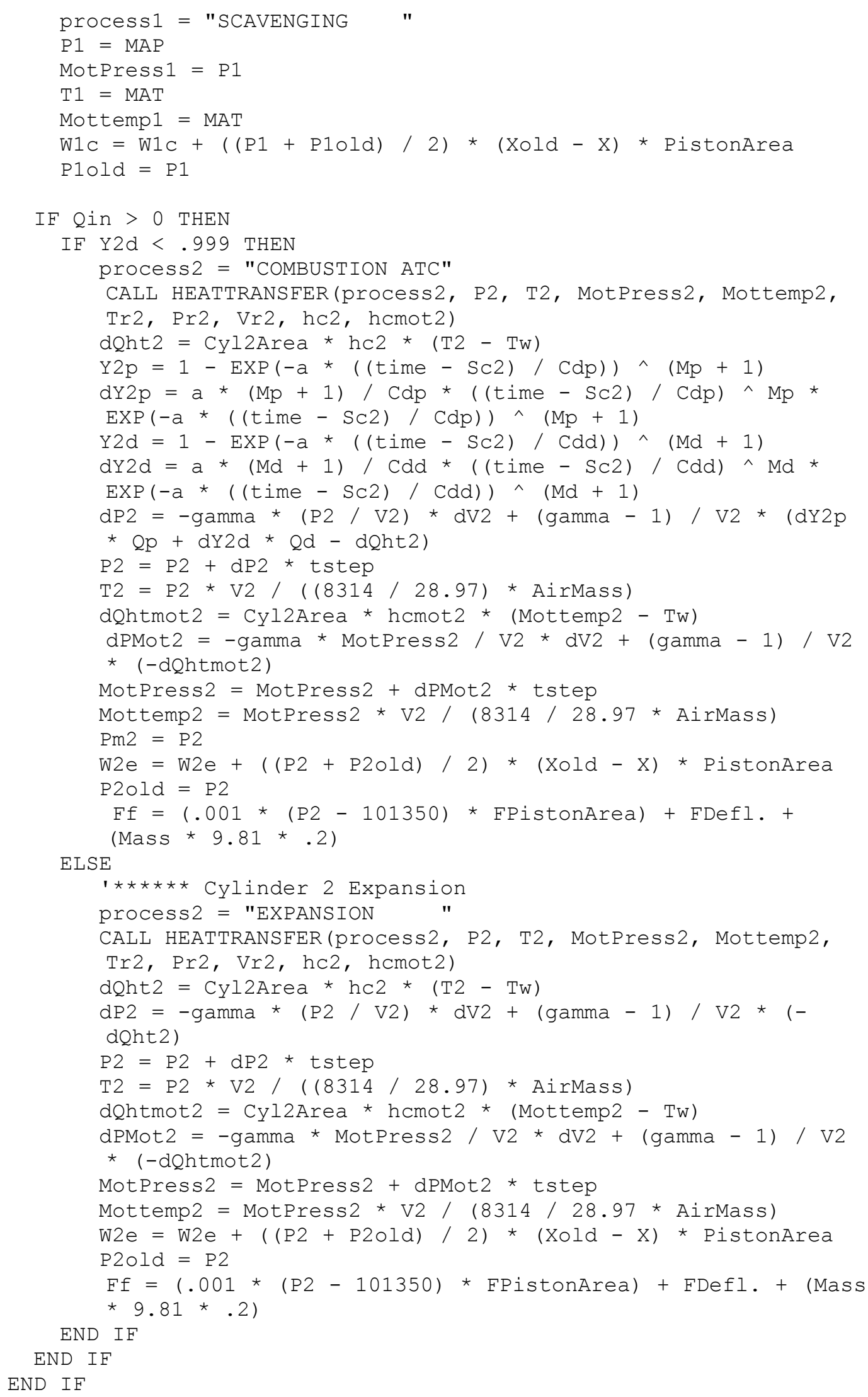




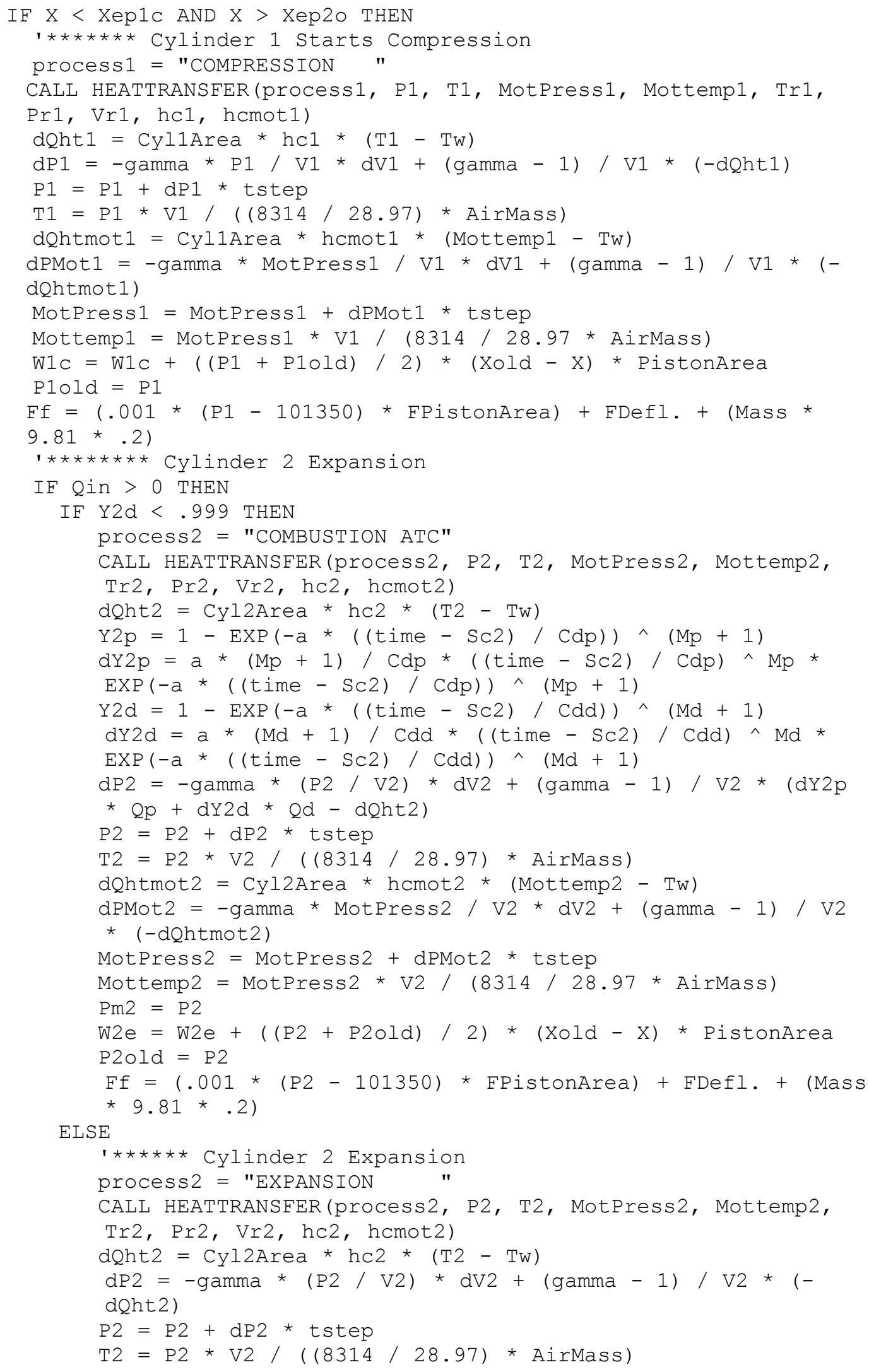




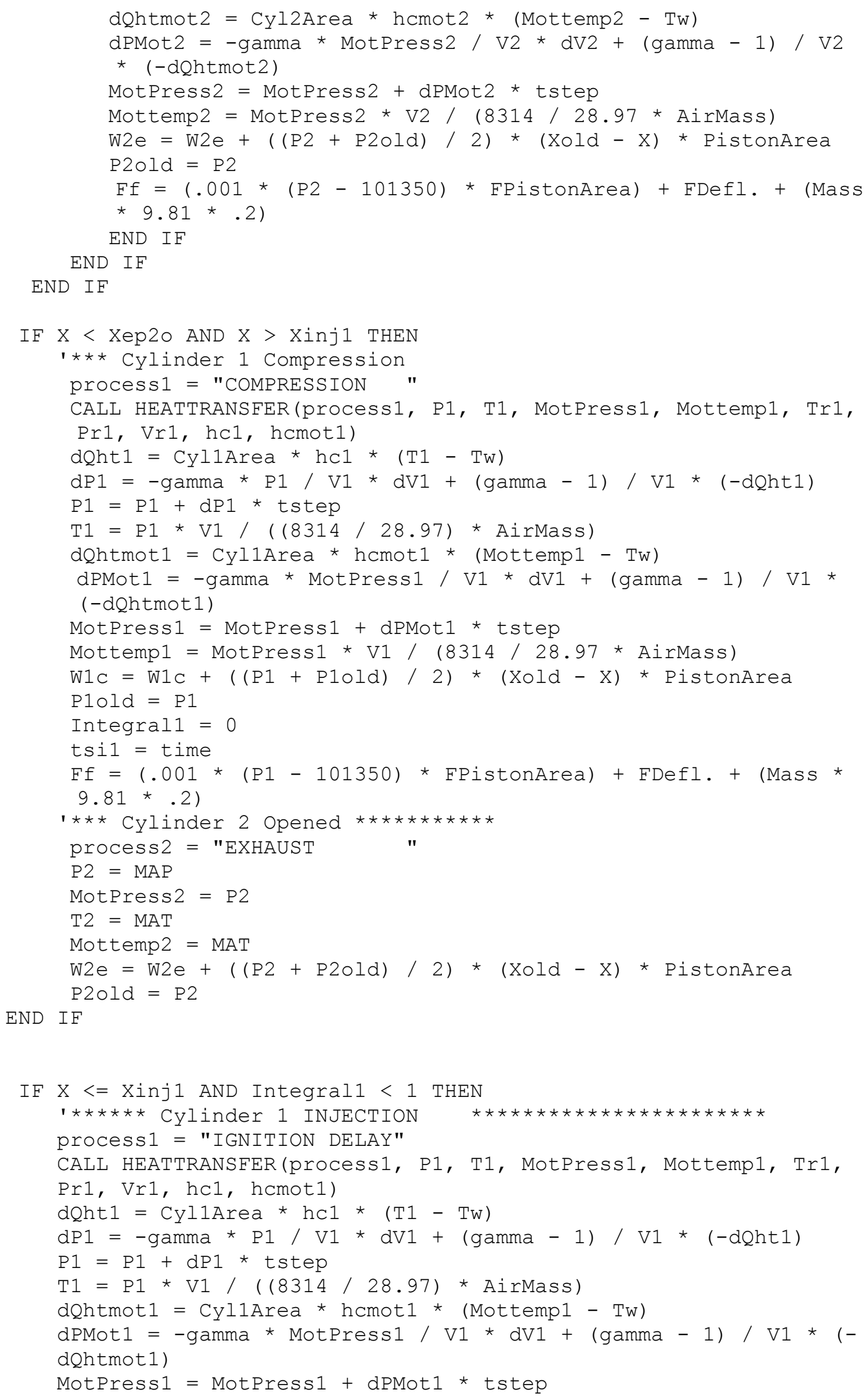




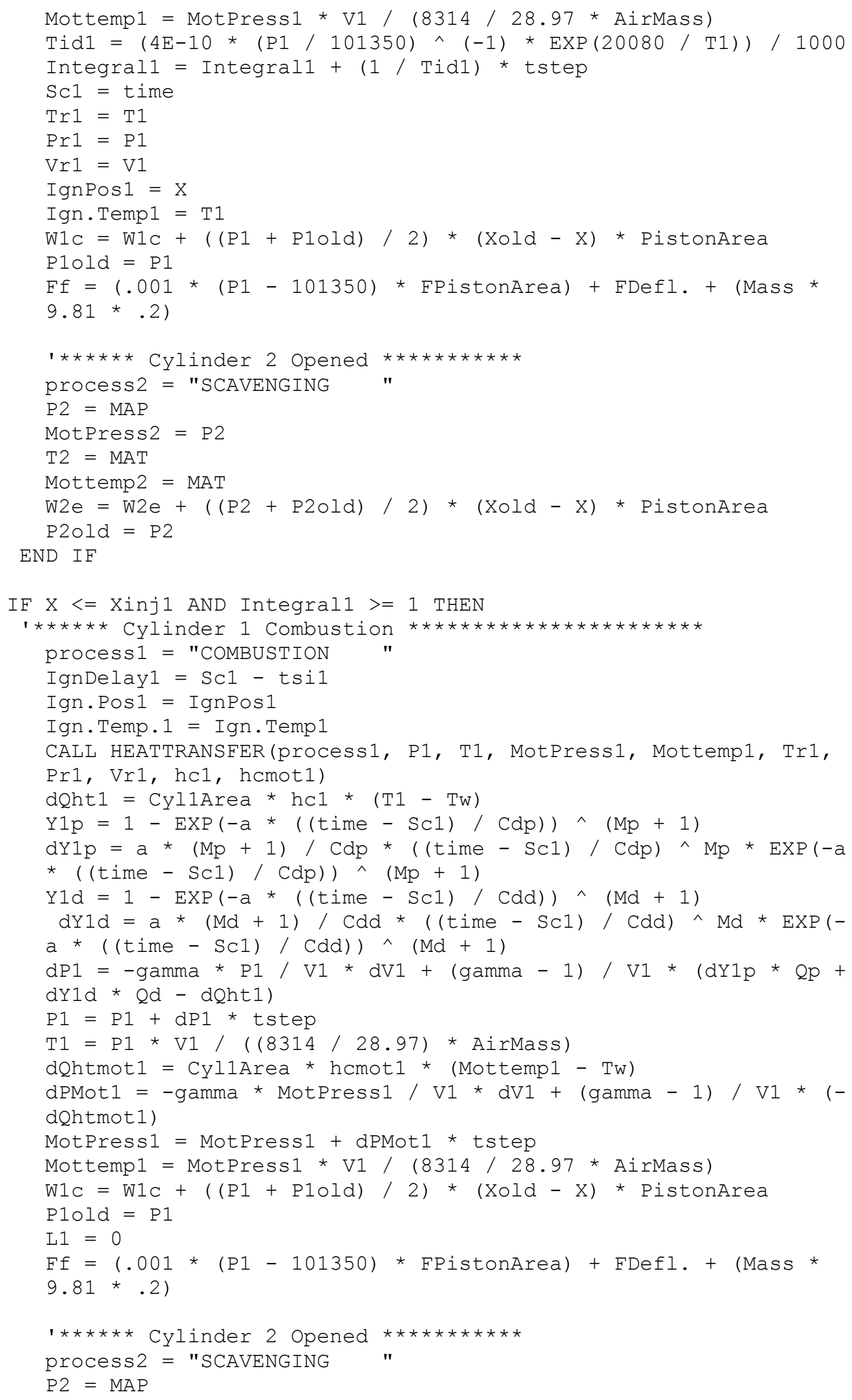




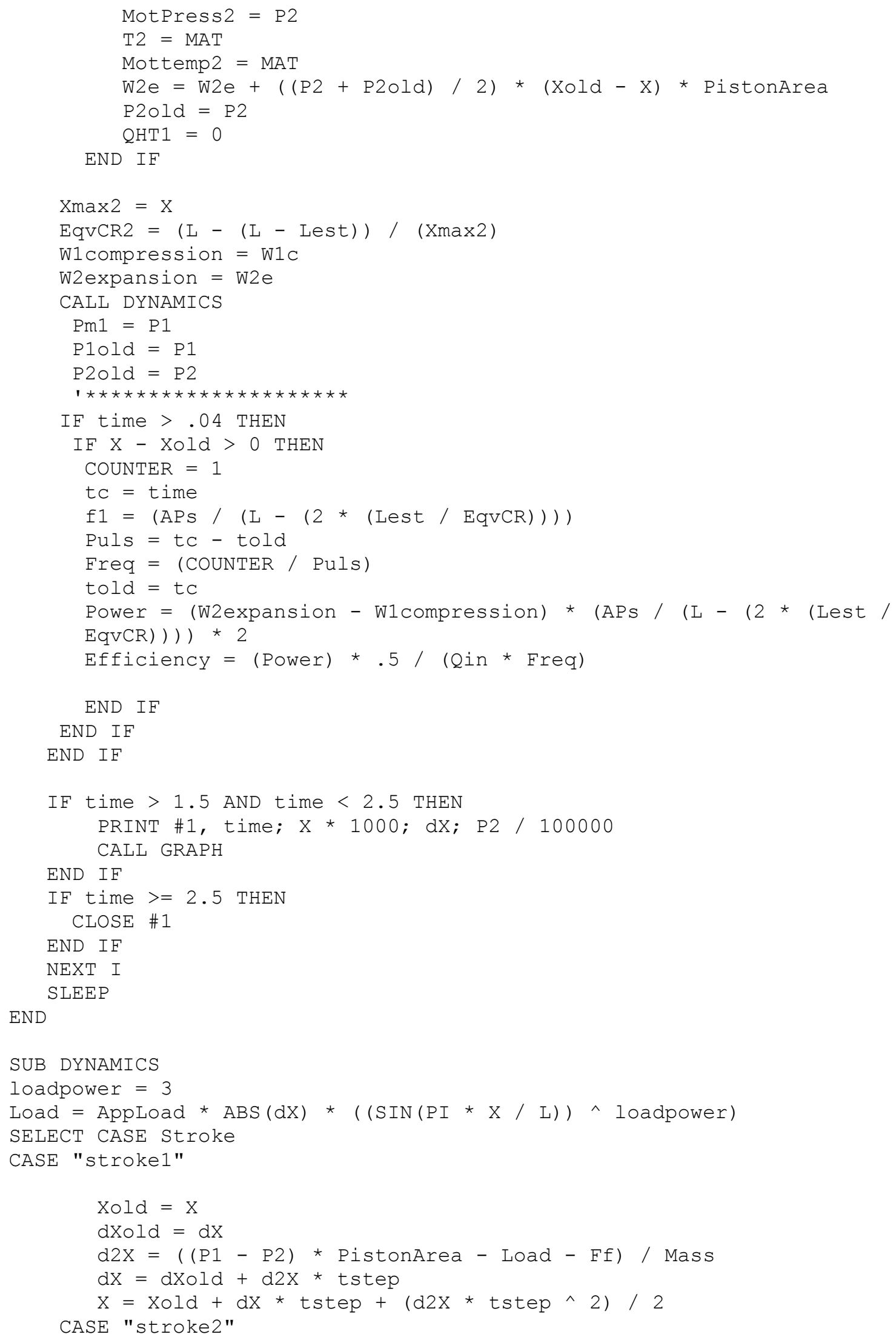




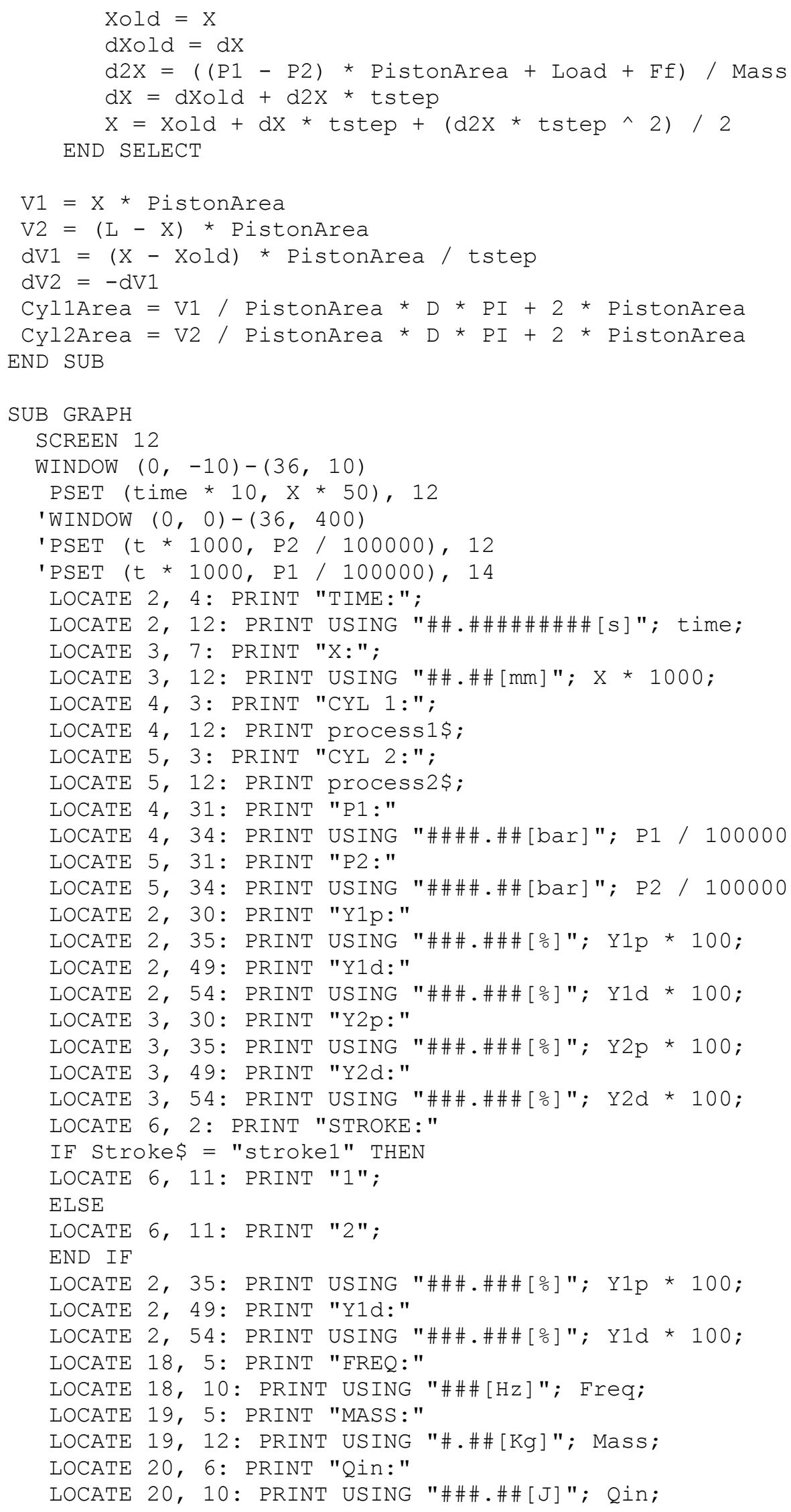




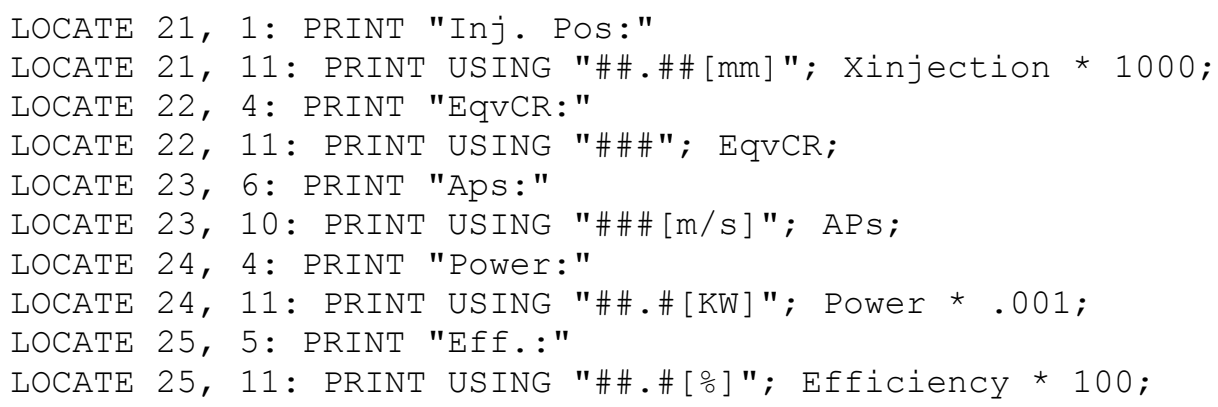




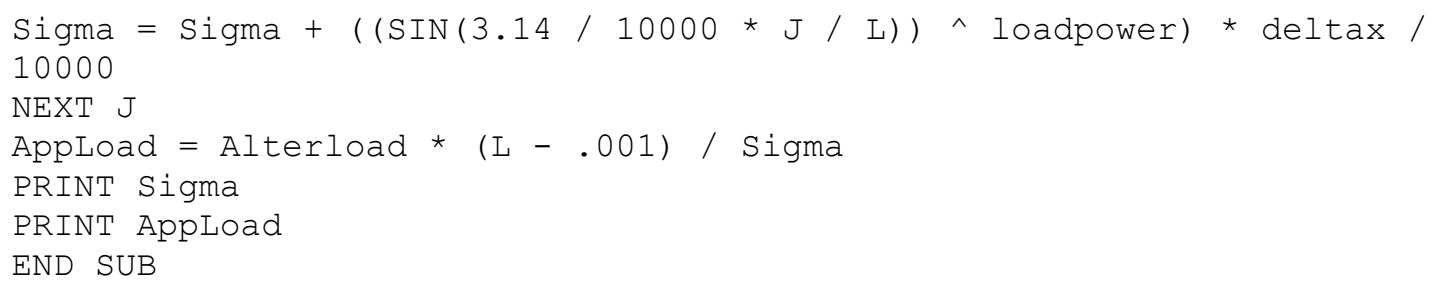

\section{B.2 FLOW CHART}




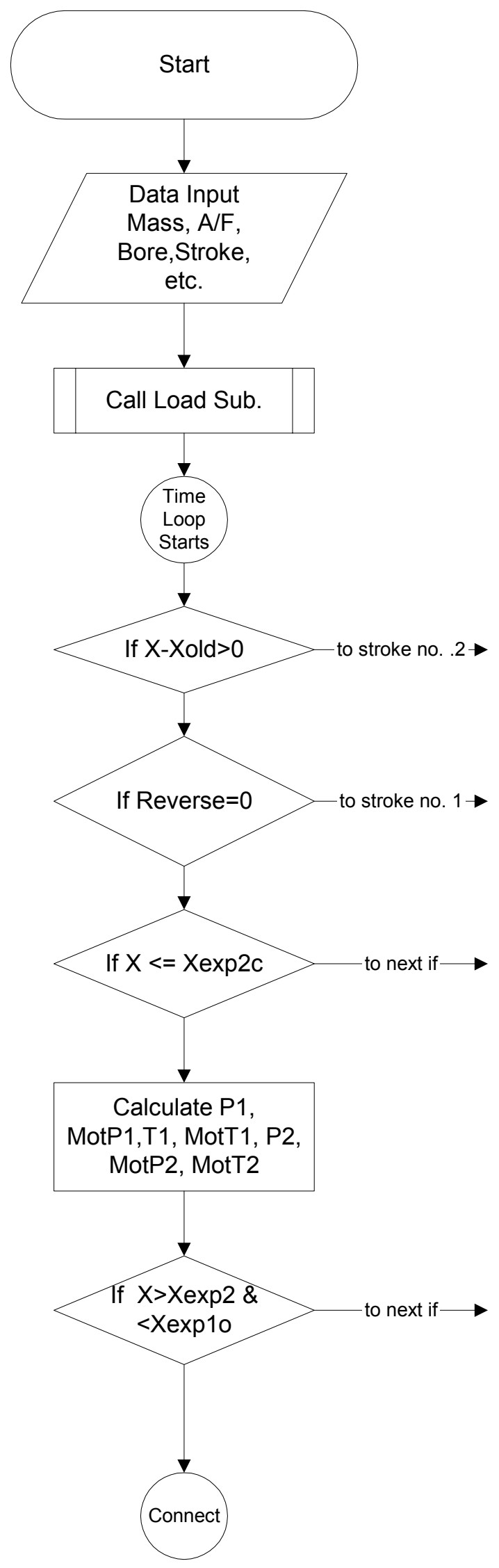




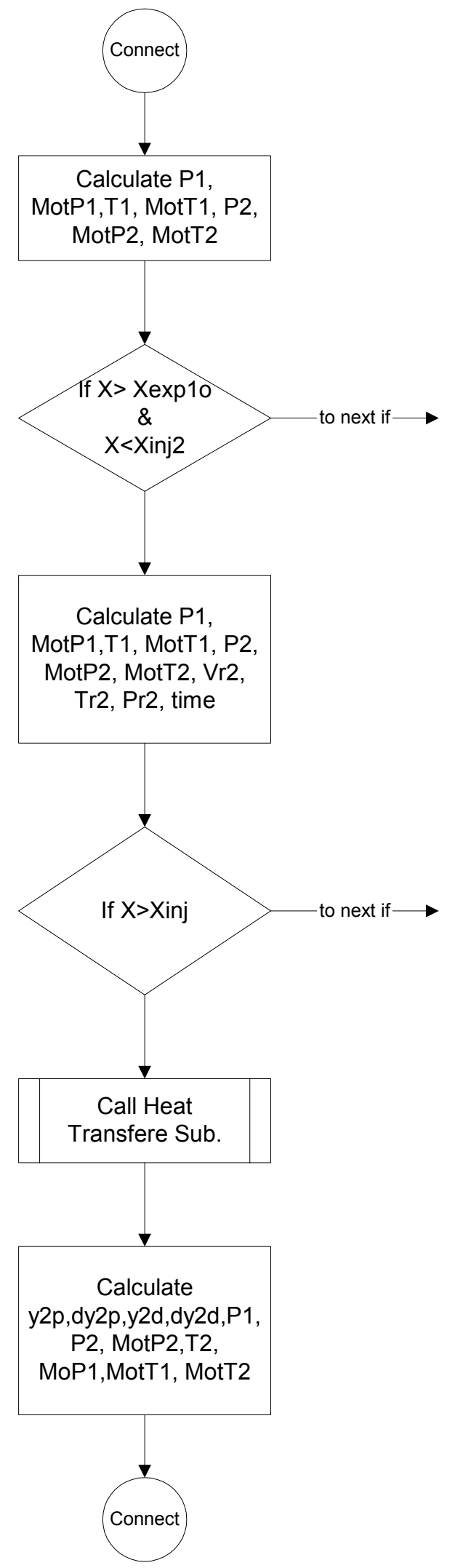




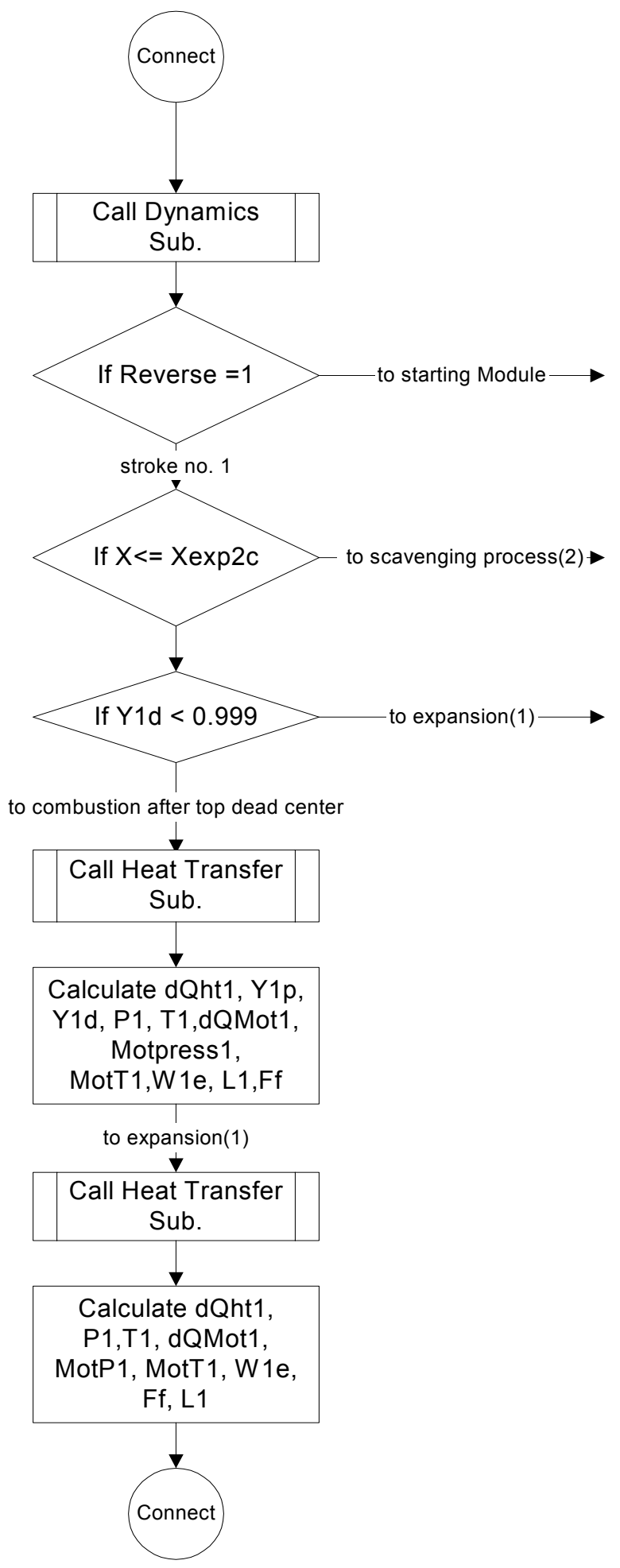




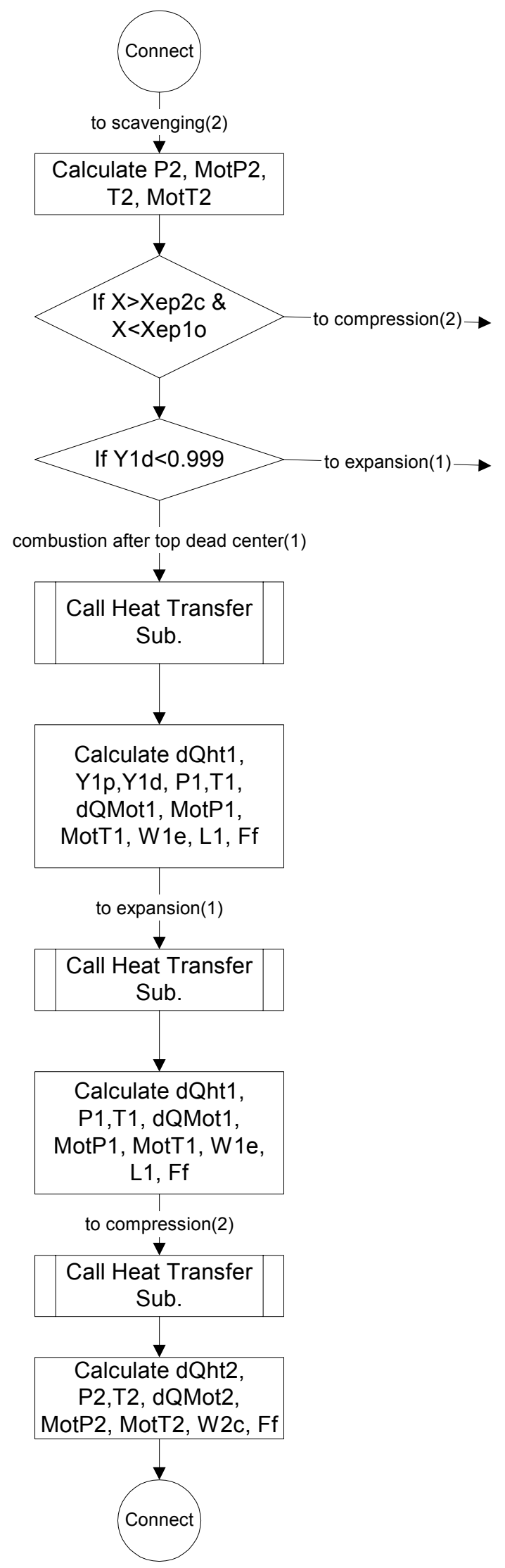




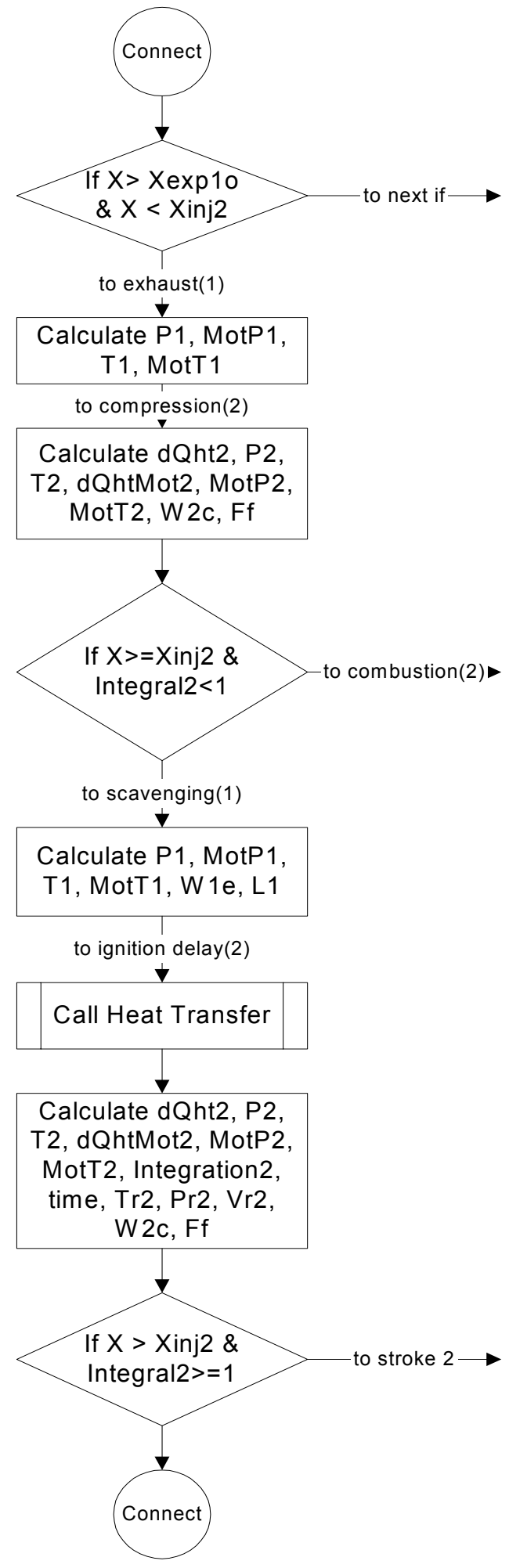




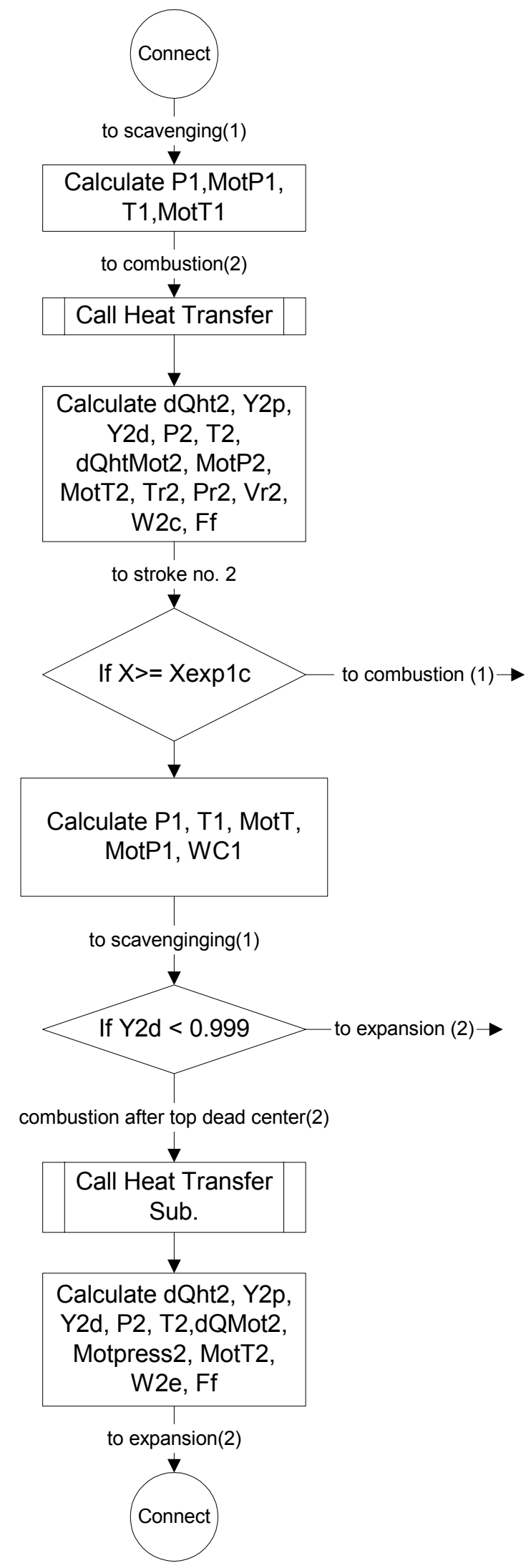




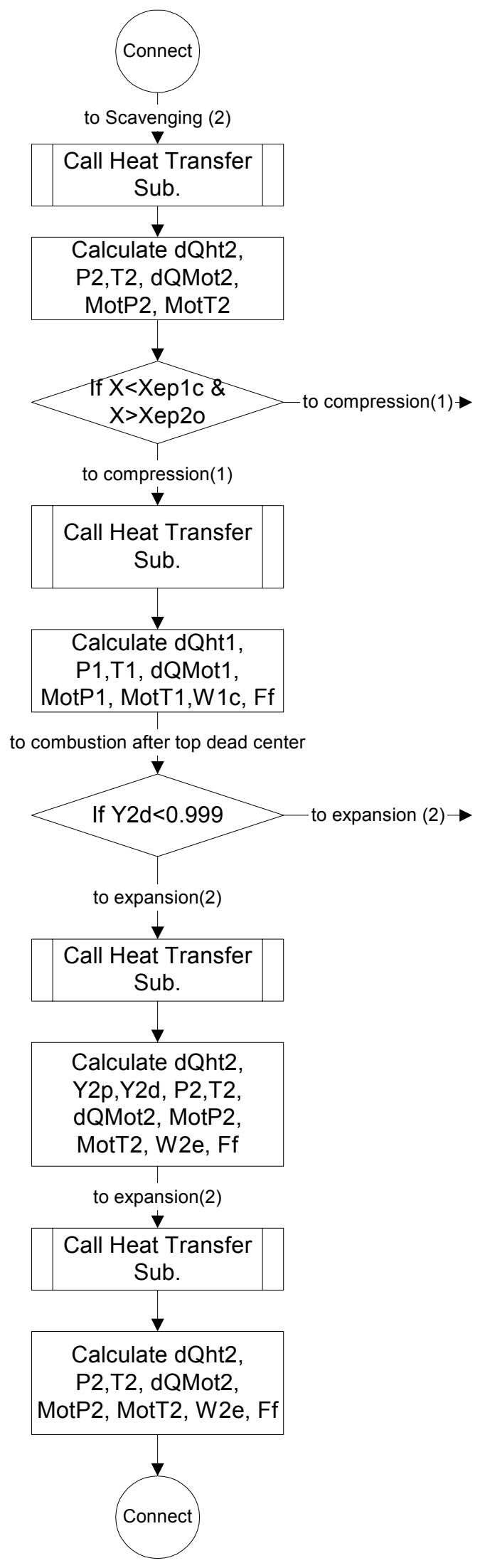




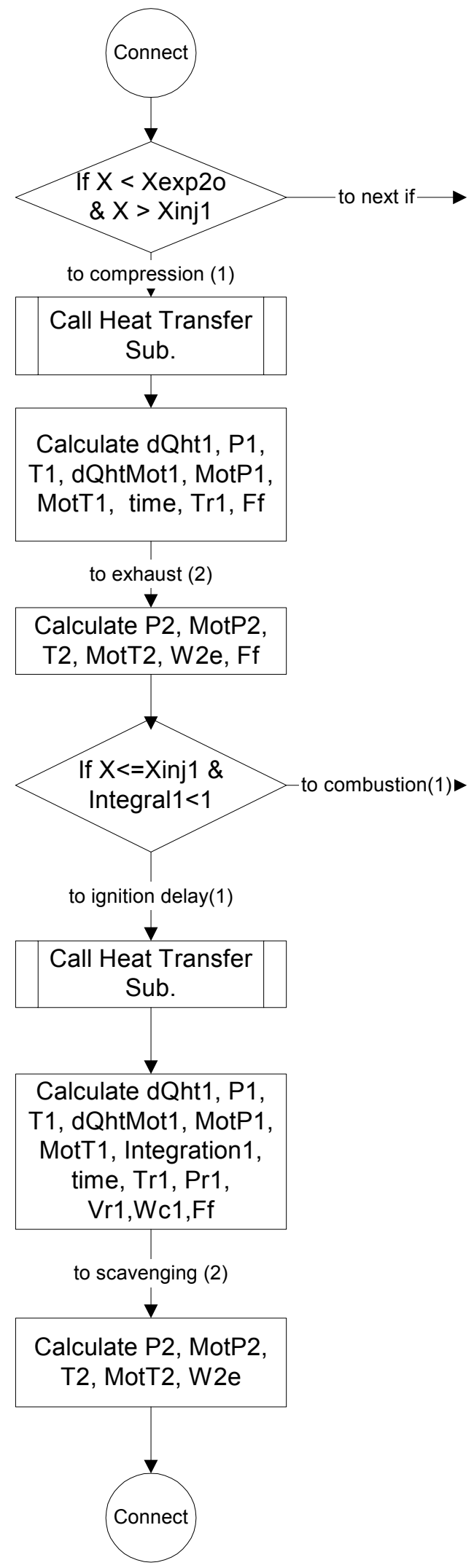




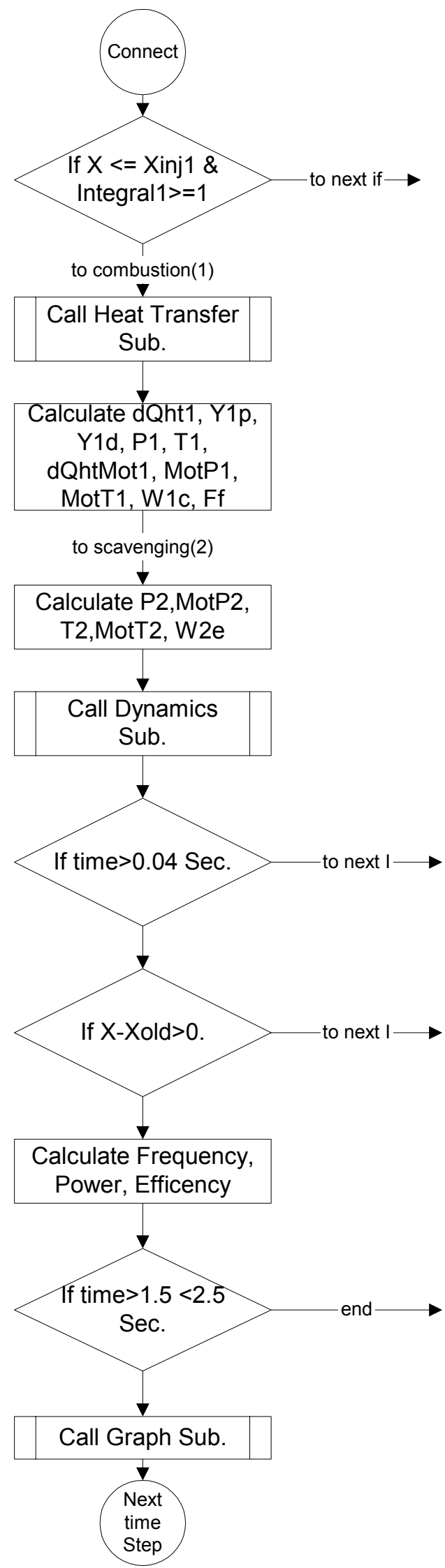




\section{APPENDIX C}

\section{LINEAR ENGINE LOAD CONSTANT LIMIT}

The model showed that the two-stroke linear engine is limited to certain values of load constant applied. It also showed that increasing the load constant more than a certain limit would result in stalling the engine, Figure $\mathrm{C} 1$. Of course the richer the fuel the higher is the load constant limit. As an exercise to find out this limit the air to fuel ratio was altered while keeping all other parameters constant. A case for a bore of 0.075 $\mathrm{m}, 0.037 \mathrm{~m}$ effective stroke length, and injection position of $3 \mathrm{~mm}$ far from cylinder head was considered as an example. Figure $\mathrm{C} 1$ shows the limit of the load constant with different values of lambda. The engine stalls in region above curve.

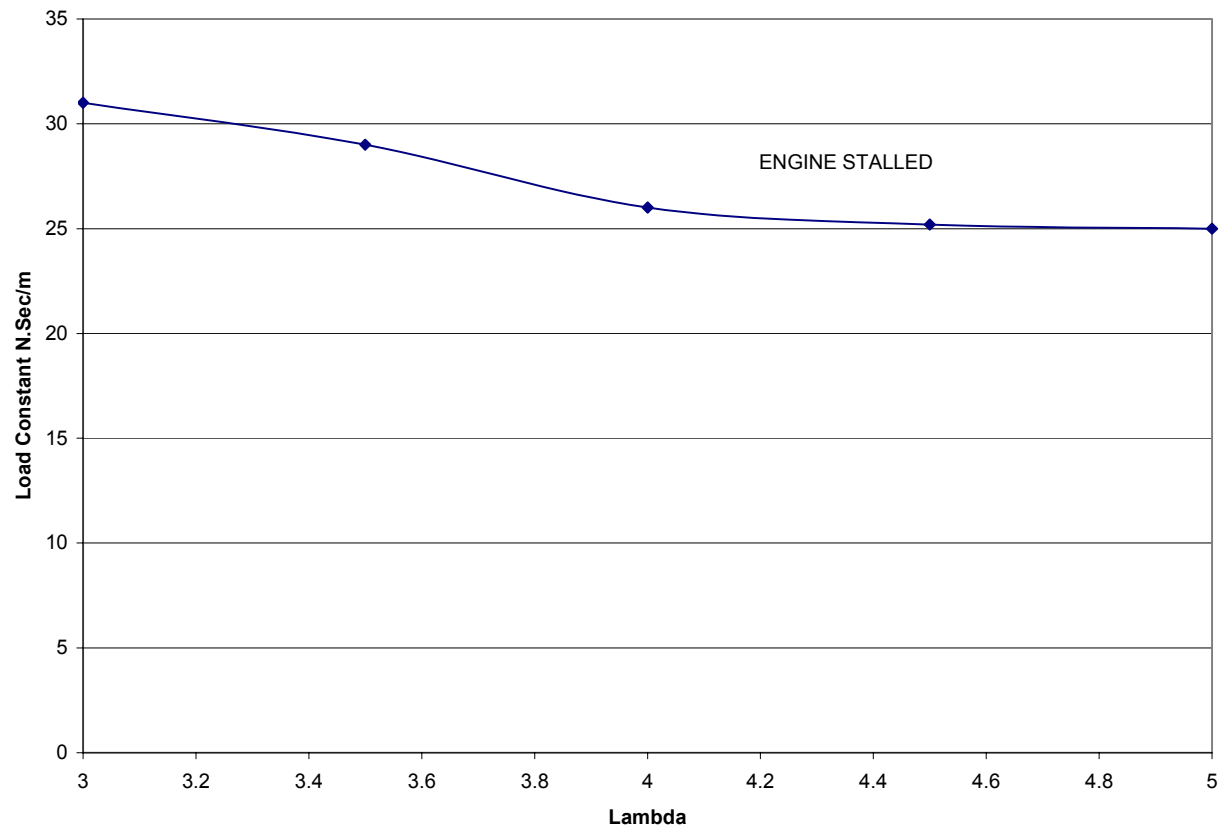

Figure C1. Load Constant Limit for two-Stroke Linear Engine for Lambda=4, Translator Mass=4kg 


\section{APPENDIX D}

\section{EFFECT OF COMBUSTION DISTRIBUTION (CONTINUE)}

Figures D1 and D2 show the change in dimensionless energy released per generator volume. The figures confirmed results previously obtained, however it can be noticed that the values of the dimensionless energy per generator volume were decreased compared to Figures $6.13,6.28$, and 6.43 , which means that increasing the premixed combustion ratio decreased the values of the dimensionless energy per generator volume.

Figures D3 and D5 show the dimensionless indicated power versus bore to effective stroke. The figures confirmed previous results illustrated in Figures 6.14, 6.29 and 6.44 .

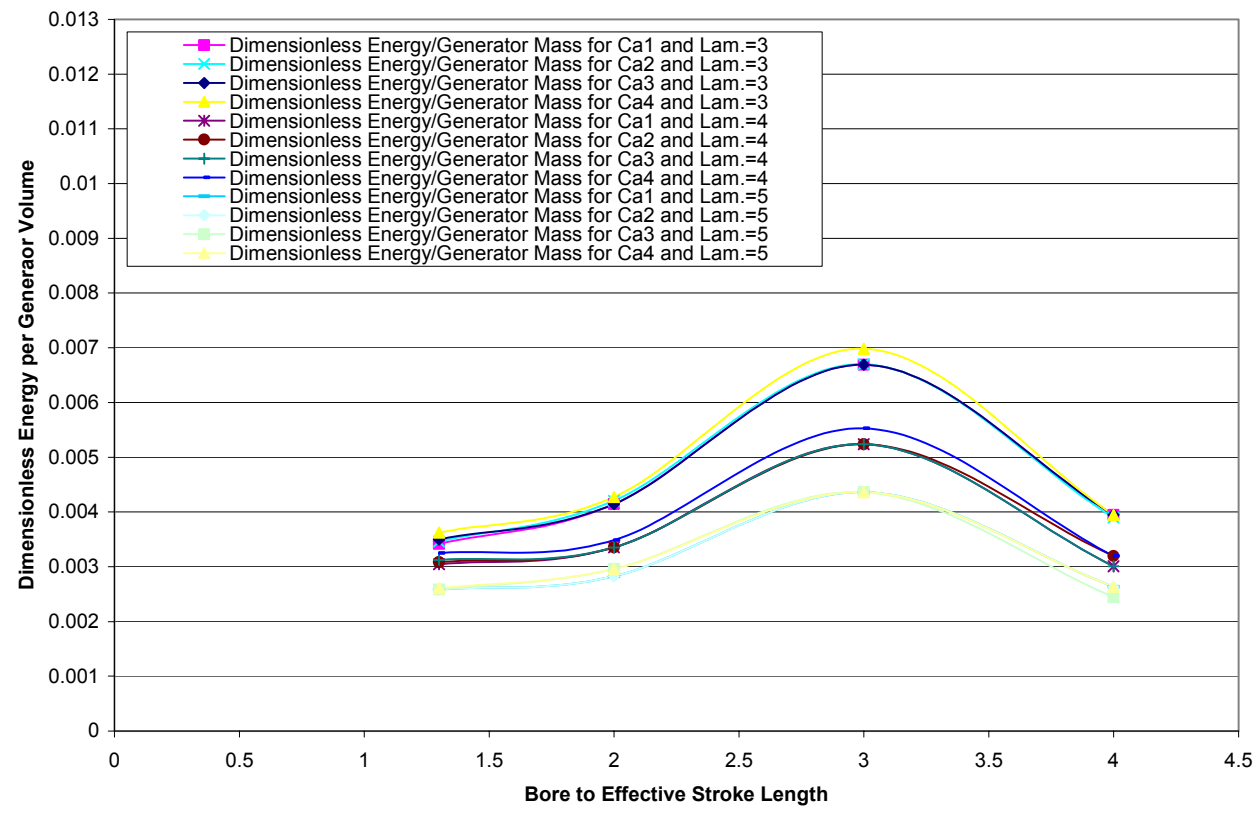

Figure D1. Dimensionless Energy per Generator Volume Versus Bore to Effective Stroke Length for Different Lambda, Different Dimensionless Load Constants, and Dimensionless Injection Position=0.018. 


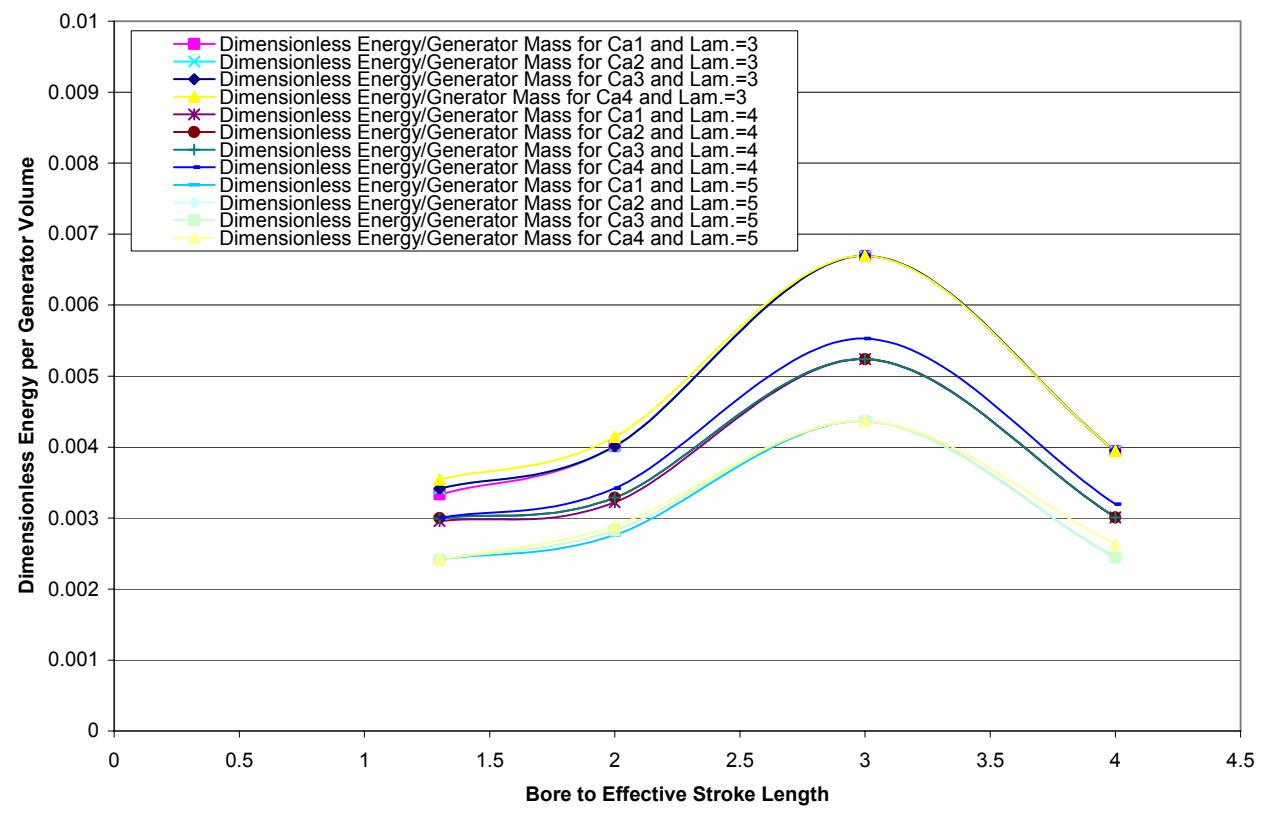

Figure D2. Dimensionless Energy per Generator Volume Versus Bore to Effective Stroke Length for Different Lambda, Different Dimensionless Load Constants, and Dimensionless Injection

Position=0.19

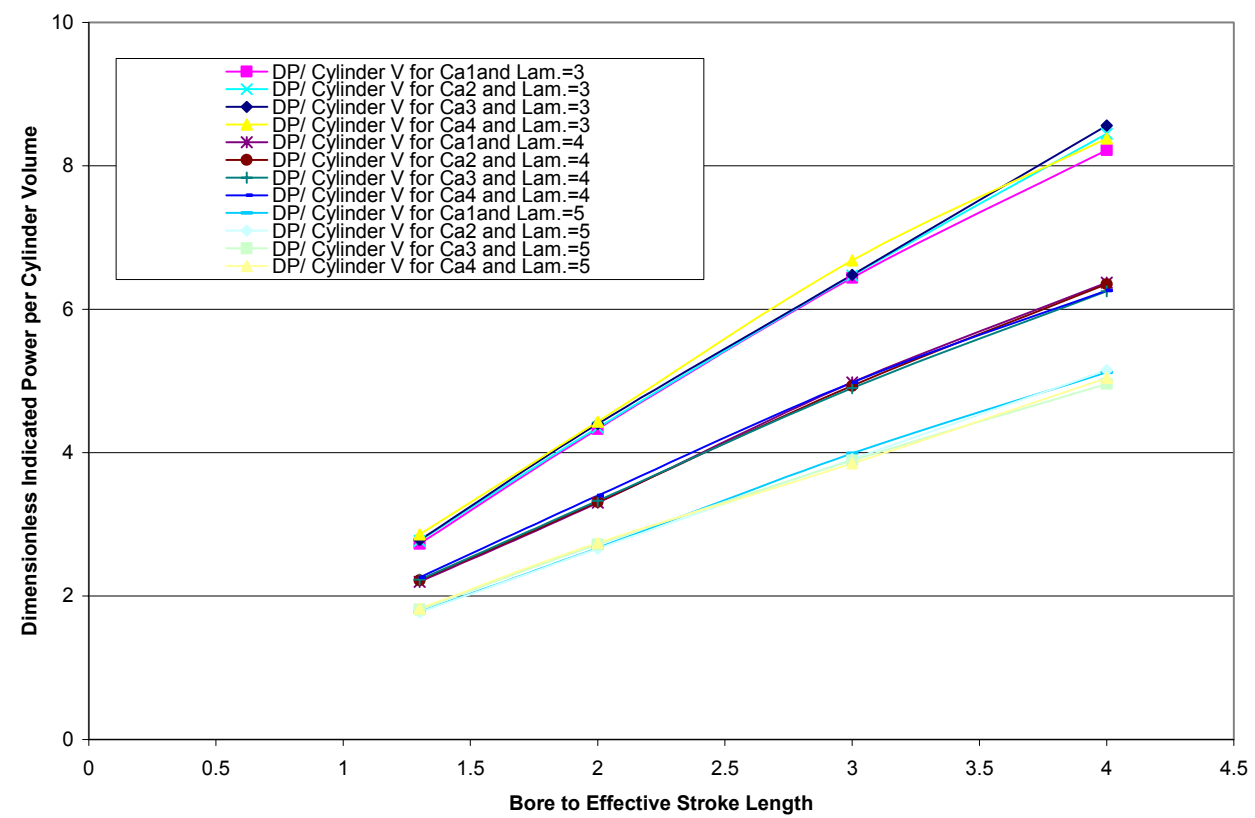

Figure D3. Dimensionless Indicated Power per Cylinder Volume Versus Bore to Effective Stroke Length for Different Lambda, Different Dimensionless Load Constants, and Dimensionless Injection Position=0.018 


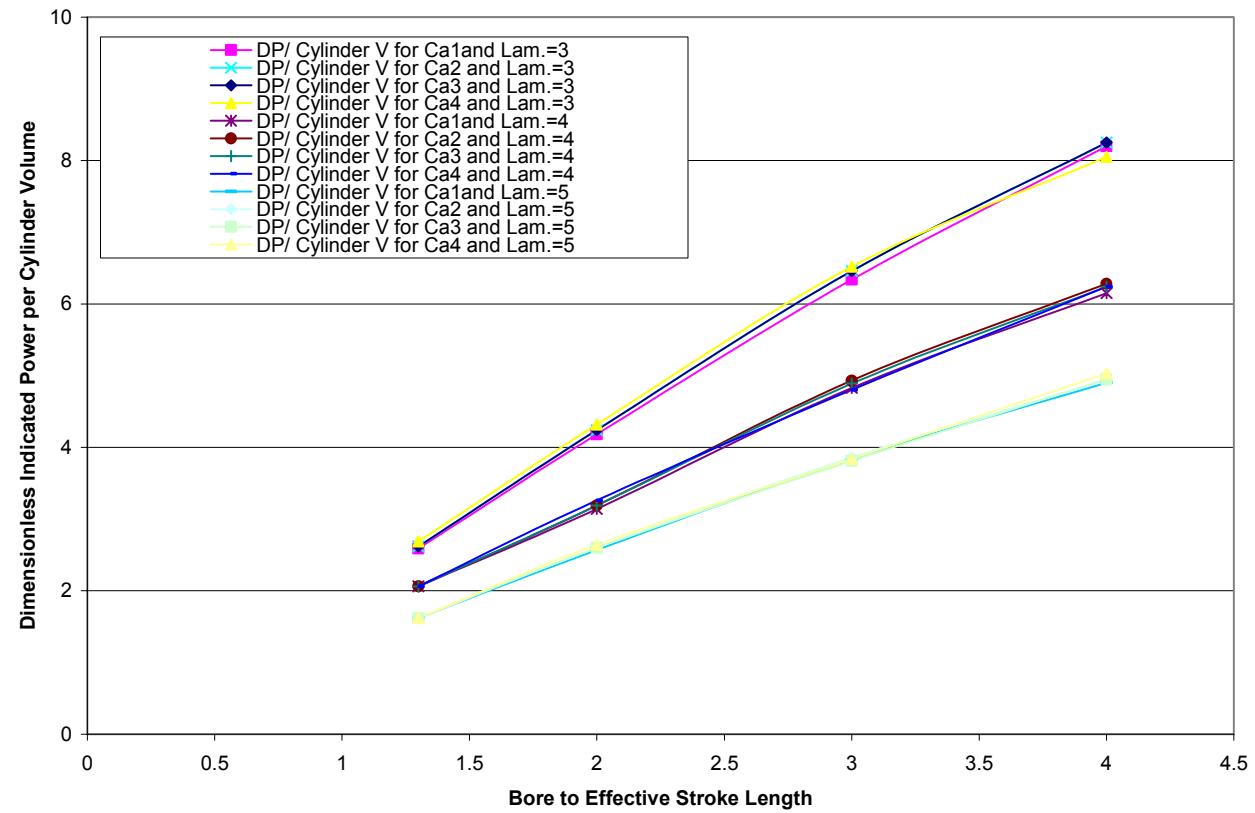

Figure D4. Dimensionless Indicated Power per Cylinder Volume Versus Bore to Effective Stroke Length for Different Lambda, Different Dimensionless Load Constants, and Dimensionless Injection Position=0.19

Figures D5, D6, D7 and D8 show dimensionless indicated power per generator mass and dimensionless energy per generator mass versus bore to effective stroke length. The figures confirmed results obtained previously. However, it can be seen that values were decreased with the case of increased premixed combustion ratio. 


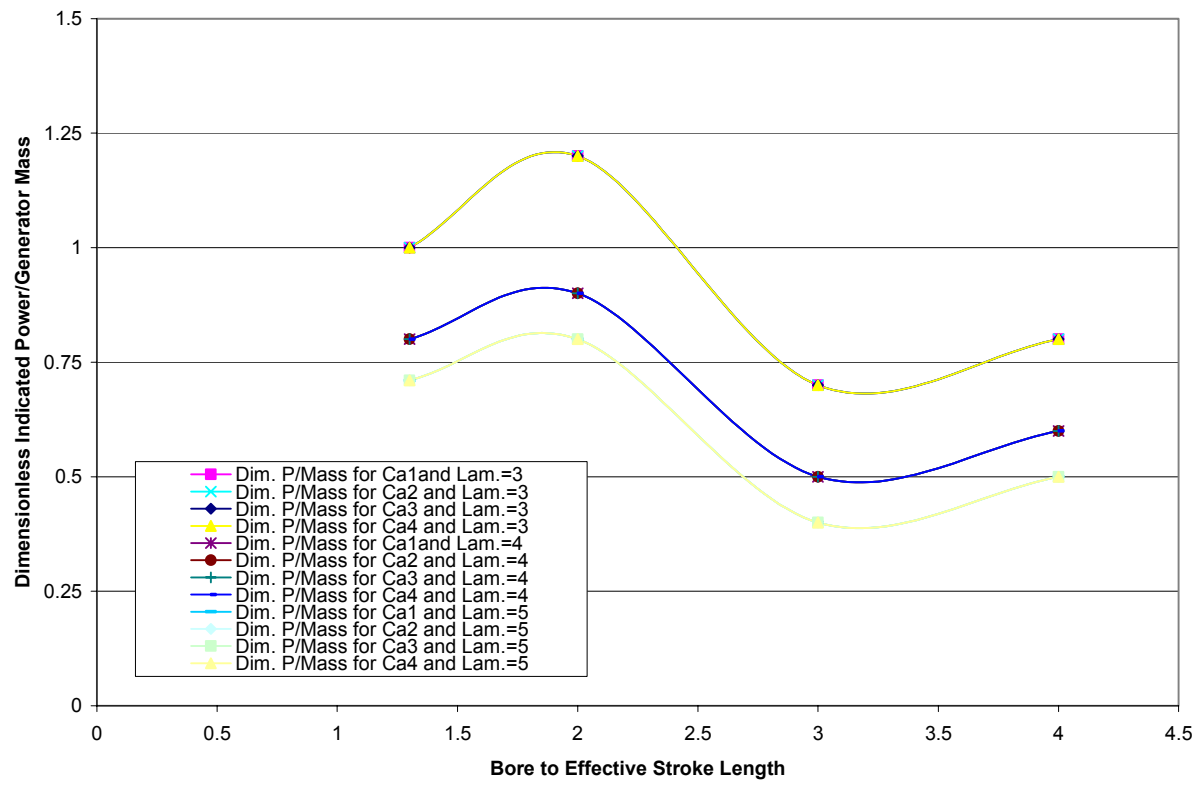

Figure D5. Dimensionless Indicated Power per Generator Mass Versus Bore to Effective Stroke Length for Different Lambda, Different Dimensionless Load Constants, and Dimensionless Injection Position $=0.018$

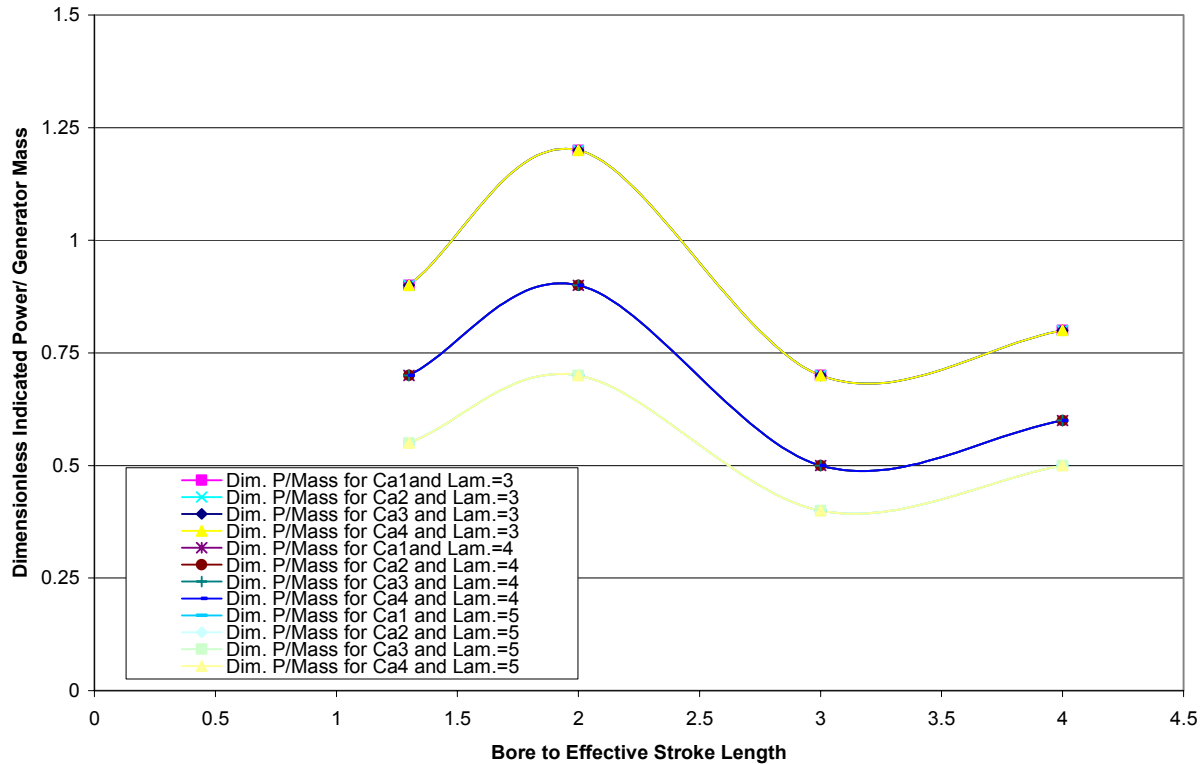

Figure D6. Dimensionless Indicated Power per Generator Mass Versus Bore to Effective Stroke Length for Different Lambda, Different Dimensionless Load Constants, and Dimensionless Injection Position=0.19 


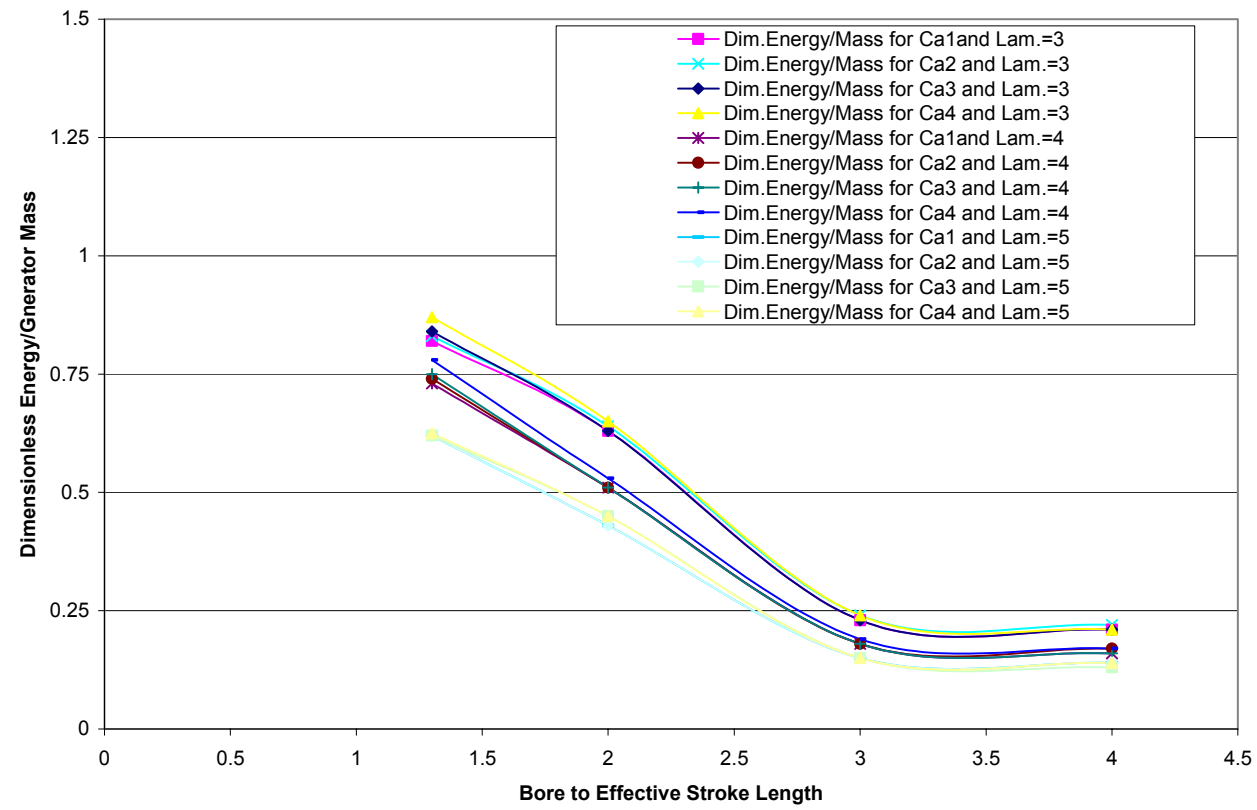

FigureD7. Dimensionless Energy per Generator Mass Versus Bore to Effective Stroke Length for Different Lambda, Different Dimensionless Load Constants, and Dimensionless Injection Position $=0.018$

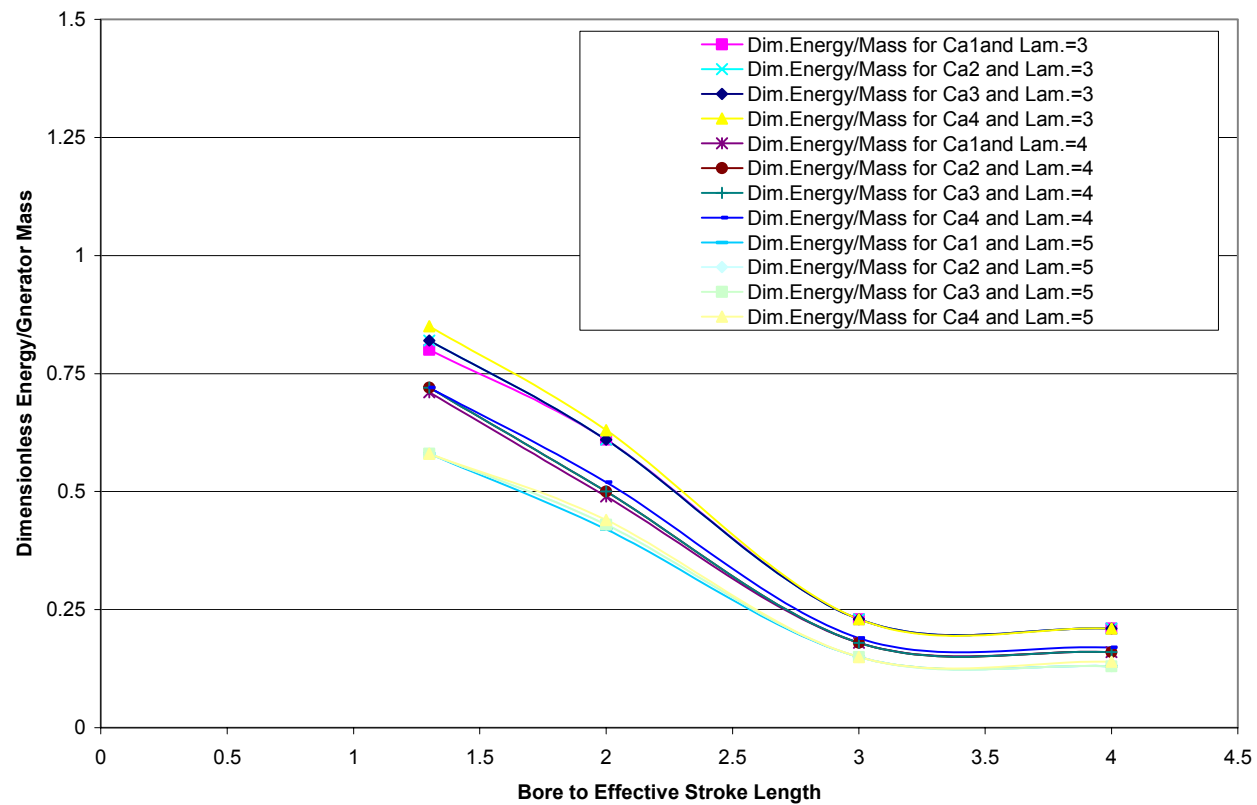

Figure D8. Dimensionless Energy per Generator Mass Versus Bore to Effective Stroke Length for Different Lambda, Different Dimensionless Load Constants, and Dimensionless Injection Position=0.19 


\section{APPENDIX E}

\section{EXPLORING OUTSIDE THE DIMENSIONLESS ANALYSIS MATRIX (CONTINUE)}

Figures E1 and E2 show dimensionless frequency and dimensionless indicated power versus bore to effective stroke length. It can be seen that the dimensionless frequency and the dimensionless indicated power were directly affected with increasing or decreasing the value of bore to effective stroke length.

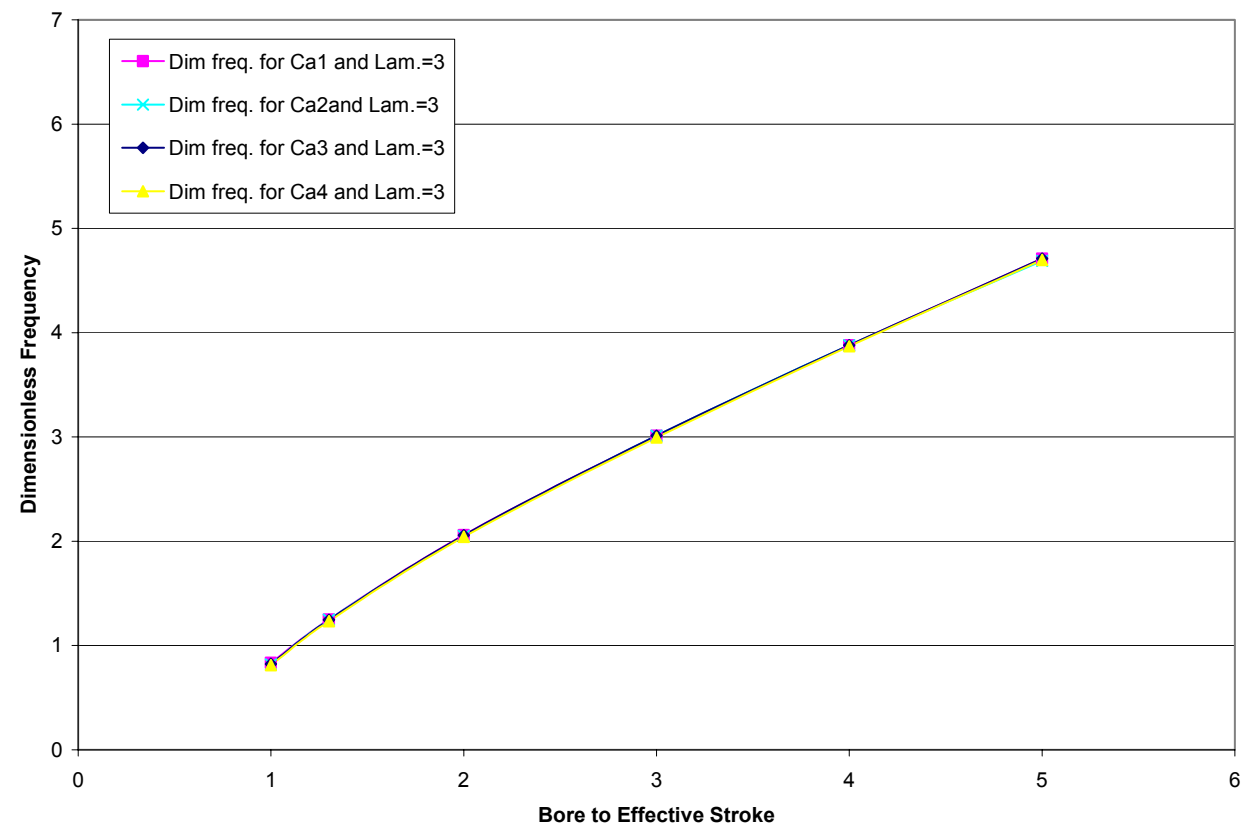

Figure E1. Dimensionless Frequency Versus Bore to Effective Stroke Length for Lambda=3, Different Dimensionless Load Constants, and Dimensionless Injection Position=0.081 


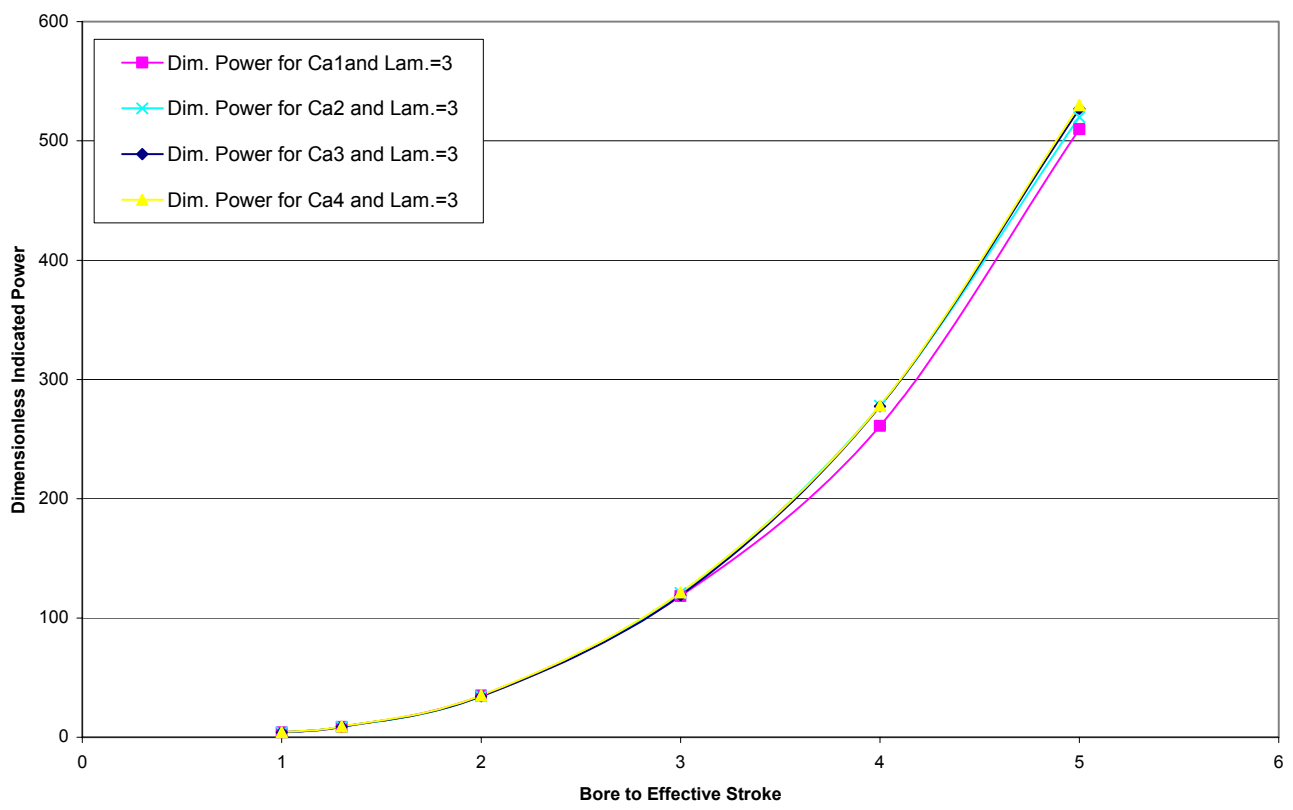

Figure E2. Dimensionless Indicated Power Versus Bore to Effective Stroke Length for Lambda=3, Different Dimensionless Load Constants, and Dimensionless Injection Position=0.081 
Figure E3 shows the dimensionless average piston speed versus bore to effective stroke length. The figure shows further decrease in the dimensionless average piston speed with bore to effective stroke length of one as a result of decreasing the input heat energy. Also, it showed a further increase with bore to effective stroke energy equal to five as a result of increasing the input heat.

Figure E4 shows the dimensionless indicated power per cylinder volume for lambda equal to 3, different dimensionless load constants, and dimensionless injection position equal to 0.081 . The figure confirmed previous obtained results.

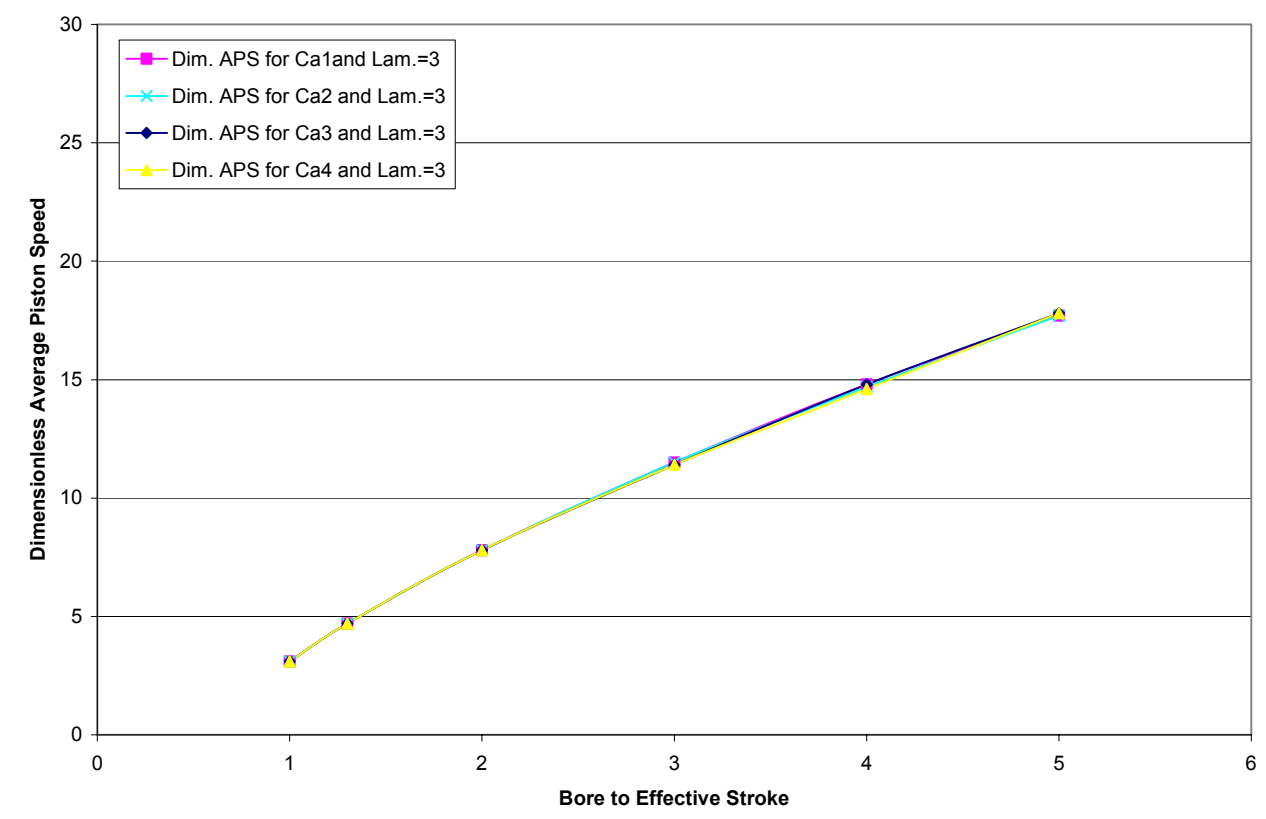

Figure E3. Dimensionless Average Piston Speed Versus Bore to Effective Stroke Length for Lambda $=3$, Different Dimensionless Load Constants, and Dimensionless Injection Position $=0.018$ 


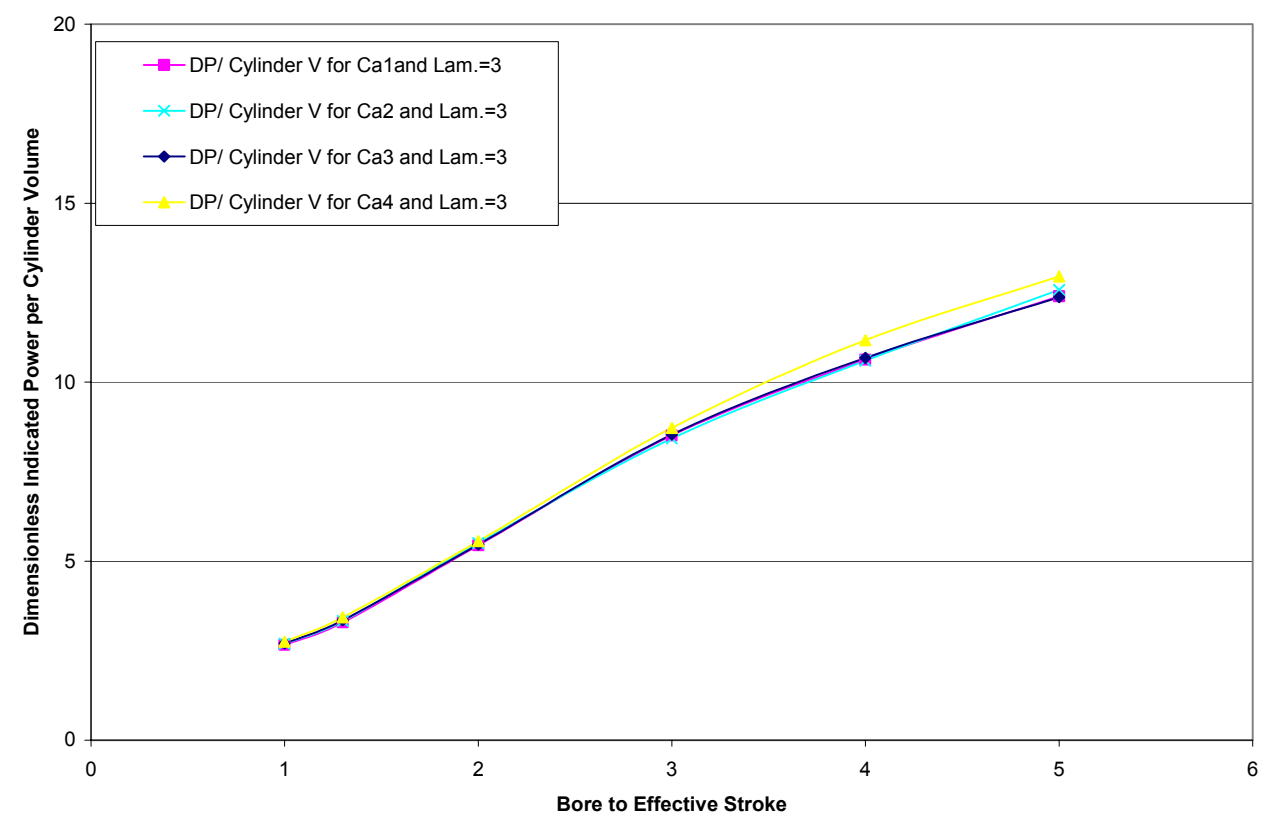

Figure E4. Dimensionless Indicated Power per Cylinder Volume Versus Bore to Effective Stroke Length for Lambda=3, Different Dimensionless Load Constants, and Dimensionless Injection Position $=0.018$ 
Figure E5 shows the change in dimensionless indicated power per generator mass versus bore to effective stroke length for lambda equal to 3 . The resulted figure shows a further decrease in the dimensionless indicated power per generator mass with bore to effective stroke equal to 1 and a further increase with bore to effective stroke equal to 5 .

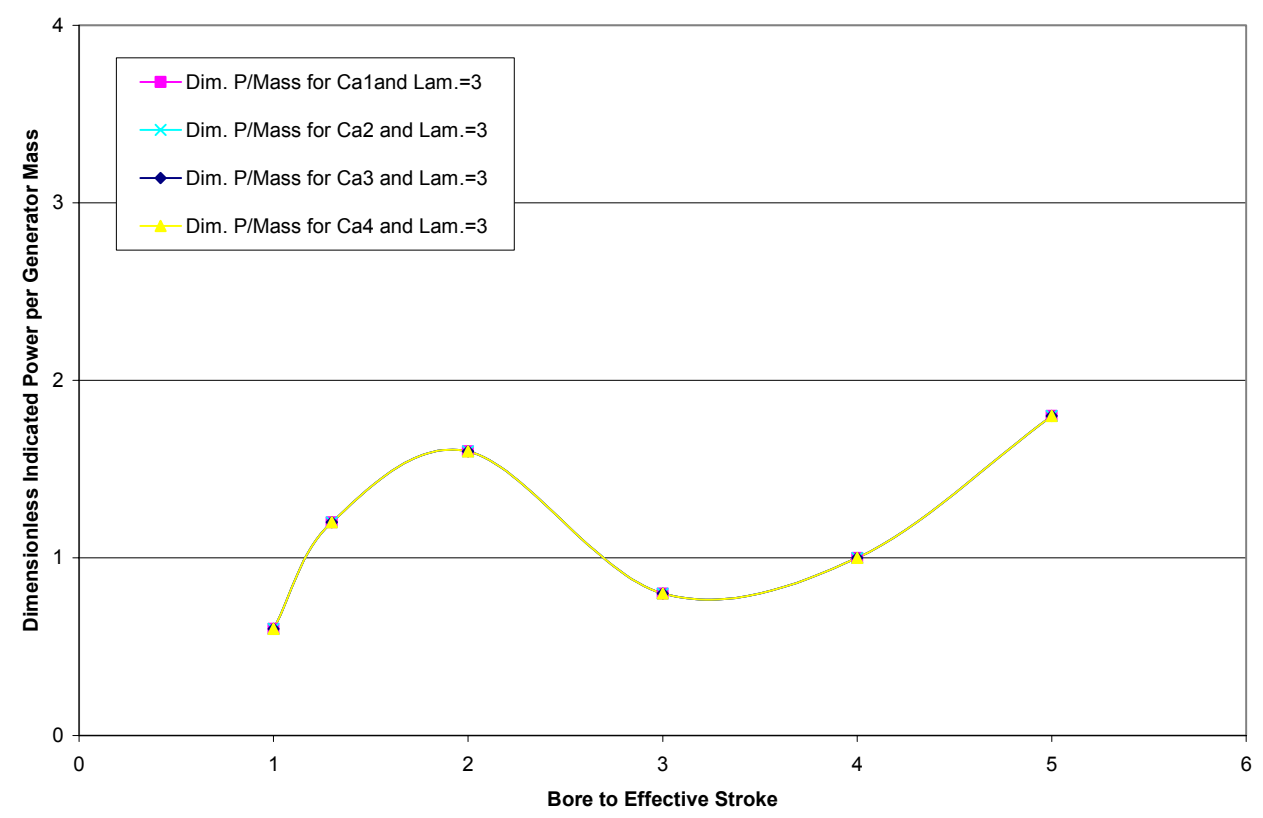

Figure E5. Dimensionless Indicated Power per Generator Mass Versus Bore to Effective Stroke Length for Lambda=3, Different Dimensionless Load Constants, and Dimensionless Injection Position $=0.018$ 
Figure E6 shows dimensionless energy released per generator mass versus bore to effective stroke length for lambda equal to 3 . The figure shows some recovery for the value of the dimensionless energy released per generator mass with bore to effective stroke greater than four and a further decrease with bore to effective stroke of one.

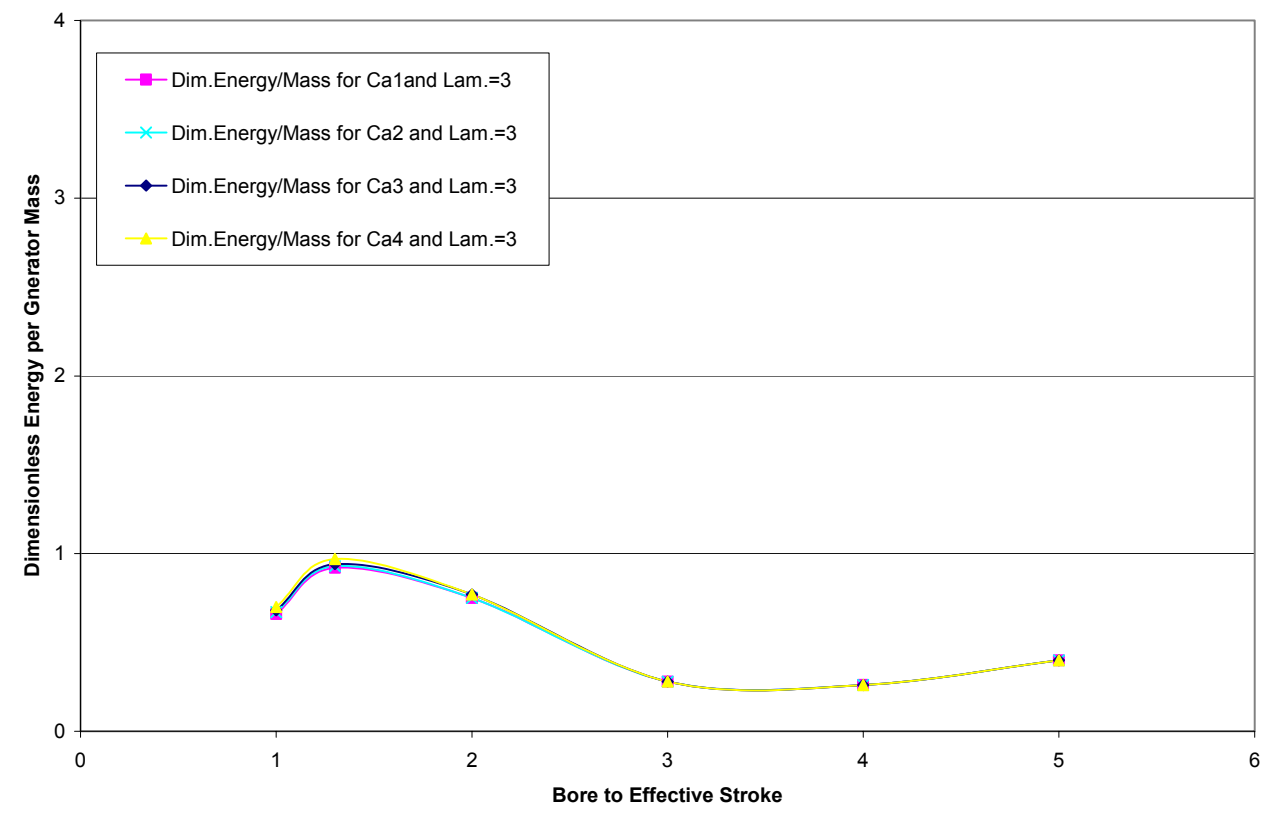

Figure E6. Dimensionless Energy per Generator Mass Versus Bore to Effective Stroke Length for Lambda $=3$, Different Dimensionless Load Constants, and Dimensionless Injection Position $=0.018$ 


\section{APPENDIX F}

\section{HEAT TRANSFER FACTOR FOR WOSCHNI'S CORRELATION}

Figure F1 shows the indicated power of the two stroke linear engine using two different values of heat transfer factor multiplied by Woschni's correlation, which examines an order of magnitude of heat transfer.

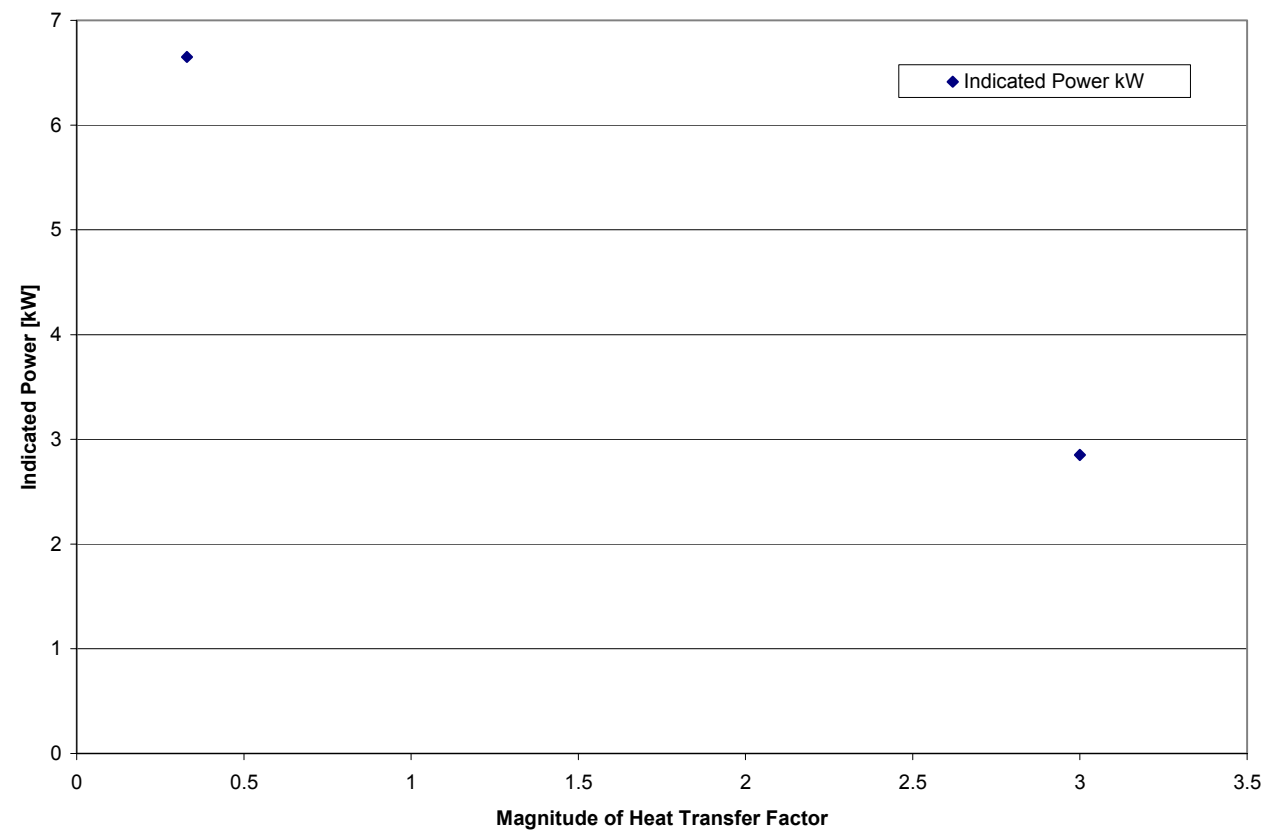

Figure F1. Indicated Power Versus Different Heat Transfer Factor for Lambda=4, Translator Mass $=4 \mathrm{~kg}$, and $\mathrm{Ca}=25 \mathrm{~N} \mathrm{Sec} / \mathrm{m}$

The work was conducted at one value which is 0.33 because it was not possible to explore a full matrix. 